\title{
[Re]interpreting Iqaluit's Social Housing Archetypes
}

by

\section{Jason Warren Borg}

A thesis submitted to the Faculty of Graduate and Postdoctoral Affairs in partial fulfillment of the requirements for the degree of

Master of Architecture

\section{Carleton University}

Ottawa, Ontario

(C) 2014, Jason Warren Borg 


\section{[Re]interpreting Iqaluit's Social Housing Archetypes}

\section{By}

Jason Warren Borg

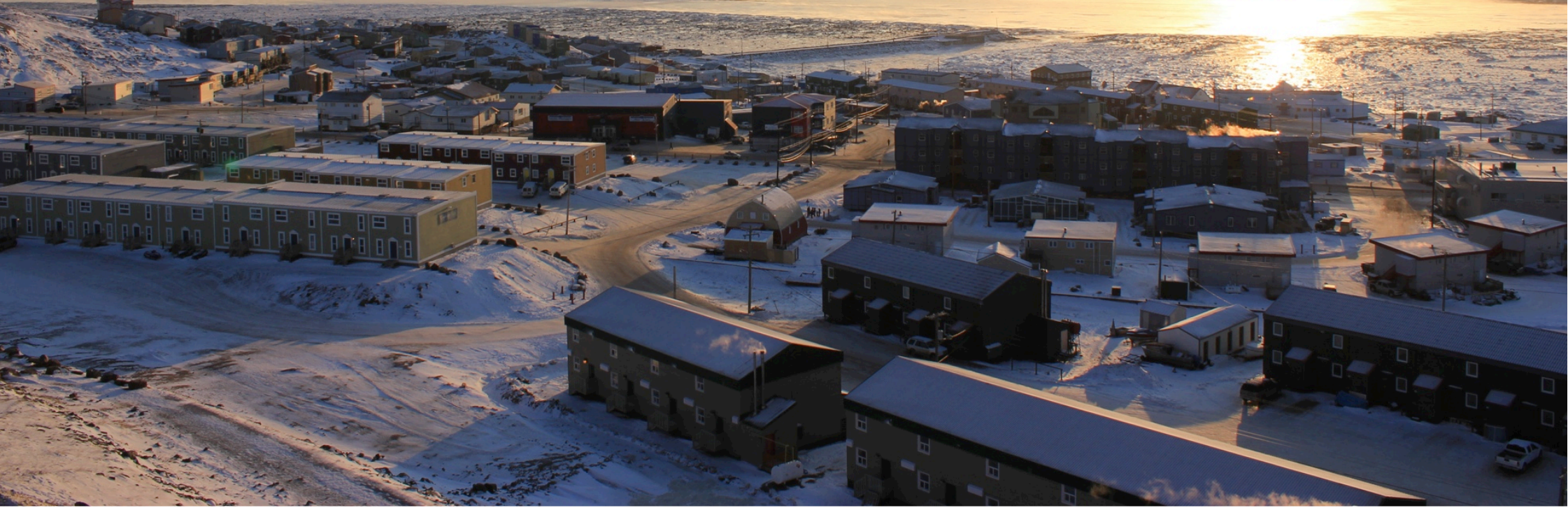




\section{Abstract}

This thesis investigates Iqaluit's social housing. Overcrowding, disease, and inferior construction are just a few of the problems that have persisted since the beginning of the housing programs in Canada's Arctic. "Nuna-Slums" are crippling the socio-economic growth of Nunavut. Northern challenges require unique solutions.

Architects and other industry professionals need to re-interpret the standard Canadian housing model through a participatory approach to allow for the Inuit lifestyle. This thesis explores alternative methods to lower housing costs and source new capital.

Social housing in Iqaluit has been sub-par over the years; how can we reinterpret the existing archetypes to better design housing that adapts to Inuit needs and overcome Arctic challenges? Solutions will focus on adaptation and flexibility while remapping the existing paradigms and instituting new praxis. 


\section{Acknowledgments}

I would have never been able to finish my thesis without the guidance of the architectural faculty at Carleton University, reviewers, peers, and the support of my family and wife.

I would like to express gratitude to my advisor, Dr. Kelly Crossman, for his excellent guidance and understanding. I would like to thank the people in Iqaluit who have given me their time and helping to contribute to this research.

Finally, I would like to thank my wife, Kerone Folkes. She is always there keeping me company in the late hours, supporting me in the good times and bad.

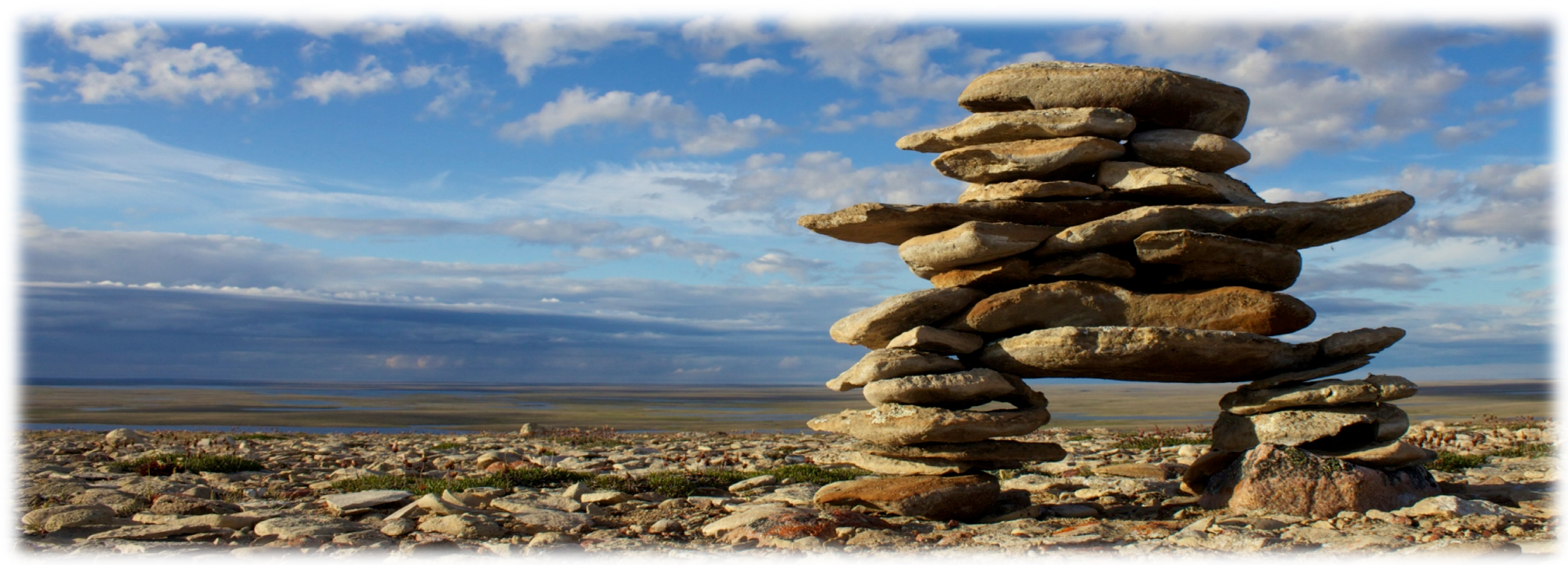




\section{Contents}

Abstract

Acknowledgments

List of Figures and Tables

Preface

1 Chapter: Defining Terms

1.1 Nordicity

1.2 Nuna-Slums

1.3 Norditecture

2 Chapter: Inuit Realities

2.1 Pre-History

2.2 Inuit Technology Prior to European Influence

2.2.1 Shelter

2.2.2 Travel

2.2.3 Clothing

2.2.4 Equipment

2.2.5 Traditional Art

2.3 Recorded History

2.3.1 Wilderness to Town

2.3.2 Nunavut was Born

2.3.3 Modern Inuit

2.4 Inuit versus Kabluunak

2.5 Nunavut

3 Chapter: Origins of an Arctic Capital

3.1 Frobisher Bay Area

3.2 Crystal II 
3.3 Frobisher Bay Airbase

Frobisher Bay Settlement

Master Proposals

3.6 Iqaluit $\Delta^{c} b \Delta^{c}$ (place of many fish)

4 Chapter: Extreme Challenges and Techniques

4.2 Temperature

4.3 Wind and Snow

4.4 Permafrost

4.5 Sunlight

4.6 Logistics

4.7 Transportation

4.8 Skilled Labour

4.9 Lots

5 Chapter: Iqaluit's Social Housing

5.1 History of Iqaluit's Social Housing Programs

5.2 Today's Iqaluit Social Housing

5.2.1 Nunavut Housing Corporation (NHC)

5.2.2 Interview with Tenants

6 Chapter: Agency Theory and the Inuit

7 Chapter: Vision to Intervention

7.1 Design Principles

7.2 Proposal

7.2.1 Construction Methodology

7.2.2 Durability

7.2.3 Example of Model Design

115

120

121

Conclusion

References: List of Figures and Tables 


\section{List of Figures and Tables}

Figure 1.1 - Overcrowded House in Cape Dorset

Figure 1.2 - Nunavut Housing Issues Chart

Figure 1.3 - Mushrooms growing in walls in Baker Lake, Nunavut

Figure 1.4 - Memory of My Life: Breaking Bottles by Inuit artist Annie Pootoogook, 2002

Figure 1.5 - Map of Canada's northern regions based on nordicity index

Figure 1.6 - The Matchbox, located in Arviat, Nunavut, built 195060

Figure 1.7 - Arctic proposals

Figure 1.8 - New Town I Proposal - Frobisher Bay 1958

Figure 1.9 - New Town II Proposal - Frobisher Bay 1960

Figure 1.10 - Arctic Town Proposal - 1971

Figure 1.11 - Frobisher Bay Proposal - Frobisher Bay 1974-77

Figure 1.12 - Ralph Erskine's Northern Studies and Proposal for Resolute Bay, 1973

Figure 1.13 - Nakasuk School, lqaluit, designed by Papineau, Gérin-Lajoie et Leblanc, architects.

Figure 2.1 - Thule whalebone shelter

Figure 2.2 - Snow village at Oopungnewing

Figure 2.3 - Qarmaq (sod house) dwelling

Figure 2.4 - Inuit Man's Clothing

Figure 2.5 - Inuit woman wearing amauti with child inside.

Figure 2.6 - Inuit woman sewing inside an Igloo.

Figure 2.7 - Inuit snow goggles made from bone.

Figure 2.8 - Inuit man catching a seal from a breathing hole.

Figure 2.9 - Illustration of Sedna, by unknown artist
Figure 2.10 - Miniature carving

Figure 2.11 - Ohotaq Houses Cape Dorset by artist Annie Pootoogook, 2012

Figure 2.12 - Cape Dorset Freezer by Inuit artist Annie Pootoogook, 2006

Figure 2.13 - Hon. George Hees, Minister of Transport, visits the Eskimos

Figure 2.14 - Map of Canada's -DEW, Mid-Canada, and Pinetree Lines- radar stations

Figure 2.15 - Soapstone snowmobile carving

Figure 2.16 - Celebration of Nunavut becoming an official territory, 1999

Figure 2.17 - Today's version of traditional Inuit women's clothing

Figure 2.18 - Inuit family living in a Euro-Canadian home by the Government of Nunavut

Figure 2.19 - Map of Nunavut

Figure 2.20 - Map of Nunavut's three regions

Figure 2.21 - Nunavut's GDP

Figure 3.1 - Map of the Crimson Air Route

Figure 3.2 - September 16, 1942 - Crystal II

Figure 3.3 - Aerial Photo of Crystal II, 1948

Figure 3.4 - Sign for segregation

Figure 3.5 - Aerial of Frobisher Bay, 1955, Courtesy of National Archives Canada

Figure 3.6 - Aerial of Crystal II, 1948

Figure 3.7 - Aerial of Frobisher Bay Airbase, 1958

Figure 3.8 - Aerial of Frobisher Bay Airbase, 1969 
Figure 3.9 - Aerial of Town of Iqaluit, 1995

Figure 3.10 - Aerial of Town of Iqaluit, 2000

Figure 3.11 - Aerial of City of Iqaluit, 2012

Figure 3.12 - Frobisher Bay New Town I, 1958 - Perspective

Figure 3.13 - Frobisher Bay New Town I, 1958 - Master Plan

Figure 3.14 - Frobisher Bay New Town I, 1958 - Sketch

Figure 3.15 - Frobisher Bay New Town I, 1958 - Exploded Diagram

Figure 3.16 - Frobisher Bay New Town II, 1960 - Exploded

$$
\text { Diagram }
$$

Figure 3.17 - Frobisher Bay New Town II, 1960 - Master Plan

Figure 3.18 - Frobisher Bay New Town II, 1960 - Perspective

Figure 3.19 - Frobisher Bay, 1974-77 - Physical Model

Figure 3.20 - Frobisher Bay, 1974-77 - Exploded Diagram

Figure 3.21 - Frobisher Bay, 1974-77 - Wood Physical Model

Figure 3.22 - Frobisher Bay, 1974-77 - Perspective

Figure 3.23 - Frobisher Bay, 1974-77 - Master Plan

Figure 3.24 - Frobisher Bay, 1974-77 - Housing Prototype

Figure 3.25 - Astro Hill Complex, 2013

Figure 4.1 - Blizzard in Iqaluit, November 19, 2013

Figure 4.2 - Iqaluit Seasonal Calendar

Figure 4.3 - Iqaluit's Average Temperature

Figure 4.4 - Snow drift

Figure 4.5 - Snow fence

Figure 4.6 - Permafrost Map of Canada

Figure 4.7 - Permafrost Layers

Figure 4.8 - Effects foundation design has on permafrost

Figure 4.9 - Sun path diagram for Iqaluit

Figure 4.10 - Solar damage on south facing wall
Figure 4.11 - Northern solar studies

Figure 4.12 - Sealift in Koojesse Inlet

Figure 4.13 - Typical Project Cost Breakdown

Figure 5.1 - Shanty dwelling

Figure 5.2 - Ikaluit tented community

Figure 5.3 - Inuit woman smoking in igloo with child on lap

Figure 5.4 - Frobisher Bay - styrofoam quonset prototype

Figure 5.5 - Medical Examination - rehabilitation centre Apex Hill

Figure 5.6 - Rigid-digit, Iqaluit, 2013

Figure 5.7 - Rigid-digit, Plans

Figure 5.8 - Rigid-digit houses in Frobisher Bay

Figure 5.9 - Matchbox house in Arviat

Figure 5.10 - Matchbox house plans

Figure 5.11 - Apex Hill Village

Figure 5.12 - 512 model, plans and image

Figure 5.13 - The Angirraq, plans and image

Figure 5.14 - The Northern Territorial Rental, plans

Figure 5.15 - NHC Organizational Structure

Figure $5.16(a-h)-$ NHC Housing Stock

Figure 5.17 - Shacks along lqaluit's Beach (Sijanga District)

Figure 5.18 - Iqaluit Social Housing Map (unofficial)

Figure 5.19 - Overcrowded House, Arviat, Nunavut (Living Room)

Figure 5.20 - Overcrowded House, Arviat Nunavut (Sleeping Area)

Figure 5.21 - Clogged drainpipe under building

Figure 6.1 - Scene from The Beverly Hillbillies Movie, 1993

Figure 6.2 - Overcrowded House, Arviat Nunavut (Children eating mussels)

Figure 6.3 - Contemporary Euro-Canadian Segregated Housing versus Traditional Inuit Housing 
Figure 7.1 - Participatory Design Approach

Figure 7.2 - Create New Architectural Language

Figure 7.3 - Iterative Design

Figure 7.4 - Integrative Design Approach

Figure 7.5 - Infill Design

Figure 7.6 - Soccer Dome as Manufacturing Plant Lifecycle

Figure 7.7 - Ekati Diamond Mine 88' x 320' Storage Facility

Figure 7.8 - Insulation for Fabric Dome

Figure 7.9 - Potential Site Locations in Iqaluit, Nunavut

Figure 7.10 - Existing Construction Cycle versus Proposed Construction Cycle

\section{List of Tables}

Table 1.1 - Nordicity Index

Table 2.1 - Comparison of traditional and modern Inuit

Table 2.2 - Comparison of Amerindian and Non-Amerindian values

Table 3.1 - Frobisher Bay Population Growth 1942 - 1969
Figure 7.11 - Model House Front Rendering at Night Figure 7.12 - Model House Front Rendering at Day

Figure 7.13 - Model House Rear Rendering at Day

Figure 7.14 - Model House Plans and Section

Figure 7.15 - Model House Elevations

Figure 7.16 - Model House Interior Rendering at Living Room 


\section{Preface}

The intentions, assumptions and departure point of this thesis must be outlined. I must make the reader aware that I am not Inuk, nor did I grow up in Nunavut. I am originally from Southern Ontario and the understanding of northern ideologies is new to me as of four years ago. Then, my wife and I decided to expand our horizons and moved to Yellowknife for a contract position. There the concept of North was transformed, through experiencing the vastness of the land, the wonders of ice and snow, and the dancing of the northern lights. It was then we realized Canada had much more to offer. In the summer, we decided to take a bus to Toronto from Yellowknife, it was grueling, but worth it, seeing the buffalo and watching the trees grow as we moved away from the tree line; and of course making friends with various First Nation people. It was a life changing experience. After completing my degree at Ryerson University, my wife and I realized it was hard to readapt to a southern lifestyle, having tasted what the North had to offer. I decided to apply for a position in Iqaluit, Nunavut. My wife to follow, having little money, I got onto the plane not knowing what to expect. All we knew was that it was above the tree line and the Inuit live there. Looking out the window, all I saw was infinite tundra, the thought of what would happen if I ever got lost constantly reverberated through my mind.

Upon arriving, everything was different; it may as well be another country, or planet. It was then that I realized that the arctic shows many different faces. Yellowknife only prepared me for the cold, but the difference in the customs and people are distinct. It was also the first day that I met my employer; he had to negotiate a place for me to stay. Walking into a staff house, called 'the Red House,' which looked like it was in the early stages of a fixer-upper. My employer said, "It will be 
like camping." It was. It has been a few years since that first day and my experience has been remarkable. I have been given the opportunity to visit many other Nunavut communities, which are only accessible by plane. This experience has deepened my understanding of the differences and vastness of the North.

It is this experience that made me realize the growing need in Nunavut, and the biases Canadian society place on Northern development. I was fortunate to acquire housing when I first arrived. The housing shortage is a serious issue in the north; it does not help when a large part of what is available is in disrepair. Unfortunately, many designs or proposals are influenced by southern policies. They are not suited to the North, either culturally or climatically. For example, repurposing shipping containers for housing is not ideal, since it brings back memories of the infamous "matchbox" houses instituted in the fifties. Today, Inuit are faced with a real challenge either to connect with the land as their forefathers did, or remain urbanized where the basic needs of housing are met. One of the aims of this thesis is to find a balance between the two. How can social housing no longer be a deterrent, but a stepping-stone to greatness as a people, and a territory? 
1, 2, 3. Anderson, E. (2008) Canada's Relationship with Inuit. Minister of Indian Affairs and Northern Development. Ottawa:

Public History Inc.

\section{Introduction}

Even though Canada's federal government and the Nunavut Housing Corporation (NHC), would argue that vulnerable areas (slums) develop due to the Arctic's construction constraints and limited budgets, Authorities like, NHC, Community and Government Services (CGS) and the city of Iqaluit, should work with the affected communities to strategize new ways of improving their conditions. Due to the rapid population growth and housing shortages of the city, unique solutions need to be explored. Iqaluit's vulnerable areas are unsafe due to overcrowding, inferior or deteriorating construction, and are diseased filled. The Inuit people occupy the majority of Iqaluit's social housing. Designs should embody cultural integrity and sustainability. This thesis will examine the contributing factors in the formation of these areas while analyzing existing and preexisting mitigation approaches.

In 1880, Canada passed an order in Council that declared sovereignty over the Arctic, specifically the northern archipelago. Almost 60 years later, "In 1939, the Supreme Court pronounced their judgment in the Re: Eskimo case, stating that, constitutionally, Inuit were classified as Indians in Canada. This distinction made Inuit the legal responsibility of the Canadian Government."1 Pressure from humanitarian groups and the United States military criticizing the welfare of the Inuit became the catalyst for the various housing programs introduced during the 1950s.

Iqaluit and its inhabitants share a unique history. As a settlement, Iqaluit was not inhabited until 1942. It was at this time that Frobisher Bay was selected by the United States military as an airstrip along the Crimson Air Route. Since fighter jets could not travel from the manufacturing plant to 
the European front lines of World War II in one leg, it was decided that they would need to pass through Canada, Greenland and Iceland at 500-mile intervals. The base was known as Crystal II. During this time, civilian presence was almost non-existent.

As the Cold War progressed, the base was later named Frobisher Bay Air Base under the control of the United States air force (USAF). In the early 1950s, due to the construction of the Distant Early Warning Line (DEW Line), many Inuit came in search of jobs, and better living conditions promised by the Government of Canada (GC). The US military officially leaving in 1963 left the civilian population in the settlement too great (population of 900) for the GC to disperse, as a result it was mandated to establish it as a village. Frobisher Bay was renamed Iqaluit (Inuktitut name meaning "place of (many) fish") in 1987. When Nunavut was born in 1999 as a separate territory from the North West Territories, Iqaluit became the Capital. Although there was no economic underpinning for its existence, by becoming an administrative center it helped Iqaluit become an established city in $2001 .^{2}$

Today, Iqaluit is rapidly growing with a population beyond its capacity; social housing has not been able to keep up with the demand. Many factors contribute to the influx of people, both Inuit and Kabluunak or Qallunaaq (white people). Over the years, mining has been booming, interest in tourism has increased, and the issue of sovereignty has been a heated topic with the advent of the North-West Passage (shipping trade route) opening up due to climate change. Inuit families are flocking to Iqaluit for employment opportunities and better healthcare. Other Nunavut communities now have a stagnant and/or declining population, while Iqaluit continues to grow. 
Lack of sufficient housing solutions has now reached a critical state for both the private and public sectors.

There are many challenges to the housing industry in Iqaluit. Construction constraints impede development. Since vernacular materials are not useful for contemporary housing standards, everything is transported, mainly by ship. 3 to 4 ships arrive per year, and are usually late, during the short construction season. Every aspect of construction is typically 2-4 times the cost of construction in the South. Skilled labor is often imported from Southern Canada and creates financial and social strains.

Iqaluit has extreme weather conditions (as low as $-50^{\circ} \mathrm{C}$ ) with the average monthly temperatures below freezing eight months of the year. Destructive blizzards are common during the winter season; for example in 2007, a blizzard hit with wind gusts up to $130 \mathrm{~km}$ per hour. Foundations have been costly to construct due to permafrost (ground that remains frozen for 2 or more years) and there is concern regarding the capacity to hold up with climate change. Iqaluit's permafrost is nearly 200 meters deep with typical pile foundations only reaching an average of 10 to 15 meters deep. Overcrowding has inadvertently led to higher maintenance costs throughout the social housing units and is additionally higher because of an increase of moisture inducing mold and number of users.

Social housing in Iqaluit is suffering from construction constraints, maintenance issues and little concern for the Inuit culture. An attempt was made in the beginning to respect Inuit traditions; "In 1956, for example, the government initiated a pilot program at Cape Dorset to build igloo style 
4. Dawson, P. C. (2008) Unfriendly Architecture: Using Observations of Inuit Spatial Behavior to Design Culturally

Sustaining Houses in Arctic Canada. Housing Studies , 23 (1), $111-128$ housing with wooden floors and six-inch thick Styrofoam walls and ceilings."3 Unfortunately, this methodology was abandoned because of the introduction of Canadian Housing standards and the high cost of prototyping. Standard housing typologies were then imported from the south. These were small, cheap and of inferior construction quality with little regard for adaptation to culture and climate. The walls were thin, resulting in high-energy consumption, proving to be a burden for anyone attempting to own. With botched attempts at cheap solutions, the driving force was to develop an efficient construction typology and have a universal design that meets with the accepted housing standards. Today, this direction can still be seen as new buildings are constructed. Those living in Iqaluit's social housing units are primarily Inuit and have shown a sense of human agency in how they live in what is known as Euro-Canadian housing models. "Inuit continue to use their houses as if they were traditional dwellings. These expressions of spatial agency have allowed many families to retain their cultural identities, as well as remain economically and socially viable within a semi-traditional lifestyle." 4 Unfortunately, to design with traditions and customs in mind is not the accepted practice. A reinterpretation of Iqaluit's social housing archetypes needs be developed. Generational dependencies are the product of the Canadian social systems and a prolonged disconnect from their traditional way of life.

This thesis will engage in a discussion of Iqaluit's social housing from historic to contemporary methodologies. In order to develop a viable framework of a more collaborative approach in designing housing, one must look at what the contributing factors to the situation have been and compare them to what we see now. An in-depth analysis will be conducted as to what are the needs of the urban Inuit today. It is the goal of this research to bridge the needs of the Inuit with housing standards, and eventually germinate independence. A prototype at the conclusion of this 
thesis is intended to respond to the objectives outlined, but remains merely a starting point for discussion.

\section{Chapter: Defining Terms}

\subsection{Nordicity}

"From what may be established from an incomplete inventory of mirages about the North, two extreme opinions frequently emerge an over-idealized vision and an excessively pessimistic vision. Whereas these two illusions have usually operated alternately, they have also undergone parallel development - and that has made them even more confused."(Hamelin) 5

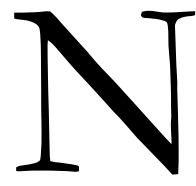

ordicity is a term coined by Canadian geographer Louis-Edmond Hamelin referring to degrees of "northerness." Canadian feelings about the North remain ambivalent in that it is full of majestic wonder while being incredibly dangerous. As Hamelin describes in the quote above, both over-idealized and pessimistic illusions run concurrently with many of the policies regarding Northern development. It is important to clarify, if possible, what is north or northerness. Boundaries and definitions are in constant flux based on a differential nordification. administration. Prior to the 20th century, all of Canada was considered north based on winter conditions, as the southern parts of the provinces developed, a denordification began to emerge.

For most Canadians, the North remains an unknown quantity. ${ }^{6}$ The North introduces the various visions by all stakeholders: a Southern Vision, the north is a hinterland to be exploited for the benefits of the south; a romanticized vision, wilderness should not be touched; a pessimistic vision, 
which sees only the problems; a developmental vision, use of mining to aid in the progress of the North. ${ }^{7}$ All visions and illusions culminate into an overwhelming pioneering spirit amongst the nonindigenous. It is in debate as to the effects on the indigenous population and their development as a culture.

Hamelin introduced a Nordicity index of ten factors that help delineate the North verses the South, as you see in Table 1.1. It is important to disregard the common northern boundaries people tend to give: such as the isoclines of the Arctic Circle, the surveyors 60 th parallel and the $10^{\circ} \mathrm{C}\left(50^{\circ} \mathrm{F}\right)$ July isotherm. ${ }^{8}$ They have little baring with regards to demarking an area northern, it should be holistic with regards to various other factors: such as; influence of the ecumene, vegetation, permafrost, and degree days just to name a few. When using his index, it is important to note that this is not complete, as there are many other indirect factors, such as telecommunication, that could influence the result. The North Pole is considered the most northern having 1000 Polar units or VAPO (French: Valeur Polaires). Hamelin compared five places in the late '70s: Shefferville, Quebec 295; Fairbanks, Alaska 337; Verkhoyansk, Russia 631; Ny-Ålesund, Norway 737; Interior Keewatin, Canada $812 .{ }^{9}$ As pertaining to this thesis, it was important to see where Iqaluit, Nunavut would rank. All numbers in red represent Iqaluit in Table 1. Iqaluit's polar units total 649. It is important to note that this number would have been higher in the 70 s due to lack of development. Iqaluit over time began a process of denordification through population growth, increased number of air and sea services, and climate change. 


\begin{tabular}{|c|c|c|c|c|c|c|c|}
\hline Criteria & Classe & & VAPO & Criteria & \multicolumn{2}{|l|}{ Classes } & VAPO \\
\hline \multirow[t]{5}{*}{ 1. Latitude } & Up to & $90^{\circ}$ & 100 & 6. Natural vegetation cover & \multirow{2}{*}{\multicolumn{2}{|c|}{$\begin{array}{l}\text { Rocky desert } \\
\text { Tundra clumps; } 50 \% \text { cover }\end{array}$}} & 100 \\
\hline & & $80^{\circ}$ & 77 & & & & 90 \\
\hline & & $70^{\circ}$ & 55 & & \multicolumn{2}{|c|}{ Sparse tundra; almost continuous } & 80 \\
\hline & & $50^{\circ}$ & 33 & & \multicolumn{2}{|c|}{ Dense tundra and shrubs; humid steppe } & 60 \\
\hline & & $45^{\circ}$ & 0 & & \multicolumn{2}{|c|}{ Open woodland (subarctic; parkland; bushes) } & 40 \\
\hline \multirow[t]{8}{*}{ 2. Summer heat } & & s above $5.6^{\circ} \mathrm{C}\left(42^{\circ} \mathrm{F}\right)$ & 100 & & \multicolumn{2}{|c|}{ Dense forest (coniferous or broad-leaved) } & 0 \\
\hline & $40 \mathrm{c}$ & s above $5.6^{\circ} \mathrm{C}$ & 80 & 7. Accessibility other than by air & \multirow{3}{*}{$\begin{array}{l}\text { No service } \\
\text { Seasonal service: }\end{array}$} & & 100 \\
\hline & 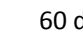 & s above $5.6^{\circ} \mathrm{C}$ & 70 & \multirow{3}{*}{$\begin{array}{l}\text { (heavy transport, including } \\
\text { water transport, pipe line, and } \\
\text { winter road) }\end{array}$} & & once per year & 80 \\
\hline & $80 \mathrm{c}$ & s above $5.6^{\circ} \mathrm{C}$ & 60 & & & for two months & 60 \\
\hline & $100 \mathrm{c}$ & s above $5.6^{\circ} \mathrm{C}$ & 45 & & & for three months & 55 \\
\hline & $120 \mathrm{c}$ & s above $5.6^{\circ} \mathrm{C}$ & 30 & & & for six months or two seasons & 40 \\
\hline & $135 \mathrm{c}$ & s above $5.6^{\circ} \mathrm{C}$ & 20 & & Year-round: & by one means (with difficulty) & 20 \\
\hline & $>150 \mathrm{c}$ & s above $5.6^{\circ} \mathrm{C}$ & 0 & & & by two means & 15 \\
\hline \multirow[t]{8}{*}{ 3. Annual Cold } & $6650 c$ & ree days below $0^{\circ} \mathrm{C}\left(32^{\circ} \mathrm{F}\right)$ & 100 & & & by more than two means & 0 \\
\hline & $5550 \mathrm{c}$ & ree days below $0^{\circ} \mathrm{C}$ & 85 & \multirow{8}{*}{$\begin{array}{l}\text { 8. Air services (either private or } \\
\text { government) }\end{array}$} & \multicolumn{2}{|c|}{ Charter flights, $1,600 \mathrm{~km}$ (1,000 miles) } & 100 \\
\hline & $4700 c$ & ree days below $0^{\circ} \mathrm{C}$ & 75 & & \multirow{2}{*}{\multicolumn{2}{|c|}{$\begin{array}{l}\text { Charter flights, } 480 \text { km (300 miles) } \\
\text { Charter flights, } 160 \text { km (100 miles) }\end{array}$}} & 80 \\
\hline & $3900 c$ & ree days below $0^{\circ} \mathrm{C}$ & 65 & & & & 65 \\
\hline & $2900 c$ & ree days below $0^{\circ} \mathrm{C}$ & 45 & & \multicolumn{2}{|c|}{ Charter flights, 48 km (30 miles) } & 60 \\
\hline & $1950 \mathrm{c}$ & ree days below $0^{\circ} \mathrm{C}$ & 30 & & \multicolumn{2}{|c|}{ Regular service, twice per month } & 40 \\
\hline & $1250 c$ & ree days below $0^{\circ} \mathrm{C}$ & 15 & & \multicolumn{2}{|c|}{ Regular service, weekly } & 25 \\
\hline & $550 \mathrm{c}$ & ree days below $0^{\circ} \mathrm{C}$ & 0 & & \multirow{2}{*}{\multicolumn{2}{|c|}{$\begin{array}{l}\text { Regular service, twice weekly } \\
\text { Regular service, daily or better }\end{array}$}} & 15 \\
\hline \multirow{6}{*}{$\begin{array}{l}\text { 4a. Frozen ground } \\
\text { Types of ice }\end{array}$} & Contin & us permafrost $457 \mathrm{~m}$ (1500 feet) thick & 100 & & & & 0 \\
\hline & Contin & us permafrost less than $457 \mathrm{~m}$ & 80 & 9a. Inhabitants in settlement & \multicolumn{2}{|l|}{ None } & 100 \\
\hline & Discor & uous permafrost & 60 & Resident or wintering population & \multicolumn{2}{|l|}{ About 25} & 90 \\
\hline & Groun & rozen for 9 months & 50 & & \multicolumn{2}{|l|}{ About 100} & 85 \\
\hline & Groun & rozen for 4 months & 20 & & \multicolumn{2}{|l|}{ About 500} & 75 \\
\hline & Groun & rozen for less than a month & 0 & & About 1,000 & & 60 \\
\hline 4b. Floating ice & Perma & nt pack ice (Arctic Ocean) & 100 & & About 2,000 & & 40 \\
\hline & Pack ic & on peri-Arctic seas (e.g., Baffin Bay) & 90 & & About 3,000 & & 20 \\
\hline & Pack is & for 9 months & 64 & & $>5,000$ & & 0 \\
\hline & Pack i & or 6 months & 36 & 9b. Population density of the & Uninhabited & & 100 \\
\hline & Pack is & or 4 months & 20 & area $250,000 \mathrm{~km}^{2}$ (or 100,000 & 0.004 per $\mathrm{km}^{2}(0$. & persons per mile ${ }^{2}$ ) & 90 \\
\hline & Pack is & for less than a month & 0 & miles $^{2}$ ) & 0.4 per $\mathrm{km}^{2}(1$ per & on per mile ${ }^{2}$ ) & 70 \\
\hline 4c. Glaciers and snow cover & Ice Sh & $1,524 \mathrm{~m}(5,000$ feet) thick or more & 100 & & 1 per km² $(2.5$ per & ons per mile²) & 50 \\
\hline & Ice she & $700 \mathrm{~m}$ (2,300 feet) thick & 96 & & 4 per km² $(10$ per & ns per mile ${ }^{2}$ ) & 0 \\
\hline & Icecap & out $304 \mathrm{~m}$ (1,000 feet) thick & 60 & 10. Degree of economic activity & No production, $\mathrm{nc}$ & e foreseen & 100 \\
\hline & Névé & & 20 & & Exploration but $\mathrm{n}$ & exploration reserves known & 80 \\
\hline & Snow & er of less than $2.5 \mathrm{~cm}$ ( $1 \mathrm{inch})$ & 0 & & 20 persons living & $f$ the land; airstrip & 75 \\
\hline 5. Total precipitation & $100 \mathrm{~m}$ & (<4") & 100 & & Low level of comn & ercial sea fisheries & 60 \\
\hline & $200 \mathrm{~m}$ & $(<8 ")$ & 80 & & Gathering, extrac & n, or handicrafts | radar site; small & 50 \\
\hline & $300 \mathrm{~m}$ & $(<12 ")$ & 60 & & factory, light inve & ment & 50 \\
\hline & $400 \mathrm{~m}$ & $(<16 ")$ & 30 & & Minerals, storage & erminal | small scale agriculture & 30 \\
\hline & $500 \mathrm{~m}$ & $(<20 ")$ & 0 & & Major "secondary & enterprises; well developed agriculture & 15 \\
\hline Table 1.1 - Nordicity Ind & & & & & Interregional cent & with multiple services; heavy invest. & 0 \\
\hline
\end{tabular}


10. UN-HABITAT. (2006). Slums: Some Definition. State of the World's Cities 2006/7 , 2.

11, 14. National Aboriginal Health Organization. Homelessness and Housing Realities for Inuit: Workshop Report. Ottawa: Inuit Tuttarvingat, National Aboriginal Health Organization

12. Statistics Canada. (2010). An analysis of the housing needs in Nunavut: Nunavut Housing Needs Survey 2009/2010. Income Statistics Division. Ottawa: Statistics

\subsection{Nuna-Slums}

It is important to define the term 'slum' with an internationally accepted definition. People have used the term in deferring applications, most often derogatorily. According to the United Nations (UN-HABITAT) a slum household is defined as a group of individuals living under the same roof in an urban area, who lack one or more of the following: durable housing of a permanent nature that protects against extreme climate conditions; sufficient living space, which means not more than three people sharing the same room; easy access to safe water in sufficient amounts at an affordable price; access to adequate sanitation in the form of a private or public toilet shared by a reasonable number of people; and security of tenure that prevents forced evictions. ${ }^{10}$ Nunavut is victim to some of these qualifiers listed by the UN, primarily within the social housing industry.

In the context of historical Canadian and Inuit relations, many of the communities, known as Hamlets, are at most 60 years of age. When the Inuit moved from a nomadic lifestyle to the urban setting, the Hamlets needed to rapidly produce infrastructure: housing, utilities, and institutional buildings. The influx of population was severe enough to cause municipalities' infrastructure to fall behind with the demand. Unfortunately today, Hamlets are left with a dual problem: much of the old housing is deteriorating, while there is an inability to keep up with the demand. Due to these constraints, when Hamlets receive funding they must choose to either repair the old buildings or build new ones. Either way, there is never enough time nor finances to solve the housing shortage.

Many communities in Canada's north, specifically the Inuit neighborhoods, have problems with overcrowding, insufficient access to potable water, and unsafe housing conditions. A resident states, "Housing is not the only issue, but all issues relate to housing."11 Of all households in Nunavut, half 
13. Impact Economics. (2012) Understanding Poverty in Nunavut. The Nunavut Roundtable Fo Poverty Reduction. Impact Economics.

14. White, P. (2011, April 1). The trials of Nunavut: Lament for an Arctic nation. The Globe and Mail are crowded and/or in need of major repair. (See Figure 1.212) Public housing makes up 57\% of occupied dwellings in Nunavut; Inuit live in $99 \%$ of them. ${ }^{13}$ When addressing the housing situation in the North, it is important to understand the context. According to the National Aboriginal Health Organization (NAHO) there are three vital characteristics to consider for Inuit regions: hidden homeless, housing design based on southern needs, and climate requires habitation. ${ }^{14}$

The first characteristic, hidden homeless, is unique as it bends the rules of the normative notions of what it means to be homeless. In contrast to the homeless in the rest of Canada, homelessness for those in Nunavut is hidden. Whereas, the cultural values of the Inuit insist on families sharing what they have with the rest of the community, housing is no exception. In the south the individual stands out and people are left to fend for themselves. For thousands of years, Inuit have always been communal with sharing of resources; it was taboo to sell country food (e.g. whale, seal, caribou, etc.). Today, much of that value system exists. However, times are changing, lifestyles are changing; i.e., some Inuit are beginning to sell country food in order to survive. A question posed is; how will this affect the hidden homeless in the future?

Another characteristic that challenges the intentions of those in policy planning is that housing is designed for southern needs not the northern Inuit. The nuclear family is the model of southern housing design. Many housing designs accommodate three to four bedrooms, where as, Inuit families are multigenerational in cohabitation requiring a larger number of bedrooms. If given the option to live in one or two houses, a large Inuit family would try to squeeze into one so as to live together. 


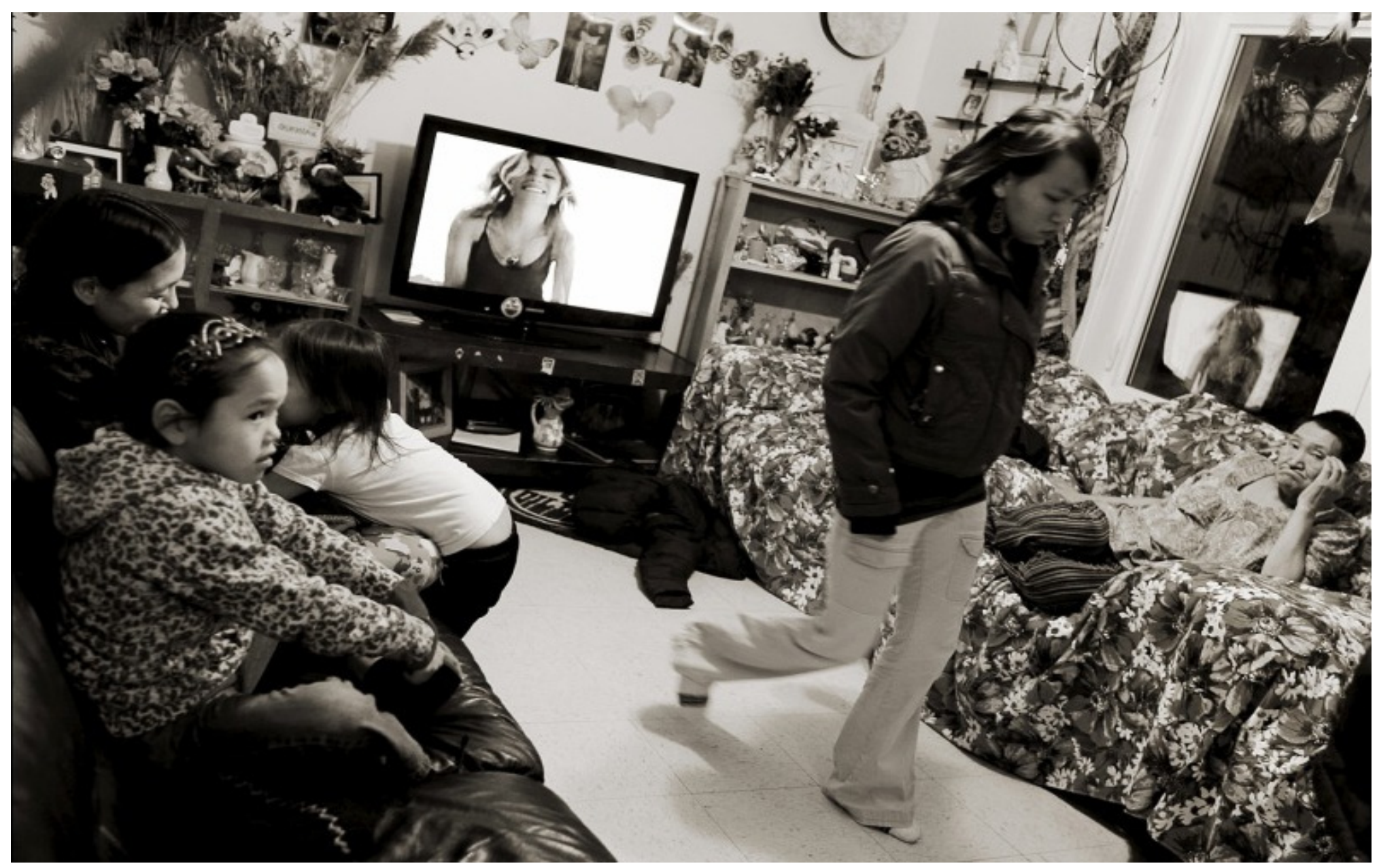

Figure 1.1 - Overcrowded House in Cape Dorset ${ }^{14}$ (White, 2011) 


\section{Nunavut Housing Issues}

¿ Crowded only

$\square$ Major repair only

$\square$ Crowded AND requires major repair

$\square$ Neither crowded NOR major repair

Figure 1.2
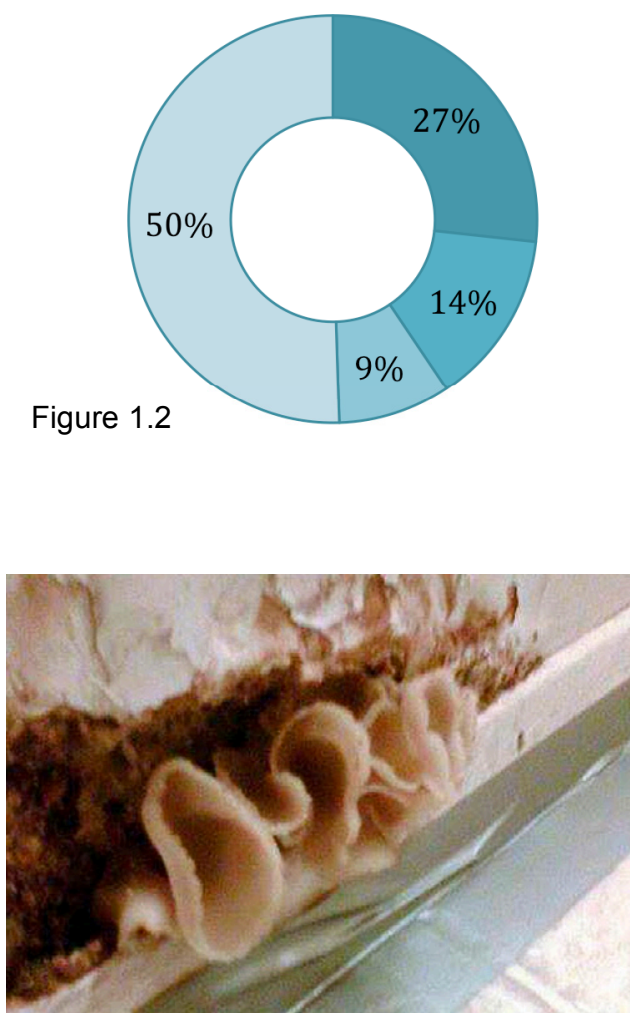

Figure 1.3- Mushrooms growing in walls in Baker Lake, Nunavut (Aupaluktuk, 2013)
Many overlook the cold climate as being a serious factor; climate requires habitation. For most of the year, a homeless individual requires shelter, or they will freeze to death. The notion of homelessness is challenged, in that they are not in 'absolute homelessness.' This situation leads to the first of three characteristics mentioned, to have hidden homeless.

This situation is the result of various factors, but mainly housing shortages. The homeless in these communities have resorted to three major solutions for shelter: shack dwelling, homeless shelters and living with friends and relatives. Shacks, informal shanties, are built with scrap construction materials; they usually possess little or no resistance to the arctic climate. Homeless shelters are not much of an option since they have extremely limited beds, and are only for the night. The third solution, living with friends and relatives, is resulting in the overcrowding levels seen today. In all four Inuit regions, most residences are acutely overcrowded. As a group, Inuit suffer the worst overcrowding in Canada. It is estimated that 53 percent of Inuit households are overcrowded, and it is common for seven or more people to inhabit a single household. ${ }^{15}$

"Inuit regions [in Canada] are experiencing a serious housing crisis...Insufficient housing can lead to overcrowding, deficient sanitation and ventilation, the spread of infectious diseases, psycho-social stresses, and violence. Among Inuit, housing problems have been associated with low acbievement levels in schools, spousal abuse, respiratory tract infections among infants, depression, and substance abuse.” 16

United Nations notes that overcrowding has been identified as a major risk factor contributing to suicide, violence, and the spread of disease in indigenous communities. ${ }^{17}$ Another consequence of improper housing design and overcrowding is the inadequate water supply. Many of the housing units in the North are not on utilidor (community serviced above-ground water and 
15, 16. National Aboriginal Health Organization. Homelessness and Housing Realities for Inuit: Workshop Report. Ottawa: Inuit Tuttarvingat, National Aboriginal Health Organization.

17. UN-HABITAT. (2005) Indigenous peoples' right to adequate housing. United Nations Housing Rights Programme, 85.

18. Anderson, E. (2008). Canada's Relationship with Inuit. Minister of Indian Affairs and Northern Development. Ottawa: Public History Inc. sewage pipes) and need to have the water and sewage serviced from a truck. Since water tanks are sized for a small family, houses that are overcrowded run out of water in a fraction of the time. Many communities do not have the capability to truck water more than twice a week. This means the occupants have to ration their water considerably. Many adults would go without bathing, and children would share bathwater. The cost to fill a tank not on schedule costs hundreds of dollars. It would cost $\$ 250$ in Iqaluit; other communities could cost more due to their lack of infrastructure. This burden is too much for those living in social housing.

"Overcrowding in northern homes is a persistent problem for Inuit families. Similarly, the construction of new homes and repairs to existing homes has not kept pace with the population growth of northern communities." 18

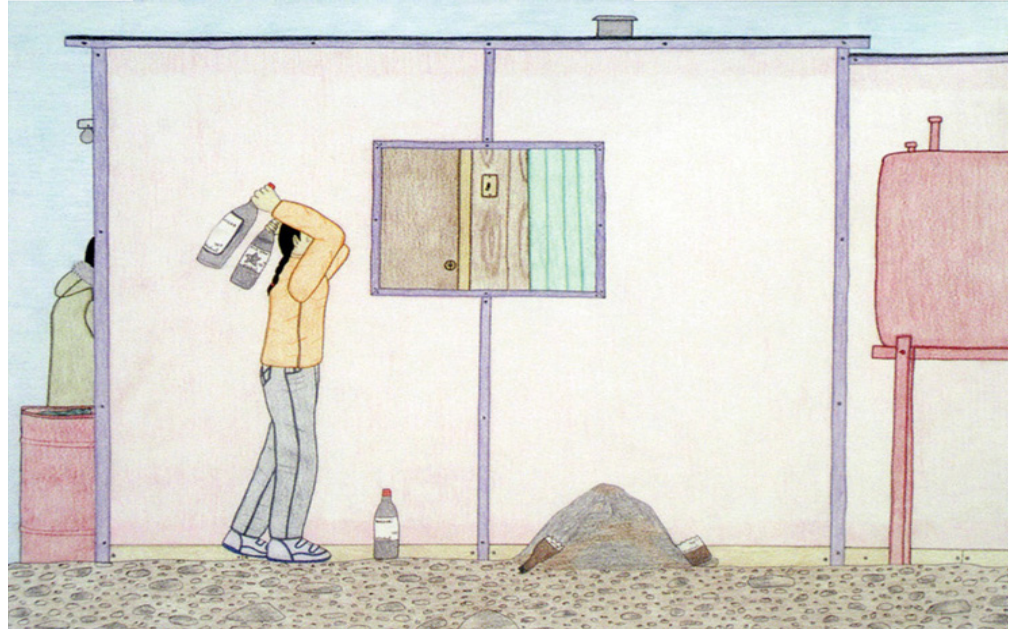

Figure 1.4 - Memory of My Life: Breaking Bottles by Inuit artist Annie Pootoogook (Pootoogook, 2002)
The other major factor that designates areas of Nunavut to be slums is the building conditions. There is a large portion of social housing units that require major renovation. The majority of the repairs are compounded due to lack of maintenance and severe arctic conditions. The harsh cold climate dictates that buildings are airtight to reduce infiltration and heat loss. These dwellings, however, were not designed for overcrowding. An increase in moisture from people and cooking has caused major mold and mildew problems. This has led to a variety of respiratory and communicable diseases: such as, tuberculosis, influenza, hepatitis, and etc. Other items that can be noted are the broken windows, large holes in interior walls, MEP (mechanical, electrical, plumbing) issues, and more. Many of these problems are dangerous 
to anyone, but specifically children. Although concerns have been voiced, many have not been addressed for years.

\subsection{Norditecture}

In many regards, regionalism is the term that fits into what northern architecture (Norditecture) should embody. Unfortunately, the definition of such has become unclear. Wendell Berry author of The Regional Motive, refers to regionalism as "sloppily defined in its usage, or more casually understood." There are some aspects of regionalism that should be applied to Norditecture theory and design. One principal stands out is the need to resist universal structures that disrespects local uniqueness. The term Norditecture is being introduced to reflect architecture that embodies the distinctiveness of what is considered north or northern. Unlike vernacular architecture, seen as inventive and created out of necessity, Norditecture embodies design principles that prescribe autonomous solutions to the needs of northerners. Vernacular architecture should not be ignored since it reflects local states: such as, climate, materials, landscape, and etc. For example, the Inuit created snow houses in the past; shacks built out of scrap material today create makeshift domiciles for the homeless.

19, 20. Dawson, P. C. (2008) Unfriendly Architecture: Using Observations of Inuit Spatial Behavior to Design Culturally Sustaining Houses in Arctic Canada. Housing Studies, $23(1)$,
The trend in Canada's north is to import building designs and methodologies to respond to the rapid growing population. Due to housing shortages, the approach has become utilitarian. This unfortunately has its price, as much of the housing is inappropriate both climatically and socially. The contrasts between 'systematized' versus 'culturally sensitive' approaches to architecture capture the central issue in northern aboriginal housing. As mentioned previously, urgent need for housing, 
coupled with the high cost of labor and shipping materials to remote northern settings, often required planners to use 'universal' rather than 'culturally specific' design criteria. ${ }^{19}$ Canadian archeologist Peter Dawson from the University of Calgary states,

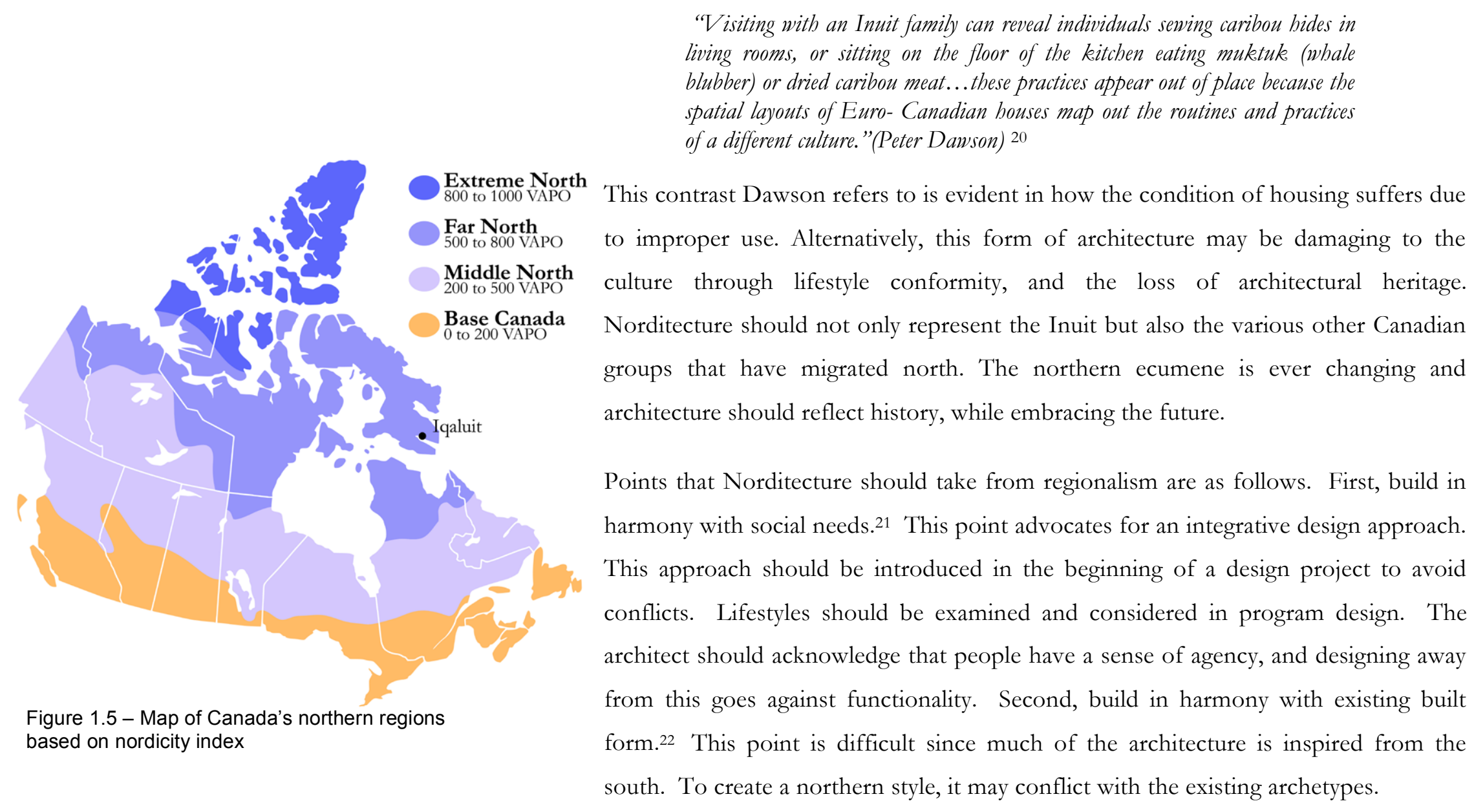


21, 22, 23, 24. Holmes, L. (2013). Nuna-Regionalism. Waterloo, Ontario, Canada: University of Waterloo.
However, any new design should consider the characteristics of its context, taking note of elements like building facades and scale. It should also complement the urban fabric that city planners have designed; such as circulation patterns, snowmobile trails, and drainage paths.

Third, build in harmony with geographic characteristics of a region. ${ }^{23}$ Climate and terrain in the North dictates a lot of building designs and methodologies. Norditecture should and must pay heed to geo-climactic conditions. Modernism has attempted to dominate nature through technology and will. This has translated to increased cost of energy, through a reliance on mechanical systems for heating and cooling. Traditionally, vernacular architecture such as igloos in winter and caribou skin tents in summer was sufficient in keeping its inhabitants comfortable. In addition, these structures were carefully placed in relation to its environment. Although they do not suit the needs of today, they should be seen as a passive design approach that could be adapted to contemporary housing. Instead of arbitrarily placing a building based on its location to a road or utilidor, it should be carefully placed to consider soil conditions, views and snowdrifts. In Iqaluit, Nunavut, a few houses were buried in snowdrifts, although the city was warned by the local elders that this could happen, housing was still built and suffered heavy damage.

Fourth, build in harmony with local resources and technology. ${ }^{24}$ This point is conflicting as to what are defined as local resources. Much of the Canadian north is above the tree line and has an insignificant number of industries produce anything of construction value. Stone and sod promote little use to conventional construction. It is said that a whole house would need to be built inside of a stone enclosure to have the same thermal resistance value. Technology is dependent on the skills of those installing and maintaining. There is no use to install sophisticated mechanical equipment if 
there is no one with the know-how to install or maintain. Traditional indigenous construction techniques offer a unique method for construction but are often seen as outdated and more symbolic than functional. Merging the two techniques could promote a more adaptive application to the dynamic north.

In keeping with these points, this thesis seeks to explore and synthesize the Norditecture of Iqaluit. Over a short period of time, Iqaluit's rapid growth has demanded modern and utilitarian architecture to fill the void. Unfortunately, the majority of architectural projects have experienced failures. Many of which have been in regards to climate, social and cultural conditions, etc. In the 1950-60s the Canadian government introduced a number of inappropriate housing strategies, such as "the matchbox" house, with a footprint of 12 by 24 feet. These 288 square foot homes -having no running water, and no sewage treatments- housed multigenerational families of the time (see Figure 1.6). Housing models similar to the matchbox littered the Territories, while having extraordinarily high-energy bills since they were inappropriate for the climate. 


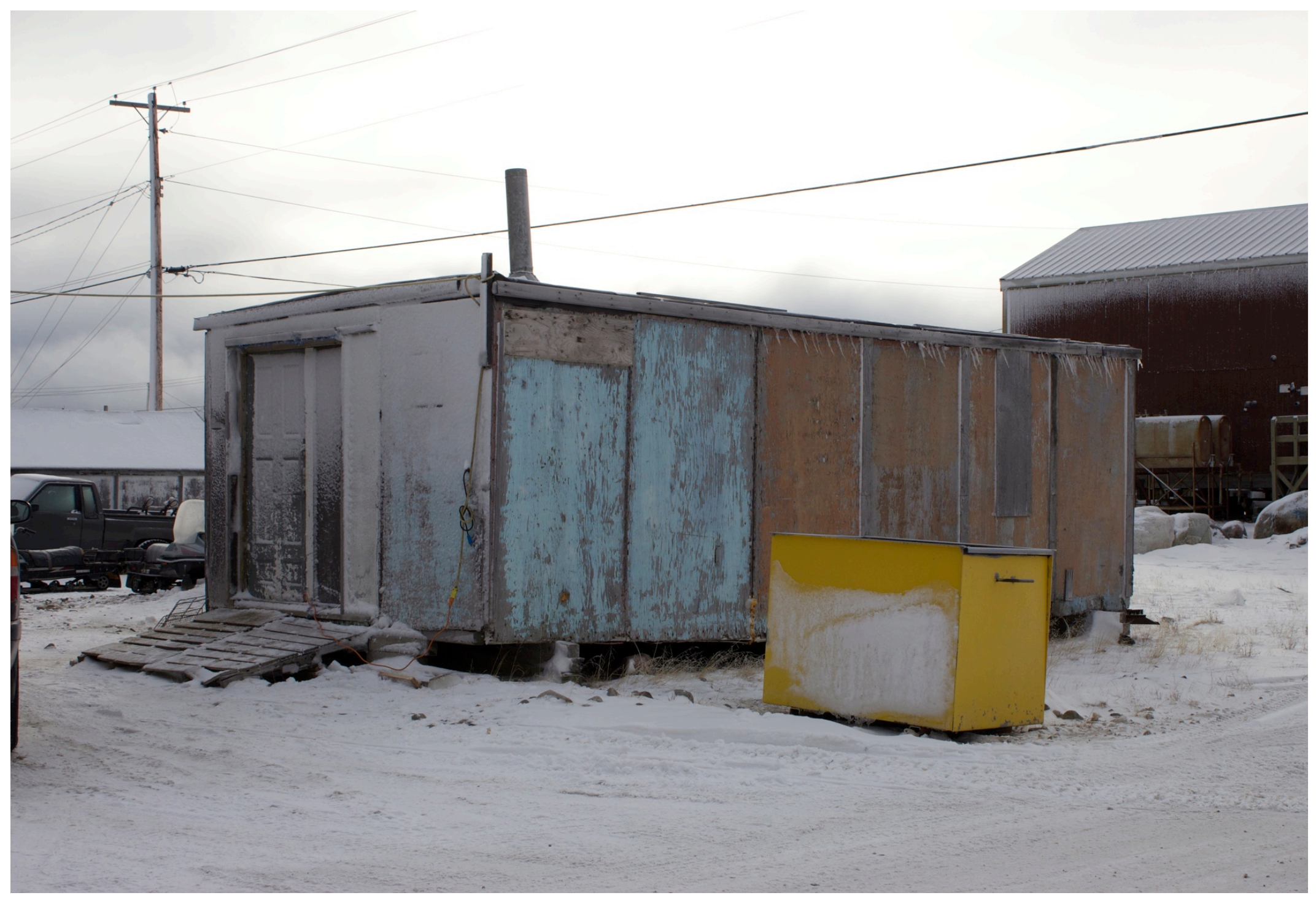

Figure 1.6 - The Matchbox, located in Arviat, Nunavut, built 1950-60 
Today, housing remains regionally unsuitable for the various conditions that the North places on buildings. Climactically, these buildings are not designed to withstand the extremes of wind and snow. At times, select buildings can become engulfed in snowdrifts. Geographically, permafrost threatens the integrity of any foundation. Economically, the cost to construct and maintain is typically four times that of the South. Socially, lifestyles are not represented in the built form such as accommodation of the snowmobile, large outerwear, and processing of large game. Culturally, the indigenous are far removed from traditional lifestyles and are forced to adapt Euro-Canadian standards.

Between the "50s and '70s, various architects took on the challenge of urban arctic design. Figure 1.7-11 reveals the experiments made for housing and amenities. Since the climate was seen to be inhospitable many of the designs reflected self-containment, some are seen as space age. The main function of establishing these structures was to exploit the resources and show sovereignty in the

25. Lee, B. (2012). Radical Arctic Proposals, 1-25.
North, 25 ultimately to conquer the Canadian Arctic.

Swedish architect Ralph Erskine was a proponent of region-oriented design. As a response to the issues growing in Resolute Bay, -such as, poor housing, lack of services, and a rapid population growth of Inuit and seasonal southern inhabitants- in 1973, Erskine designed a complete town, to relocate the existing. It accommodated and celebrated regional elements (Figure 1.12). He studied traditional concepts from the indigenous with modern construction methods (then). In many respects, 
26. McLellan \& Associates Limited.

(1980). Environmental-Social

Program, Northern Pipelines.

General Development Plan,

Resolute Bay, N.W.T. Ottawa.

27, 28. Pressman, N. (1995) Northern Cityscape; Linking Design to Climate. Kitchener: Aljon Print-

Craft Limited.
Besides the climatic and topographical considerations, Erskine also considered the psychological aspects of arctic living and their relevance to the project's planning. In an effort to bridge the segregation that was apparent at the old site between the Inuit and the Southerners, and to counter the effects of living in a socially isolating and topographically homogenous desert environment, all inhabitants agreed to live in a more concentrated schema of town houses and single family houses at the new site. The closeness of the new town structures would encourage outdoor commutes to both indoor and outdoor common spaces, in a climatic milieu that is dominated by indoor living. 26

Through this method of allowing the towns planning to be "dictated by climatic and topographical concerns...[Erskine's planning responds]...meaningfully to human needs, local materials, and natural forces." 27 Erskine carefully analyzed climate and topography in conjunction with snow patterns and permafrost to propose the most appropriate design to the government of Northwest Territories (Nunavut was not establish then). Using an integrated design approach, working with the inhabitants, there was an agreement to enclose the town structure with a northern windscreen composed of buildings. The layout would provide a "micro-climatic shelter" within the interior of the town. ${ }^{28}$ Due to budget and politics, the project was halted in its early stages. 

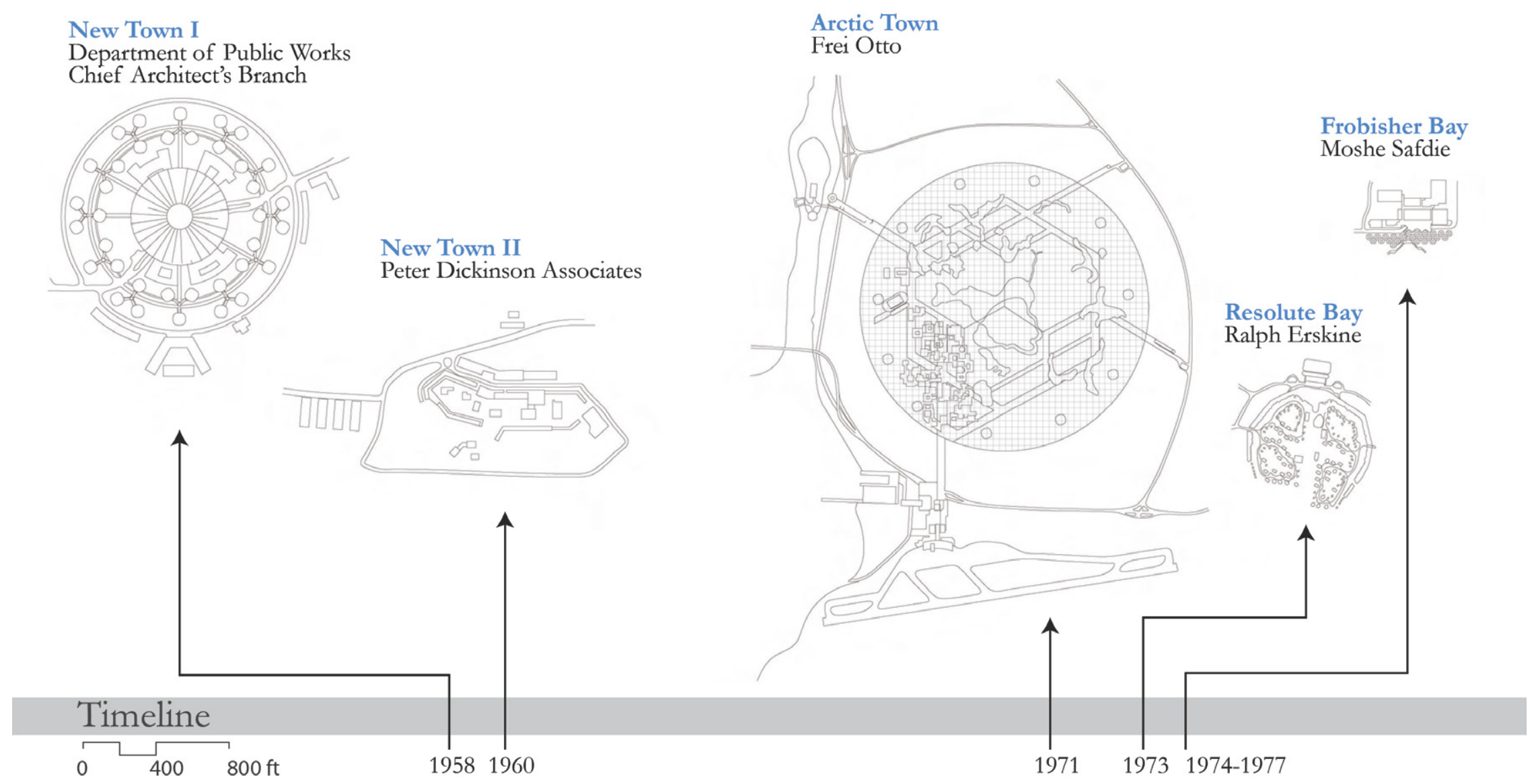

Figure 1.7 - Arctic proposals (Lee, 2012) 


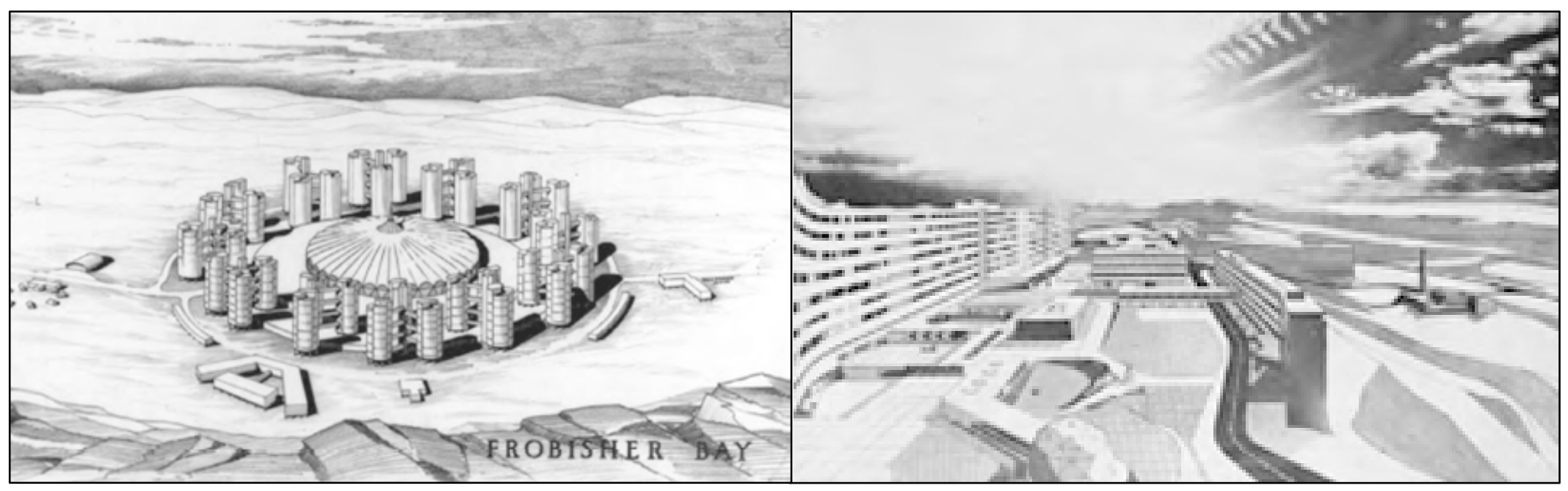

Figure 1.8 - New Town I Proposal - Frobisher Bay 1958

Figure 1.9 - New Town II Proposal - Frobisher Bay 1960
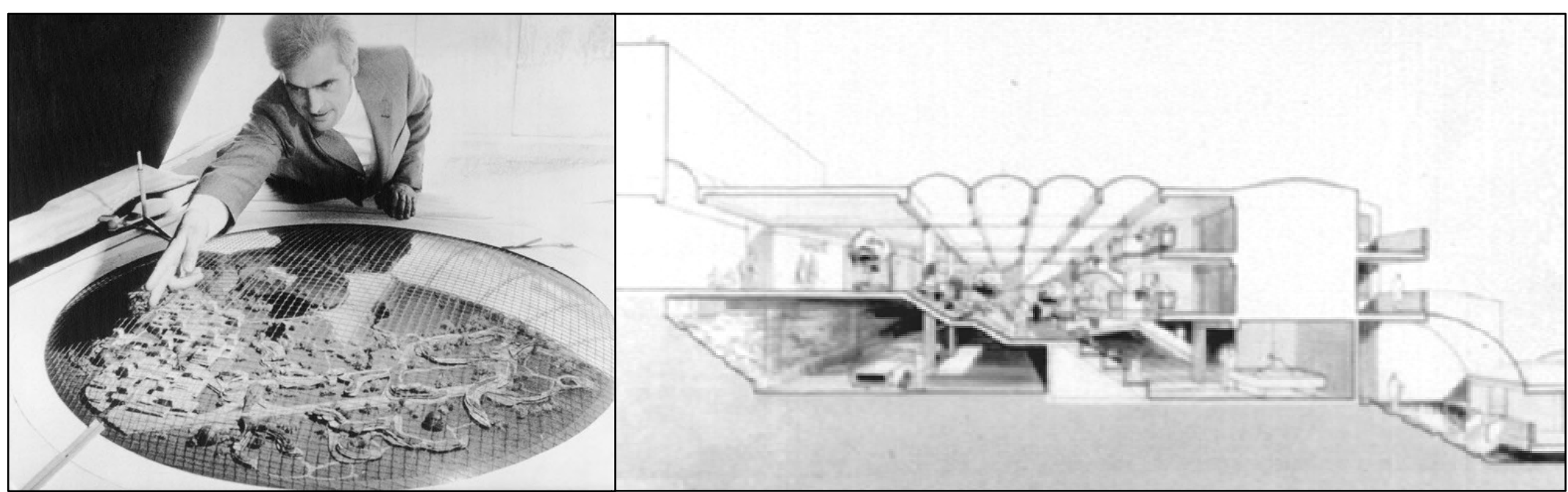

Figure 1.10 - Arctic Town Proposal - 1971

Figure 1.11 - Frobisher Bay Proposal - Frobisher Bay 1974-77 

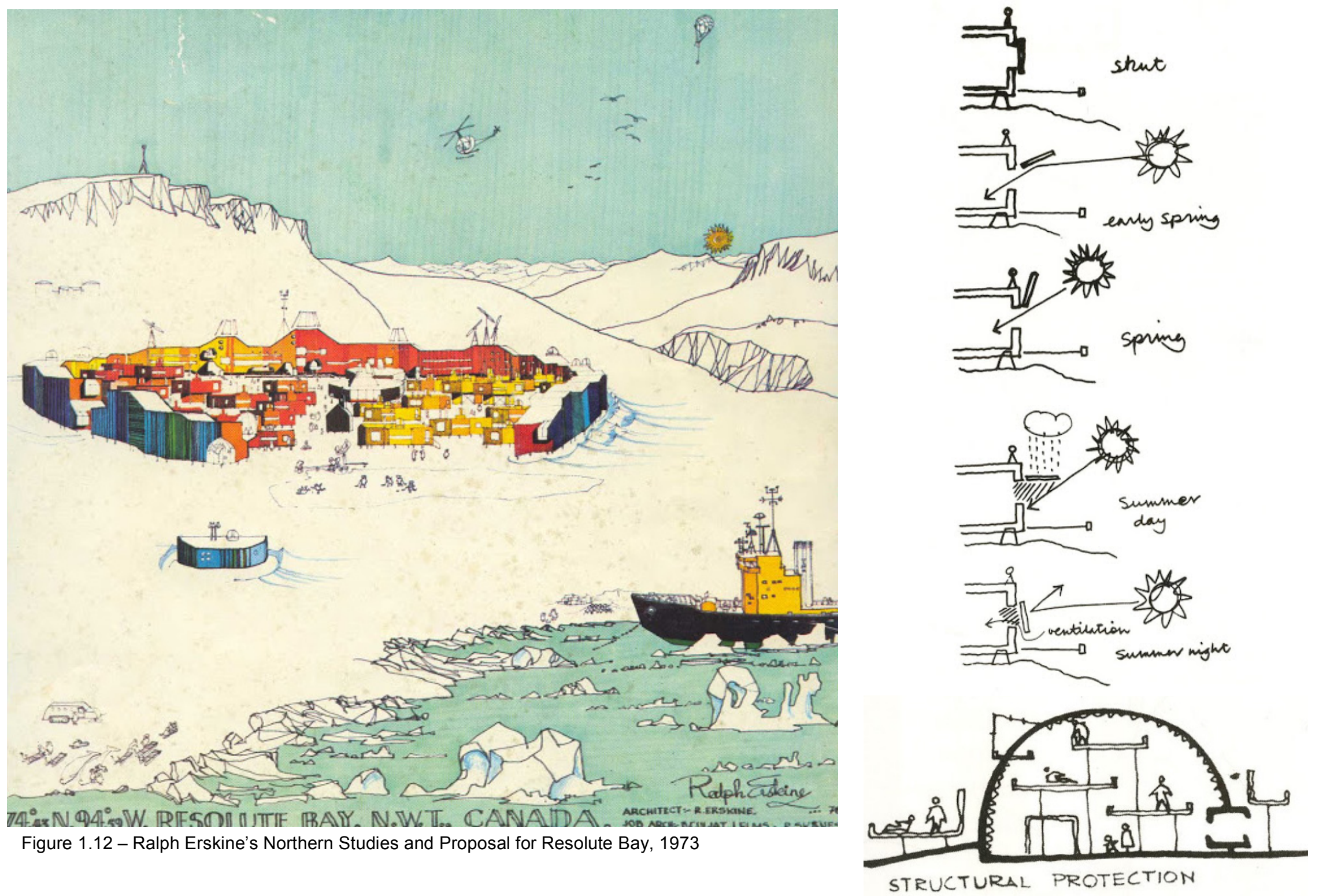
29. Strub, H. (1996). Bare Poles: Building Design for High Latitudes (Vol. 186). McGill-Queen's Press -

MQUP.

In Iqaluit, respect to Norditecture is less prevalent, and any substantial attempt vanished in the '70s. Attempts made in the past included; the row-housing scheme by Moshe Safdie that was aborted, and the high tech reinforced fiberglass panel institutional structures designed by Papineau GérinLajoie LeBlanc still existing today. ${ }^{29}$ (Figure 1.13) These structures were designed to deflect snow and wind. Having prefabricated panels accommodated the short construction season. The visual language is out of place in that the design reflects more of science fiction, with its ship like windows and modern curvatures. Their inherent unique, or authentic, characteristics do however create a unique relationship that fosters memorable experiences with the users. This is an important aspect to norditectural principals, in that they establish a unique identity. It is however, a question of whether this identity reflects the inhabitants.

By having architecture that embodies values of Norditecture, Iqaluit will begin to establish a strong identity and possibly cultivate pride of place. Because Iqaluit is the capital of Nunavut, any intervention introduced into the city will act as a catalyst influencing the other northern communities.

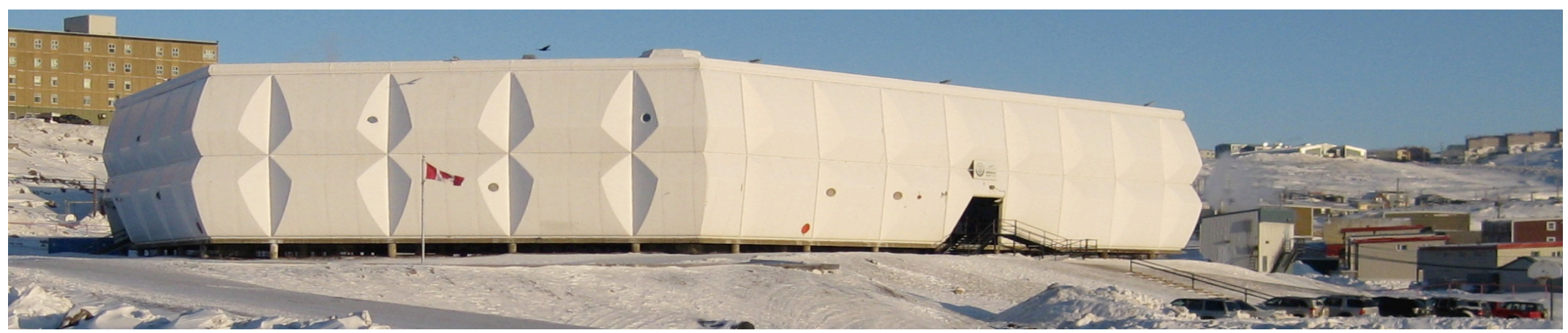

Figure 1.13 - Nakasuk School, Iqaluit, designed by Papineau, Gérin-Lajoie et Leblanc, architects. 


\section{Chapter: Inuit Realities}

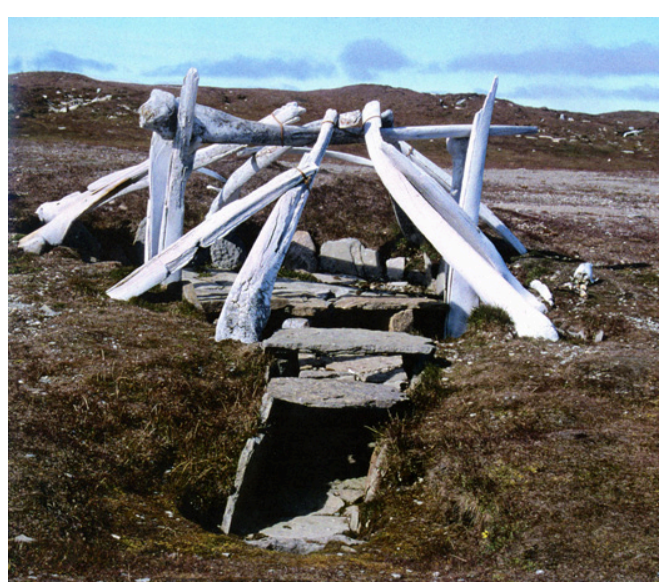

Figure 2.1 - Thule whalebone shelter (Newberry, 2009)

30. Inuit Tapiriit Kanatami. (n.d.) Inuit Historical Perspectives. Retrieved November 6, 2013, from Inuit Tapiriit Kanatami: www.itk.ca

31. Athropolis Productions Limited. (2005). Inuit History: 300-1000 Years Ago. Retrieved November 6 2013, from Athropolis: http://www.athropolis.com

\subsection{Pre-History}

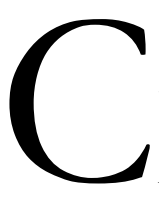

anada has had its share of diverse populations for thousands of years. 5000 years ago the Paleo-Eskimo group inhabited the North. They first appeared in the area now known as

Alaska. They used stone knives and stone tip harpoons and arrowheads. Over time they eventually headed eastward. 3000 years ago some of the Paleo-Eskimos, living in the central and eastern Canadian arctic, developed into the Dorset people. Their technology adapted to the harsh region, with ivory snow-knives, soapstone lamps and seal oil for heat. They were also known as artisans. Modern Cape Dorset was named after them for being Nunavut's art capital. About a thousand years ago, with warmer weather, the Thule people came across the Bearing Strait looking for whales and other game. The Thule people are the ancestors of the modern day Inuit. They replaced the Dorset people. It was not known why the Dorset people disappeared, but it is known that the Inuit had better technology to adapt to the extreme arctic conditions.

'Thule are the ancestors of today's Canadian Inuit... Archeological evidence shows the Thule culture had skills and technology to harvest large whales, seals, caribou, muskox, fish and birds, depending on the season and location. Before Europeans arrived, Inuit handcrafted their own tools from resources found on the land and in the animals they barvested." (Inuit Tapiriit Kanatami) 30

The ability to hunt whales gave these people a better way of life. They built settlements and homes of stone and whalebone - the remains of which can still be seen today. ${ }^{31}$ (see Figure 2.1) For centuries they have survived through a hunter-gatherer lifestyle. Due to the barrenness of the arctic desert, they needed to be nomadic as a society. To be more accurate, they were semi-nomadic 
32, 33, 34. Carpenter, E. (1973). Eskimo Realities. New York, New York, United States: Holt, Rinehart and Winston. based on the availability of natural resources. They would travel by foot or dog team over vast distances to follow the migratory patterns of land and sea mammals. Typically they would live in a tent (tupiq) made of skins and bones in the winter. Summer months usually meant caribou and whale hunting. Winter was better for hunting seals as they reach for the breathing holes in the ice. For hundreds of years the Inuit covered a larger territory spreading from Alaska, along Canada's Archipelago and into Greenland. In the 1500s, the North went through what is called the 'Little Ice Age,' placing severe strain on the Inuit livelihood. Colder temperatures and larger ice flows resulted in a reduction in the whale population migrating through the Canadian Archipelago. Inuit then migrated south toward the tree line and along the Hudson Bay coast where game was more plentiful.

\subsection{Inuit Technology Prior to European Influence}

During the time of pre-history and into recorded history, the Inuit fully adapted to the Arctic environment. Much of their technology is innovative and is still being used today in different forms. It is important to understand that these are a people of ingenuity and fastidiousness, understanding their background would help to frame a better model for housing their people for tomorrow. Anthropologist Edmond Carpenter explores the complexity of Inuit's mechanical aptitude and states "there is something here not easily explained...part of this ability is the obvious hand dexterity, particularly in manufacturing small objects...the first thing that impresses them about Western culture is its machinery." 32 The following is a list of what a typical Inuit family's lifestyle would possess prior to the 1900s. 


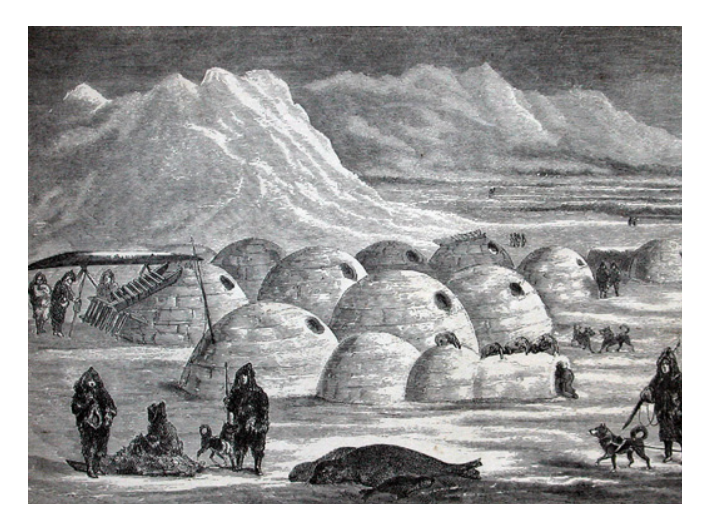

Figure 2.2 - Snow village at Oopungnewing (Hall, 1866)

"Central Inuit observed rituals in connection with snow-house building. For instance, to ensure good luck for their children, they removed from the house any chips left over from fitting the blocks together." 33

\subsubsection{Shelter}

There are three main types of shelters the Inuit used: the igloo (snow house, see Figure 2.2), the tupiq (summer tent), and the qarmaq (sod house, see Figure 2.3). The igloo was vital to survival while hunting along ice flows during the winter. Because the igloo only took approximately two hours to build, it allowed the hunter to keep mobile. In some instances, there would be groups of igloos joined together, usually if the family grew. If there was a gathering of Inuit, for cultural events, qaggiqs (large scale snow house) were constructed. The design utilizes methods practiced in architecture today. There were three main elements designed into the snow house: porch, main domed area and platform. The porch acted as a cold trap since it was lower than the rest of the igloo floor. Because of the dome shape, heat dispersed evenly in the upper part of the room, creating a natural heat stack effect. The raised platform allowed the occupants to stay within the warmest part of the structure.

"An [Inuk] doesn't mold his igloo from the outside looking in, but from the inside looking out. Working from the center, he builds a series of concentric circles, tapering upward conically. When the keystone at the apex has been set in place, [Inuk] and structure are one. Only then does be cut the small bole at the base through which he crawls-in effect, doffing his igloo." (Carpenter) 34

Because the summer months could not support usable ice for igloos, aside from the high arctic, tupiqs were constructed. The terrain was still cold during the summer, and rain could have been met with illness. Tupiqs were designed to be warm and waterproof by using animal hides and overlapping the seams to make them water tight. As with the igloo, the tupiqs were domed in shape. The skins had to be collected while the animals were molting to make it easier for fur removal. The 


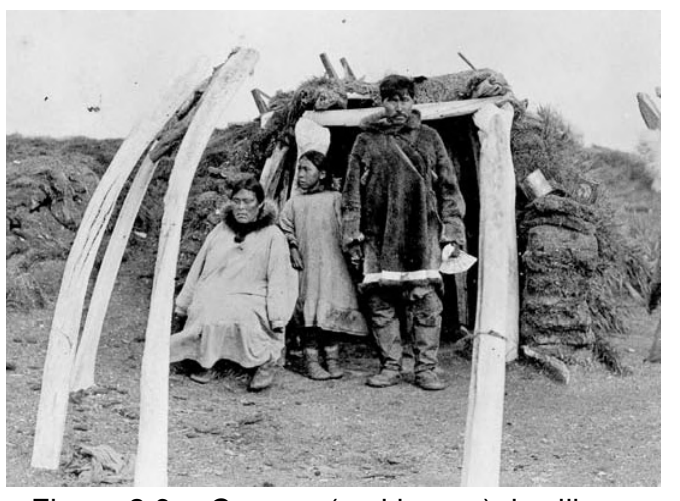

Figure 2.3 - Qarmaq (sod house) dwelling (Canada, 1960)

structural members were made of whalebone, narwhal tusk or driftwood. If the Inuit were stationed close to the tree line, timber was utilized. Stones were used to anchor the skins to the ground. These structures were similar to the igloo, in that they were at times joined together to accommodate larger families.

As these dwellings were made with the materials at hand, qarmaqs were used in conjunction with the tupiqs. These structures were usually semi-sub terrain and used wood, whalebone or tusks for the roof supports. Sod was then placed on top of the structure creating a waterproof, insulated house. Some of these qarmaqs lasted for generations, making them reusable to whoever passed through the area during hunting season.

\subsubsection{Travel}

Traditional methods of transportation are important to understand for a nomadic people. The landscape is harsh and difficult to maneuver. Searching for game forced the Inuit to cross over treacherous land, dangerous ice flows and large bodies of water. Land based and water based travel methods were innovative, and is an example of the ingenuity they possess.

Water based travel was key since much of their diet was seal during the winter and whale during the summer. They crafted the kayak and the umiaks. Kayaks are a one man decked over small boat made of whale ribs or driftwood as the frame and wrapped in sealskins. Great for maneuvering around ice flows. The umiaks (typically 20 to 40 feet long) were large boats mainly used in whale hunting or moving large families, constructed similar to the kayak, but with an open deck and flat bottom to allow for easy mooring. 
There were two main methods for land-based travel, by dog or by foot. A dog team would typically pull a qamutik (sled). The dogs, 'Eskimo Huskies', were known to have the ability to pull 500 to 1000 pounds. These were the product of breeding dogs and wolves. Without the dogs, the survival of the Inuit in the North would be questionable. Dogs were not pets, but the pups were cared for carefully as they would help with the continuity of generations to come for both animal and family. The qamutik was made of bone, antlers, and driftwood or traded wood from the South. Caribou sinews were used as rope to tie the pieces together. Since the structure is tied, there was more flexibility on a rough terrain. Fish was sometimes affixed to the bottom runners for better glide, if food was scarce, they would eat the fish. It was understood that when the Inuit travelled, all they possess was on the qamutik. At night, the qamutik had to be kept separate from the dogs, or they would end up eating the sinews.

During the winter, there were areas that the dogsled could not reach, but they were great for hunting. Snowshoes, made from a mixture of bone, antler, driftwood and caribou sinews were used. These allowed the Inuk's weight to be dispersed along the snow and not get stuck. Summer travel was without the assistance of dog sleds; the best way to traverse large distances was waterbased.

Because of the scale of the North and the distances Inuit travelled for sustenance, navigation was key. Unlike modern technological methods of navigation, they had a keen understanding of the landscape. Modern navigation tells you where you are relative to a fixed point on a map. Inuit had a direct relationship with the land, comprised of a knowledge base that was passed down for generations. Carpenter describes this understanding of the land, 
35. Carpenter, E. (1973). Eskimo Realities. New York, New York, United States: Holt, Rinehart and

Winston.

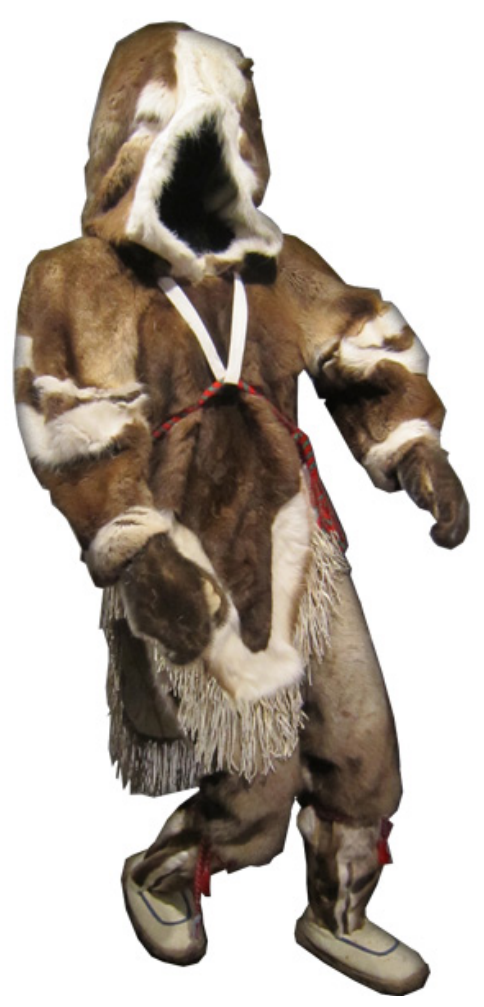

Figure 2.4 -Inuit Man's Clothing
"Their astonishing gifts of observation, their familiarity with the smallest details of this monotonous land, particularly its coastline, never failed to amaze me. Rarely did a man seem uncertain. But as I looked about, at the utter sameness of the land, I simply could not imagine what reference points he was using...through natural reference points. By and large these are not actual objects or points, but relationships: relationships between, say contour, type of snow, wind, salt, air, ice crack." (Carpenter) 35

Some of the reference points were understood by previous travel and by vivid stories from other Inuit. Inuit also erected Inuksuk's to act as natural landmarks representing various meanings based on their configuration. Some were for way finding, location of deep snow, good fishing and hunting grounds, also if there was an event that occurred on that spot.

\subsubsection{Clothing}

Prior to contact with Europeans, hunting produced animal hides, sinews and intestines, for the crafting of adequate clothing. Clothing for the arctic regions must fulfill three specific needs: insulation, moisture management, and reduce wind infiltration. Similar to Vitruvius's conditions for good architecture, -firmness, commodity and delight-, Inuit clothing embodied durability to the elements, functionality, and were cultural in their adornment. Clothing in cold climates is as important as the shelters. Similar to buildings they need a strong envelope, thick insulation and ventilation.

Heat retention in the extreme cold is fundamental. Similar to a wet suit in water, where the water trapped next to the body becomes warm, so does the air in traditional Inuit clothing. The women of the family would sew the outfits together, and the skills were of high standard since it was imperative to not let any of the warm air escape. (see Figure 2.6) Although heat retention was 
"Men sometimes fall into water so we usually pack extra clothes for them when they go bunting. What you bave to do when you get wet is wring your duffle socks well and pour the water out of your hoots. You turn your socks inside out, wring them, stamp on them and slap them with a stick repeatedly. Then you allow them to freeze, while keeping your feet covered. You have to do it fast so that you don't get too cold. Once the socks are frozen you remove the ice by slapping your socks against something hard. They'll become dry if you do that." 36

Akinisie Novalinga of Purvirnituq

37. Buijs, C. (2001, December 12). Clothing from East Greenland. Retrieved November 10, 2013, from National Museum of Ethnology: http://volkenkunde.nl/

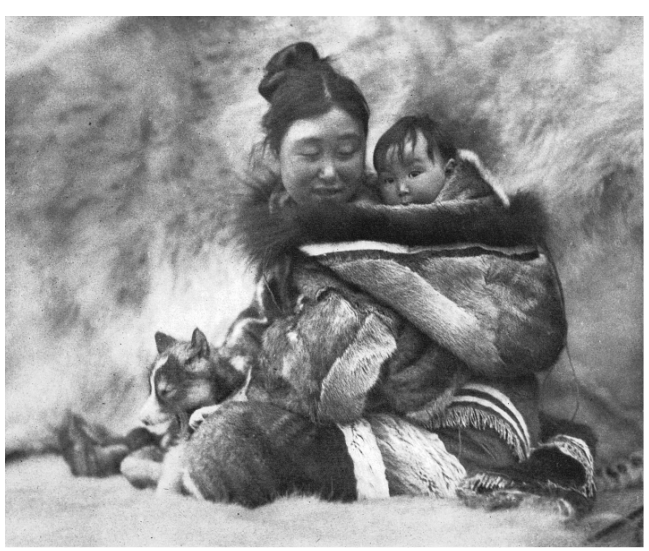

Figure 2.5 - Inuit woman wearing amauti with child inside. (Flaherty, 1920-21) paramount, allowing the body's humidity to evaporate was vital. Moisture management is critical to those who stay outside in the cold for hours, and are in direct contact with water through most of the year. Two main sources of moisture were considered when designing Inuit clothing: exterior and perspiration. Wind protection is just as important as any other, since the big enemy is wind chill. Some days the wind-chill temperature could be twenty degrees lower than the actual temperature. Some clothes, like the closed coat, did not have any front fastening not allowing wind to infiltrate. Materials such as fur and leather were wind-proof, whereas sealskin was more ideal for waterproofing.

The hairs of the fur are hollow and contain air, which has an insulating effect. Fur without pigment, as in the case of the polar bear's white pelt, contains more air than other kinds of furs, because the empty space in the hairs (normally containing pigment) is also filled with air. For this reason clothing made of polar-bear fur is the warmest... The length of the hairs and thickness of the pelt also play their part. Seal fur is shorthaired and less warm, but conversely it is waterproof, and it is also easier to remove the bairs for making leather. (Buijs) 37

Inuit clothing is pragmatic. Every detail has meaning and purpose. The hunter and the mother would have unique aspects to their attire suited to the familial roles they provide. The children would have an opening at the back that only opened when they needed to squat for elimination purposes. Hunting along the water meant a need for lightweight and waterproof design. The hunter would constantly get wet from getting in and out of the kayak. Flexibility was key when maneuvering the ice flows. Alternatively, when fishing and seal hunting at breathing holes, the hunter would have to patiently wait long periods with his harpoon in a frozen position. This would 


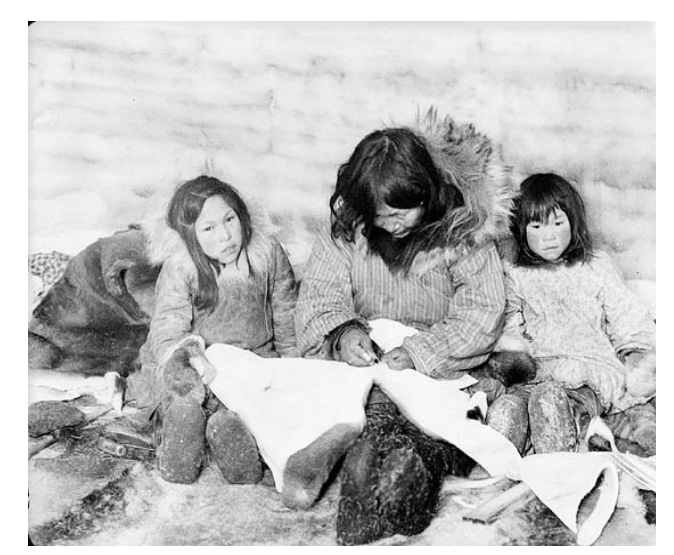

Figure 2.6 - Inuit woman sewing inside an Igloo.

36, 38. Issenman, B. K. (1997). Sinews of Survival: The Living Legacy of Inuit Clothing. Vancouver, BC, CAN: UBC Press.

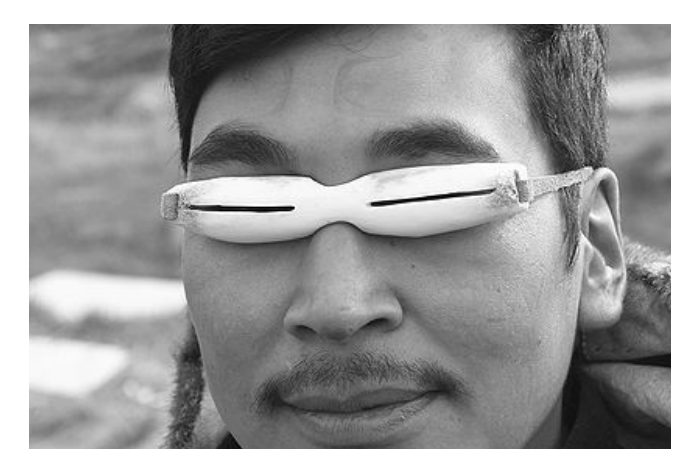

Figure 2.7 - Inuit ilgaak (snow goggles) made from bone. mean that he would not be moving around to produce heat. The clothing needed to become much thicker.

A man's traditional double-layered winter outfit usually consists of nine articles of caribou-skin clothes, of seven named categories: a qulittuq (a closed, hooded parka with fur to the outside); an atigi (the same with fur to the inside); two pairs of qarliik (trousers)', pualuuk (mitts); two pairs ofmirquliik (stockings); a pair of kamiik (boots); and sometimes a pair oftuktuantik (overshoes). ${ }^{38}$ Other members of the family wear similar items, but the married women wear an upper garment known as the amauti. (see Figure 2.4)

The amauti (see Figure 2.5) is one of the most innovative and culturally distinct pieces that the Inuit have developed. Although styles are different from clan to clan, the basic functions are the same. The main part of the amauti is the amant. This is the large hood where a child up to the age of two would stay. The baby would nestle against the mother's back, allowing her to hear and tend to both the physiological and psychological needs of her child. The parka's hood is large enough to allow for protection for both the mother and child against the elements. An apron is used to help with keeping the child warm while cleaning and tending to him or her. Ample room around the shoulders allows the mother to swing the baby to the front without having to take it out and expose it to the elements. The tail of the design is to allow for the mother to sit and keep separate from the snow and ice, in addition to privacy when the mother needs to take care of her personal sanitation needs. 
An accessory to mention is the ilgaak (snow goggles, see Figure 2.7). Snow blindness is a real issue in the North. The Inuit designed the ilgak out of either bone or antler. The Inuk would look through a slit. With the majority of the Arctic with long and wide horizons, the goggles would show what was important and block the light reflection off the snow.

\subsubsection{Equipment}

Inuit used a variety different tools and weapons. Battles were not as common as the southern Amerindians. Equipment was primarily used for survival. In the past, men would carry a long knife and the women would carry an all-purpose $u l u$. Men would carry with them an ivory knife. This was usually derived from a walrus tusk. Its uses varied, but were largely for cutting snow blocks for the construction of igloos. The Inuk would lick the tip to create frozen droplets, resulting in a serrated edge. The women's ulu was traditionally made from either bone or a thin stone with a sharp edge. Its primary use was for cutting up game, cleaning skins and preparing garments. The ulu is still in use to this day, and is a widely used cultural symbol.

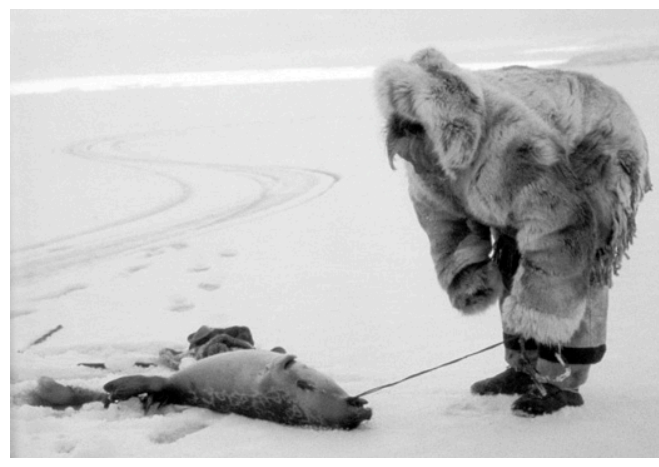

Figure 2.8 - Inuit man catching a seal from a breathing hole.
A qulliq is a stone lamp for heating, cooking and lighting. Traditionally, the fire was sourced from using moss and seal/whale oil. A stone pot was placed above for cooking. Because of the insulated properties of the igloo, only a small fire was needed. Qulliqs were usually passed down from generation to generation. Bows and harpoons were the primary choice of equipment for hunting. Bows and arrows, made from wood or bone with a stone tip, were used for hunting caribou and polar bears. Harpoons are ropes connected to spears made of a combination of ivory, wood or stone. They allowed the user to pull the spear back after penetrating game. Harpoons were mainly used for seal and whale hunting. 


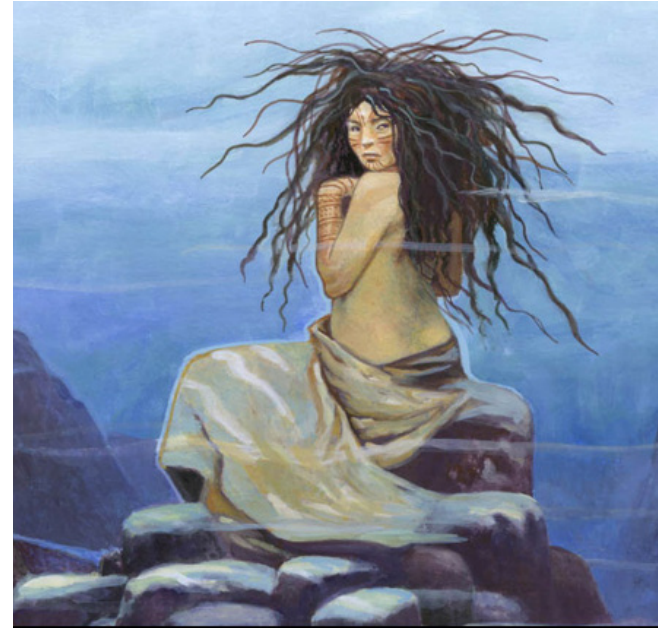

Figure 2.9 - Illustration of Sedna, by unknown artist

39, 40. Carpenter, E. (1973) Eskimo Realities. New York, New York, United States: Holt, Rinehart and Winston.

\subsubsection{Traditional Art}

"Every adult Eskimo male is an accomplished ivory carver: carving is a normal, essential skill, just as writing is with us. A carving is done for a purpose, just as writing is with us. The carver doesn't divide his products into works of art and utilitarian objects, for the two are usually one..." (Carpenter) ${ }^{39}$

Traditional Inuit art is as Carpenter states "Art of the Eskimo is an act, not an object; a ritual, not a possession." 40 Of all the equipment made by the natural materials, nomadic people could take with them very little non-utilitarian objects. Some objects were carved in miniature so they could be carried around or adorned on clothing. These were used to tell legends of mythical beings. The mythological being, Sedna (see figure 2.9) is a goddess of the sea and marine animals; she is also known as the 'Mistress of the Sea.' They were also used to help assist in their oral history. Today, miniatures are uncommon. Figures are less about continuity of mythological culture and more about the natural world. The one of the most common carving made today is the polar bear.

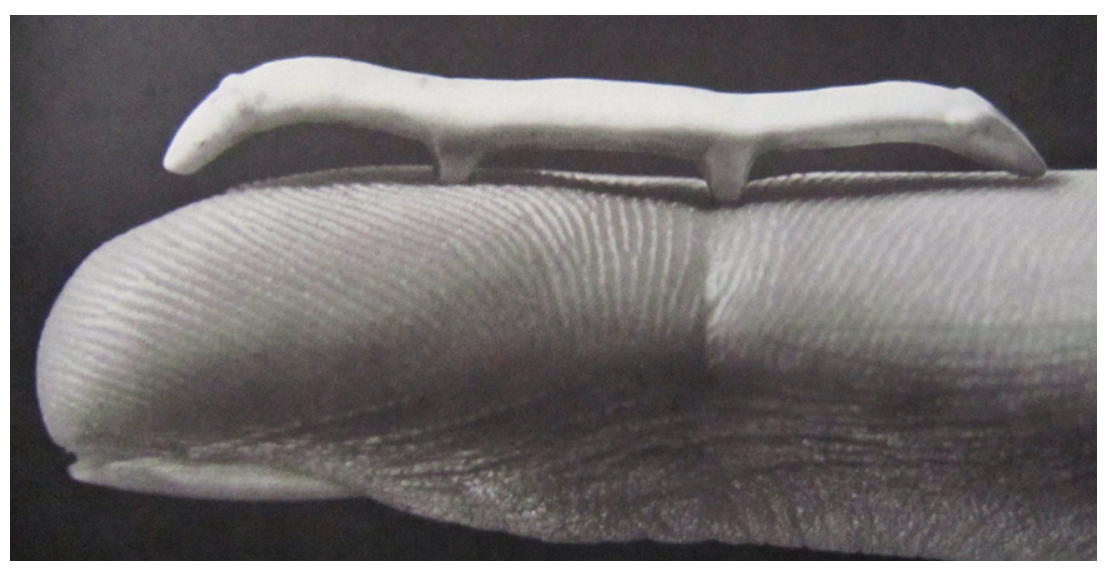

Figure 2.10 - Miniature carving 
Table 2.1 - Comparison of traditional and modern Inuit

\begin{tabular}{|c|c|c|}
\hline & Traditional Inuit & Modern Inuit \\
\hline Living Areas & Camps based on good hunting grounds & Established Communities \\
\hline Shelters/Homes & $\begin{array}{l}\text { Vernacular: tupiq (skin tents), igloos (snow house), } \\
\text { qarmaqs (sod house) }\end{array}$ & $\begin{array}{l}\text { Community: wood frame houses, some prefabricated } \\
\text { On the land: cabins, canvas tents, igloos (temporarily } \\
\text { during the hunt) }\end{array}$ \\
\hline Clothing & All clothes made from hunted skins or furs & $\begin{array}{l}\text { Summer: Clothes made from imported fabrics, or } \\
\text { ready-made clothes. } \\
\text { Winter: traditional boots (kamiks), } \\
\text { sealskin mittens and other outerwear }\end{array}$ \\
\hline Nutrition & Balanced: protein, dietary fat, and low carbohydrates & $\begin{array}{l}\text { Food from supermarket (like in South), Inuit make poor } \\
\text { choices for diet; country food (meat, fish) as supplement }\end{array}$ \\
\hline Food acquisition & $\begin{array}{l}\text { Hunting, fishing and gathering by bow, harpoon, and } \\
\text { traps. }\end{array}$ & $\begin{array}{l}\text { Hunting by firearms, fishing by modern tackle and nets. } \\
\text { Gathering similar. }\end{array}$ \\
\hline Handiwork & $\begin{array}{l}\text { Survival: construction of tents, igloos, qarmaqs, } \\
\text { kayaks, umiaks and qamutiks. } \\
\text { Tools used: Stone or ivory knifes; and copper ulus }\end{array}$ & $\begin{array}{l}\text { Subsistence: maintenance of equipment, } \\
\text { preservation of tradition, artistic ventures. } \\
\text { Tools used: industrial axes, hammers, chisels, knives, } \\
\text { power tools etc. }\end{array}$ \\
\hline Transportation & $\begin{array}{l}\text { Snowshoe (asham) } \\
\text { Dogsleds (qamutiit) } \\
\text { Skin boats (kayak, umiaq) }\end{array}$ & $\begin{array}{l}\text { Snowmobile \& sleds, ATVs, Vans, trucks } \\
\text { Motorboats, canoes (with outboard motors); } \\
\text { Supply vessels, aircrafts }\end{array}$ \\
\hline Energy \& Water & $\begin{array}{l}\text { Stone lamp (qulliq) with seal oil produced: light, heat } \\
\text { and cooked food. } \\
\text { Water was usually sourced from rivers, melting ice } \\
\text { and snow. }\end{array}$ & $\begin{array}{l}\text { Community electricity and private generators at cabins. } \\
\text { Heat from oil and gasoline. } \\
\text { Community water supply and sewage disposal by truck } \\
\text { or utilidor }\end{array}$ \\
\hline Communication & Verbal or by Inuksuk's & Phone, fax, radio, internet \\
\hline
\end{tabular}




\begin{tabular}{|c|c|c|}
\hline & Traditional Inuit & Modern Inuit \\
\hline \multirow[t]{5}{*}{ Social Life } & Camp: family group having a collective of tents. & Modern house: families smaller than traditional, but \\
\hline & $\begin{array}{l}\text { Traditional Tent: extended family. organized } \\
\text { between man (hunting gear, etc) and woman } \\
\text { (cooking, sewing utensils). }\end{array}$ & $\begin{array}{l}\text { larger than the nuclear family. } \\
\text { Activities in house: } \mathrm{TV} \text {, Traditional story telling on } \\
\text { radio, house visitors. }\end{array}$ \\
\hline & $\begin{array}{l}\text { Activities in the tent: games, storytelling, and } \\
\text { visitors. }\end{array}$ & $\begin{array}{l}\text { Working Inuit: Typically dual income } \\
\text { Unemployed or part-time: Leisure time, usually } \\
\text { welfare recipients. }\end{array}$ \\
\hline & Religion: shamanism and superstition & Religion: Predominantly the Anglican/Catholic church \\
\hline & $\begin{array}{l}\text { Law: Traditional laws often influenced by } \\
\text { shamanism. }\end{array}$ & $\begin{array}{l}\text { Law: Canadian and territorial laws; often } \\
\text { misunderstood. }\end{array}$ \\
\hline Means of Subsistence & $\begin{array}{l}\text { Hunting and gathering, trade with other indigenous } \\
\text { tribes to the south below the tree line. }\end{array}$ & $\begin{array}{l}\text { Income: Wages, welfare, self-employed. } \\
\text { Sources: administration, hunting, art, tourism, and } \\
\text { some mines. Note: high rate of unemployment due to lack of } \\
\text { skills and few jobs. }\end{array}$ \\
\hline Property & $\begin{array}{l}\text { Land: common property } \\
\text { Camp: occupied by family groups } \\
\text { Property: only personal goods }\end{array}$ & $\begin{array}{l}\text { Land: private property } \\
\text { Property: includes houses (unless public housing), } \\
\text { cabins, snowmobile, boat, etc. }\end{array}$ \\
\hline Education & $\begin{array}{l}\text { Learning from parents: observation and imitation } \\
\text { Learning from the environment. }\end{array}$ & $\begin{array}{l}\text { Most communities: day care, kindergarten, elementary } \\
\text { school, high school (most places) } \\
\text { Large communities: college, residential schools } \\
\text { In the south: universities }\end{array}$ \\
\hline Health / Medicine & Natural remedies by experience & Contemporary medical system \\
\hline Causes of Death & $\begin{array}{l}\text { Known: accidents, infectious diseases, food } \\
\text { poisoning, freezing, starvation } \\
\text { Unknown: diabetes, heart and circulation diseases }\end{array}$ & $\begin{array}{l}\text { Major: accidents, suicides and cancer. } \\
\text { Others: Increase of Diabetes mellitus and Coronary and } \\
\text { vascular diseases; alcohol, drug, and nicotine abuse }\end{array}$ \\
\hline Art & $\begin{array}{l}\text { Miniature sculptures (carvings) scaled small for travel } \\
\text { purposes, used for storytelling. Usually made from } \\
\text { ivory, bone and other natural sources. }\end{array}$ & $\begin{array}{l}\text { Carvings large in scale to sell for high profit. } \\
\text { Printmaking is world renown. Use of a larger range of } \\
\text { materials, natural to synthetic. }\end{array}$ \\
\hline
\end{tabular}




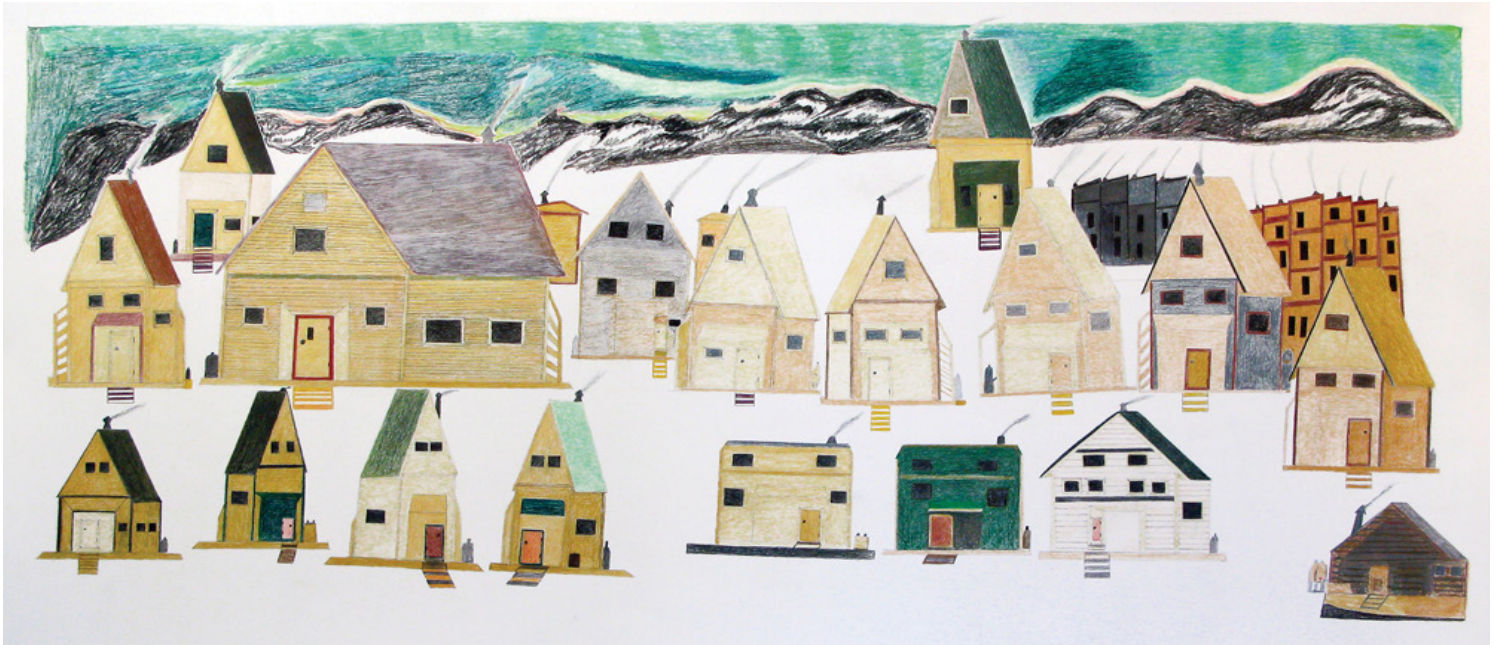

Figure 2.11 -Houses in Cape Dorset by artist Ohotaq Mikkigak, (Mikkigak, 2011)

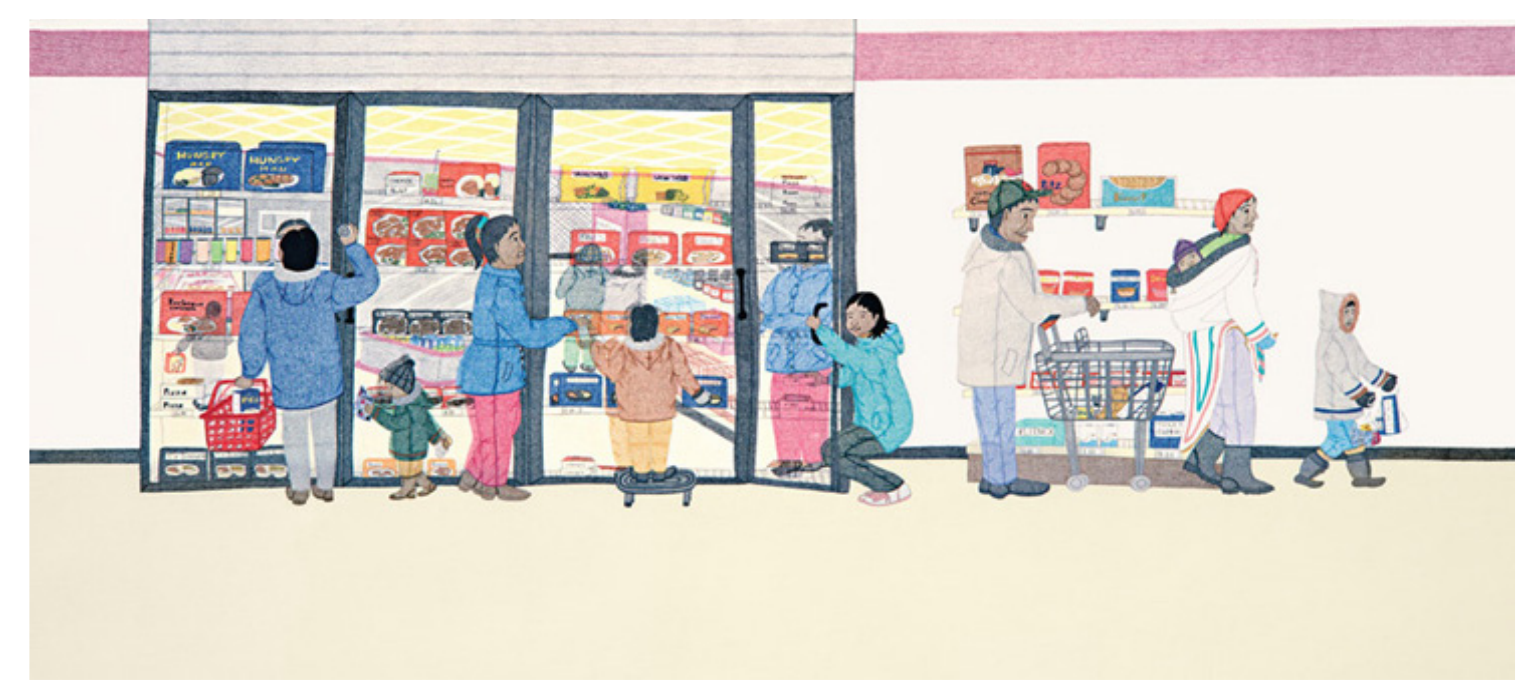

Figure 2.12 - Cape Dorset Freezer (Annie Pootoogook, 2006) 


\subsection{Recorded History}

41. Issenman, B. K. (1997). Sinews of Survival: The Living Legacy of Inuit Clothing. Vancouver, BC, CAN: UBC Press.

42. McGhee, D. R. (2010, April 26). 1576: A Meeting of Two Worlds Retrieved November 7, 2013, from Canadian Museum of Civilization: http://www.civilization.ca
Over the past 500 years, the Inuit have had run-ins with explorers, whalers, traders and missionaries. At the time of European contact, there were approximately 60,000 Inuit living sparsely across the North. ${ }^{41}$ These people brought with them advanced technology, foreign ideologies, religion, and disease. The population diminished greatly through various diseases for which it had no natural immunities. The earliest recorded contacts were with the European explorers looking for the elusive Northwest Passage from the Atlantic to the Pacific. One such voyage was from English privateer and pirate Martin Frobisher in the 1570s. Frobisher's second in command George Best stated during their first encounter,

"And being ashore, vpon the toppe of a hill, be perceiued a number of small things fleeting in the Sea a farre off, whyche hee supposed to be Porposes, or Ceales, or some kinde of strange fishe: but comming nearer, be discouered them to be men, in small boates made of leather." 42

When Frobisher sent five men to shore they did not return. He took it upon himself to take three Inuit as hostages, demanding an exchange. As this was fruitless, he ventured to mine out "gold ore" from a nearby small island and return to England, with the hostages. Much to his disappointment, the gold ore was worthless pyrite. The bay was and still is known as Frobisher Bay. During the times of European exploration, relations were not defined, since the explorers only saw the arctic as an obstacle to fortunes beyond. They had no real interest with the Inuit and what they had to offer. There were at times trades, which introduced the aboriginals to iron for making harpoons and knife blades. 
43, 44. Inuulitisivik Organization (2013). Who are the Inuits? Retrieved November 7, 2013 from Inuulitisivik: http://www.inuulitsivik.ca/
The next encounters were with European and American whalers. The commercial values of whales led the ships to the Inuit's doorstep. In the 1850s, many of the whalers were unmatched killing thousands of whales. They hired hundreds of Inuit to work on their ships as hunters and seamstresses. ${ }^{43}$ This transformed the Inuit lifestyle due to the quantity of manufactured goods received during their exchanges; the rifle had a great impact. This era was also a critical point for Inuit's survival. Diseases from the whalers killed thousands of Inuit; some regions had groups disappear completely.

By 1905, as the whaling industry began to be less economically viable, the fur trade became the dominant trade between Inuit and Euro-Canadians. The Hudson's Bay Company began to make its presence known in the North. The fur trade became the catalyst for other groups to enter the Arctic, such as the Royal Canadian Mounted Police and the Anglican and Roman Catholic churches. By 1925, the Inuit had become subjects if not quite citizens of the Canadian state. ${ }^{44}$ The missionaries suppressed many of the traditional practices and beliefs. Much was lost or went underground.

During the 1930s, the economy experienced a depression, famines were rampant, and game was scarce. This had an effect on the trade industry and on the sustenance of the Inuit. Ever since Canada established sovereignty in the Arctic, in 1880, there has been a burden of responsibility. In 1939, the province of Quebec sued the Supreme Court of Canada, in a case called Re-Eskimo. Quebec wanted to put the duty of care on to the federal government, since many of the Inuit began to starve. Quebec essentially won the case and began the shift into making the Inuit 'civilized.' 


\subsubsection{Wilderness to Town}

45. Billson, J. (2001). Inuit Dreams, Inuit Realities: Shattering the Bonds of Dependency. American Review of Canadian Studies (31), 284.

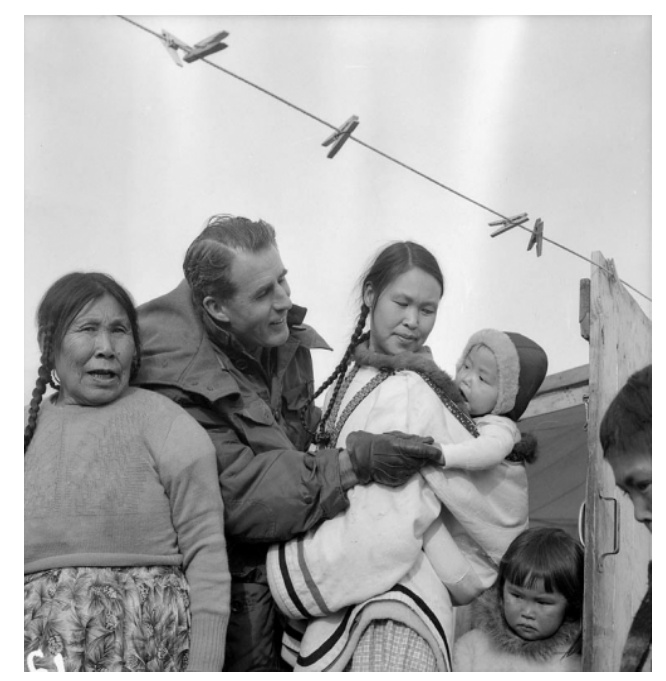

Figure 2.13- Hon. George Hees,

Minister of Transport, visits the Eskimos (Grant, 1958)
"Nunavut can be understood only within the context of this dramatic shift from the land to village life" Janet Billson 45

The first initial change towards the amalgamation of nomadic people into clusters was when they began to work with hunters and trappers for trade. This altered the interest of Inuit to stop following the traditional migration patterns and focus on small non-migratory animals. At this time, the government allowed the Inuit to remain scattered, as they did not want to take the responsibility of treating them as full Canadian citizens.

World politics altered the face of the globe and the Arctic was no exception. The circumpolar north was viewed as having high importance for the various military powers. During World War Two (WWII), the United States made an agreement with Canada to establish airbases along the Crimson Route that mobilized fighter jets from Montana to the European war efforts. The government began to promote the shift from Inuit living on the land to living in settlements, establishing sovereignty in the North. Some Inuit from Northern Quebec relocated to help populate places like Resolute Bay and Grise Fiord. Unfortunately, this caused serious trauma. They relocated with the promise of a return trip in two years if they did not like the new location(s). What they discovered was the hidden stipulation of needing to pay their way back. Having little to no money, they ended up getting stuck. Since the high Arctic has little game, hunting would not have produced a ticket home. 
"Until 1953, however, the federal government advocated the maintenance of a traditional way of life for Invit and occasionally relocated families to areas with supposed abundance of natural resources. Most of these projects failed because resources in the new location were not sufficient and Inuit continued to go hungry. Many relocated Inuit became quickly disillusioned." 46

46. Anderson, E. (2008). Canada's Relationship with Inuit. Minister of

Indian Affairs and Northern

Development. Ottawa: Public History Inc.

47. Lackenbauer, P. W., \& Shackleton, R. (2012). When the Skies Rained Boxes: The Air Force and the Qikiqtani Inuit, 1941-64. Waterloo: Munk School of Global Affairs.
When WWII ended, the United States and USSR became enemies and the Cold War began. During this time the United States and Canada constructed the Distant Early Warning Line (DEW Line, see Figure 2.14). These were a series of installations across the North American Arctic to detect anything coming over the top from the USSR. This gave the US a strategic advantage of obtaining advance notification of any imminent threat of invasion from their enemies in the region. Both the existing airstrips from WWII and the DEW Line employed Inuit for the construction. The Inuit were making $\$ 350$ to $\$ 650$ a month. The money earned would be spent on new tents, rifles, boats, gasoline and other goods. ${ }^{47} \mathrm{~A}$ wage-based sustenance altered the lifestyle of the Inuit. Wages at the site were good and helped to feed many of the families. This created a migration towards town living as it helped to ensure families received, food, health care and education. However, the Canadian government wanted this situation to be temporary and only established semi-permanent structures for the Inuit.

In the 1950s, famines and epidemics were spreading throughout the Arctic, causing the Inuit to choose living in a settlement versus on the land. As more Inuit started to trickle in from the land, shacks were built from the scrap construction material the US left behind. The US military criticized the Canadian government for not taking actions based on the conditions of the Inuit in these settlements. In the " $50 \mathrm{~s}$ to " 70 s the Inuit people were at the mercy of the Canadian government. They had limited rights in determining how they could educate their children, hunt on the land, housing, and make decisions on land claims. 


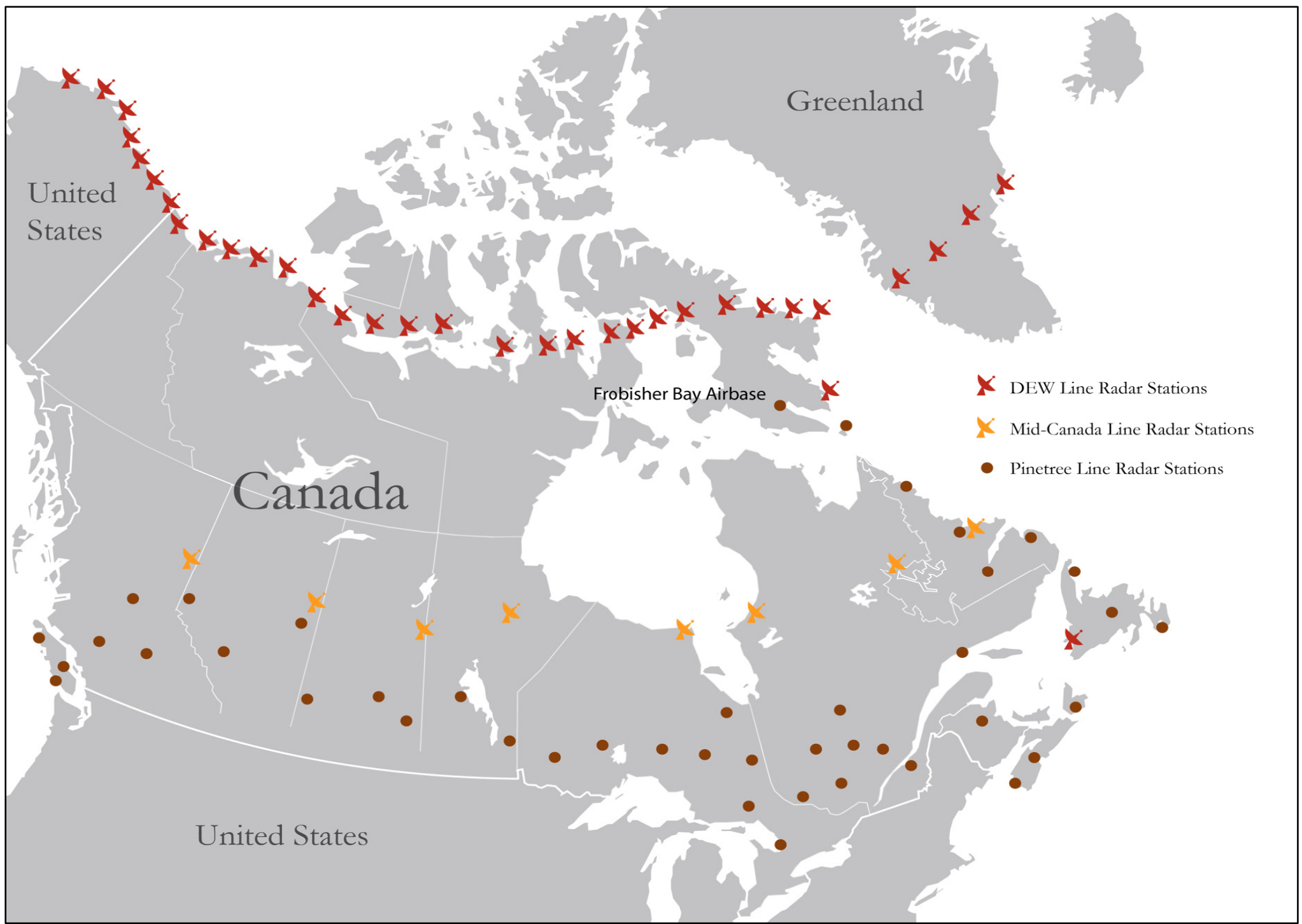

Figure 2.14 - Map of Canada's -DEW, Mid-Canada, and Pinetree Lines- radar stations 


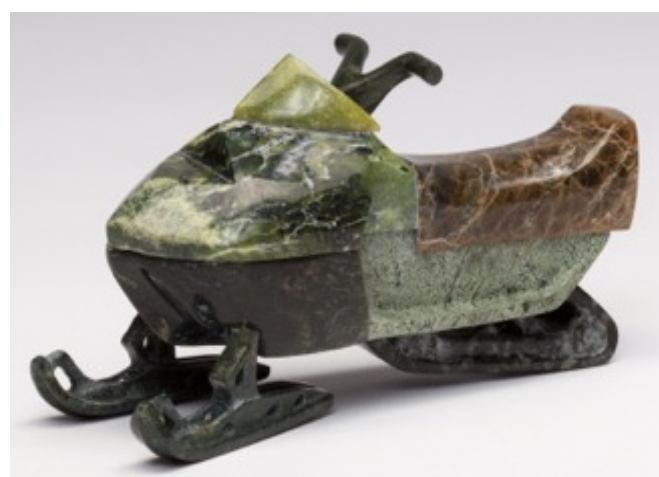

Figure 2.15 - Soapstone snowmobile carving (Pitseolak, 2006)

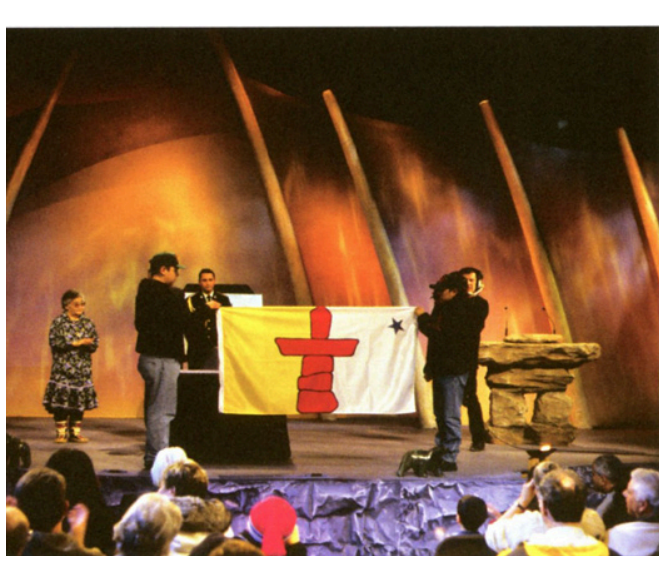

Figure 2.16 - Celebration of Nunavut becoming an official territory, 1999 (Newberry, 2009)

48, 49. The Globe and Mail. (2012). Our Nation's Finest. Booktango.
In the 1980s, the Inuit began to take action against being patronized by the federal government. At this time aboriginal rights were legally recognized and had large effects on the Canadian administration. Government agencies and organizations began to take Inuit concerns to the head of politics. By this time the Inuit worldview had modernized both technologically and socially. Figure 2.15 is an example of how traditional carvings changed to reflect the times. Much of Inuit art today reflects the conditions and lifestyles of the north. The snowmobile is now the dominant form of transportation above dogsledding.

\subsubsection{Nunavut was Born}

In 1971, a group of politically minded Inuit formed what was called the Inuit Tapirisat of Canada (today known as Inuit Tapiriit Kanatami). They represented the Inuit from all across the North. This group campaigned, from 1976 to 1993, to establish an Inuit territory, governed by the Inuit. In 1993 the boundaries were drawn, splitting the North West Territories, and on April 1st 1999 the Nunavut Act and the Nunavut Land Claims Agreement was passed, establishing Nunavut as a Territory. (see Figure 2.16) The choice fell to Iqaluit as the Capital, since Rankin Inlet (first choice) voted against it.

About a year after its formation, the editor-in-chief of Nunatsiaq News forecasted the future of Nunavut as being a "made-for-failure territory." The territory was and still is overburdened with bureaucracy, paralyzed with an inadequate budget, destined to be a political basket case into the foreseeable future. ${ }^{48}$ The question of how the government can invest in a non-self-sustaining territory is crippling the growth. The only thing that officials and critics can agree upon is that 


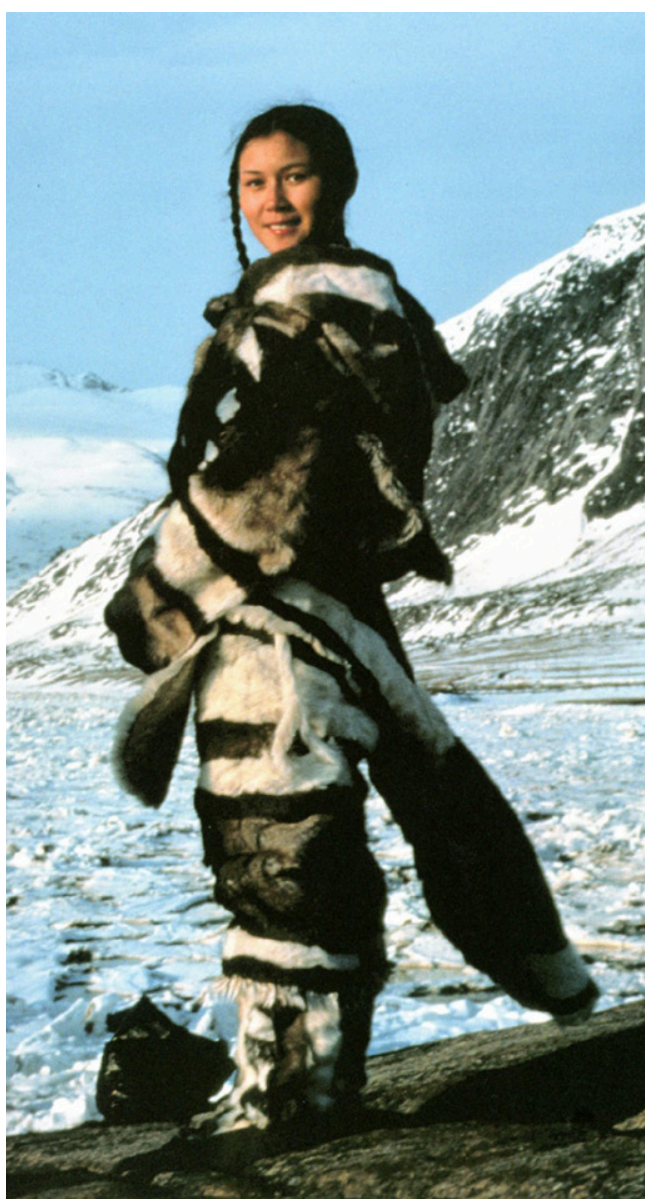

Figure 2.17 - Today's version of traditional Inuit women's clothing (Newberry, 2009)
Nunavut has created a place where the Inuit identity can grow and be expressed. Although the territory is pushing for devolution, as North West Territories achieved on June 25th 2013, Nunavut is in trouble since the basic needs of its residences have not been met. As an example of the situation, Nunavut was scrambling to fill a $\$ 110$ million shortfall (10\% territorial budget) in the Housing Department, not keeping pace with the rapid population growth,

"...the Nunavut Act bars its government from holding debt greater than \$200-million. Already owing \$140-million, the territory has little room to borrow or sell bonds to erase the shortfall, especially with an ever-growing list of badly needed infrastructure projects it can't afford." (The Globe and Mail) 49

The federal government has been stepping in for its financial shortcomings. It is clear that there are some serious, financial, infrastructure, and political issues with the Government of Nunavut. Many proponents believe nepotism and unregulated policies are to blame. In any case the territory is having a rocky start.

\subsubsection{Modern Inuit}

It is important to understand that there was an intense cultural shift in that the Inuit had to adapt from a traditional lifestyle to a world of contemporary education, communication, philosophies, etc. It is easy to judge their inadequacies today, but having only 40 to 60 years to adapt has been a challenge. Although there is a strong connection to the land and regret about the passing of the old ways, the Inuit do not want to return to their traditional lifestyle. There is still the memory of the miseries and hardships of then. There is a big respect for those who can still maintain a close relationship to the land and traditional ways. 
Many traditional practices remain alive today, such as sharing food and other natural resources. However, the sharing of wages with the community is not included in these customary practices. An abiding principle that has survived is the ability to thrive despite their struggles. A trait that is still clearly evident to this day,

50, 51. Boult, D. (1992). The Inuit way: a guide to Inuit culture. "...is their degree of independence and ability to meet life's challenges with innovation, resourcefulness and perseverance. Traditionally, these were traits that would greatly increase the chance of survival for the individual and the group." 50

The future of the Inuit culture is unclear, and if the modern lifestyle is a hint of what is to come, it may be endangered. Due to distractions of southern culture plus contemporary urban issues, the children do not spend as much time with the parents as in the old ways. This limits the succession

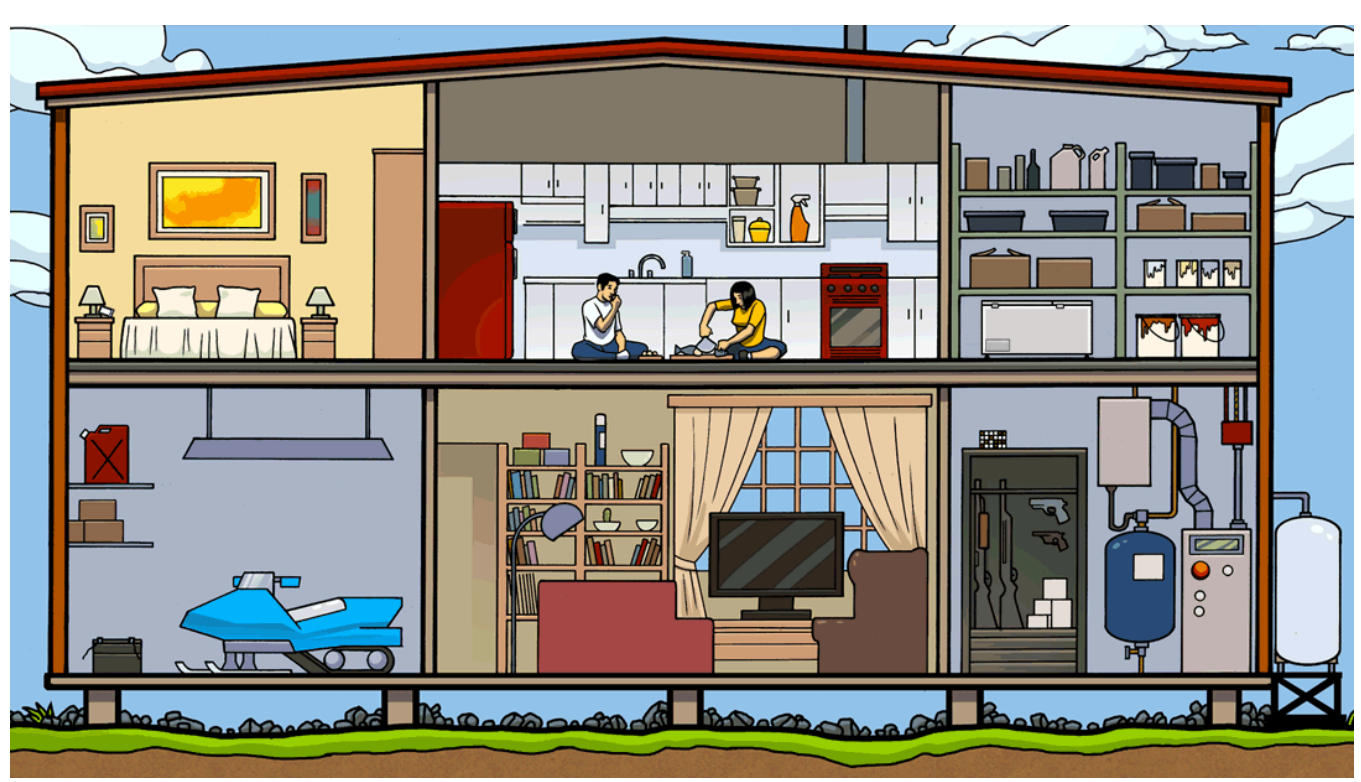

Figure 2.18 - Inuit family living in a Euro-Canadian home by the Government of Nunavut of values and traditional practices. Education in schools at time conflict with customary principles; for example, competition is not part of the curriculum. It is important to be strong for survival on the land and competition was a way to build character, and skills. A dual education is necessary for both values to co-exist.

Figure 2.18 depicts a modern Inuit family in a EuroCanadian home. The Government of Nunavut posted it to educate the users about waste reduction and storage of hazardous materials. This illustration 
suggests a symbiotic relationship with Inuit lifestyle and contemporary housing design. Notice the snowmobile, gun rack and Inuit eating country food off the kitchen floor. This harmony is purely suggestive.

Although Inuit were "pulled" to settlements -for access to housing, health, social programs- and "pushed" from the land -by famine, low fur prices- modern Inuit continue to live according to their traditional values. "All Inuit are proud of their culture and recognize the importance of keeping it alive" 51 


\subsection{Inuit versus Kabluunak}

It is clear that the Inuit and Kablunnak or Qallunaat (white people) think differently. The first impression of the European was a stereotype: 'kabluu' meaning eyebrows and 'nak' meaning big stomach. It may be semantics, but the word is still used today. Canadian geographer LouisEdmond Hamelin makes a clear distinction between the two worlds in this table below (see Table 2.2).

Although this thesis is written by a non-Inuk, living with them has helped in understanding the

52. Alia, V. (1998). Indigenous Peoples and Media Ethics in Canada. Aboriginal Media Aboriginal Control.

53. Boult, D. (1992). The Inuit way: a guide to Inuit culture. differences. Because of the history between the two cultures, issues of prejudice and nepotism prevail. The Nunavut Government has instituted a mandate to have 85 percent of its staff Inuit. Some Kabluunak have stated, since they have not achieved that number, the government has become desperate and have chosen to staff permanent high-ranking positions with unqualified Inuit. Kabluunak are feeling marginalized by this seemingly unfair practice. People with better qualifications are outmatched by a phrase within job descriptions "Priority will be given to Nunavut Land Claims Beneficiaries."

In the northern media, a fierce debate is brewing concerning the roots of racism, the limits of free speech, and the representation of Inuit and Qallunaat within the political structure of Nunavut. ${ }^{52}$ The editor of Nunatsiaq News headlined it "The politics of exclusion." Much of this situation is perceived as post colonization hang-ups.

Some Inuit see the Kabluunak as aggressive, nosey, domineering and are too free with their uninvited opinions. In public positions, they are often valued for their ability to "handle people", to 


\begin{tabular}{|c|c|}
\hline Amerindian Values & Non-Amerindian Values \\
\hline \multicolumn{2}{|l|}{ Bravery } \\
\hline $\begin{array}{l}\text { To do something difficult without } \\
\text { showing fear, or fleeing before an }\end{array}$ & $\begin{array}{l}\text { Material achievement and monetary } \\
\text { success }\end{array}$ \\
\hline $\begin{array}{l}\text { A mante } \\
\text { according to natural cycles and his }\end{array}$ & A man works every day (9 to 5) \\
\hline \multicolumn{2}{|l|}{$\begin{array}{l}\text { hiolamical clorl } \\
\text { Adaptation to nature }\end{array}$} \\
\hline To adapt to the group & To create competition within the group. \\
\hline To adapt to nature & $\begin{array}{l}\text { To conquer nature (scientific progress); } \\
\text { to reorganize things }\end{array}$ \\
\hline \multicolumn{2}{|l|}{ Individual liberty } \\
\hline To decide for oneself & To decide for oneself \\
\hline $\begin{array}{l}\text { To do something in the right manor and } \\
\text { to follow advice }\end{array}$ & No conflicts \\
\hline \multicolumn{2}{|l|}{ To survive at the best possible level } \\
\hline $\begin{array}{l}\text { To do what one wants (if one does only } \\
\text { what one wants, one cannot have cars, a } \\
\text { decent life for one's family, etc.) }\end{array}$ & $\begin{array}{l}\text { (If one works every day for cars, a } \\
\text { decent life, etc., one cannot do what one } \\
\text { wants) }\end{array}$ \\
\hline \multicolumn{2}{|l|}{ Generosity and sharing } \\
\hline Desire to share & Desire to keep \\
\hline $\begin{array}{l}\text { Happiness } \\
\text { The good council of wise men; access to } \\
\text { knowledge of the comprehension of } \\
\text { nature and people to make oneself } \\
\text { understood, resulting in peace and } \\
\text { happiness }\end{array}$ & $\begin{array}{l}\text { Sense of efficiency and practical sense; } \\
\text { access to the knowledge of the } \\
\text { fabrication of things and the acquisition } \\
\text { of money, resulting in power and } \\
\text { possessions }\end{array}$ \\
\hline $\begin{array}{l}\text { The Indian judges people by what they } \\
\text { are }\end{array}$ & $\begin{array}{l}\text { Practical knowledge: maximum } \\
\text { production; wealth is appreciated }\end{array}$ \\
\hline
\end{tabular}

Table 2.2 - Comparison of Amerindian and Non-Amerindian values manipulate people and situations in order to improve production, solve problems etc. ${ }^{53}$ Inuit see these traits as a threat to their way of life. There is a feeling that the Kabluunak are taking all the jobs and leaving the Inuit without any opportunities. Because of the injustices of the past, there is little in the way of reconciliation between both parties. Many are bitter against the Kablumnak and would prefer them to leave the Territory. Due to the lack of human capital, fulfilling the many critical positions requires outsiders.

Aside from the politics, other conflicts are of lifestyle, values, and culture. Since the two groups are so different, it is hard to establish a somewhat symbiotic relationship without friction. As an example, an Inuit's diet usually includes raw seal, walrus and whale, which usually repulses Kablunnak. Very few people from the south have the stomach for trying foods so radically different.

Although differences are almost binary, there is an inherent desire for a better Canada from both parties. Nunavut celebrates Canada day and conversely Kablunnak living in the territory celebrates Nunavut Day. With hard work and understanding, Nunavut has the potential of becoming a prime example of successful relations between Aboriginal and non-native people co-existing as a society. 


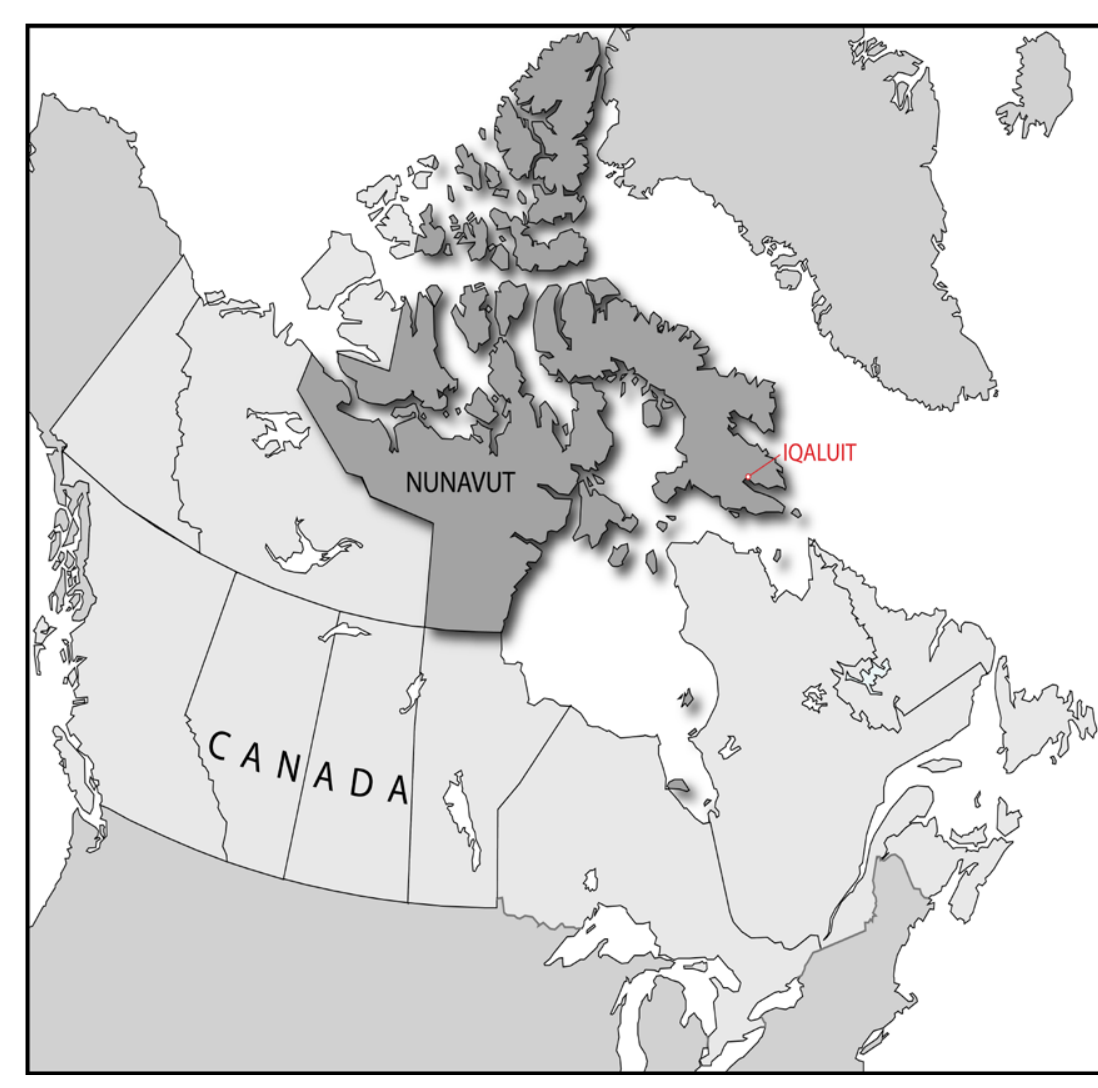

Figure 2.19 - Map of Nunavut

\subsection{Nunavut}

Nunavut, "our land" in Inuktitut, has been the home to the Inuit of for thousands of years. Since Nunavut was born out of NWT in 1999, the territory has undergone various changes. Today, Nunavut has three regions: Qikiqtaaluk (or Baffin), Kivalliq (or Keewatin), and the Kitikmeot. (see Figure 2.20) Despite forming one fifth of the landmass of Canada, Nunavut has a population of over 35,500 (2013), according to the Government of Nunavut. Being one of the most sparsely populated areas of the world, it boasts a landmass (combined mainland and archipelago) of over 1.8 million square kilometers or 20.4 percent of Canada. The people of Nunavut are known as Nunavummiut.

Eighty five percent of all those living in Nunavut are Inuit. As there are various dialects among them, across the circumpolar regions, Nunavut has many variants. In Nunavut, dialects are divided into two main groups: Western Inuktun and Eastern Inuktitut. The government has mandated the preservation of the various dialects.

Unfortunately, this has been difficult since an increasing number of Inuit children are learning English and forgetting their native tongue. Also, the government is trying to enforce Inuktitut as an official language, but the vast range of dialects across the North is making it difficult to be established. 
Nunavut has the lowest GDP of all the provinces and territories. What makes it unique is that with a low population, Nunavut has a GDP of 2.2 billion as of 2012. When calculated, this would mean a per capita of $\$ 62,000$ per person. Public administration, followed by construction, is Nunavut's largest employer since 1999. (see Figure 2.21)

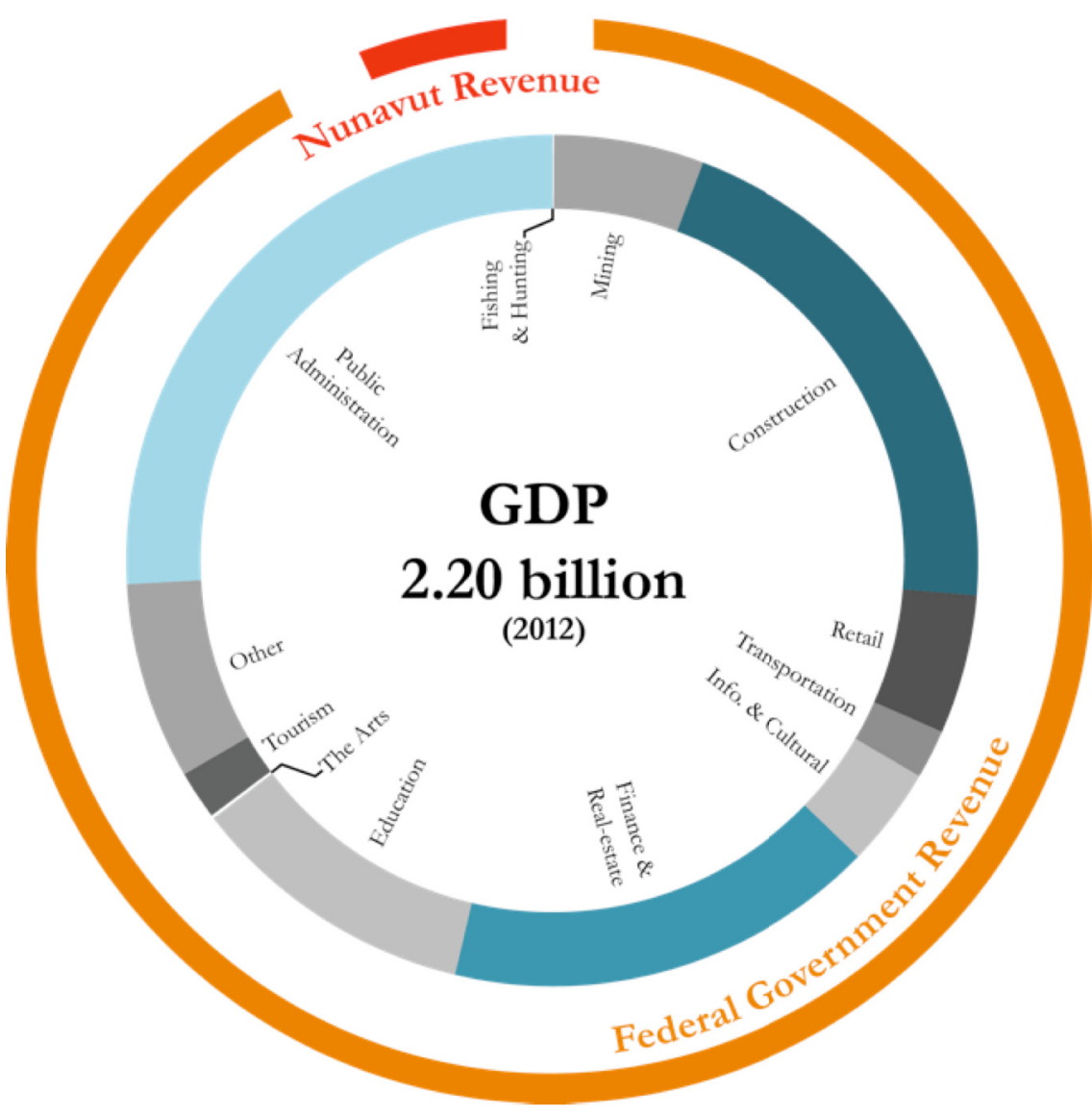

Figure 2.21 - Map of Nunavut's three regions

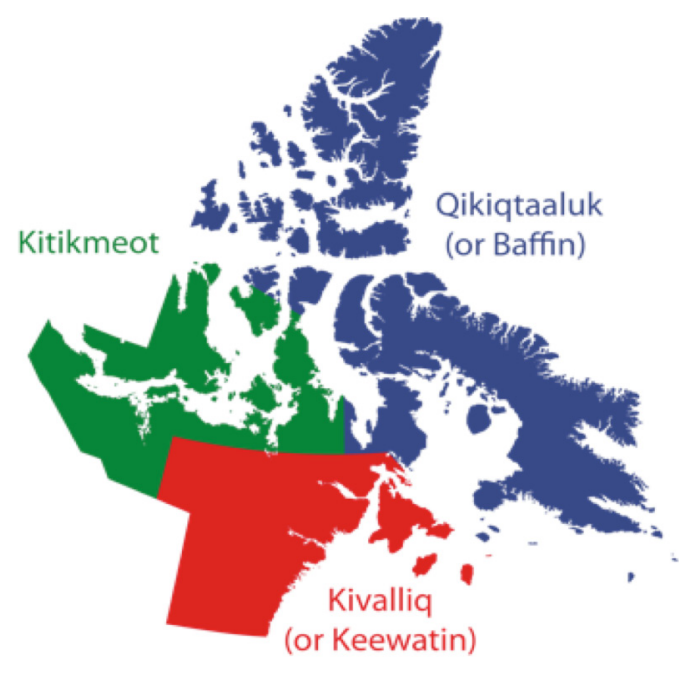

Figure 2.20 - Map of Nunavut's three regions

It is important to note that the territory has a mix of both a wage and land-base (or traditional) economies, in addition to government transfers. The later economy is not included in Nunavut's GDP and includes; for example, hunting, fishing and trapping activities used for trade or household use. 
54, 55, 56. Vail, S., \& Clinton, G. (2001). Examination of the Nunavut Economy. Conference Board of Canada. Conference Board of

Canada.
Nunavummiut typically tries to balance the two economies since sustenance is important with the territory having the highest unemployment rate. The land-based economy is estimated to have a value of about 40 to 60 million dollars per year. ${ }^{54}$

The Nunavut Land Claims Agreement dictates the political environment. It has a major influence in how developmental capital is managed. Provisions include hiring policies favorable to the Inuit in administration; preferential procurement policies by the federal and territorial governments for Inuit firms; and greater control of natural resources. ${ }^{55}$ Inuit Qaujimajatuqangit (Inuit traditional knowledge and way of thinking) is ideally the principal decision-making process expected to influence the development of the Inuit and Nunavut economy.

According to the Conference Board of Canada, Nunavut is still young and has many issues. First, infrastructure or physical capital is a serious problem that is affecting socio-economic development. Second, Nunavut has the fastest growing population in Canada that it is at present having difficulty sustaining. Third, human capital is at a crisis level. Education and family income levels are below the national mean. Health levels are suffering. Fourth, there needs to be better management and understanding of natural capital such as geoscience.

Three main objectives that Nunavut should follow to stimulate the various forms of capital: life sustenance, self-esteem and freedom of choice. Ultimately it is up to Nunavummiut. 56 


\section{Nunavut's Guiding Principles of Inuit Qaujimajatuqangit ${ }^{57}$}

Inuuqatigiitsiarniq - Respecting others, relationships, and caring for people.

Tunnganarniq - Fostering good spirit by being open, welcoming and inclusive.

Pijitsirniq - Serving and providing for family and/or community.

Aajiiqatigiinniq - Decision making through discussion and consensus.

Pilimmaksarniq - Development of skills through observation, mentoring, practice, and effort.

Ikajuqtigiinniq - Working together for a common cause.

Qanuqturniq - Being innovative and resourceful.

Avatittinnik Kamatsiarniq - Respect and care for the land, animals and the environment.

57. Government of Nunavut. (n.d.). About Nunavut. Retrieved November 13, 2013, from Government of Nunavut: http://www.gov.nu.ca/about-nunavut 
"The settlement is unique in terms of its origin and development. Unlike so many Canadian Arctic settlements, it had no prebistory, no early history as a trading post, whaling centre or trans-shipment centre; it was not established because there were mineral reserves in the vicinity." 58

58. Newberry, N. (2009). Iqaluit. Iqaluit, NU, Canada: Nortext Publishing Corporation.

59. Eno, R. V. (2003). Crystal Two: The Origin of lqaluit, 67.

\section{Chapter: Origins of an Arctic Capital}

\subsection{Frobisher Bay Area}

lthough some archeologists believe that the Vikings were the first visitors to the Baffin
region, the first confirmed contact was by explorer Martin Frobisher in 1576 . He
kidnapped some of the Inuit, fought with others and left with an arrow in his buttocks. From 1860, American Charles Francis Hall thoroughly explored Frobisher Bay. By this time tensions had settled because of Inuit's dealings with whalers. In 1914, the Hudson Bay Company (HBC) established its first trading post along the Bay. Up until 1942, Frobisher Bay remained uninhabited aside from some non-permanent Inuit camps and the HBC trading post.

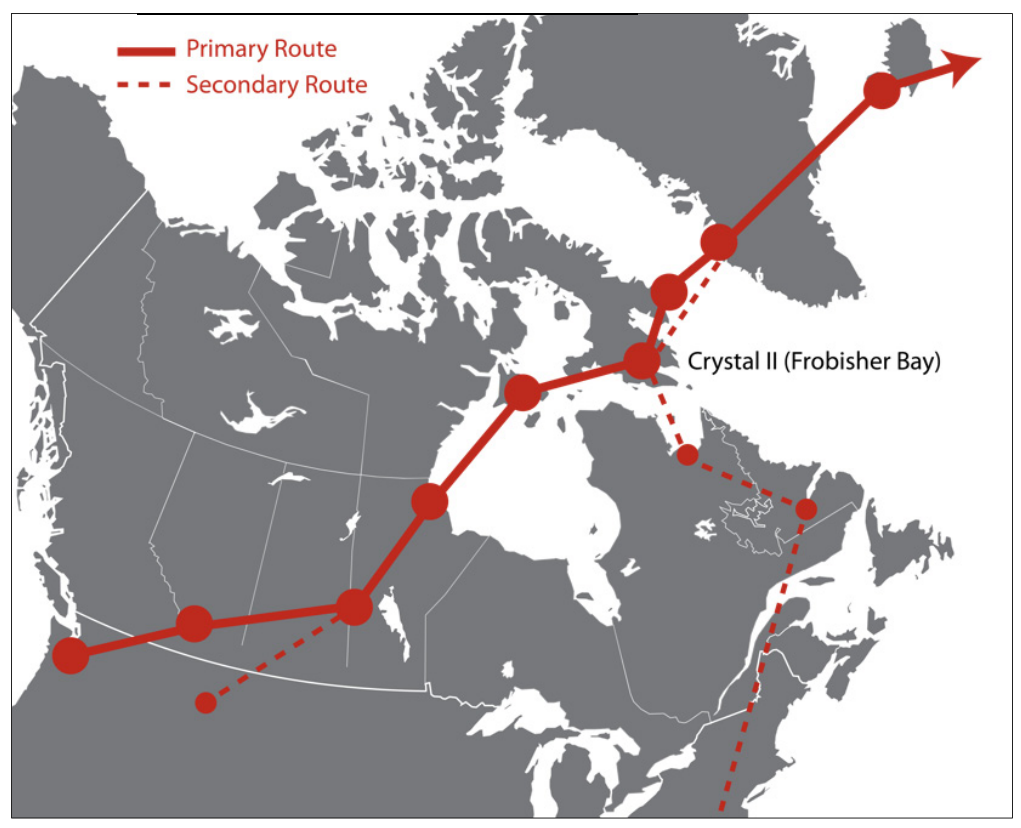

Figure 3.1 - Map of the Crimson Air Route (MacBain, 1970)

\subsection{Crystal II}

By 1941, the population of Inuit camps around Frobisher Bay was 183 and the people, despite some contact with outsiders, were continuing to live a lifestyle totally dependent on the land.59 In 1942, WWII was in full swing and the technology for aeronautics had advanced. Short-range fighter aircrafts needed to be transported from the US to Europe. It would take too long shipping them, and they could not fly it in one leg. Frobisher Bay was selected to be part of the Crimson Air Route (see Figure 3.1). The route was a series of airfields, of distances not more than 500 miles apart that left from Seattle (US), across Canada's Eastern Arctic, through to Greenland and Iceland. 
"The three bases to be located in the Canadian Arctic were code-named "Crystal One" (Fort Chimo, now known as Kumjuak), "Crystal Two" (Frobisher Bay), and "Crystal Three" (Padloping Island)." 60

60, 61. Eno, R. V. (2003). Crystal Two: The Origin of lqaluit, 68

62. MacBain, S. K. (1970). The Evolution of Frobisher Bay as a Major Settlement in the Canadian Eastern Arctic, 1-312.

\begin{tabular}{cccc}
\multicolumn{4}{c}{ Frobisher Bay } \\
Population Growth \\
Year & Non- - 1969 \\
1942 & 500 & N/A & 500 \\
1950 & 66 & $* 25$ & 91 \\
1956 & 93 & 258 & 351 \\
1958 & 441 & 650 & 1091 \\
1959 & 437 & 654 & 1091 \\
1960 & 983 & 770 & 1753 \\
1961 & 1040 & 761 & 1801 \\
1963 & 713 & 906 & 1619 \\
1966 & 566 & 1036 & 1602 \\
1969 & $* 530$ & 1174 & 1704 \\
Sources: Indian and Northern Affairs \\
Department, RCMP, \\
John Honigman, MacBain
\end{tabular}

Table 3.1

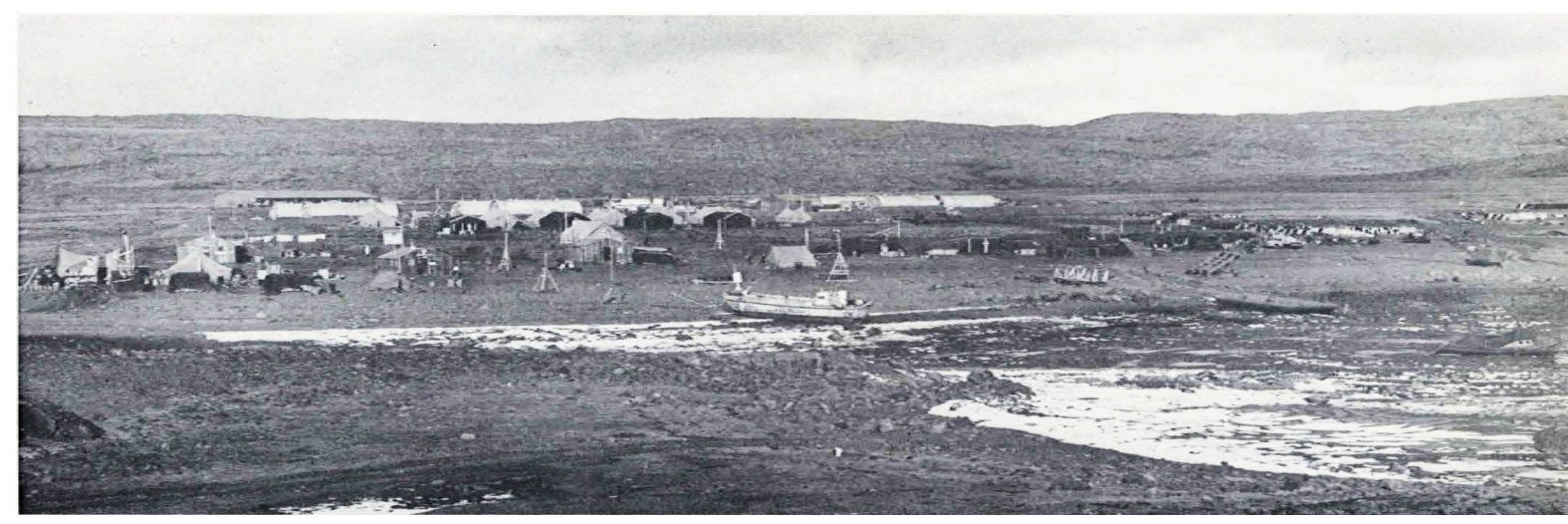

Figure 3.2 - September 16, 1942 - Crystal II (Forbes, 1953)

Although underutilized, the route was used to traffic supplies and military personal back and forth from Europe. The US military constructed an airbase at Koojesse Inlet at the head of Frobisher Bay. (see Figure 3.2-3) "The site fulfilled the basic requirements: it was accessible by sea, it offered a good anchorage with reasonable foul-weather protection from most directions, and it had a large, flat open plain on which to construct an airfield." Construction had some setbacks, for example Chatham, one of the cargo ships bringing supplies (6000 tones) was sunk by a U-517 (Nazi Submarine) off the Labrador coast. ${ }^{61}$ After construction in 1943, the airbase was manned by only a handful of personnel, as it became a satellite to the larger airstrip at Goose Bay, Labrador. During this time, only fifty Inuit were living near the base year round.

"With the arrival of the survey and construction crews at Koojesse Inlet in the summer of 1942, Eskimos began drifting up the bay to the construction site to see what was going on. Despite efforts by military authorities to discourage them from camping near the base site, many Eskimo families persisted." 62 


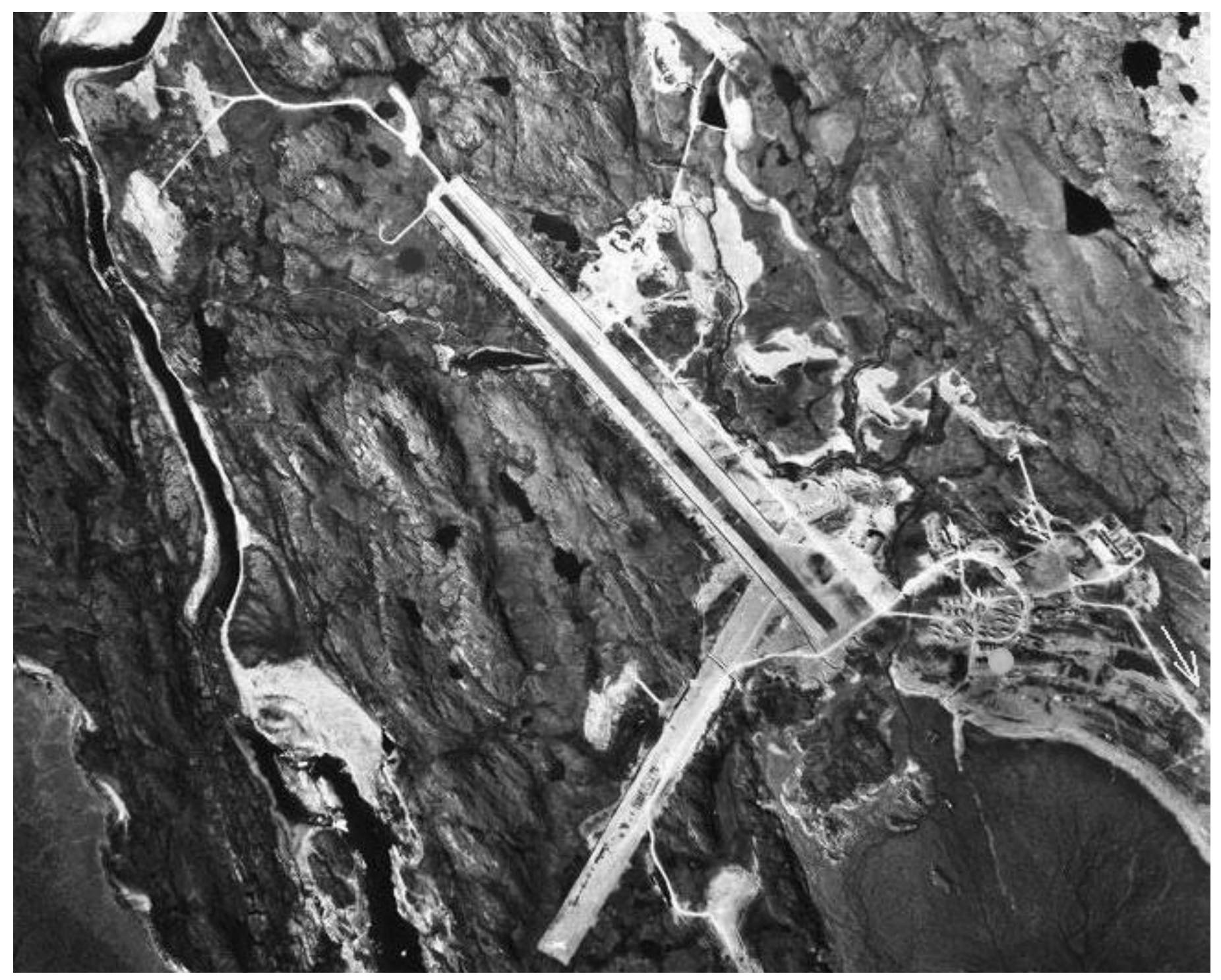

Figure 3.3 - Aerial Photo of Crystal II, 1948 (National Air Photo Library, 1948) 
63. Newberry, N. (2009). Iqaluit Iqaluit, NU, Canada: Nortext Publishing Corporation.

"In 1955, Jean Lesage, the Minister of the Department of Northern Affairs and National Resources, announced a new policy for Inuit administration, to remedy the "almost continuing state of absence of mind" in which Inuit had previously been administered, and to ensure that Inuit had the same rights, privileges, opportunities and responsibilities enjoyed by other Canadians." 64

64, 65. Public History Inc. (2008) Canada's Relationship with Inuit. (E. Anderson, Ed.) (pp. 1-259). Ottawa: Minister of Indian Affairs and Northern Development.

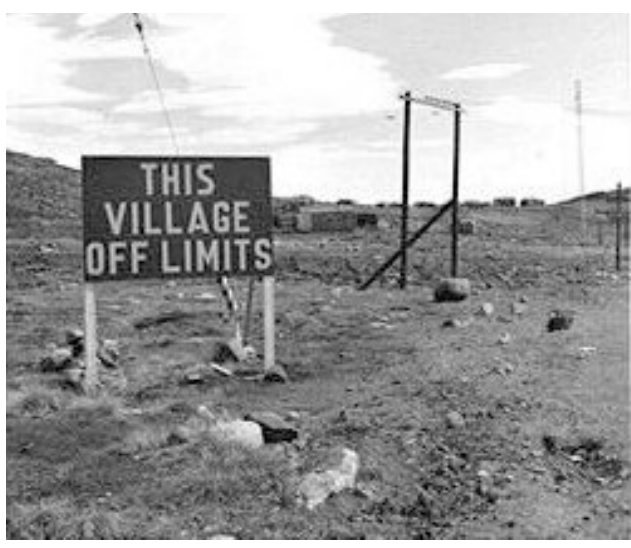

Figure 3.4 - Sign for segregation
The only near permanent inhabitant would be the HBC outpost further along the Bay. The airbase began to construct its infrastructure, which consisted of a hospital, living quarters, garages, warehouses and roads. In 1944, the US military withdrew from Crystal II and USAF sold it to the Canadian Government, where a skeleton Canadian crew manned it for the next six years.

\subsection{Frobisher Bay Airbase}

After the war tensions between the USSR and United States began to heat up. In 1951, Frobisher Bay's Airbase became populated with the return of the American military, but at this time Canadian officials had a larger presence. The base was used as a trans-shipment point for materials being airlifted to Greenland. In 1955, the US military decided to install the DEW line. The base now called Frobisher Bay Airbase became an important hub for the transport of workers and materials for all the other stations within the Eastern Arctic. This airbase also served as a tanker base for refueling B52 bombers in the air. At its peak the rejuvenated airbase was handling as many as 300 take-offs and landings per day. ${ }^{63}$ Although civilian jobs were limited, Inuit began to migrate from all over south Baffin Island to the base looking for work, bringing with them their families. Many of the first Inuit families to arrive at the base, camped along the beach next to the main area. The camp was named 'Ikaluit.'

The Canadian government decided to establish a village at an area called Apex Hill, to accommodate the influx of Inuit, one kilometer from the base, with services of a school, nursing station, and a rehabilitation centre. This was because the military mandated they couldn't stay in proximity to the base. After 1959, the government of Canada established a permanence of medical care and social services. The Inuit population began to spike in response to the new services. 
66. MacBain, S. K. (1970). The Evolution of Frobisher Bay as a Major Settlement in the Canadian Eastern Arctic, 1-312.
During this period, interactions between the American military and the Inuit were limited and policed by the RCMP. There were times that the two groups overlapped. Locals got to see their first film and taste their first Coca-Cola. Inuit women were strictly forbidden on the base. Alternatively the American personnel were not allowed to visit the Inuit settlements at night. (see Figure 3.4) The dump was used to smuggle foodstuff and other goods to the Inuit. There they could go and take whatever they wanted. The Americans left Frobisher Bay in 1963, not without criticizing the Canadian Government about the Inuit housing conditions. ${ }^{65}$

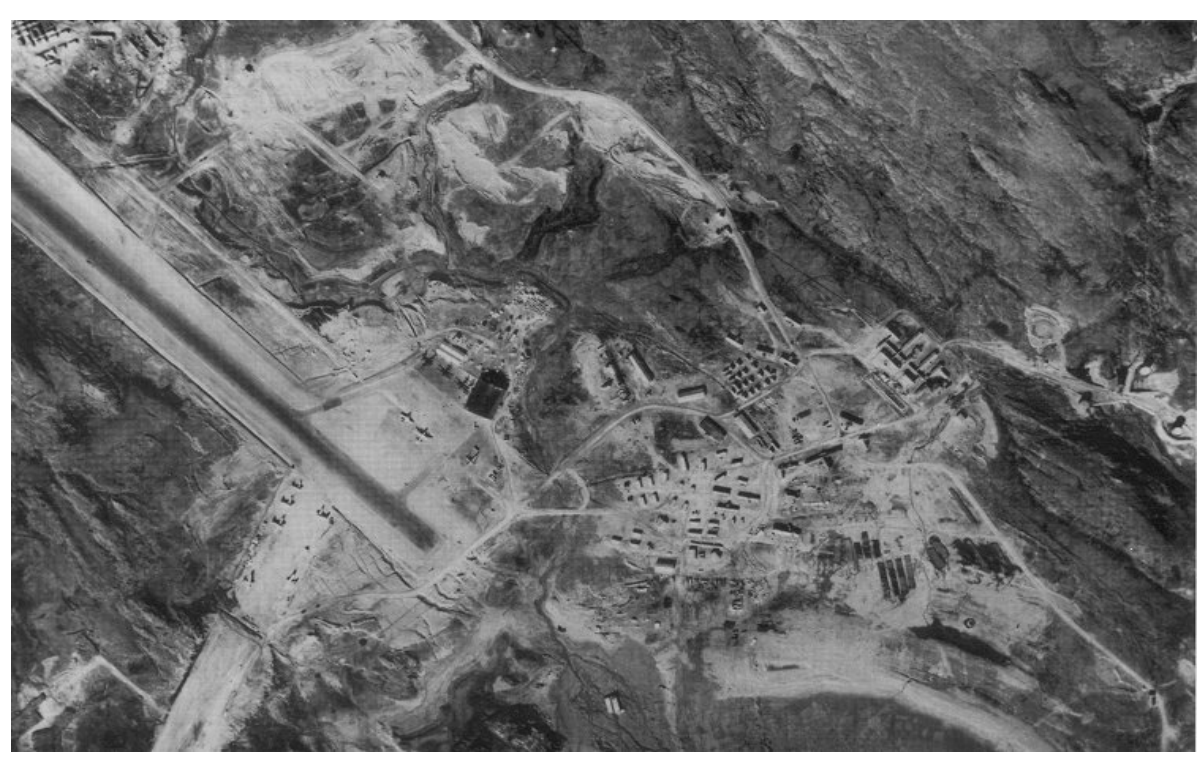

Figure 3.5 - Aerial of Frobisher Bay, 1955, Courtesy of National Archives Canada

\subsection{Frobisher Bay Settlement}

In the 1950s, the Canadian government was encouraging the Inuit to come off the land and live in settlements, by enticing them with social programs, housing, education and healthcare. Ultimately this was to enhance the standard of living. When the US military pulled out of Frobisher Bay, there was a population of approximately 900 , which was decidedly too large to disperse into other settlements. There was a decision by the GC to support the community and begin to fund large infrastructure projects based on an economic model and rational. Three continuing functions were: one, the airfield would continue to be used; two, it would become a centre for mineral exploration; three, it would become a government administration centre for the Canadian eastern arctic. 66 

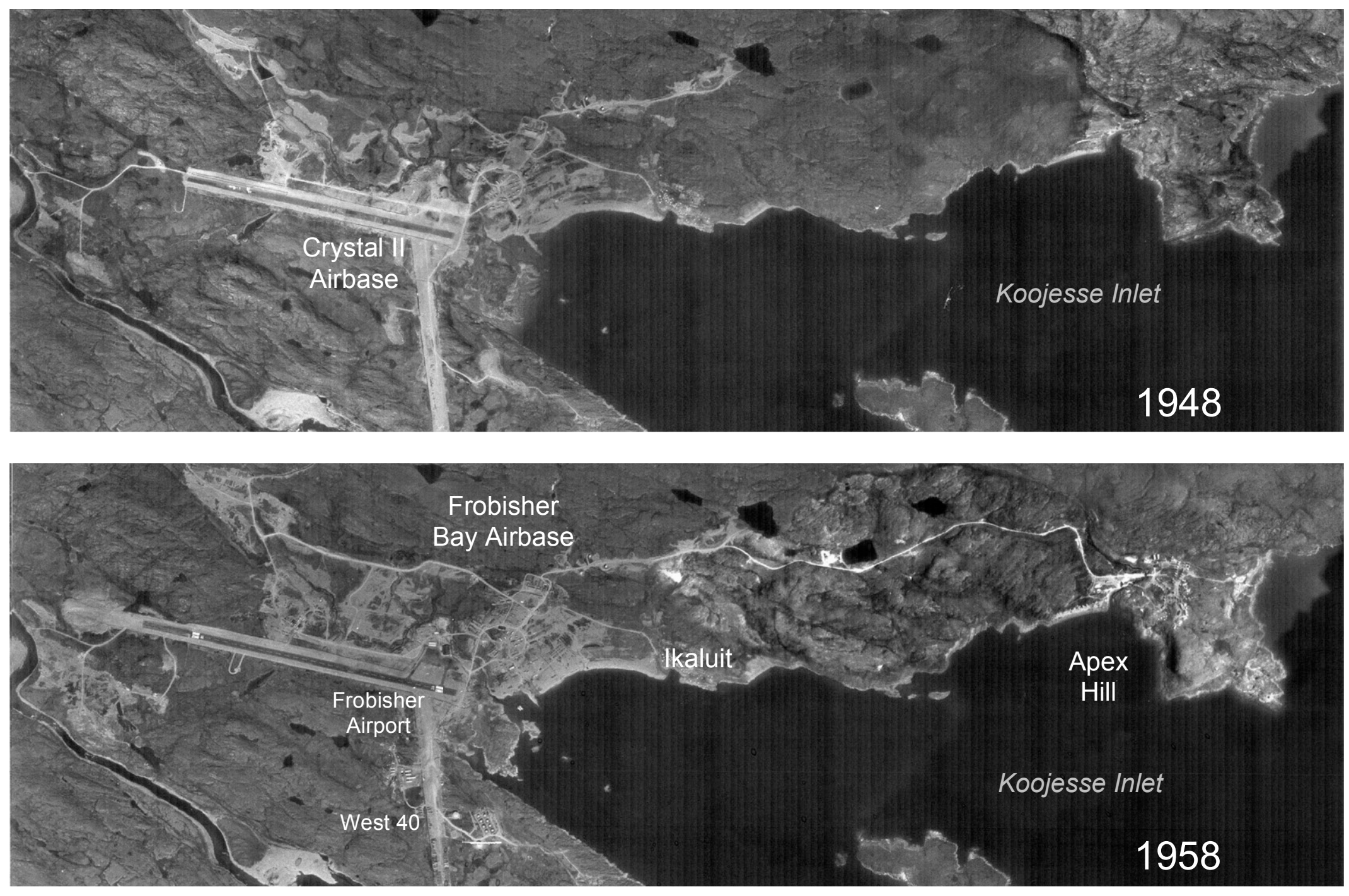

Figure 3.6, Figure 3.7 

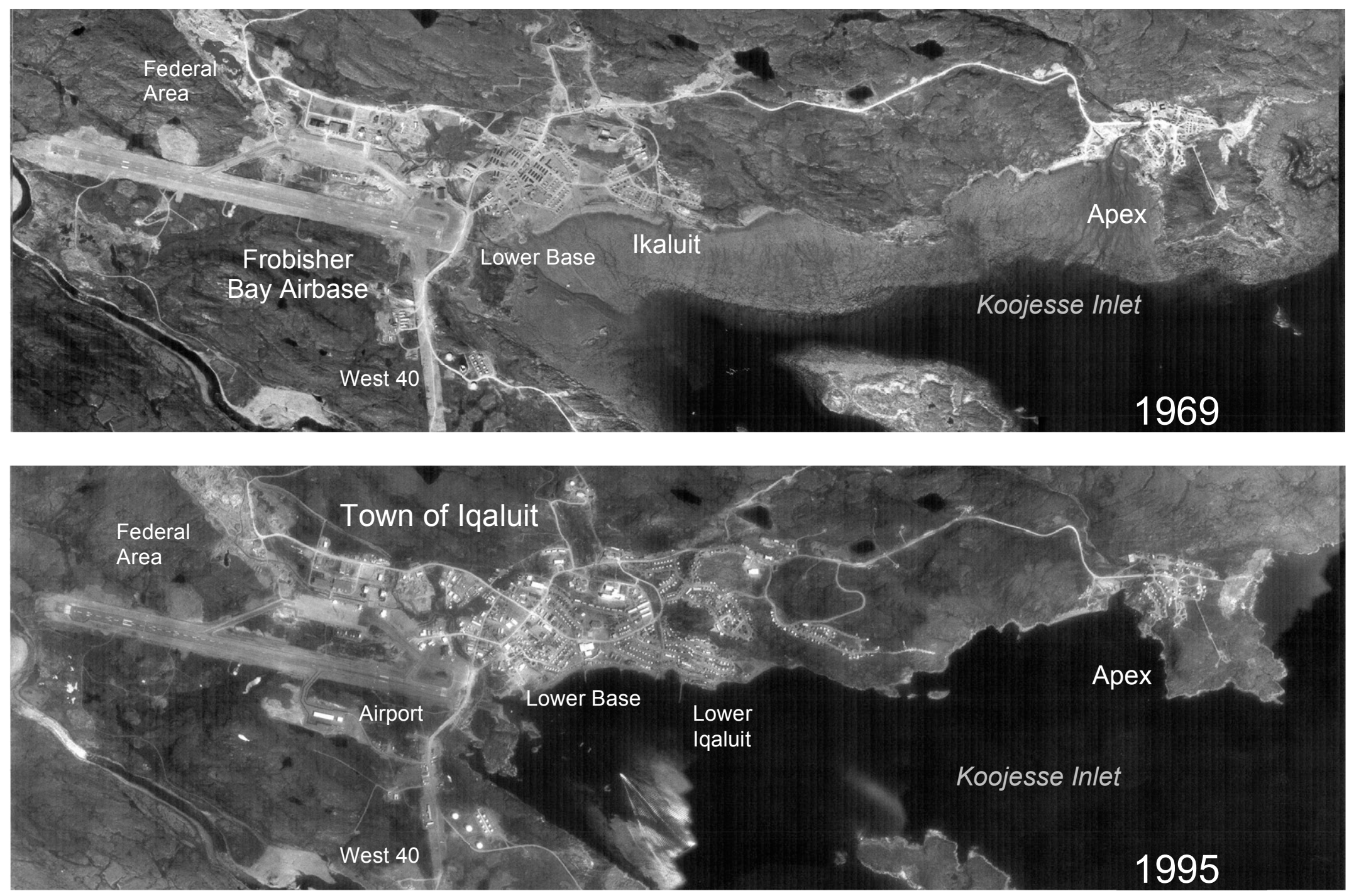

Figure 3.8, Figure 3.9 

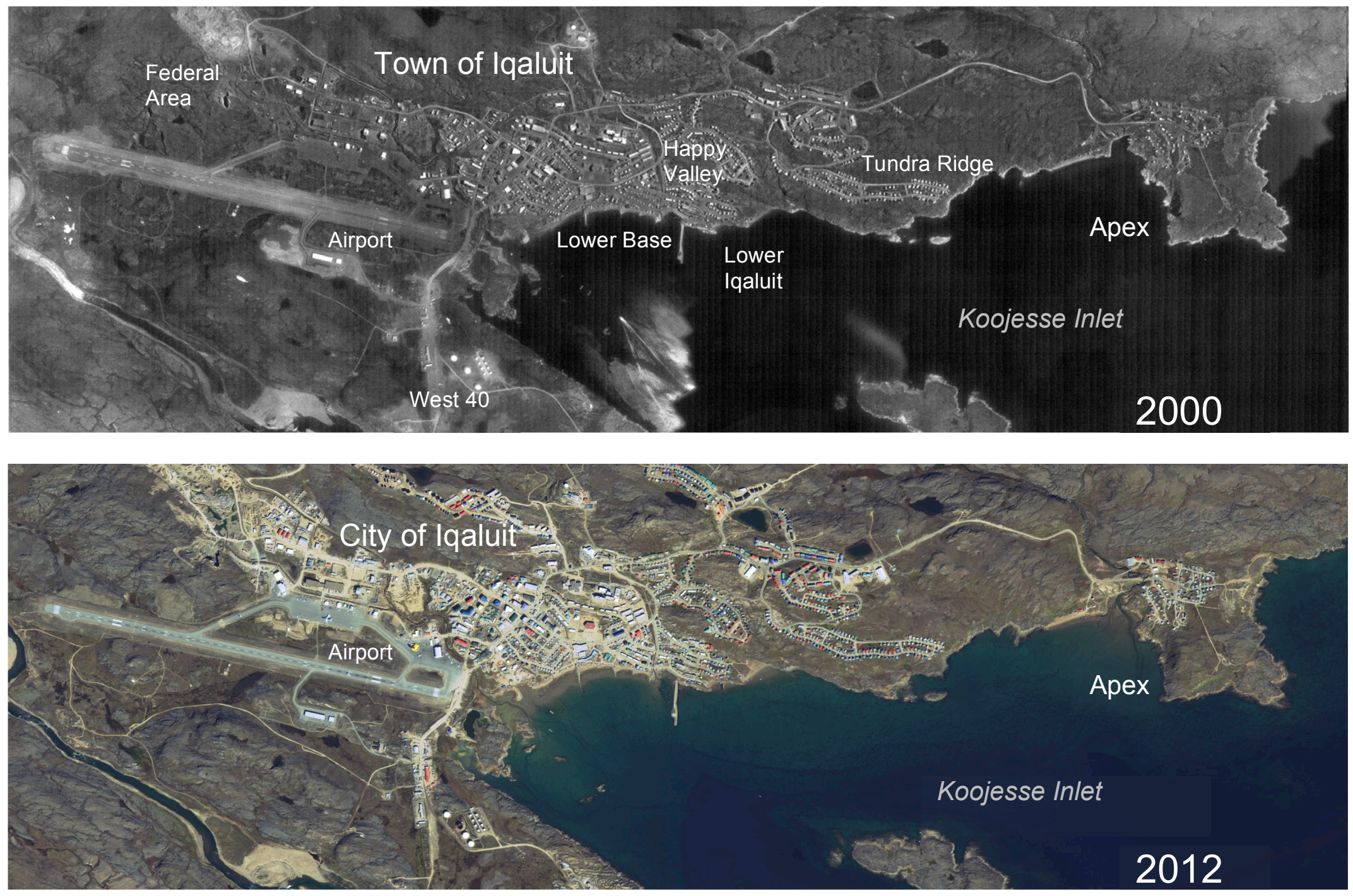

Figure 3.10, Figure 3.11 
67. Waldron, A. (2009). Frobisher Bay Future: Megastructure in a Meta-Land. In Architecture and Ideas: Experimental Modernism (Vol. VIII, pp. 20-35). Ottawa,
Onas: Experimental Modernism Ontario, Canada: Carleton University.

68, 69. Lee, B. (2012). Radical Arctic Proposals, 1-25.
"The Arctic setting was "desolate, barely inhabitable, waste of rock, ice winds, possessing for some an awesome beauty, constituting for others a totally demanding challenge... a successful northern community was one that "overcame four factors, namely, Exposure, Daylight/Darkness, Seasonal Cycles, and more importantly, Scale...protection from physical and psychological exposure." (The Canadian Architect, 1958) ${ }^{67}$

Since there was no formal urban design for the settlement, many of the buildings were in sporadic clusters based on the various entities that were present. By the mid-1960s, Frobisher Bay consisted of five distinct areas: Federal Area, Lower Base, Ikaluit, Apex Hill or "Eskimo Village", and the Airport. Modernist architects wanted to create a self-contained "oasis" in the arctic desert that ended up rejecting themes similar to Norditecture.

\subsection{Master Proposals}

In 1958, a housing development, Frobisher Bay New Town I (see Figures 3.12-15) by the Department of Public Works (DPW), Chief Architects Branch, was proposed to accommodate the rapid growth. The named 'space-age' design is in contrast to their consistently 'conservative modernism' approach, and as a result shocked many. The project was to house over one thousand residences in concrete towers (using sliding form and lift slab floors) surrounding an aluminum or plastic dome supported by concrete columns. The dome would be used for town amenities and services: schools, churches, a community center, a fire hall, federal buildings, shops, restaurants, atrium and a hotel. ${ }^{68}$ The dome's temperature would not go lower than 15 to $20^{\circ} \mathrm{F}$ if the outside were to drop to $-40^{\circ} \mathrm{F}$. There were also rumors of establishing nuclear power. The ring of towers was to act as a buffer against the harsh winter conditions. This design was not meant to be public and was tentative at best, but was leaked by The Canadian Architect magazine. 
In 1960, the DPW decided to readjust the original design and created the Frobisher Bay New Town II (see Figures 3.16-18). This proposal was less radical and costly by introducing mid-rise buildings. Over 1000 people were housed in three long buildings, with commercial, government, etc. on a raised central plaza. Institutions were meant to be located on the outside of the main structure. The structural system was of locally pre-cast reinforced concrete with cast in place or lift-slab floors. ${ }^{69}$ Although this was a more pragmatic approach than the DPW, economics and politics steered away from realizing it. Neither the 1958, nor 1960 plans were erected; their scale for a population of fewer than 300 seemed outlandish. These proposals may have been designed solely based on politics, propaganda and a way to enforce sovereignty in the North, if ever realized.

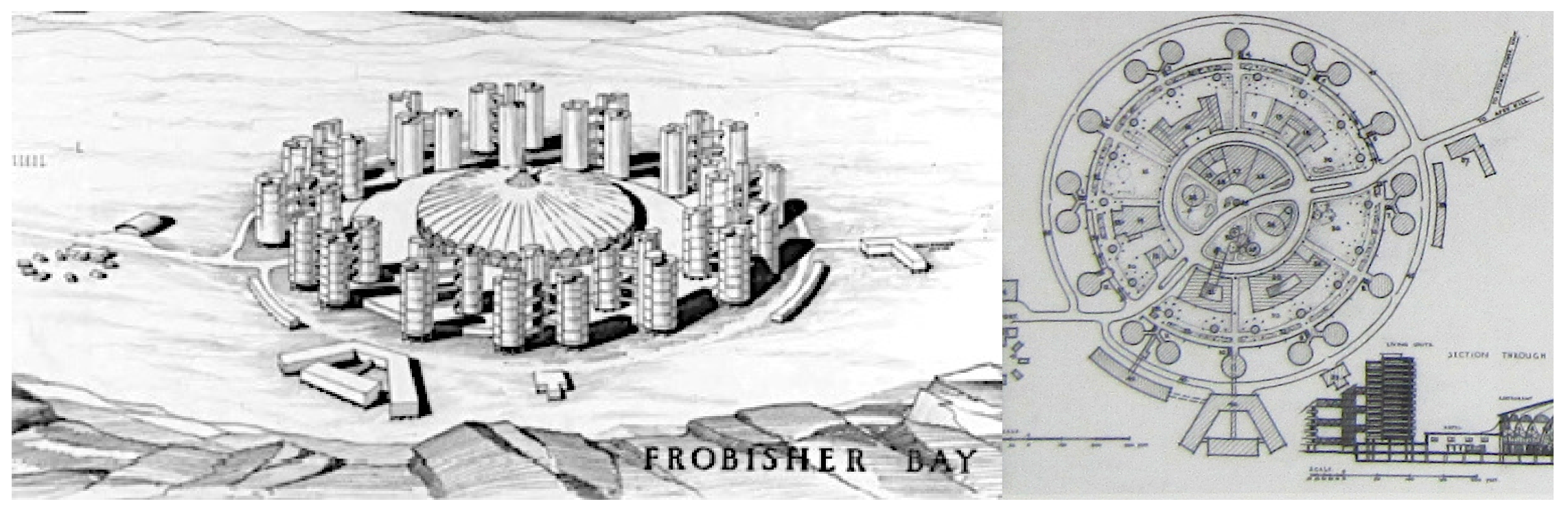

Figure 3.12, Figure 3.13 


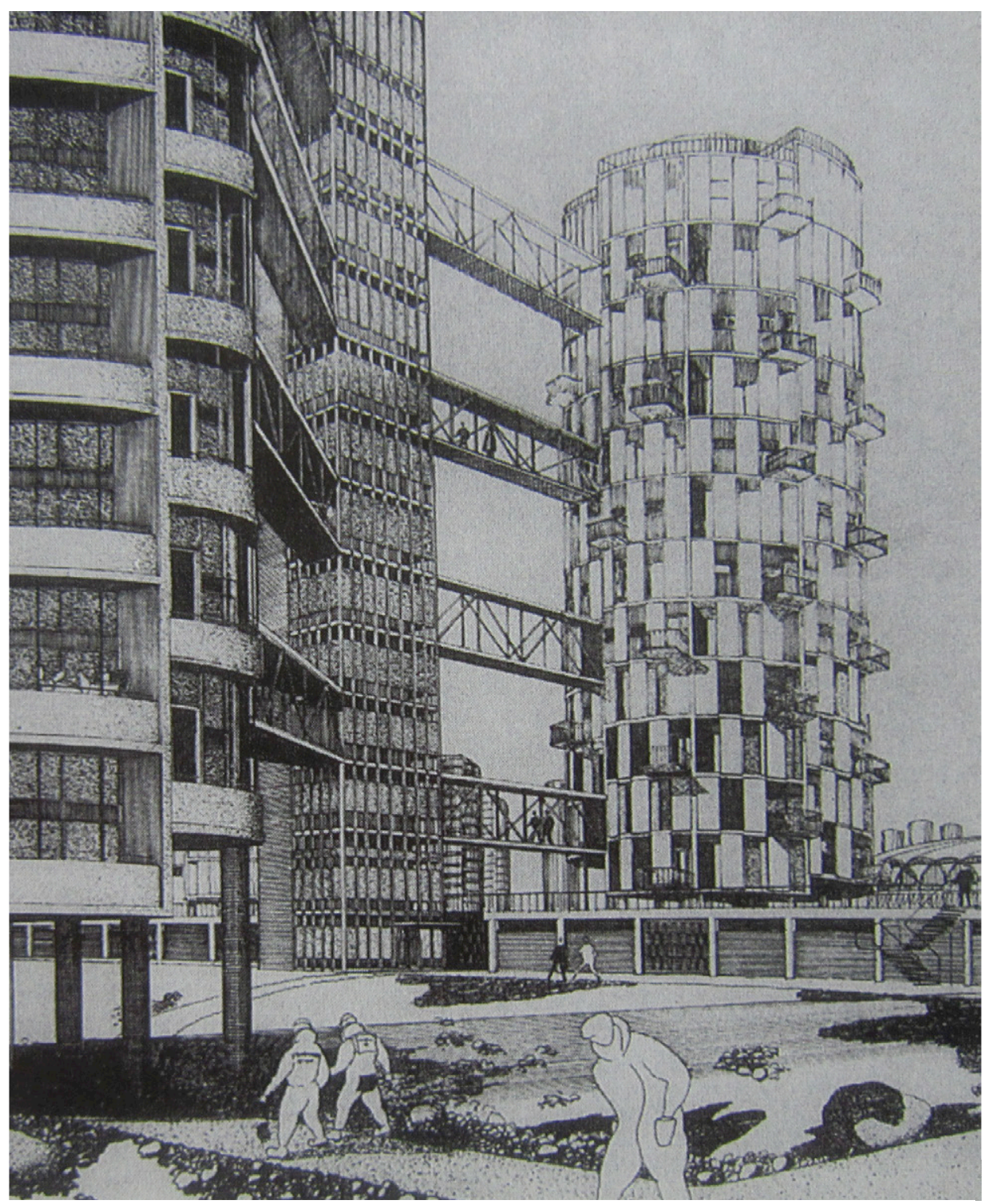

Frobisher Bay New Town I, 1958

By Department of Public Works
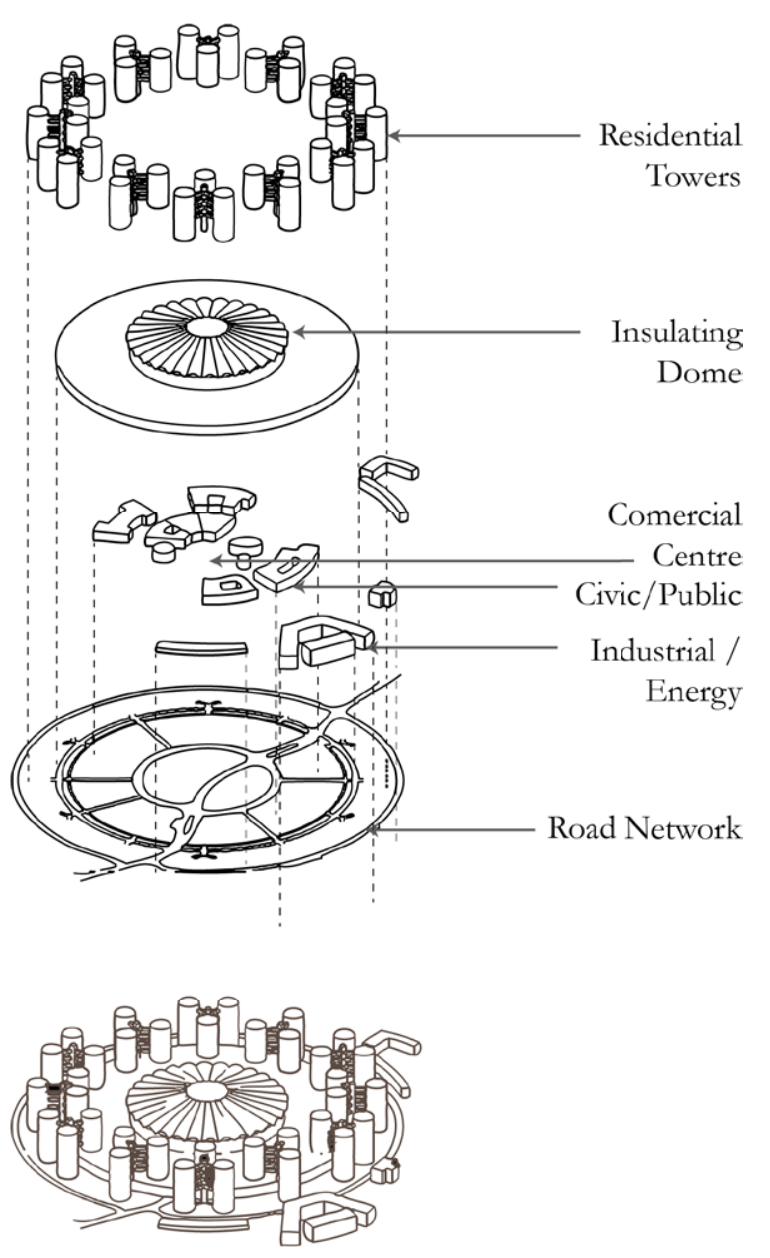

Figure 3.14, Figure 3.15 


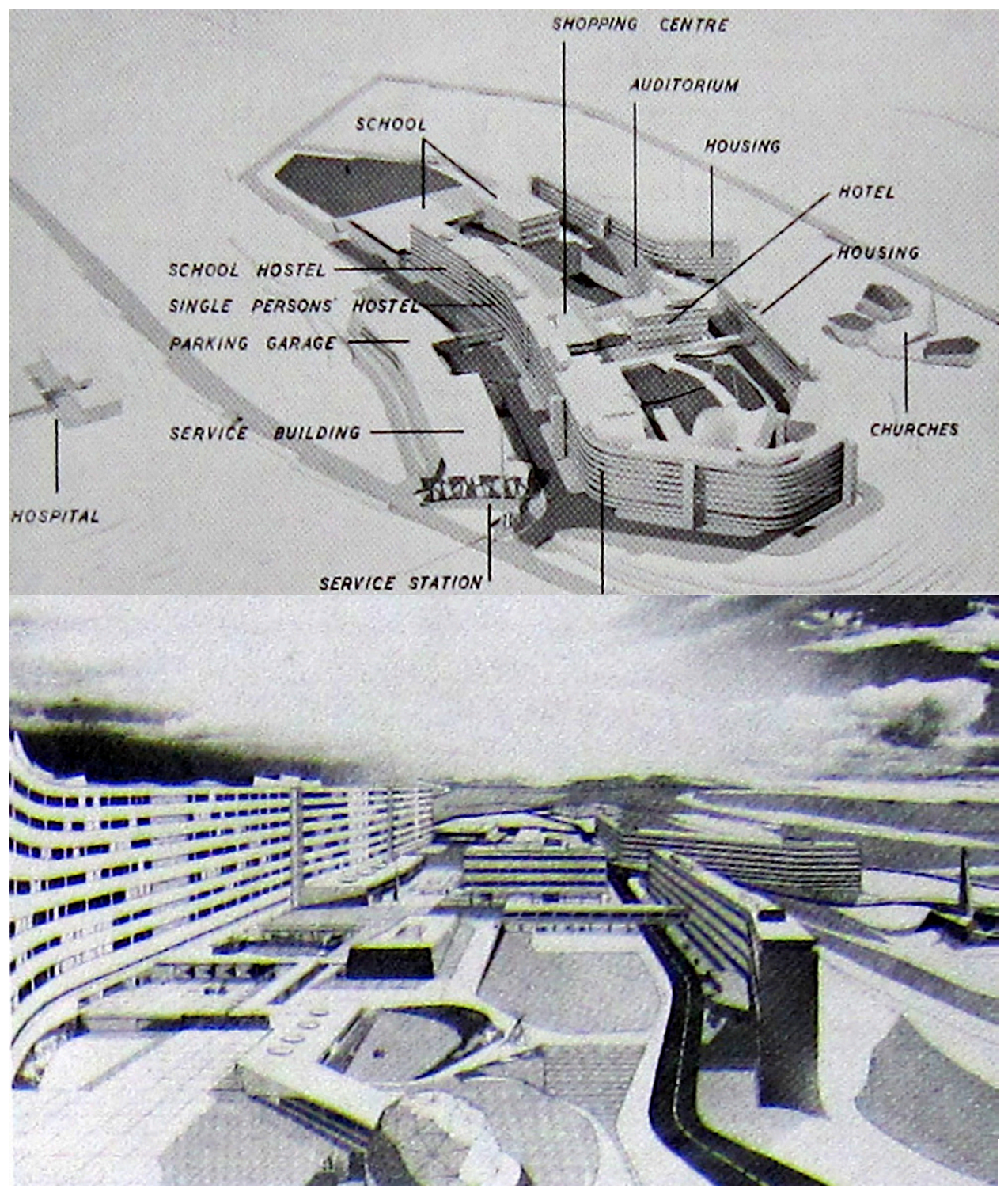

Frobisher Bay New Town II, 1960

By Department of Public Works

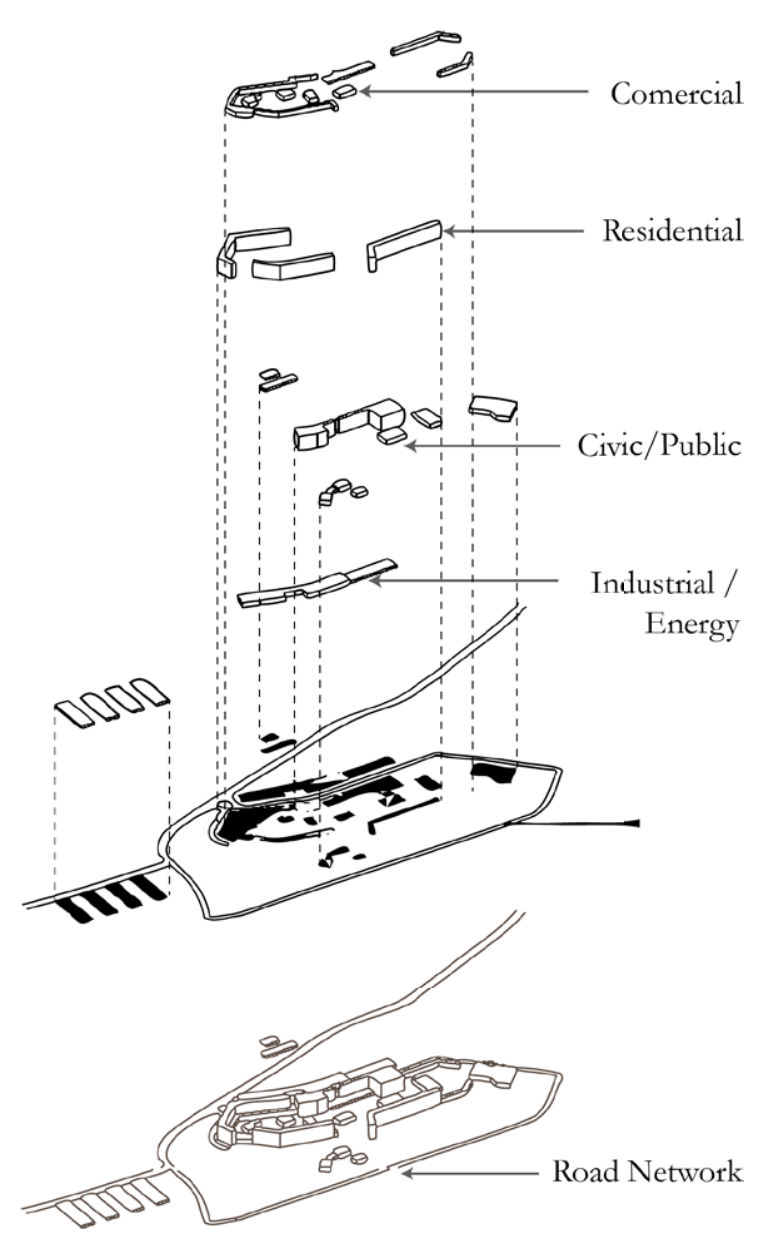

Figure 3.16, Figure 3.17, Figure 3.18 


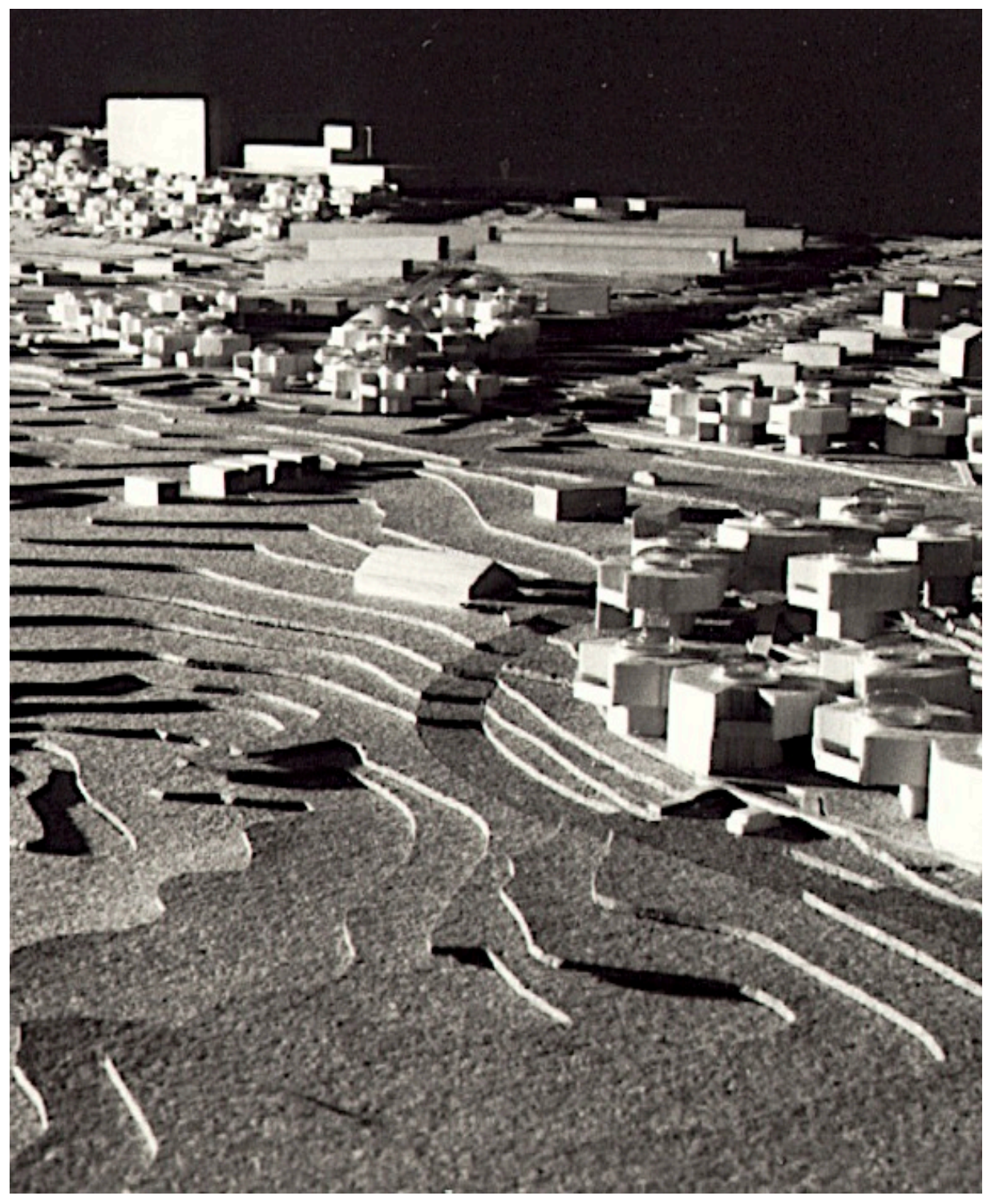

Frobisher Bay, 1974-77

By Moshe Safdie

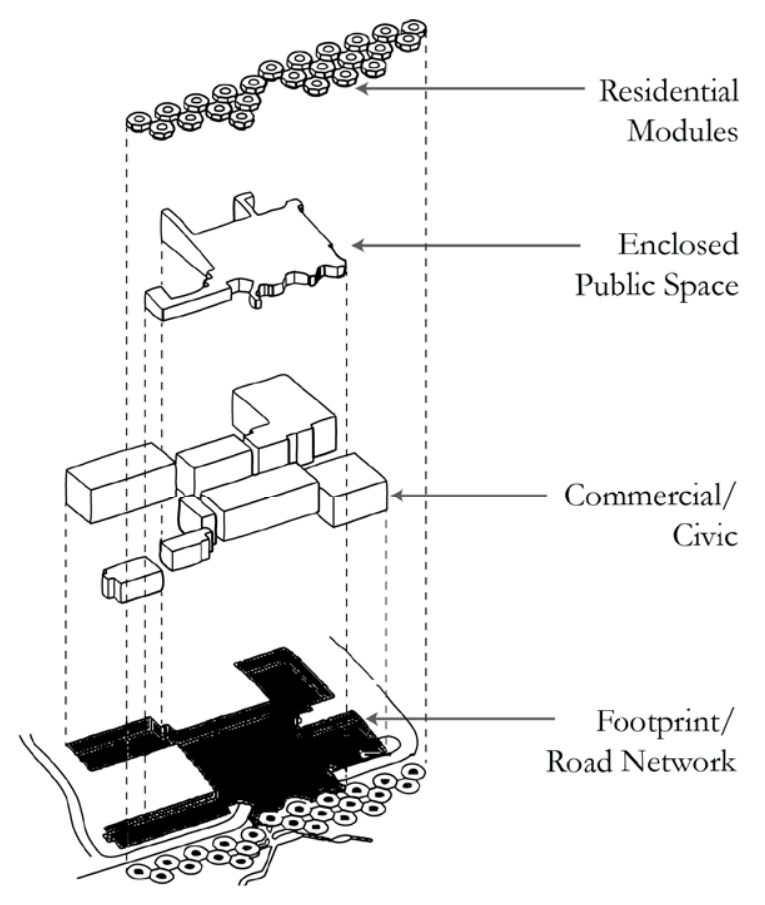

Figure 3.19 , Figure 3.20 

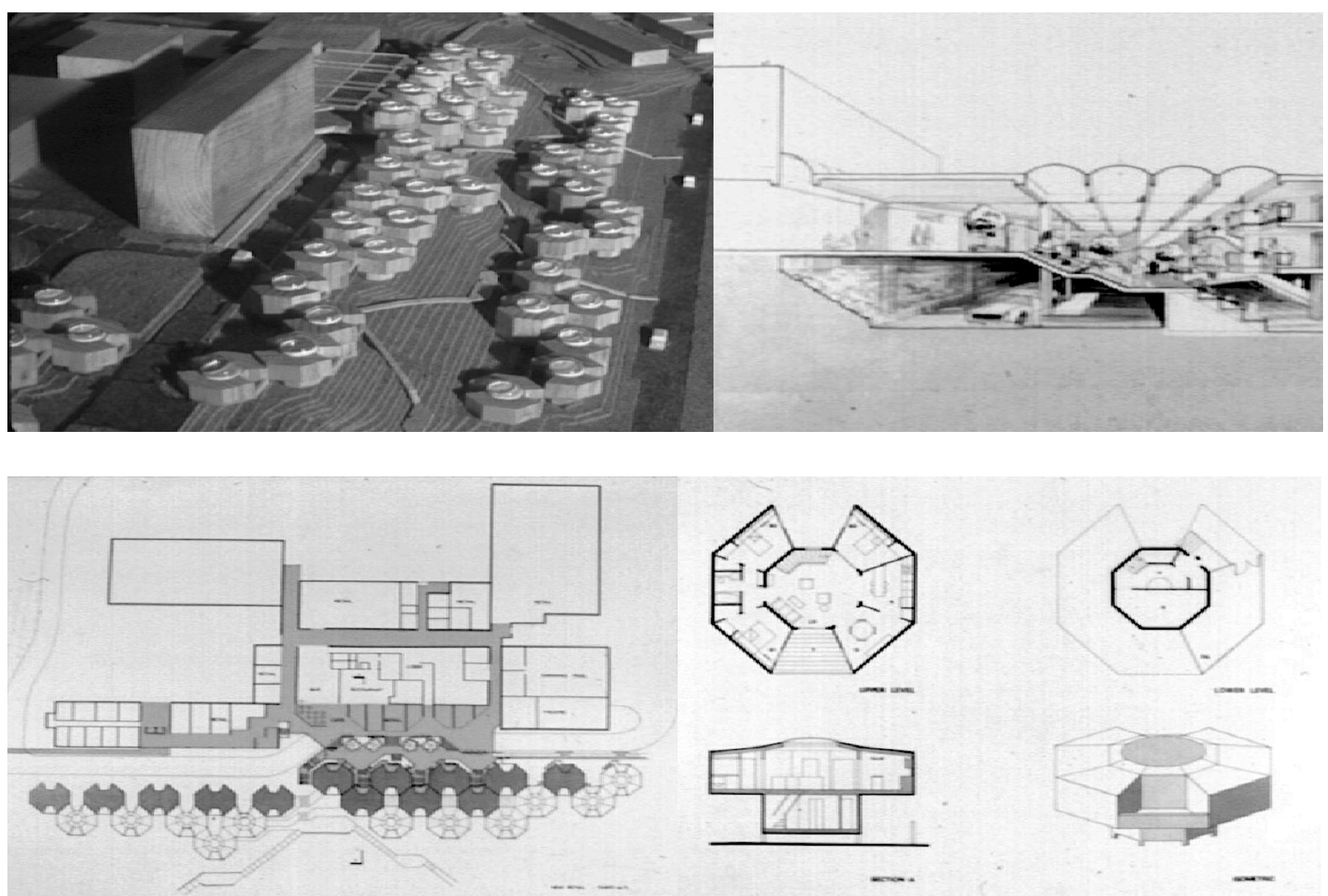

Figure 3.21, Figure 3.22, Figure 3.23, Figure 3.24
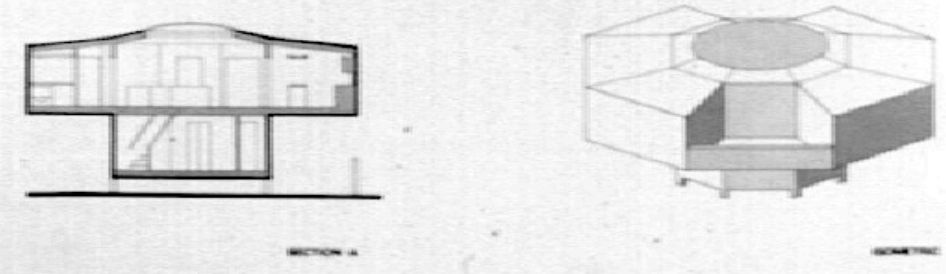
70, 71. Waldron, A. (2009) Frobisher Bay Future: Megastructure in a Meta-Land. In Architecture and Ideas. Experimental Modernism (Vol. VIII, pp. 20-35). Ottawa, Ontario, Canada: Carleton University.

72. Lee, B. (2012). Radical Arctic Proposals, 1-25.
In 1961, the government approved a minimum plan (designated as part of phase I of the Frobisher Development Plan) to construct three buildings with the New Town II as its design influence. These buildings were built on blasted solid rock. The director of Arctic Administration stated,

$$
\begin{aligned}
& \text { "...use of relatively high-rise precast concrete structures on a rock base and coupled with } \\
& \text { the shortest practical sewer and water lines, not only lowers initial costs but substantially } \\
& \text { reduces operating and maintenance costs and gives virtual freedom from fire hazard." } 70
\end{aligned}
$$

In the sixties, the three buildings contained a 120-unit apartment, 16-room school and a 20-bed hotel. ${ }^{71}$ In 1970, Queen Elizabeth II stayed in the highest $(24.9 \mathrm{~m})$ of the three buildings, called the '8-storey.' Locals call the building 8-storey because it is the tallest building of all Nunavut. Today the buildings are part of Astro Hill Complex (see Figure 3.25) with much of the program repurposed. The site now boasts a hotel, movie theatre, two restaurants, housing apartments, and offices.

In 1974 to 1977, Architect Moshe Safdie, designer of Habitat 67, proposed another concept for Frobisher Bay (see Figures 3.19-24). Safdie was commissioned to replace the existing government staff housing and develop a general urban plan that would be the basis of growth for the next decade. His concept was detached two-storey octagonal housing units arranged systematically from a public urban centre. The units employed the use of gel-coated fiberglass panels on a wood frame. In contrast to the other two Frobisher plans, Safdie's design allows for urban expansion, and is respectful of human scale in the housing units. "The organization of the units is reminiscent of a medieval town with an important public center surrounded by housing." 72 This project was never implemented. 


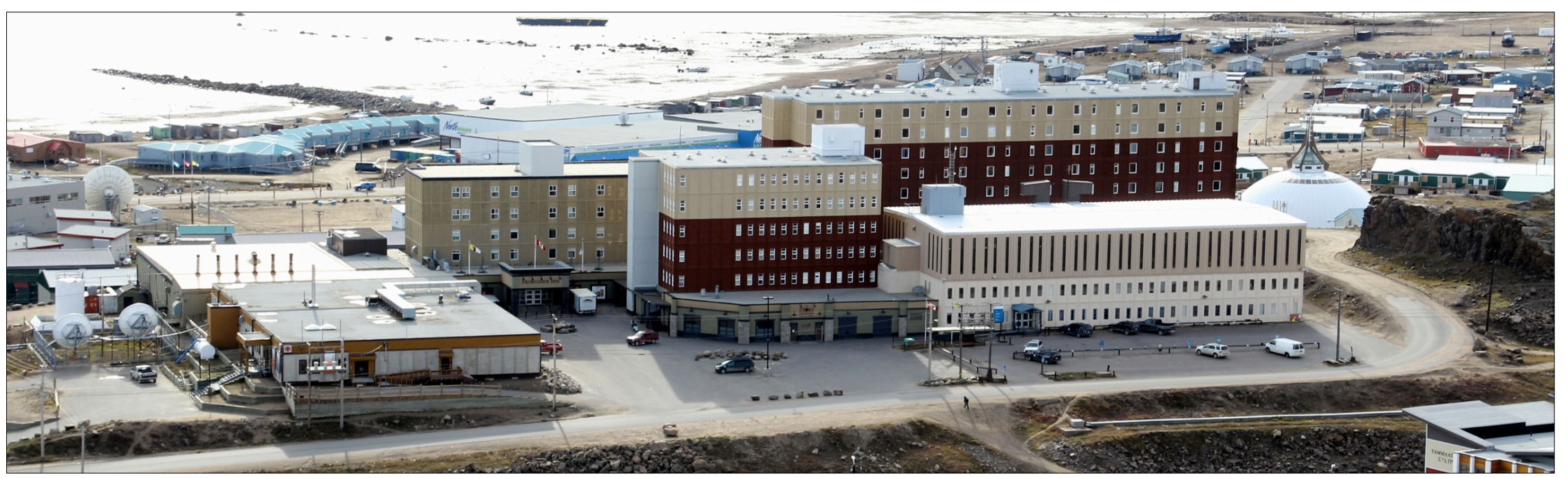

Figure 3.25 - Astro Hill Complex, 2013 (Kasten, 2011)

73. Lee, B. (2012). Radical Arctic Proposals, 1-25.
Various concepts were proposed, but many of them were not realized and left the settlement to grow in a clustered urban form. In the 70 s and ' 80 s a trend was emerging called pioneer futurism. "Many architects working in cold regions are making their buildings into icons-visions of future societies and statements about alternative values. These projects share an aesthetic goal: the use of architecture to express a bold pioneering spirit." 73 This is evident in a list of buildings: The airport terminal, City Hall, Nakasuk Elementary School, Inuksuk High School and Baffin Correctional Centre. These buildings demand presence to the onlooker, and become unique in their streamline curves and solid color prefab panels. One would question if they were uniquely northern, or a product of utility. In the 1970s, Canada experienced an energy crisis and these buildings were constructed to perform with low energy consumption, having minimal glazing and little infiltration 
with prefab panels. Many of these structures are in use to this day. Frobisher Bay underwent some designation changes in the next few decades: 1970 recognized as a settlement, 1980 recognized as a town, 1987 renamed Iqaluit (place of many fish), 1995 Iqaluit became the capital of Nunavut, and in 2001 Iqaluit was recognized as a city.

\subsection{Iqaluit $\Delta^{\mathrm{c} b} \mathrm{~b} \Delta^{\mathrm{c}}$ (place of many fish)}

Today, Iqaluit is the largest city in the Territory of Nunavut. As with many other cities in Canada, there are the typical amenities and services: hotels, hospital, museum and recreation. There is a population of more than seven thousand. In contrast to other communities in the Territory, the demographic is roughly half Inuit and the other half is a mix of cultures; including Caucasian, Filipino, Latin, Asian, etc. With the advent of various economic stimulants, such as mining, tourism and the North West Passage, the face of Iqaluit may change in the next twenty years. To accommodate the changes the Government of Nunavut $(\mathrm{GN})$ and Federal Government have initiated infrastructure projects. One will be a new international airport terminal building, estimated over 300 million dollars. The airport is receiving a larger volume of passengers, in addition to accommodating various military and commercial functions. The Iqaluit airport has also been the site of cold weather testing, due to its long runway. This has created the demand for a new terminal. Since the cost is past budget, the GN entered into a P3 joint venture. Another is a new recreation centre, estimated at 44 million dollars. The city is trying to keep up with the growth by servicing new subdivision lots, in addition to upgrading the roads.

Since Iqaluit is the capital, the main function of the city is administrative. The legislative assembly of Nunavut is located within the Central Business District (CBD). The building includes an igloo- 
inspired chamber with sealskin seats. Various government office buildings litter the urban landscape. The CBD surrounds the four corners (four-way stop signs) where congestion happens three times per day: morning, lunch and evening commutes. Many of the residences complain about the 5-10 minute traffic.

The life of the city and surrounding tundra is active all year with flights landing and taking off, motorists zipping all over the limited roads, boats racing the tide during summer, and snowmobiles or the occasional dogsled crossing the frozen bay during winter. Communications are lacking in speed, but are comparable to the South. Iqaluit as a city has great potential, but the biggest setback is that it is not sustainable. There is no economic support other than the federal government, and this will always pose a hindrance when it comes to self-determination. 


\section{Chapter: Extreme Challenges and Techniques}

\subsection{Climate}

74. Nunavut Tourism. (2013). Sylvia Grinnell Territorial Park. Retrieved November 19, 2013, from

he city of Iqaluit is a place of extremes. The challenges imposed are not easy even for the seasoned architect. Various environmental and logistical problems arise during the life and design of a project. Environmentally, weather can be unpredictably harsh and terrain http://www.nunavuttourism.com unforgiving. Logistically, projects are subject to difficulties with the environment and remoteness creating high project costs and crippling schedules. The image below was taken outside my window during a blizzard, with up to $80 \mathrm{~km}$ per hour, on November 19th, 2013.

Iqaluit like many other Arctic communities boasts punishing climates. In general, the city has short summers and long winters. The Inuit calendar has six seasons: ukinq (winter), upirngassaq (early spring), upirngaaq (spring), aujaq (summer), ukiassaaq (early fall) and ukiaq (fall). ${ }^{74}$ (see Figure 4.2) From spring to summer, the tundra is colorful, but the growing season is too short to allow for tree growth or possible agricultural initiatives. This season is known as construction season. The winter months see shorter days and more volatile weather patterns.

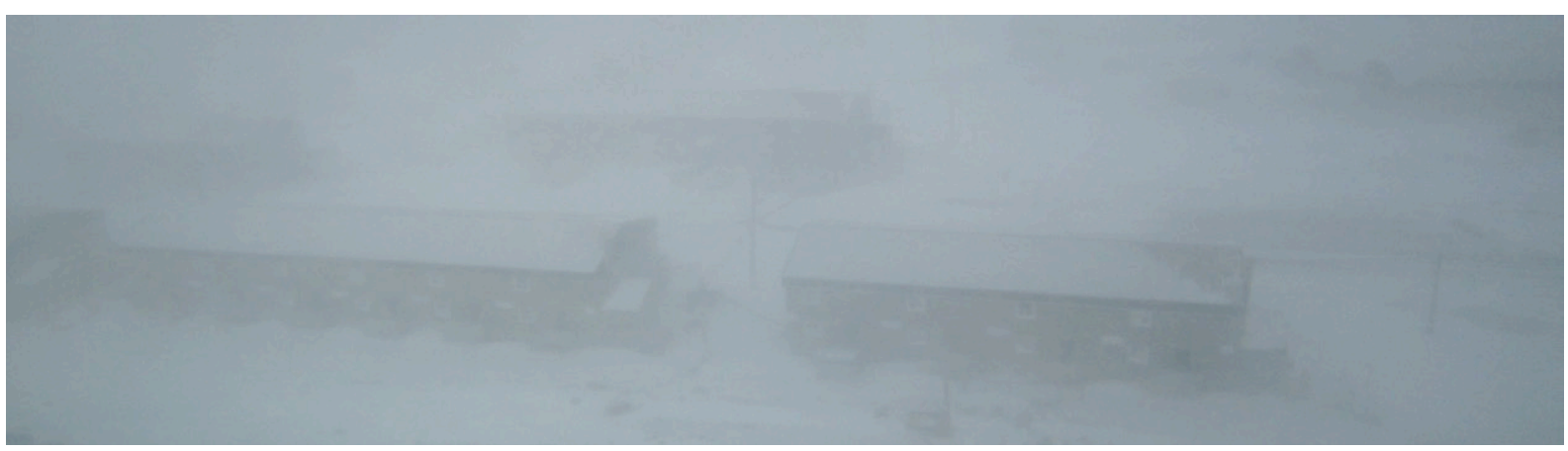

Figure 4.1 - Blizzard in lqaluit, November 19, 2013 


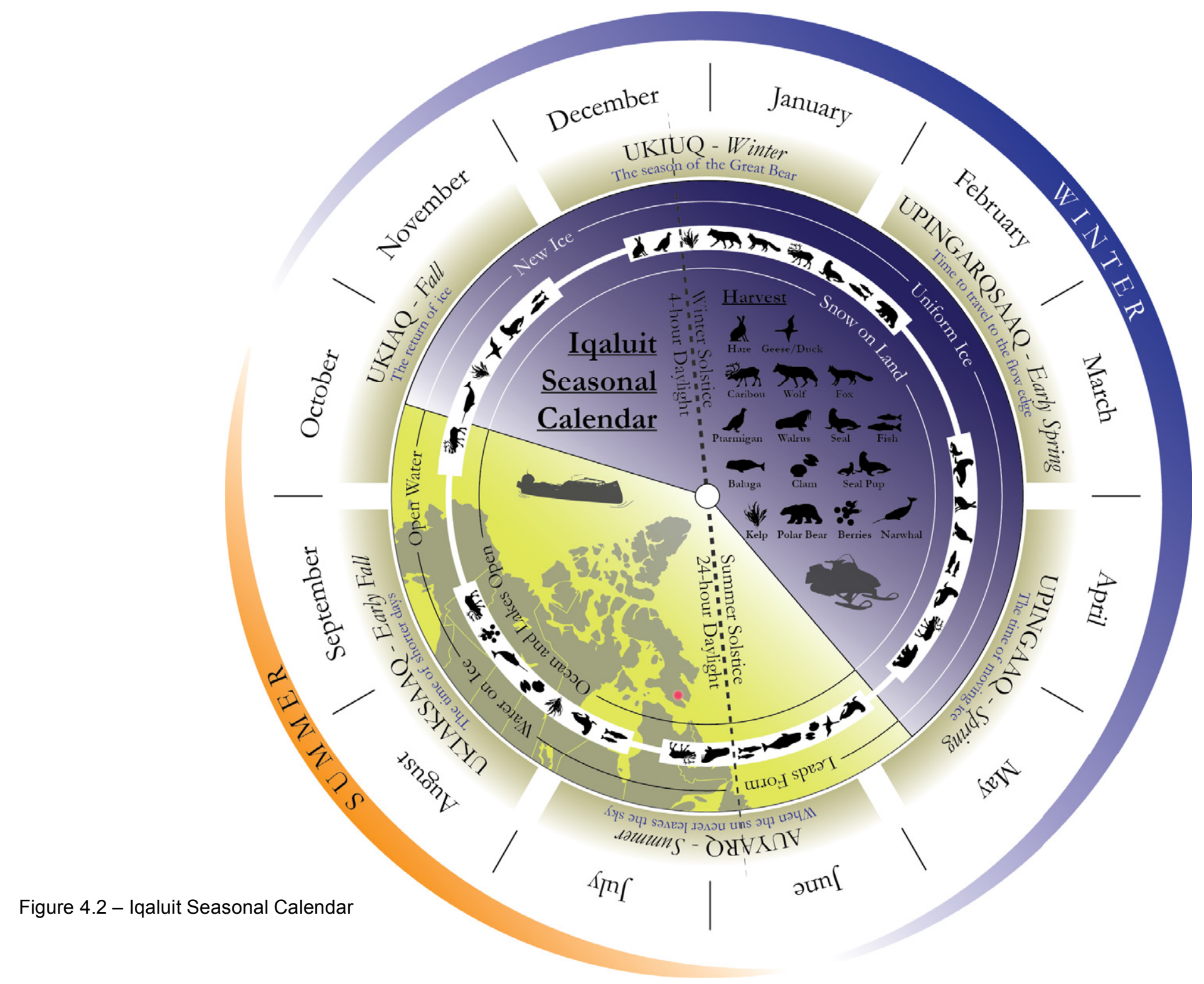


75. Strub, H. (1996). Bare Poles: Building Design for High Latitudes (Vol. 186). McGill-Queen's Press MQUP

Figure 4.3 - Iqaluit's Average Temperature

\subsection{Temperature}

The arctic temperature can drop to below $-40^{\circ} \mathrm{C}$ in the winter. (see Figure 4.3) Many would point out that this temperature could be noticed in other Southern parts of Canada. This is true, but what is different is how long that temperature remains at that level. Iqaluit can be $-40^{\circ} \mathrm{C}$ for days if not weeks. This puts a great strain on buildings. Low outside temperature affects buildings in four main ways: heat loss, water or gas changes state in confined places, freeze thaw at envelope surface, and contraction of exposed materials. ${ }^{75} \mathrm{Wind}$-chill has little effect on a building envelope, but it will have a dramatic effect on a person. Wind-chill advances the rate of heat loss on a surface but only to the level of mean temperature. If it is $-30^{\circ} \mathrm{C}$ a building surface will only go down to that level. The human skin cannot survive at $-30^{\circ} \mathrm{C}$ and a wind-chill can make it feel like $-65^{\circ} \mathrm{C}$. Living in Iqaluit, I have observed both a wind-chill of $-65^{\circ} \mathrm{C}$ and received frostbite on my face from one gust of wind entering the hood of my parka.

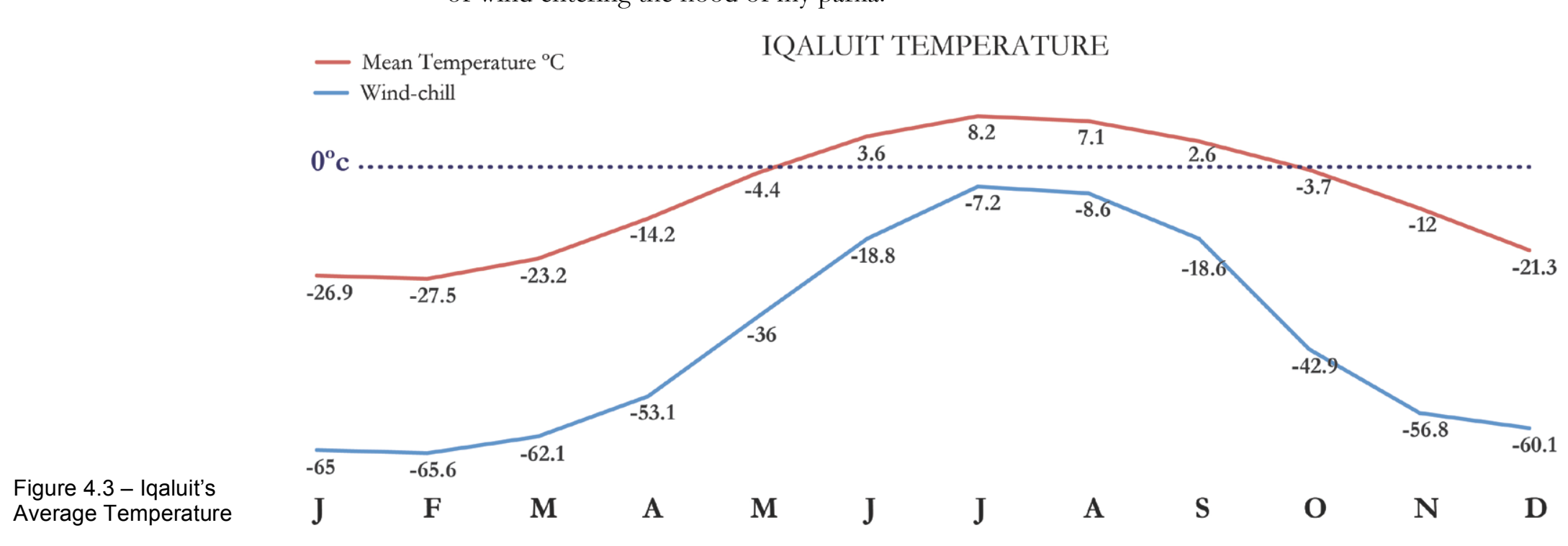


"The two people appear to have gone out on the land on the afternoon of Feb. 1, [2013] just a few hours before a powerful winter storm swept across Iqaluit, creating blizzard conditions for almost two days...Police said they found the bodies just two miles north of the airport runway."

$$
\text { Nunatsiaq News, } 2013^{76}
$$

\section{$x$ Green Fail}

Wind energy is under review, but many systems are not adapted to the arctic frost. Wind turbines would seize.
The lower the temperature outside the greater rate of heat loss. This requires much more insulation inside the building envelope, with an average 12" wall thickness. Housing typically employs, 5.5" batt and 2" rigid insulation on the walls, 11" batt on the floor, and 11" batt and 2" rigid on the roof. Due to ice damming, CMHC recommends the use of a cathedral type ceiling versus an unheated attic. Unfortunately, this requires a greater heat load for the building.

\subsection{Wind and Snow}

Wind is a serious factor in the arctic for both constructing and maintaining buildings. Some are most destructive with gusts up to $130 \mathrm{~km}$ per hour in Iqaluit. Roofs get damaged, and a construction site could lose its material. Some construction material can be seen along the airport fence after a windstorm. Pangnirtung, Nunavut sees very high winds and requires that roofs be anchored with cable to the ground. Wind mixed with snow create white out conditions. Blizzards in the arctic are unique, since they usually do not produce a vast amount of snow, because of its aridity, but drifting snow is serious enough to bury a house. (see Figure 4.4) Much of the arctic is considered a desert since it has little precipitation; Toronto has an annual rainfall of over 32 inches, Iqaluit has over 7 inches. Iqaluit tries to mitigate the snow drifting problems by installing a snow fence at the city's perimeter (see Figure 4.5), and by requiring any large building design be subject to review by an engineer that specializes in thermal dynamics. One of the design requirements is to have an open area under the building to allow for snow to drift through without building up. Northern buildings typically avoid having an eave to avoid uplift problems. 


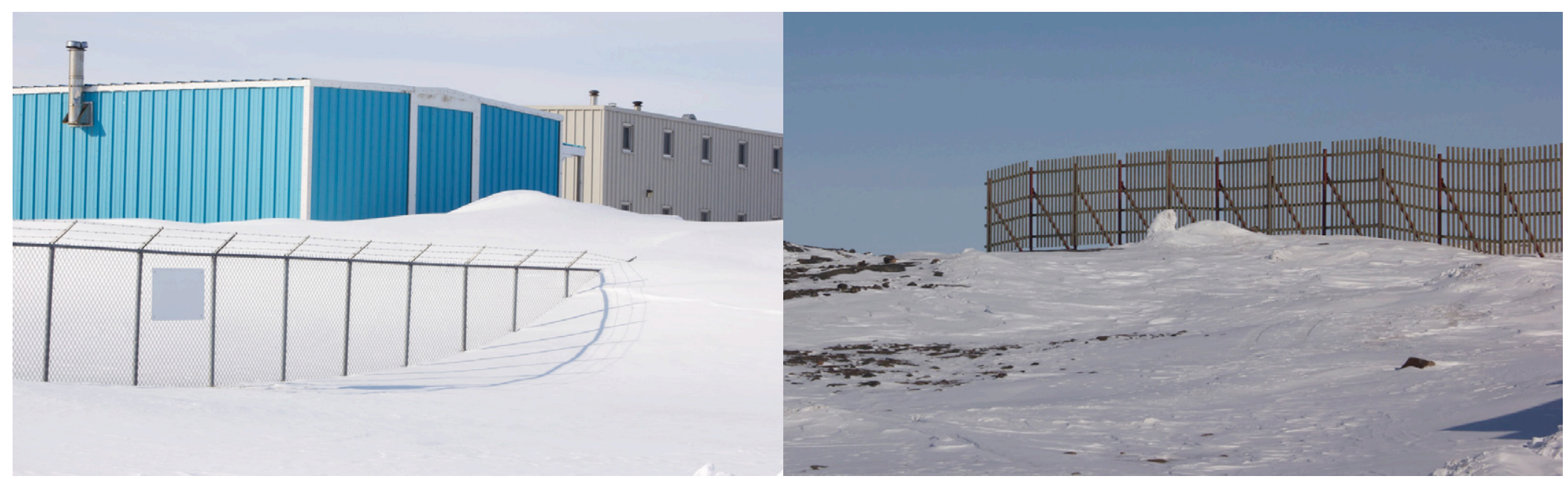

Figure 4.4 - Snow drift Figure 4.5 - Snow fence

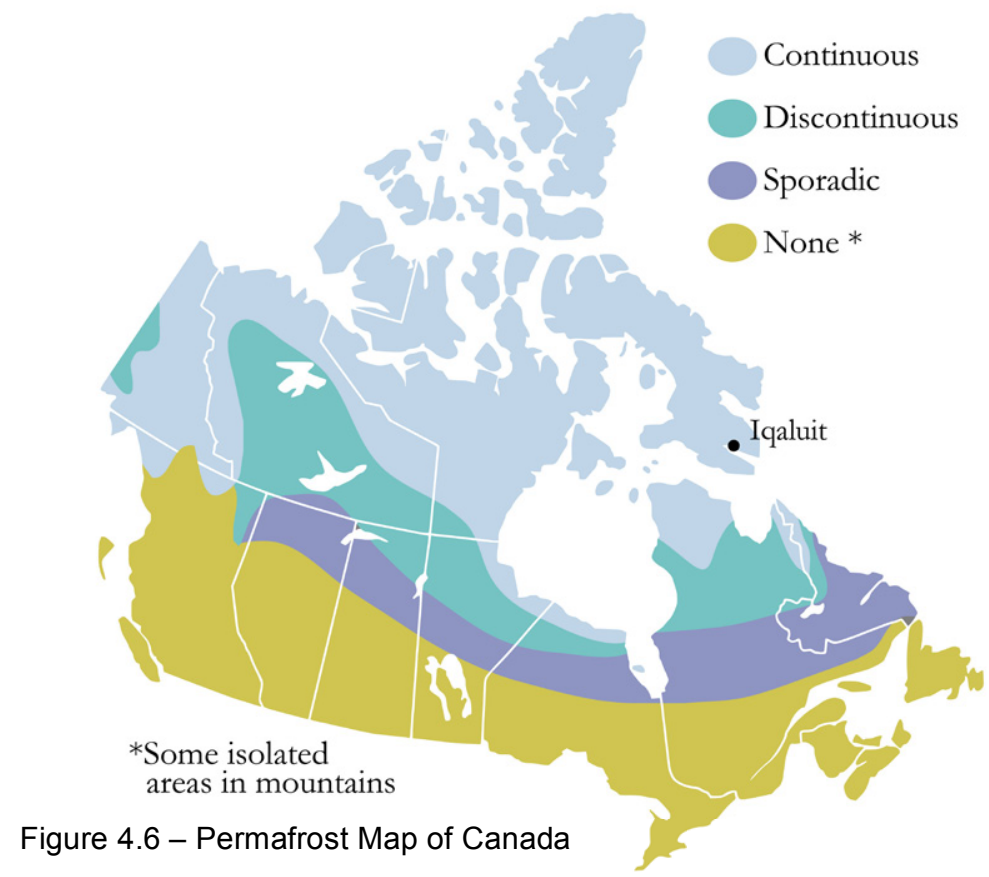

\subsection{Permafrost}

Any architect must respect permafrost and how it affects a building's foundation. In the past, when western civilization decided to construct in the North, they would place the building directly on the ground. In the years following the building would tear apart from the shifting. At times buildings would have autonomy and move after a freeze thaw cycle. Over a decade, a structure could have moved over a meter from where it was originally constructed. Permafrost was the culprit; it is the soil, rock or sediment permanently frozen under the ground. There are four main regions regarding permafrost in Canada: continuous, discontinuous, sporadic and non-existent. (see Figure 4.6) Iqaluit is located in the continuous permafrost region with a 
77. Strub, H. (1996). Bare Poles: Building Design for High Latitudes (Vol. 186). McGill-Queen's Press MQUP

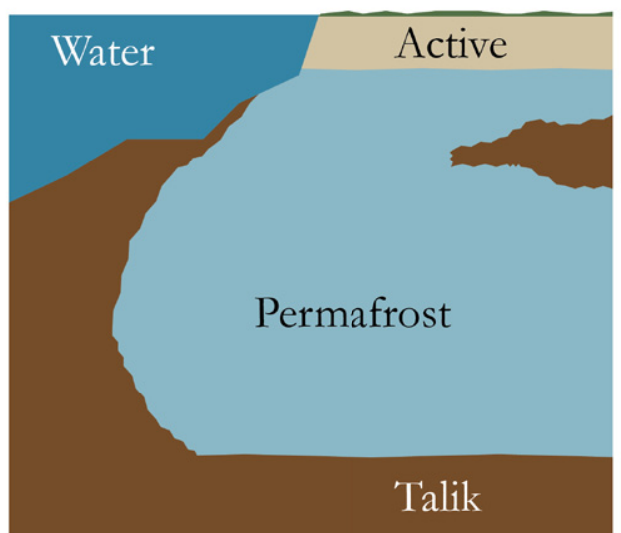

Figure 4.7 - Permafrost Layers

\section{$x$ Green Fail}

Permafrost is always frozen and makes geothermal systems useless depth of nearly 200 meters. Permafrost has three layers, the active layer, frozen layer (permafrost) and the talik layer. (see Figure 4.7) The talik is unfrozen beneath both the permafrost and between the active layer and permafrost in areas. The active layer thickness can range and is of great concern to the engineer. It is the layer that thaws and freezes with the seasons and can thicken if additional heat is applied.

Permafrost dictates the design of foundations. A heated building set directly on the ground develops a zone of thawed soil - a thaw bulb- in the perennially frozen soil below it. ${ }^{77}$ This condition melts the permanently frozen soil and thickens the active layer, compromising the integrity of the supporting ground. To avoid this effect, architects employ the use of piles to raise the structure above the surface or thermosyphons to draw the heat out from under the building. (see Figure 4.8) An alternative that is slowly being introduced is the space frame foundation. It allows for the ground to keep cool and adapts to setting problems. Unfortunately this technology is still new and has not been fully proven or accepted. A small handful of spaceframe foundations have been constructed in Iqaluit. Traditionally, the temporary structures were not concerned with the long-term effects of permafrost.

Climate change is having an effect on the permafrost. While the outside air temperature is rising during the summer months, the active layer gets thicker. During the winter, the raise in temperature increases the snow falls insulating the ground from freezing. The result is a thickening active layer. In a structure that is flush with the ground, the result could tear the structure by uneven settling regardless of thermosyphons. In a building on piles, a thicker active layer may result in frost heaving, creating the same result. It is important for designers to look for ways to design for the 
site conditions of the time, as well as the effects climate change would have on the buildings. The GN is exploring different options to dealing with an infrastructure that may be compromised in the next 20 years.

\section{On Ground}

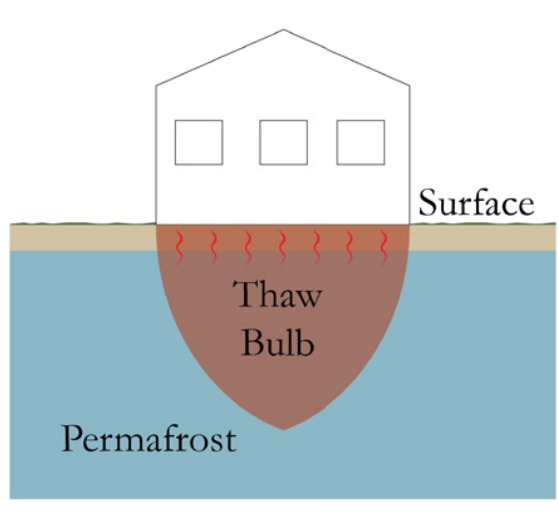

On Piles

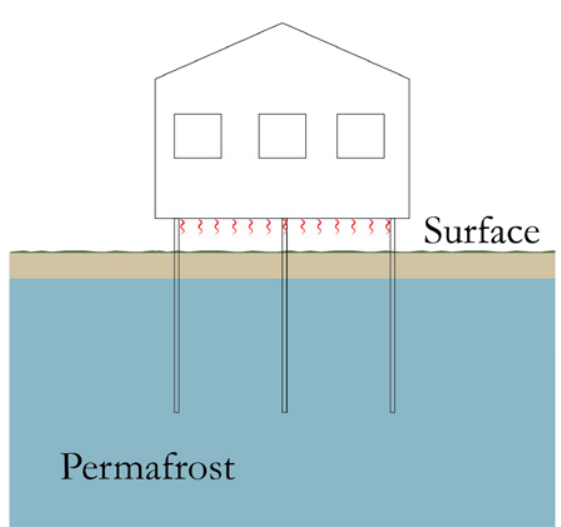

On Ground With

Thermosyphons

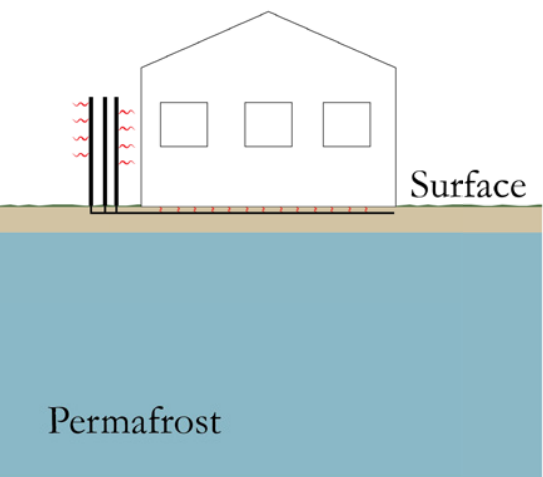

Figure 4.8 - Effects foundation design has on permafrost

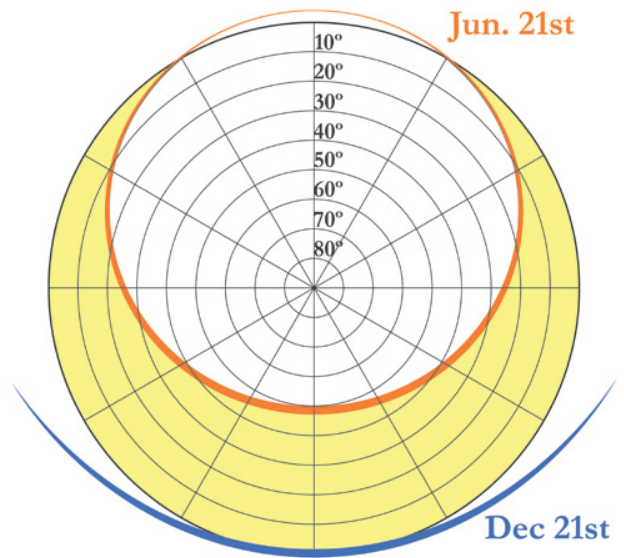

Figure 4.9 - Sun path diagram for Iqaluit

\subsection{Sunlight}

Sunlight is celebrated in the north. In the high arctic, it may be weeks before seeing the sun during the winter solstice. When the sun reaches the horizon, a new year begins. People typically celebrate the summer more in the arctic than anywhere. Traditionally, Inuit would orient their igloos to allow for light to enter into the ice window. Snow blindness is a concern since the sun is at lower angles, compared to the south, and reflects of the surface of the snow to create an intense glare. In the North, solar optimization is just as important as the insulation. Unfortunately, in northern Canada, most buildings and communities are laid out as if the sun did not exist (in some European countries 
78, 79. Strub, H. (1996). Bare Poles: Building Design for High Latitudes (Vol. 186). McGill-Queen's Press - MQUP

\section{$x$ Green Fail}

Sun angles, volatile weather and short daylight hours make the use of solar panels not economically viable.

"In summer they plunge into the chilly lakes and wander the streets in the midnight sun, in winter they draw up their fur collars and burry from bouse to house, and spirits droop unless lights are lit both indoors and out. Here bouses and towns should open like flowers to the sun of spring and summer but, also like flowers, turn their backs on the shadows and the cold northern winds, offering sun-warmth and wind-protection to their terraces, gardens and streets."

Ralph Erskine 80

80. Erskine, R., (1967), Architecture and town planning in the north, The Polar Record.

(Vol.14), Nr. 89, s. 165-171 access to sunlight is a legal right). ${ }^{78}$ Iqaluit has only recently mandated that the buildings be oriented on the site for optimal solar gains; this can be seen in the plateau subdivision developments. There is a negative side, sunlight at low angles tend to bake the cladding. (see Figure 4.10) Surface temperature of the building material exposed to the sun can range from $-40^{\circ} \mathrm{C}$ in winter to $60^{\circ} \mathrm{C}$ in the summer, altering the chemistry and reducing durability. ${ }^{79}$ Contractors are in the process of experimenting with various products that can counter being sunbaked.

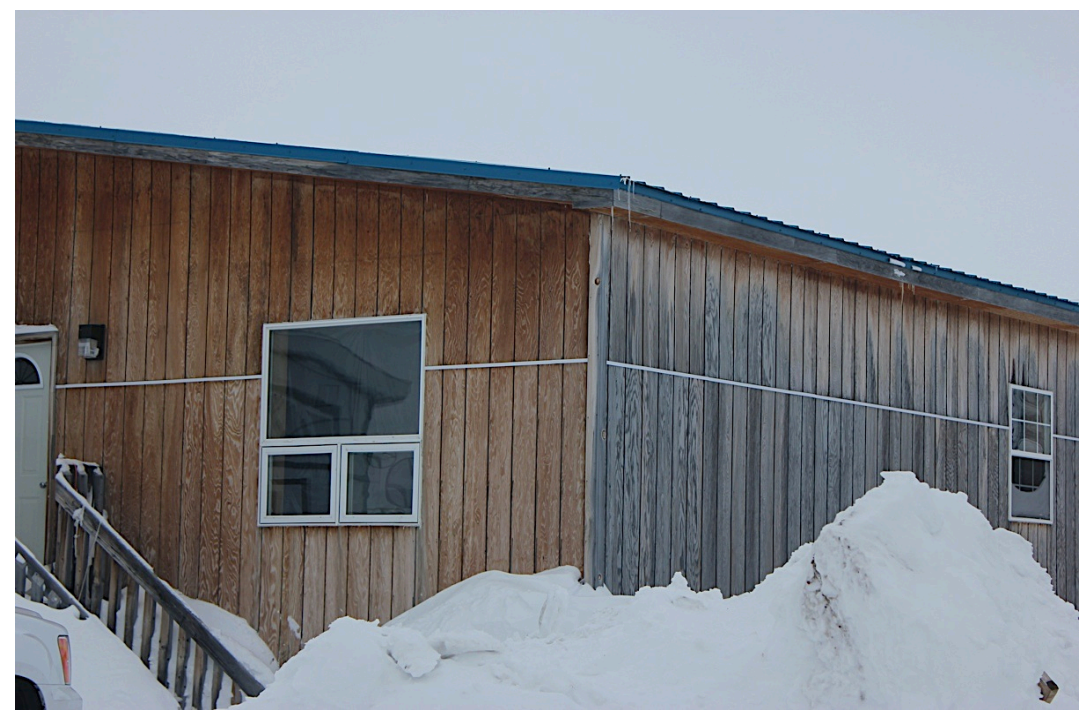

Figure 4.10 - Solar damage on south facing wall

Designing in the arctic is a delicate balance between a reduction of glazing to increase R-values or increase it to allow for more solar gains. Both have their side effects. The least amount of glazing would allow for no solar gain and cause pure reliance on the heating system, additionally users would not enjoy the space. Alternatively, more glazing would increase heat loss, and solar gain in 
the spring can be too intense for a space enclosed with super-insulated walls. Because of the lightness of the materials, the high level of heat is only temporary during the day. Thermal mass can collect the heat and disperse it over the night, but this solution is not easily available because of the high cost of shipping. Anything heavy would cost too much to import. Although local stones could be used, they are costly to source and would cause environmental impacts on the Tundra, among other issues. Sunlight is much more of a resource in the north than in the south. The city of Iqaluit slopes down to the South coupled with a zoning height limit of four storeys. This allows for a greater opportunity to maximize solar gains. Below are three diagrams: left shows how sunlight angles are relative to the arctic; middle shows different shading strategies based on latitude; right shows how glazing can cause the greenhouse effect at lower sun angles.

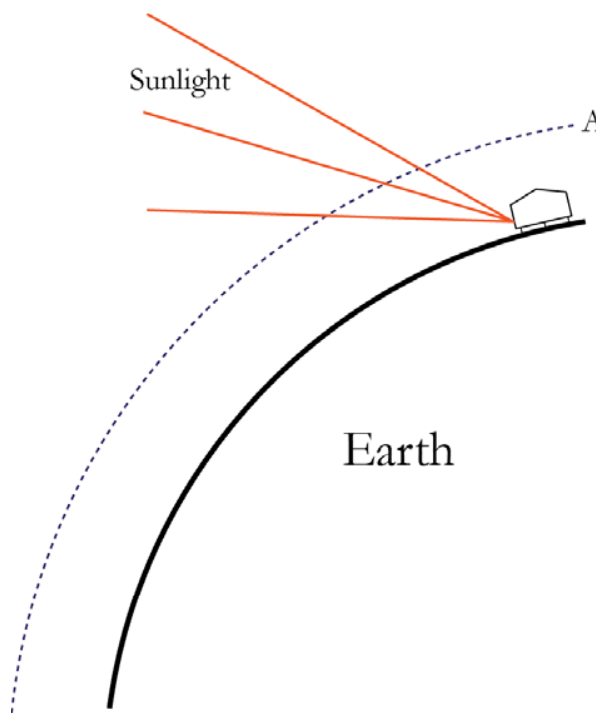

Atmosphere

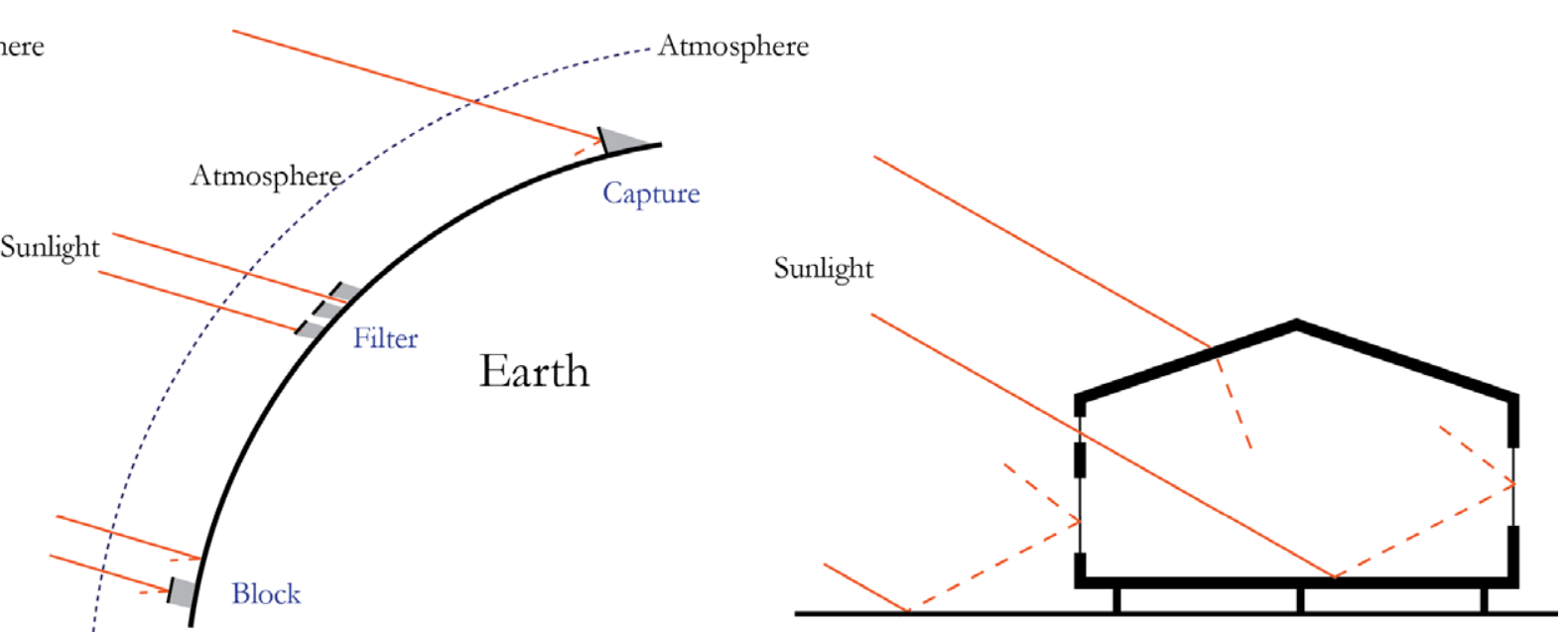

Figure 4.11 - Northern solar studies 
81. Mayer, P. (2007). Mayor Report on Nunavut Devolution. qaluit: Aboriginal Affairs and Northern Development Canada.

\section{$x$ Green Fail}

Most all construction material is shipped up to the north resulting in a high-embodied energy. Vernacular material needs to be applied and tested.

\subsection{Logistics}

Coordinating a project in the North is a challenge. Because of a short construction season and the remoteness of the location, few projects get completed in a year. Various factors that are acute to the North include; shipping of material, equipment and skilled workers to the site; small margin of error for the architect and engineer; highly time sensitive; and subject to volatile weather patterns. All of which greatly affect the cost of construction. In 2006, the cost to build in Iqaluit is $\$ 330.00$ per square foot compared to $\$ 103.00$ per square foot in Ottawa. ${ }^{81}$

\subsection{Transportation}

For the visitor, Iqaluit can be accessed by air year-round, a cruise ship during summer that ports one time a year or a snowmobile in winter from the nearby community Kimmirut. Costs of flight tickets are typically $\$ 2000$ round-trip from Ottawa. Goods are normally shipped up from a sealift 3 to 4 times during the late summer, when the ice in the bay melts. The ships anchor about a kilometer away from shore since the tide is the second highest in the world with a tidal difference of 12 to 15 meters (second to the Bay of Fundy). At high tide, barges meet the ships and take the sea-containers closer to shore. As the tide drops, the barges get beached, and then large forklifts drive out and carry the containers to solid land. Not only are the ships limited per year, but also unloading them is a challenge. This process has been done since the Americans were present. Talks of establishing a port have been discussed for years, but no official plan has been established. 


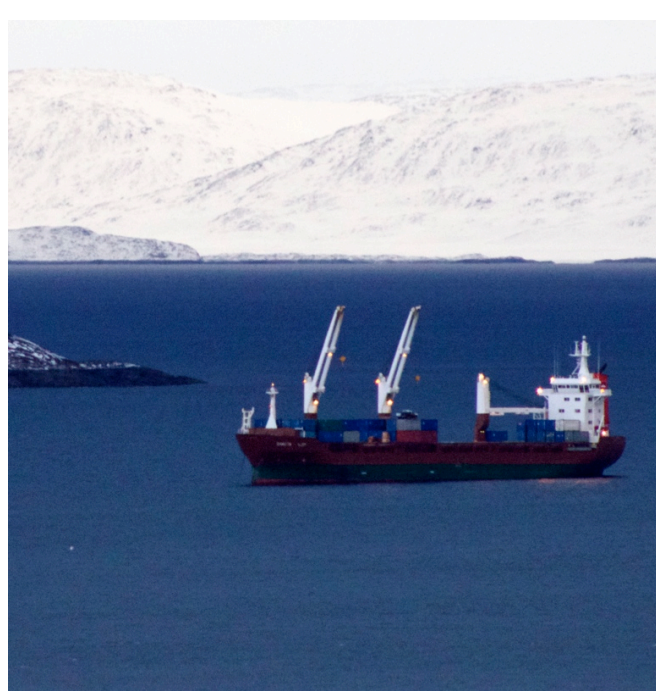

Figure 4.12 - Sealift in Koojesse Inlet

For the contractor, materials are cheaper to send through the sealift companies, however, construction season begins typically in May, but the first Sealift would arrive in late July. Much sea transportation is based on the bay conditions. In July 2012, the ship Zelada Desgagnés was damaged by ice and was escorted back to Montreal, causing major construction delays. To keep costs low and max out the construction season, the structural material is ordered a year in advance, finishes are shipped later. Multi-year construction, having a multi year material layover at times is subject to possible weather damage due to inadequate packaging, as well as vandalism and theft. Storage risks are acceptable for contractors, since they can replace damaged or stolen portions rather than miss the project deadline. Considerable pressure is placed on the architect to ensure the drawings are accurate. For example, a 10" x 8" steel I-beam 8' long is cut to size in the South then shipped north. If the drawings were out by a few inches, there would need to be a new one sent up. Since it is the construction season, this delay would be costly. The only choice would be to fly it up. The weight of the new I-beam would be about 300 lbs., resulting in a shipping cost of over $\$ 1600$, not including the construction delays.

\subsection{Skilled Labour}

One of the serious concerns with Nunavut is that there is not enough skilled labour for construction projects. This problem is then absorbed into the cost of a project. Workers get flown up from various places in Canada and stay in a staff house or hotel with food allowances. Usually they are on rotation, flying every 2-3 weeks from their home. Importing workers results in an inflated construction cost. Although the GN is pushing for more Inuit on the site, the quota is rarely filled. Inuit are mechanically intuitive, but skilled tradesmen among the Inuit are not common. 


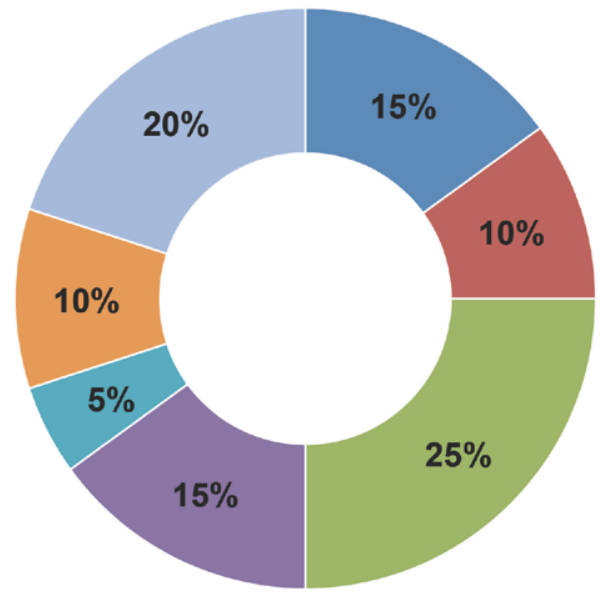

$\begin{array}{ll}\text { Materials } & \begin{array}{l}\text { Water and sewer } \\ \text { services }\end{array} \\ \text { Freight } & \text { Land } \\ \text { Labor } & \begin{array}{l}\text { GE's: Airfare, } \\ \text { accommodations, } \\ \text { Piles }\end{array} \\ & \text { overhead and profit }\end{array}$

Figure 4.13 - Typical Project Cost Breakdown

82, 83, 84. Nunavut Housing Corporation. (2012). The Nunavut Housing Trust: Lessons Learned. Iqaluit: Nunavut Housing Corporation.
Training programs have not succeeded as hoped. The Nunavut Housing Corporation has decided to steer away from training programs since it caused a large deficit in their budget. "Adding training and economic development initiatives to the construction process naturally added to the unit costs but was not factored into the math. Cost per unit used should have been increased accordingly." 82

\subsection{Lots}

Due to the Nunavut Land Claims Agreement, an individual or company cannot own land. Lots are on an average of a 60 -year extended lease of $\$ 20,000$ to $\$ 75,000 .{ }^{83}$ Buildable lots are in short supply. The City of Iqaluit is not keeping up with the demand for servicing lots. A new subdivision is being planned between main Iqaluit and Apex, but this will take a while before breaking ground, due to land politics. When a group of lots open up, usually there is a lottery for those living in Iqaluit. The winner has to pay for the lease up front and build within two years. The NHC and government Agencies are given assigned lots from the onset of planning the sub-division. Larger housing lots for multiplexes are awarded based on competition by contractors and Architects. The city looks for density and aesthetics.

Available lots are rare and scattered across Iqaluit. They can be difficult to construct on, requiring the use of gravel to level the grade at full cost to the contractor. If the lot slopes lower than the service utilidor (usually along the road) the building needs to be raised to allow for gravity flow. One construction project comes to mind, in 2012 on the plateau subdivision, where the contractor had to lift the building on piles almost 20 feet for gravity feed and filled the site with gravel, costing tens of thousands of dollars. With gravel costs of $\$ 25$ - $\$ 45 /$ cu.yd; gravel pads for single-family detached units cost up to $\$ 75,000 .{ }^{84}$ 


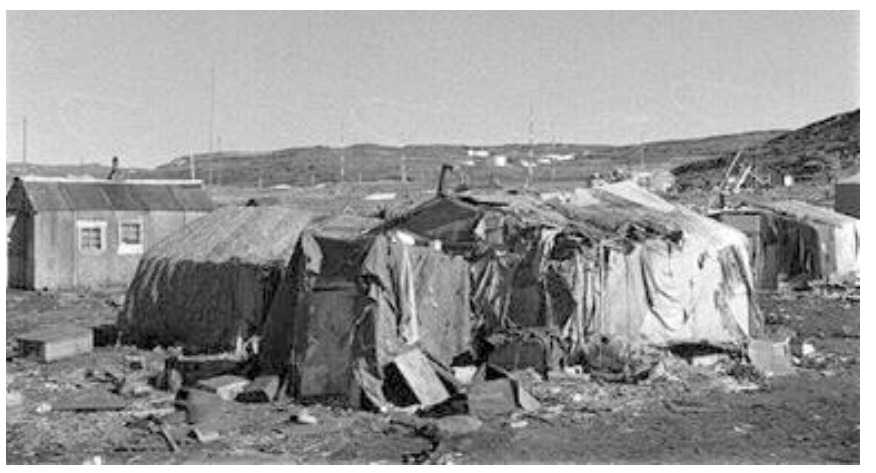

Figure 5.1 - Shanty dwelling (Anonymous, 1954)

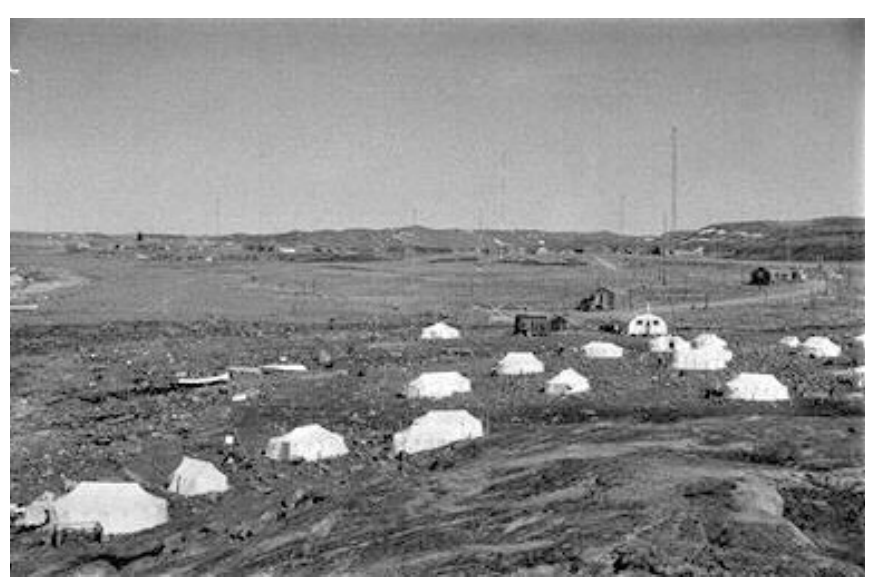

Figure 5.2 - Ikaluit tented community (Anonymous, 1954)

85. Services, C. D. O. N. H. A. W. I. A. N. H., \& Branch, C. N. A. (1961). Eskimo Mortality and Housing. Queen's Printer.

\section{Chapter: Iqaluit's Social Housing}

\subsection{History of Iqaluit's Social Housing Programs}

lthough Iqaluit began as a settlement in the 1940s, housing programs did
not begin until the 1950 s when the Canadian Government began to
encourage Inuit to settle permanently in communities. Many of the Inuit were camping next to Frobisher Bay's Airbase looking for work. Much of the structures were both traditional and informal (Shanty), at times a mix of the two (snow house/shack). Many of the tents and shacks, with tar-papered roofs, at the time were made of scrap material that could be scrounged from various military construction projects and shipping waste. (see Figure 5.1) They had no insulation and were heated by makeshift heaters furnished from powdered milk tins. Over time, summer canvas tents would spring up in the area known as Ikaluit (see Figure 5.2); the Inuit usually purchased these with wages from the DEW line projects. These tents were preferred in the summer months but too cold in the winter. Inuit would then return to either a shack or snow house constructed nearby. At this time Inuit were living in filth causing much criticism from the US military. Eskimo Mortality and Housing states, "The shack is warmer but dirtier than the tent. For the [Inuit] infant the choice is probably gastroenteritis in the shack or pneumonia in the tent." 85 These dwellings marked the beginnings of Nuna-Slums. 


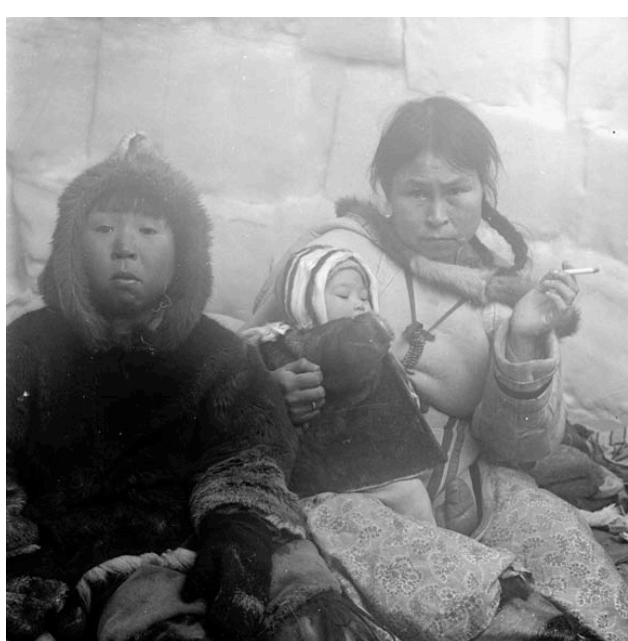

Figure 5.3 - Inuit woman smoking in igloo with child on lap (Lunny, 1956)

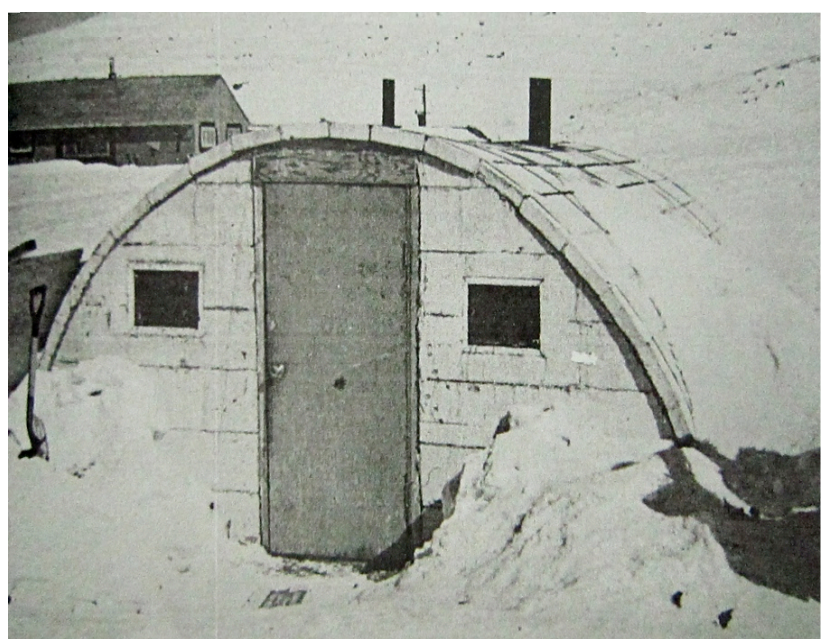

Figure 5.4 - Frobisher Bay - Styrofoam Quonset Prototype (Canada, 1960)
Although the Canadian Government wanted to preserve the Inuit traditional way of life, it was soon apparent that it was too late. The impact of the military's presence in the arctic was irreversible. Inuit became accustomed to the ways of the Qallunaaq, eating Qallunaaq food, watching films, and etc. Some of the Inuit in Frobisher Bay had been living this new lifestyle for over a decade by the 1950s and presumably lost the ability to survive off the land.

The image on the left, taken in 1956 in Frobisher Bay, shows how Western Civilization has infiltrated the Inuit culture by depicting the contrast of a woman smoking a cigarette inside an igloo. Between the years 1945 and 1954, much of the government was dealing with recognition of the needs and development of policies. In 1954, times were changing, Inuit finally had a right to vote and the National Housing Act was established promoting various programs to aid in Inuit housing.

Low cost prototypes that merged traditional typologies with modern material were introduced, but failed due to criticism about their durability. An example of this was the Quonset-style Styrofoam house, designed for winter living, shown in the image below erected in Frobisher Bay. Another more igloo-shaped model was designed and erected in Cape Dorset. Today, there are no traces of their existence. The RCMP also experimented with double wall canvas tents but they also were not successful. 
86, 87. Anderson, E. (2008) Canada's Relationship with Inuit.

Minister of Indian Affairs and Northern Development. Ottawa: Public History Inc.

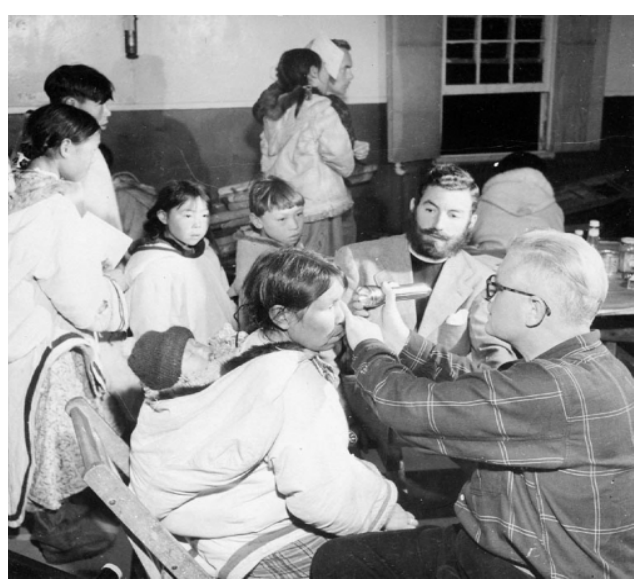

Figure 5.5 - Medical Examination rehabilitation centre Apex Hill (Doucette, 1951)

88. Association, Q. I. (2013). Qikiqtani Truth Commission (pp. 1268). Iqaluit: Inhabit Media Inc.
In the early 1950s, it was felt that improving housing would enhance sanitary conditions of homes resulting in a lower incidence of disease and infant mortality. ${ }^{87}$ The Government of Canada devised a plan to accommodate the needs of the Inuit and reduce further damage the American soldiers would have on them. It was decided to create an "Eskimo village" by Apex Hill, five kilometers away from the base. Aside from housing, important buildings were located in the village, including a rehabilitation centre, a municipal storage building, a community freezer, a bathhouse, a cadet building, an HBC post, a theatre, a snowmobile repair shop, and a school. ${ }^{88}$

Built in 1956; the rehabilitation centre was one of the earliest social housing programs in Frobisher Bay. This became the cornerstone of the community. It was a halfway house for Inuit returning from southern hospitals and infirmaries, which had suffered from cases of Tuberculosis. These Inuit were from all over Nunavut and were considered "outlanders" to the Inuit who lived in Frobisher Bay permanently. Of those admitted, half were children. The residents would learn skills; art, crafts, sewing, carpentry and baking. Later individuals with mental illnesses were admitted. The centre closed in 1964 with little succession. Many of the patients returned to their respective communities, but had to wait since they could not afford the airfare back.

Wood structures became the choice of home construction, since they could be built quickly and cheaply. In 1955, three "temporary" dwellings for Inuit staff were sent to Apex Hill, known as the "rigid digit" or Model 319. (see Figure 5.6-7) Essentially it was a rigid frame single room structure, 256 square feet, with a wooden floor and metal walls. The frame employs the use of arch principals with linear structural members having plywood gussets reinforcing the corners. Construction was relatively simple using standard 4' x 8' plywood sheets. The National Research Council of Canada 


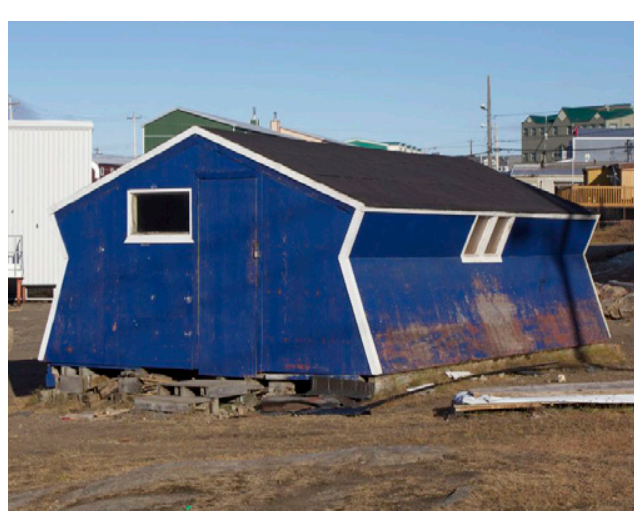

Figure 5.6 - Rigid-digit, Iqaluit, 2013

(NRCC) carried out various durability tests on the design. Typically they were furnished with a cot, table and two chairs, a sink and an oil-burning stove. There was no plumbing, so "honey bags" were picked up once a day. Walls were not insulated well. Many of the Inuit living in shanti-like dwellings were eventually forced into homes like this rigid frame. The Department of Northern Affairs and National Resources considered the rigid digit somewhere between the size and durability of an igloo or tupiq and typical Canadian housing standards in the south. The total cost of each rigid digit unit was $\$ 500$, making construction of many units attractive for the federal government. ${ }^{89}$ The previous shack dwellings were later bulldozed. Figure 5.8 shows three rigid frame homes in Frobisher Bay, 1959. Some still exist in Iqaluit but are mainly used as storage sheds.

89. Anderson, E. (2008). Canada's Relationship with Inuit. Minister of Indian Affairs and Northern Development. Ottawa: Public History Inc.

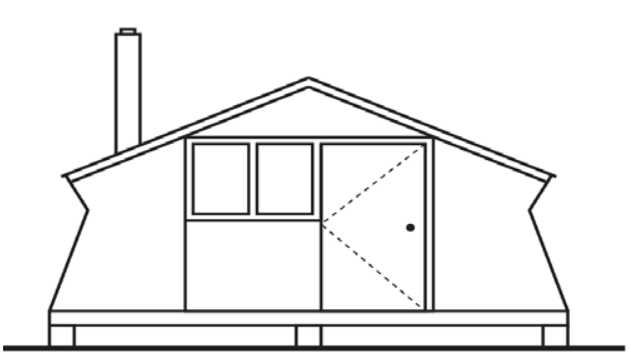

Front Elevation

Figure 5.7 - Rigid-digit, Plans

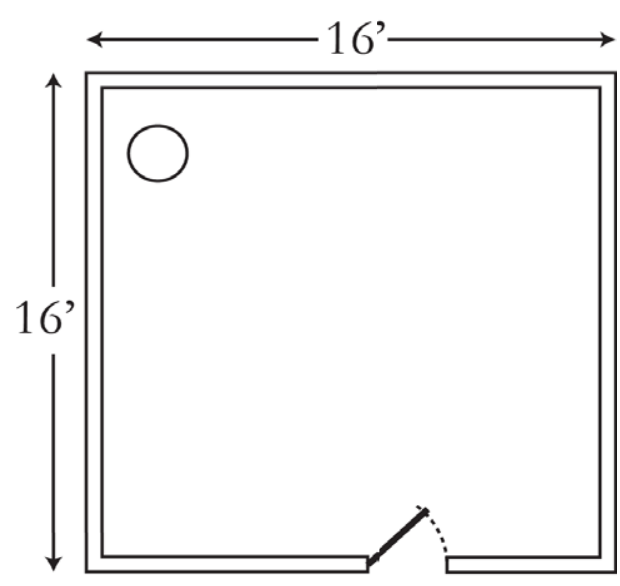

Floor Plan 
90. Association, Q. I. (2013). Qikiqtani Truth Commission (pp. 1268). Iqaluit: Inhabit Media Inc.

91. Housing Education Program for Canadian Eskimos, June 1966- June 1968. (1969). Department of Indian Affairs and Northern Development, p7.

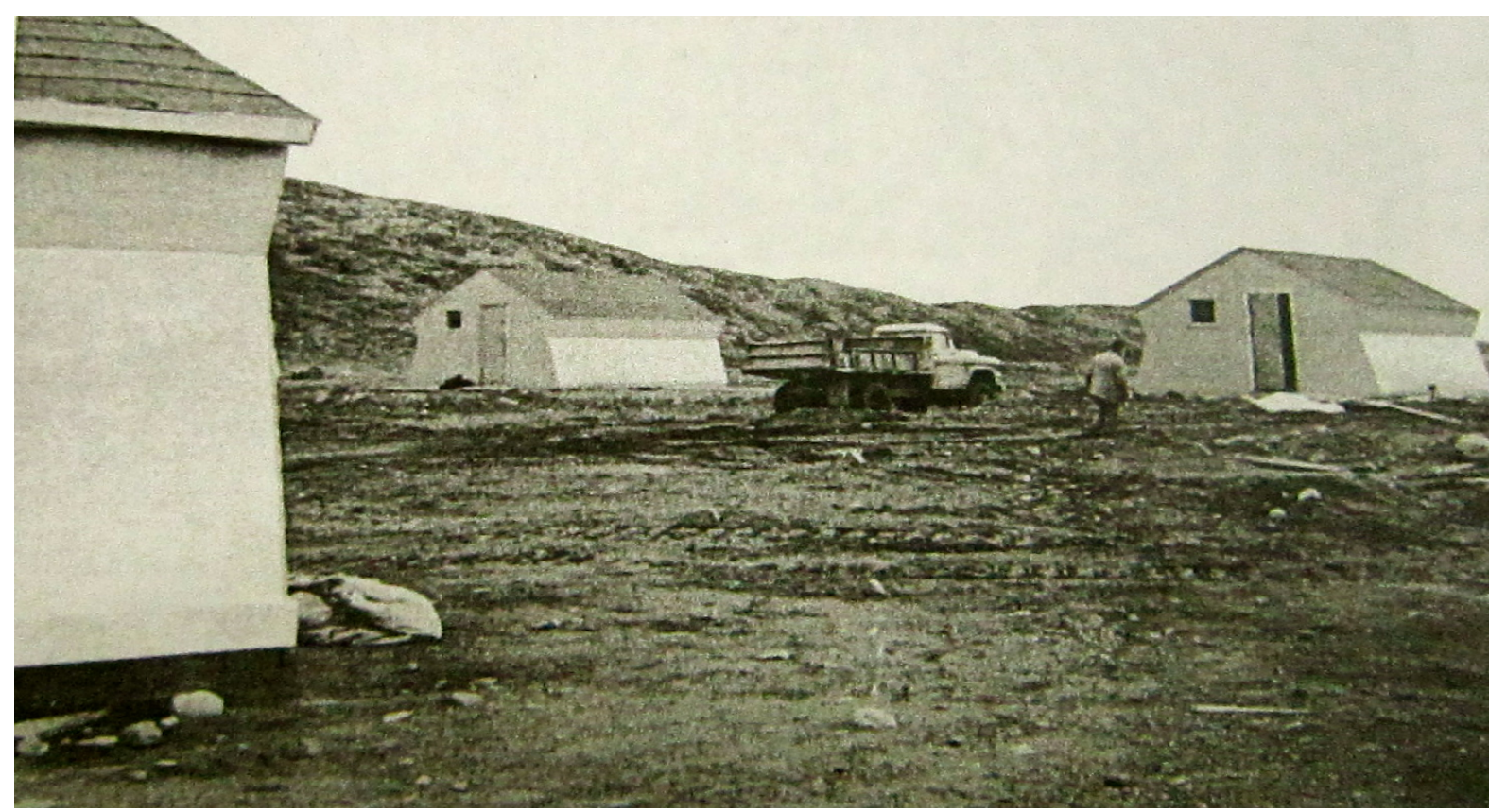

Figure 5.8 - Rigid-digit houses in Frobisher Bay

This rigid digit ultimately failed since the Inuit were becoming sedentary and the design was not accommodating. In 1959, the government's reaction was the introduction to the one or two room "matchbox" (model 380) or the 512 (named for its 512 square feet). The matchbox, as many as 28 were built, was also nicknamed the Illukallak. (see Figure 5.9-10) A program of rent to own was introduced, to help promote ownership and establish a wage-based sustenance among Inuit. At the time, the total cost of erecting a 288 square foot matchbox on site was $\$ 1200-\$ 2000$. They were heated by oil-fueled space heaters, had a tub and sink, and honey buckets were still in use. The design was inappropriate for the North and the Inuit way of living. In 1965, the federal government 


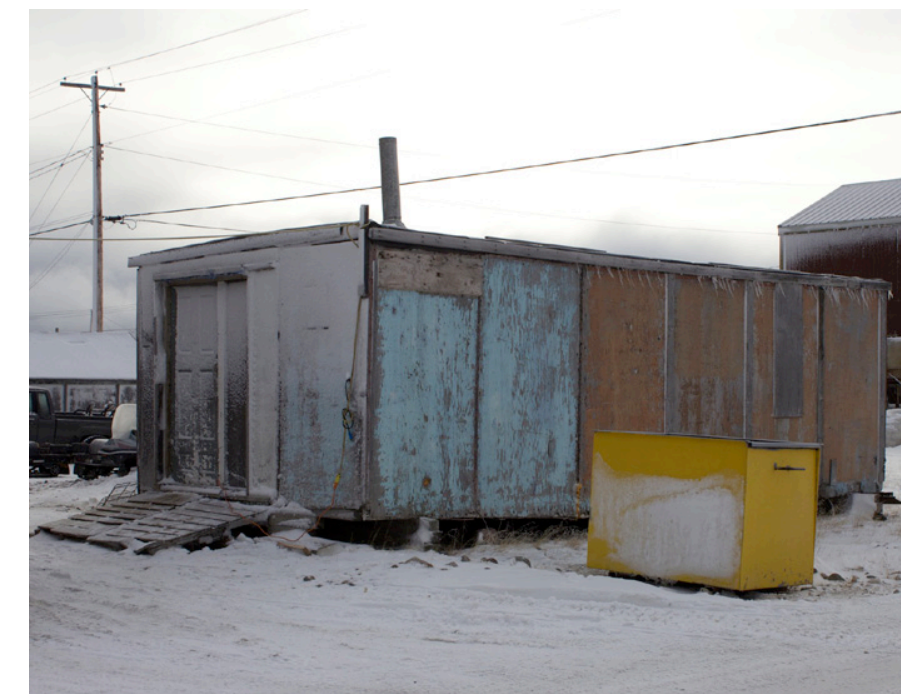

Figure 5.9 - Matchbox house in Arviat

approved a housing program that would ship 1,560 matchbox houses North; a portion landed in Frobisher Bay. ${ }^{90}$ The result was a disaster. The new plywood frame homes were worse than the makeshift shacks, apart from the fact that Inuit, lacking reliable wage employment, could not afford them. They turned into slums quickly, comparable to the makeshift shacks they were intended to replace. Many of them became overcrowded with large families living in a single house. "A housing survey undertaken in 1965 showed that in the Arctic District only 81 of the 817 one room houses had fewer than three persons living in each - the majority had five or more persons eating, sleeping and living in one room." 91 Further outbreaks of tuberculosis and other infectious disease accompanied them. The last Matchbox in Iqaluit burned down in 2009; the image on the right is from Arviat Nunavut, the floor plan was flipped.

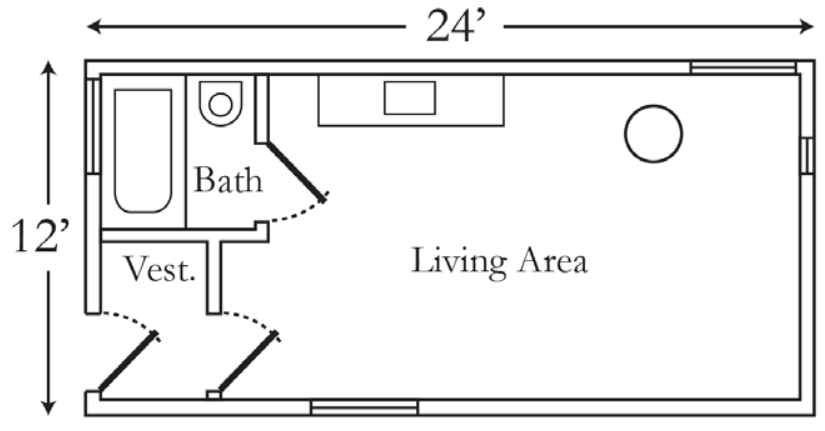

Floor Plan

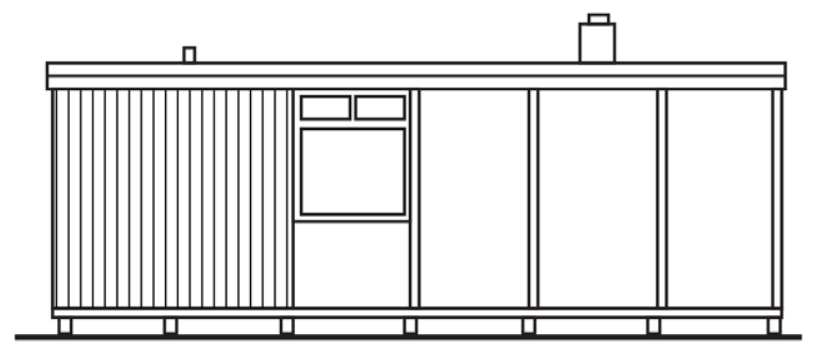

Side Elevation

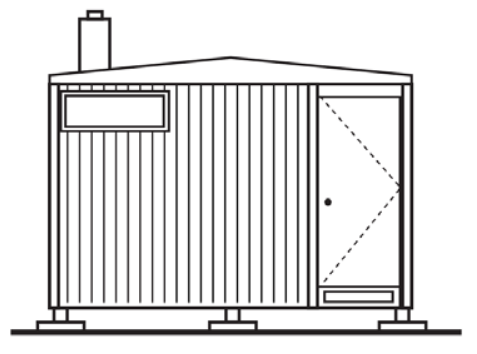

Front Elevation

Figure $5.10-$ Matchbox house plans 


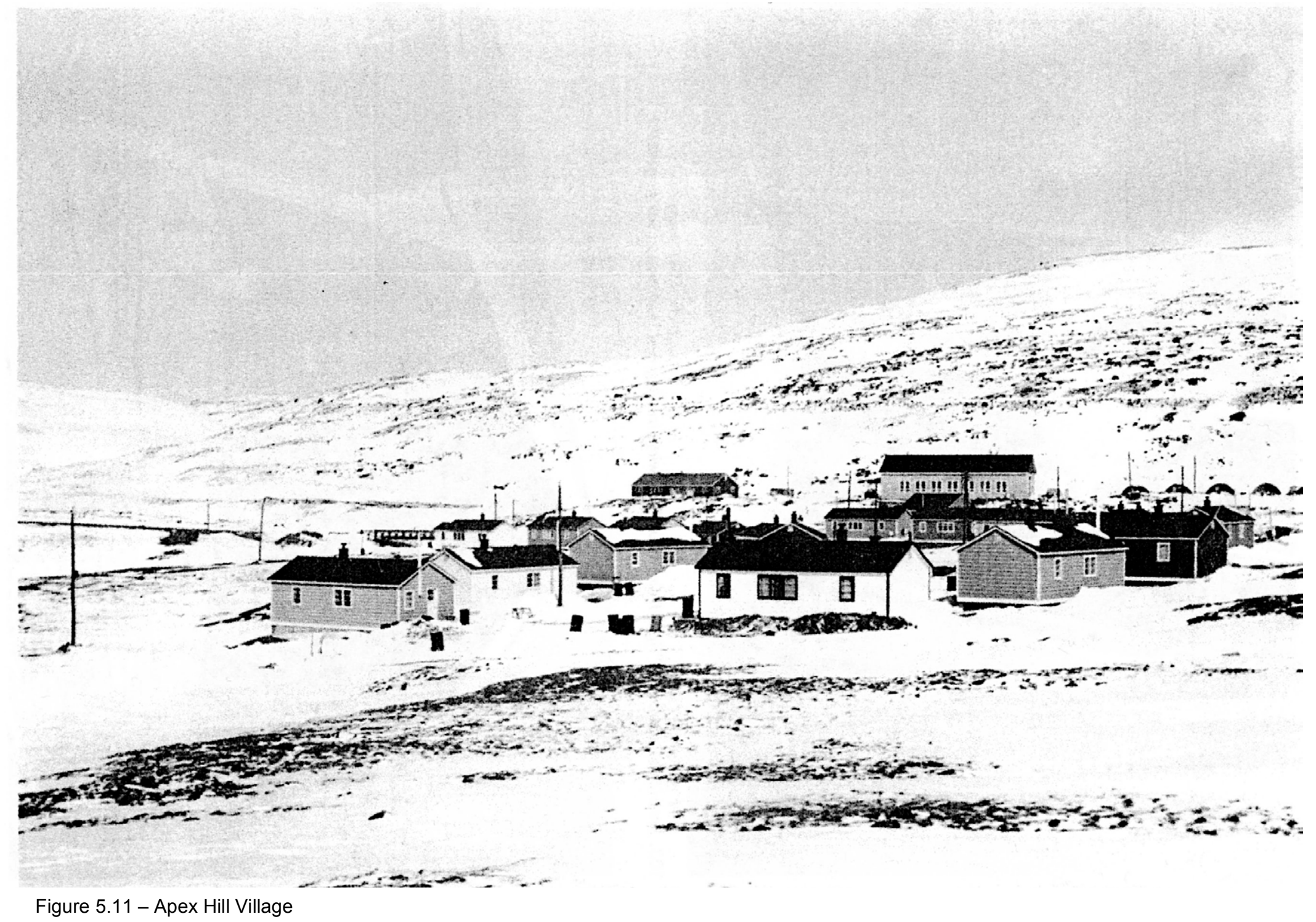



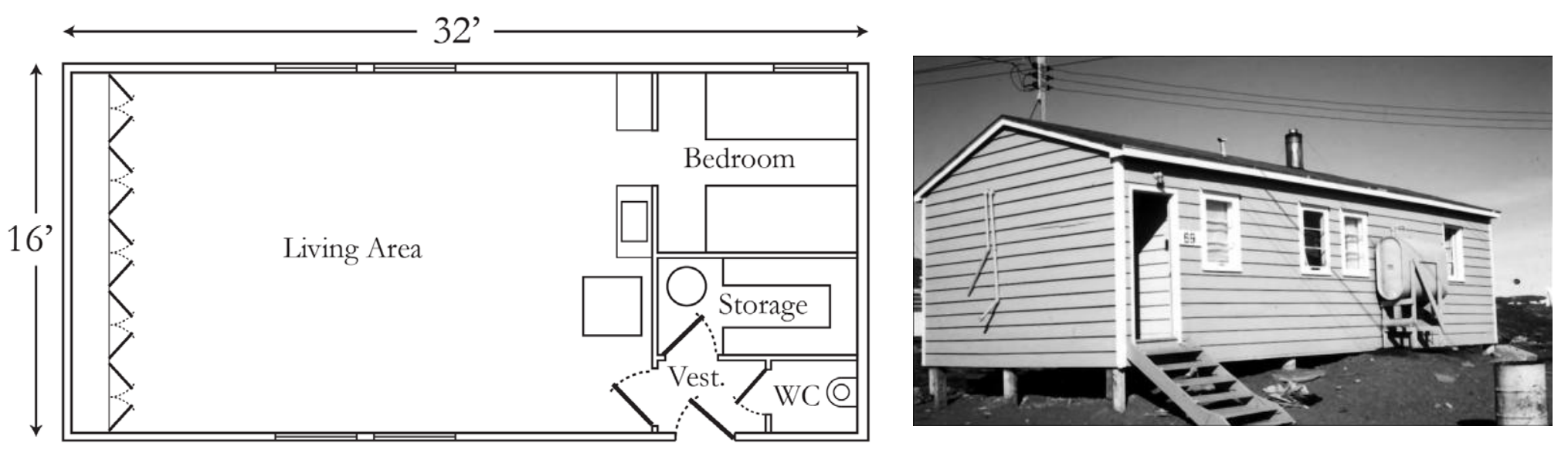

Floor Plan

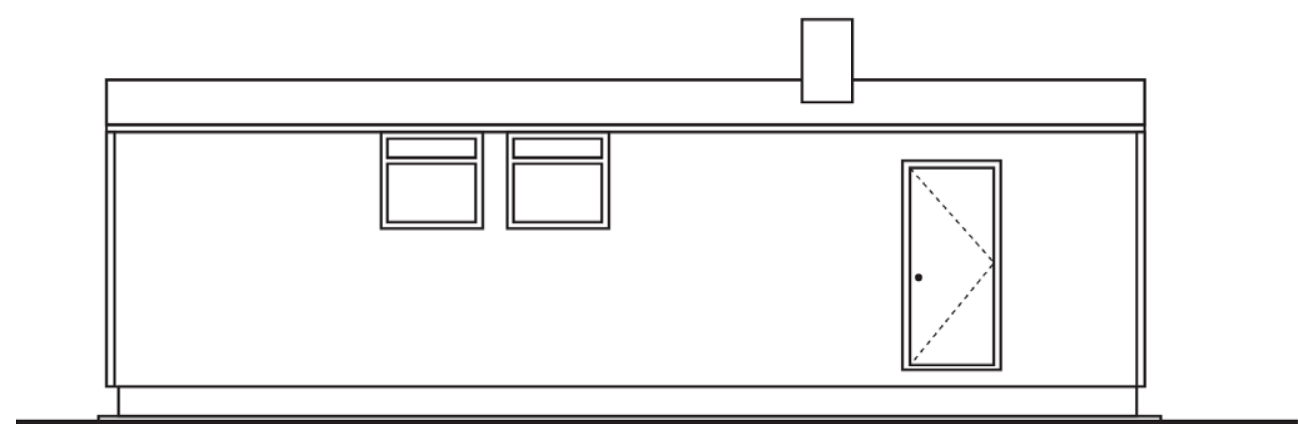

Front Elevation

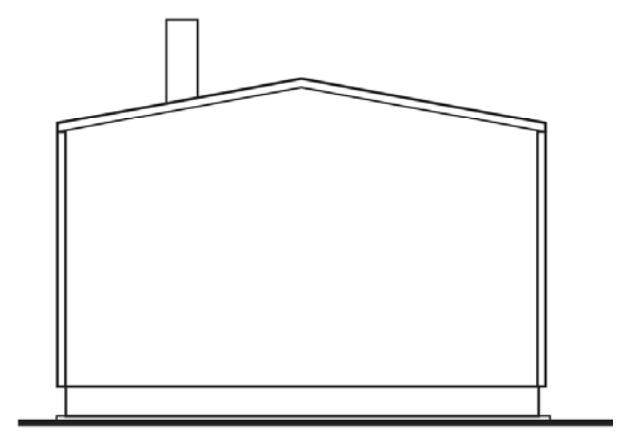

Side Elevation

Figure $5.12-512$ model, plans and image

The second model introduced at the same time (in 1959) as the Matchbox was the 512 (see Figure 5.12). The floor layout varied, as did the entrance, but what remained the same was the 512 footprint and material selections. Thirty-three were built in Frobisher Bay. Many of them were built on Apex Hill. (see Figure 5.11) It is obvious that the owner had to choose between having a larger 
footprint or a bathtub. In any case, because they were not designed with an adequate porch, many Inuit used the tub for storing large game country food. Today, few are found as some were moved and used for other purposes, not housing. For example, some are used as sheds or craft workshops.

The 1965, 384 square foot prefabricated “Angirraq", or Model 424, (see below) was designed by military groups and tested by the Tower Company in Quebec. This design was to stand up to the harsh arctic environment. The shape resembles the Rigid Frame. Very few were made. Frobisher Bay witnessed only a handful. None exist in Iqaluit today, possibly all of Nunavut.
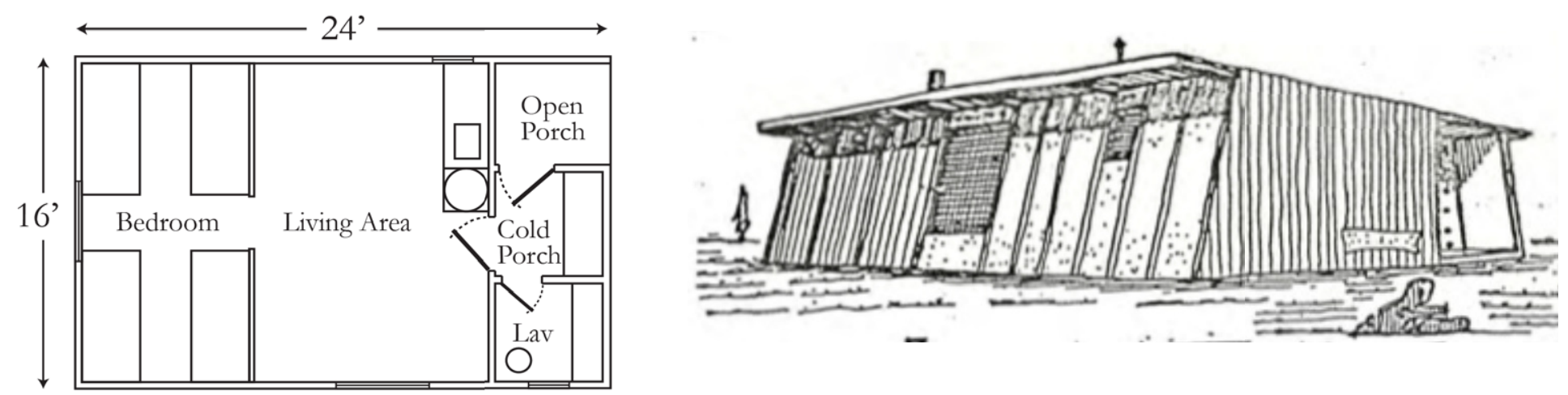

Floor Plan

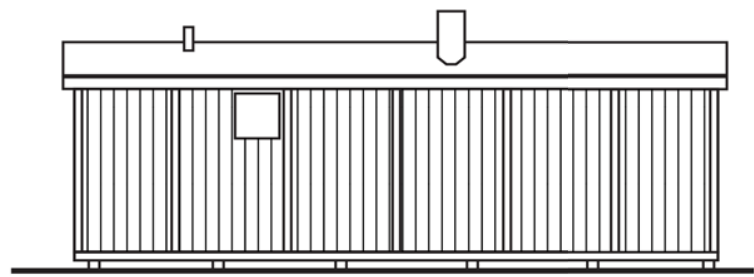

Side Elevation

Figure 5.13 - The Angirraq, plans and image

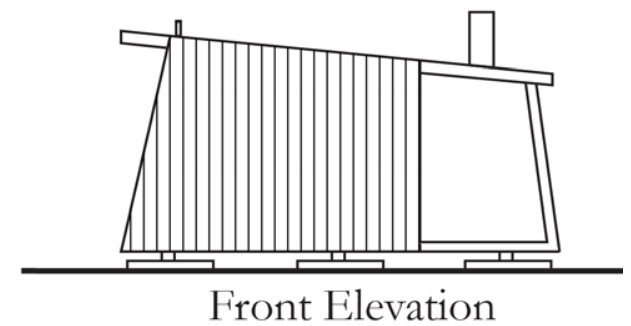


92, 93. Association, Q. I. (2013). Qikiqtani Truth Commission (pp. 1268). Iqaluit: Inhabit Media Inc.
From the onset, Frobisher Bay was seen as a temporary community since it had no economic sustainability. Much of the housing models produced were expected to be eventually abandoned, but instituting programs like the Eskimo Housing Program, was intended to assist in the Inuit's transition to the Western World.

In spite of its investment in Apex and the airport, Canadian bureaucrats continuously expressed concern during the 1950s that Iqaluit's future was uncertain. As a result, investment in infrastructure and services was done using a "temporary-only" approach. A 1958 government memo stated that Iqaluit's "economic potential is quite limited and we can see no prospect of it becoming a self-sustaining community in an economic sense in the fore- seeable future." 92

In 1963, after the US military left Frobisher Bay the Inuit and Qallunaaq began to live together. The population was too large to disperse, and pushed Canada into sustaining the community. The mindset began to change from 'temporary' to 'permanent' housing, thus houses were required to be larger, according to Canadian housing standards. Although many of the services, such as the hospital, relocated to the main town, many Apex residents did not leave. Today, Apex exists as an annex community of Iqaluit.

Co-operative housing was introduced in 1961 in Frobisher Bay, when fifteen men gathered together to share the cost of fifteen three-bedroom houses, with the assistance of government subsidies. The families participated in the construction in 1962. Seen as a success, two more housing cooperatives opened up in 1963. At the time this opportunity was only open to those who had a steady income and could pay the $\$ 120$ (over $\$ 900$ today) a month for mortgage and utilities. ${ }^{93}$ 
By the mid 1960s, administrators were still pushing toward ownership programs. The government subsidized a portion through the Eskimo Loan Fund. Unfortunately because of the thin walls, they became difficult to heat. Due to the unstable nature of the Inuit's income, paying a mortgage and high utility bills were not possible. It was agreed that the program was a disaster and designed a new program called the Northern Rental Housing Program in 1966, implemented in 1969. In 1969, many of the programs were handed over from the Federal Government to the Government of Northwest Territories, Housing Division of the Department of Local Government. From there a series of home designs were introduced known as the Northern Territorial Rentals (NTRs, see Figure 5.14). They did not have any special names, but letters and numbers: "L", 168, 396, 436, 455 , and etc.

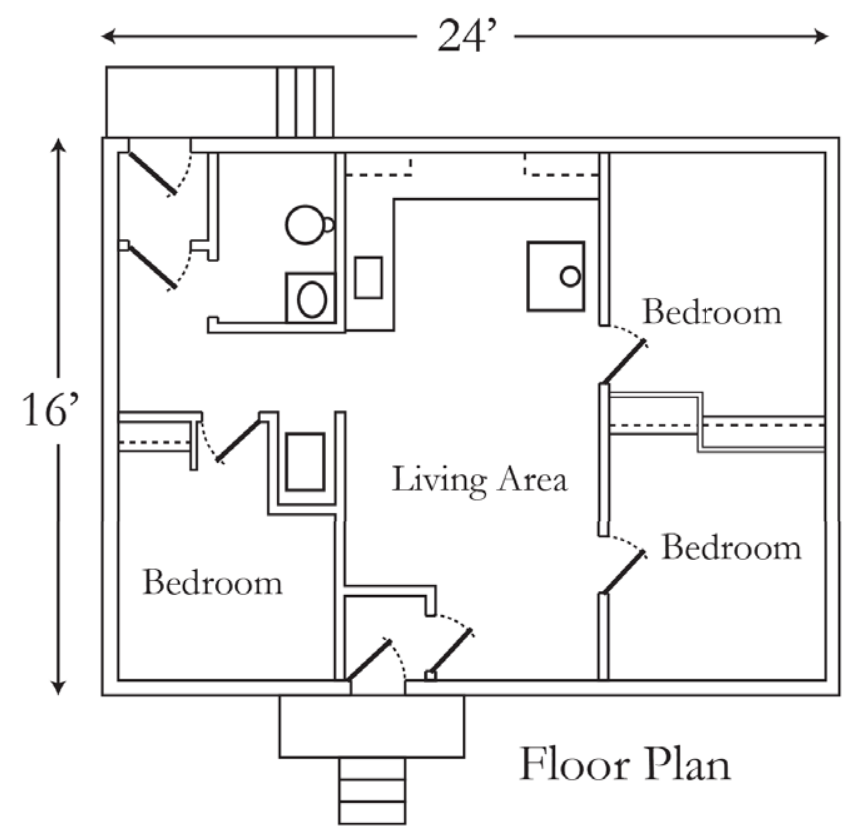

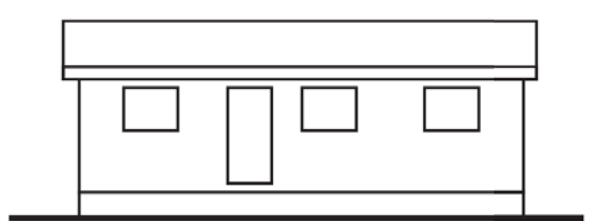

Front Elevation

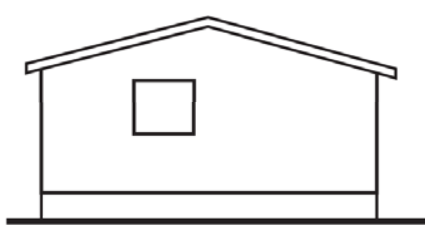

Side Elevation

Figure 5.14 - The Northern Territorial Rental, plans 
Approximately 100 units were constructed in Frobisher Bay. They were conventionally built with typical 2x4 stud walls and 2x6 joist cathedral-ceiling roofs. Grey water drained outside and honey buckets were still in use. Rent consisted of a percentage of total income. The government acted as landlord. Over time, many NTRs have been retrofitted and are hard to make out from the Iqaluit housing stock. Some of them have been transformed or combined to enlarge the floor plate.

In 1973, Northwest Territories Housing Corporation, a crown corporation, created through financial support from the National Housing Act, in conjunction with support from CMHC, to build both public housing rental and co-operative units. Subsidized rental units were introduced because of the hardships of the average Inuit. Several modifications to the existing housing types were introduced; many of them used the names of people or firms such as the "Weber", "Woolfendeen" (Woolfendeen Group Architects), FSC (Ferguson, Simek, Clark Ltd.) and \#10 GRP (Number Ten Architectural Group). The first was the "Weber Home," used 1974 to 1978. These were substantially larger than the previous designs used by over 200 percent. They ranged from 896 to 1600 square feet, having 2 to 5 bedroom layouts. Many "Webers" built in Iqaluit, are prefabricated and ended up moved around town in pieces or as a whole. They had the insulation at ceiling level with trusses. These units failed with the vapor barrier moving and tearing in 4-foot sections. The water would get in the attic and freeze, then melt and run on to the people. Home designs in later years were varied, - inclusive of multiplexes, row houses, apartments - but the unit layout became standardized with the custom bachelor, one, two or three bedroom layouts found typical of the South. Many include a standard kitchen, bathroom, storage and living room. The toilet eventually replaced the honey bucket and tubs were included in all plans. 
94. Anderson, E. (2008). Canada's Relationship with Inuit. Minister of Indian Affairs and Northern Development. Ottawa: Public History Inc.
"The housing designs and divisions of space in early Inuit homes were based on patterns of family activity common to southern Canada, and did not necessarily reflect Inuit spatial needs for activities such as preparing country foods, repairing hunting and transportation equipment, and entertaining. Boiling was a common method of Inuit food preparation, and it created bigh levels of condensation in homes, leading to iced windows, and warped walls and floors." 94

From the 1970 s various programs were initiated to help families out of the rental assistance programs and into home ownership. In 1977, the Small Settlement Home Assistance Grant (SSHAG) was instated to assist families living in communities less than a population of 1000 to help pay for local construction material. This had no bearing on Frobisher Bay, but became the catalyst for further homeowner assistance programs. In 1982, the Homeownership Assistance Program (HAP) was introduced to succeed the SSHAG. The program would offer any eligible Nunavut tenants materials to build their own house. The HAP represented the territory with the first supplyside housing strategy for the eastern Arctic. Although it was successful in the early years, because of the satisfaction of owning what you build, the project eventually died in the early 1990s. A possible reason was that many of those constructing had little understanding of how to read working drawings. It also became a hardship to have a mandated engineer to oversee the project. After this program ended, other similar programs were initiated to help tenants eventually lead into homeownership; such as the 1992 Owner build program (OBP), the 1993 Senior citizens home repair Program (SCHBP), the 1997 Expanded down payment program, and the 1997 Independent housing program. 
95. Nunavut Housing Corporation (2013). Corporate Outlook. Retrieved November 26, 2013, from Nunavut Housing Corporation: http://www.nunavuthousing.ca
In 1999, the Northwest Territories split, creating an independent Nunavut Territory. By legislation, the separation also included many of its departments and agencies. The Nunavut Housing Corporation (NHC) was established in 2000, under the Nunavut Housing Corporation Act, to take up all the programs, - to create, coordinate, and administer housing programs, - previously administered by the NWT Housing Corporation. The directorate office is now located in Iqaluit. The corporation is a public agency of the Government of Nunavut that reports to the Legislative Assembly (in Iqaluit) through the minister in charge of housing. Their mission, "To ensure families and individuals in Nunavut have access to a range of affordable housing options...that support a healthy, secure, independent and dignified lifestyle through working with our communities to allow them to assume the role of providing housing to Nunavummiut." 95 According to the Auditor General of Canada, there are many shortcomings that the NHC needs to overcome. It is important to note that many of the issues are over six decades old and have been carried over from the NWT Housing Corporation's administration. 


\subsection{Today's Iqaluit Social Housing}

\subsubsection{Nunavut Housing Corporation (NHC)}

The NHC is a crown corporation that is at arms length from the Government of Nunavut. They provide both non-market rental public housing and non-market staff housing to Nunavut's communities. Figure 5.15 shows the organizational structure of the NHC as it relates to the Federal

96. Nunavut Housing Corporation. (2013). NHC's New Housing Allocation System. Iqlauit: Nunavut Housing Corporation.
Government, GN, down to the tenant. This is unofficial, since it is still being coordinated with NHC. Funding is typically through the GN's Financial Management board. They decide on how much of the territory's budget gets allotted. At times, the Federal Government and CMHC get involved by contributing large sums for building more units. For example, on March 21, 2013, the Federal government announced its intention to provide $\$ 100$ million in new funding for additional housing in Nunavut as part of its proposed 2013/14 budget. ${ }^{96}$ Contributions of this magnitude would need to be approved by the GN.

The NHC has a portfolio of housing units that are distributed among both public and staff tenants. In some cases, additional units are leased from external property management companies. In order to reduce costs, the NHC has a library of housing templates that are reused to construct without the need of a third party designer. This can be seen when travelling across the communities and witnessing similar housing designs. This process can be counter-intuitive to new and improved designs and materials; however, at times the NHC does investigate alternative systems that are potentially cheaper and faster to construct. One example is the Structural Insulated Panels (SIP) for housing. Unfortunately, after completing heat-loss calculations on a prototype being reviewed, there is a $30 \%$ increase of thermal bridging when compared conventional construction. This would 
negate the initial construction savings with high-energy costs. It only means that solutions working in the South should be tested, but re-engineered for the North.

Iqaluit's public housing is administered by a local housing organization, known as the Iqaluit Housing Authority (IHA). They maintain both public and staff housing. The IHA decides who qualifies to be on the waitlist and who gets picked for new public housing units. Due to issues of maintenance and limited housing stock (see Figure 5.16a-h), the public has vilified the IHA and the NHC as a whole. 


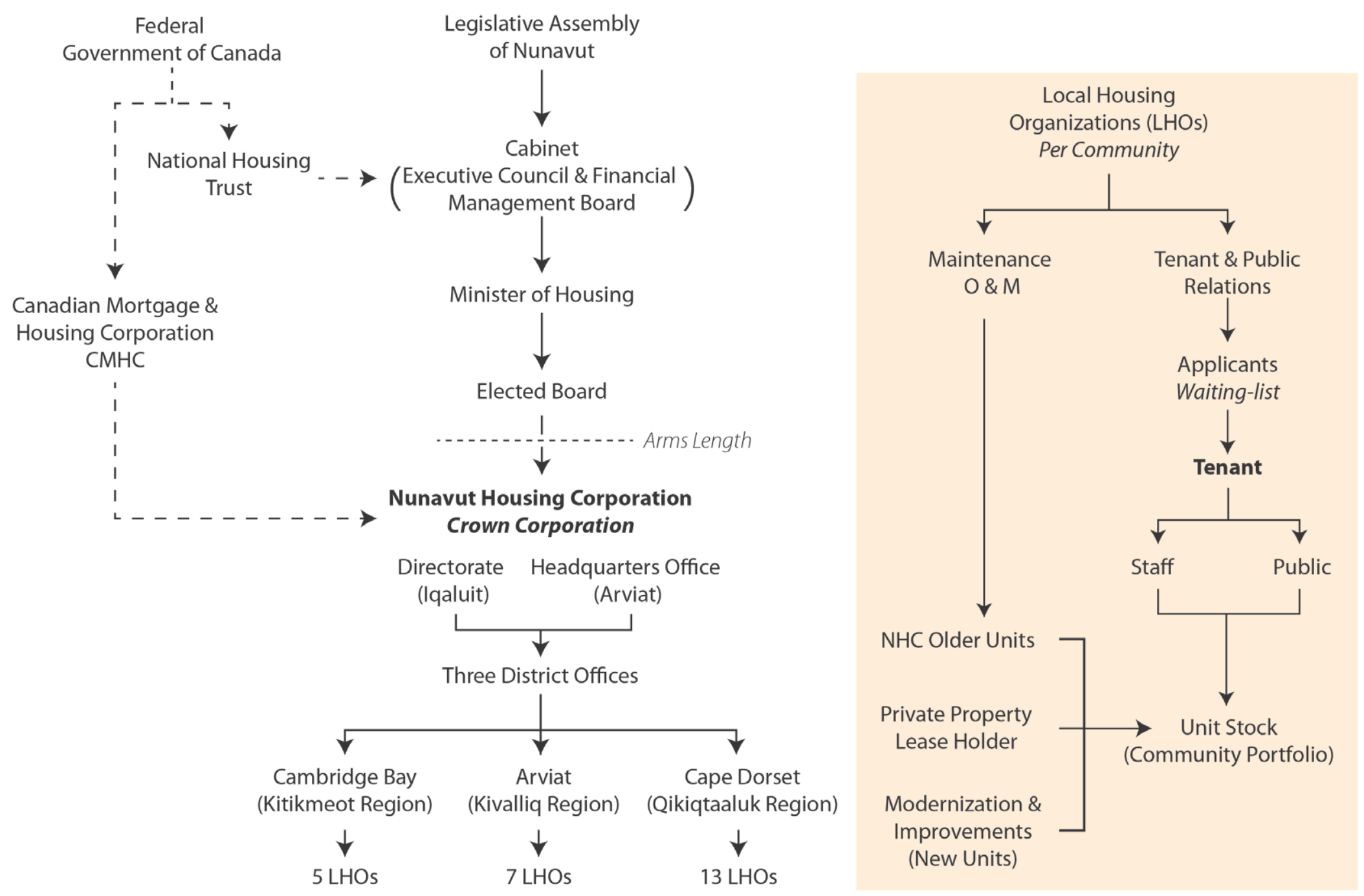

- - Funding \& Reporting 

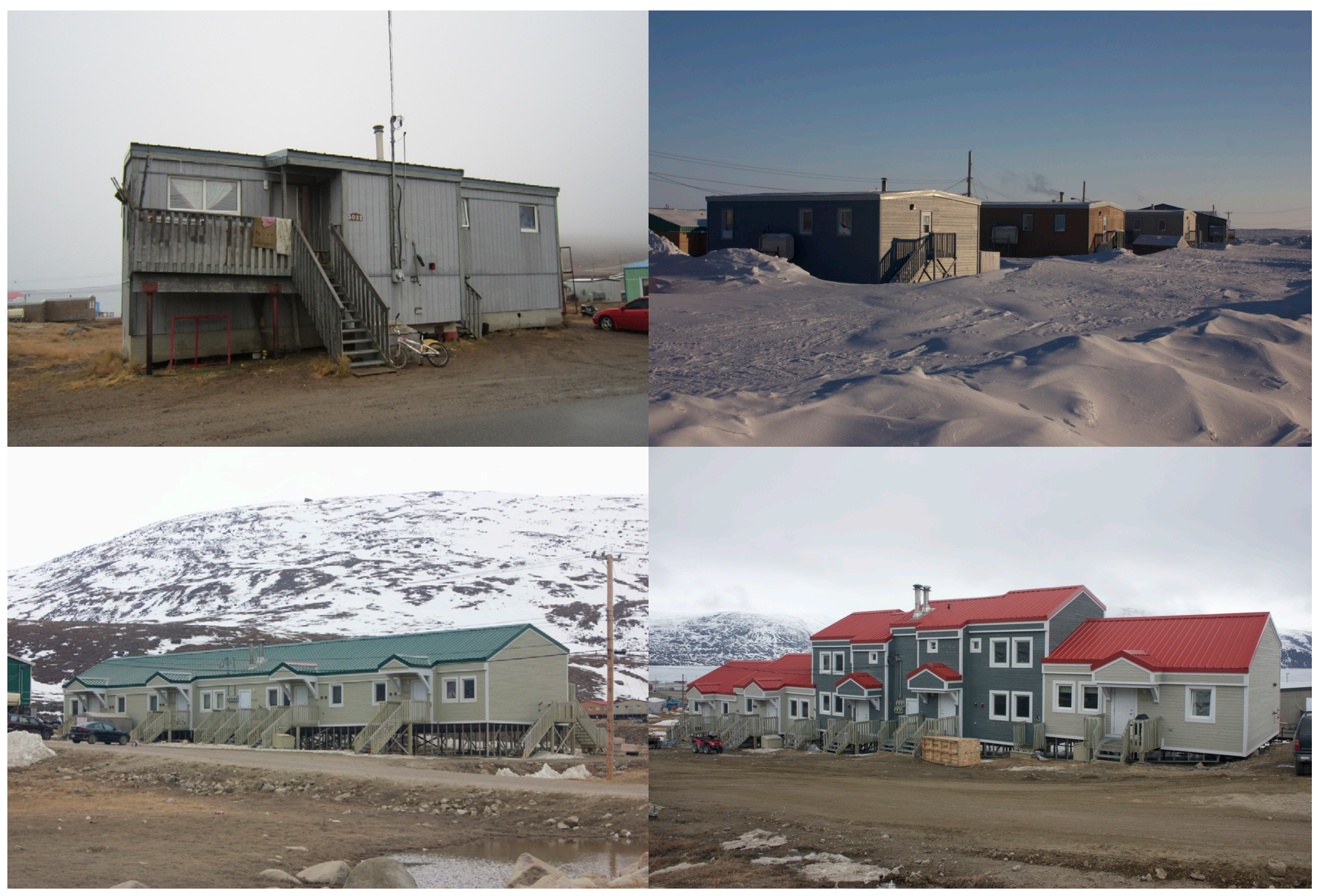

Figure $5.16(a-d)-$ NHC Housing Stock 


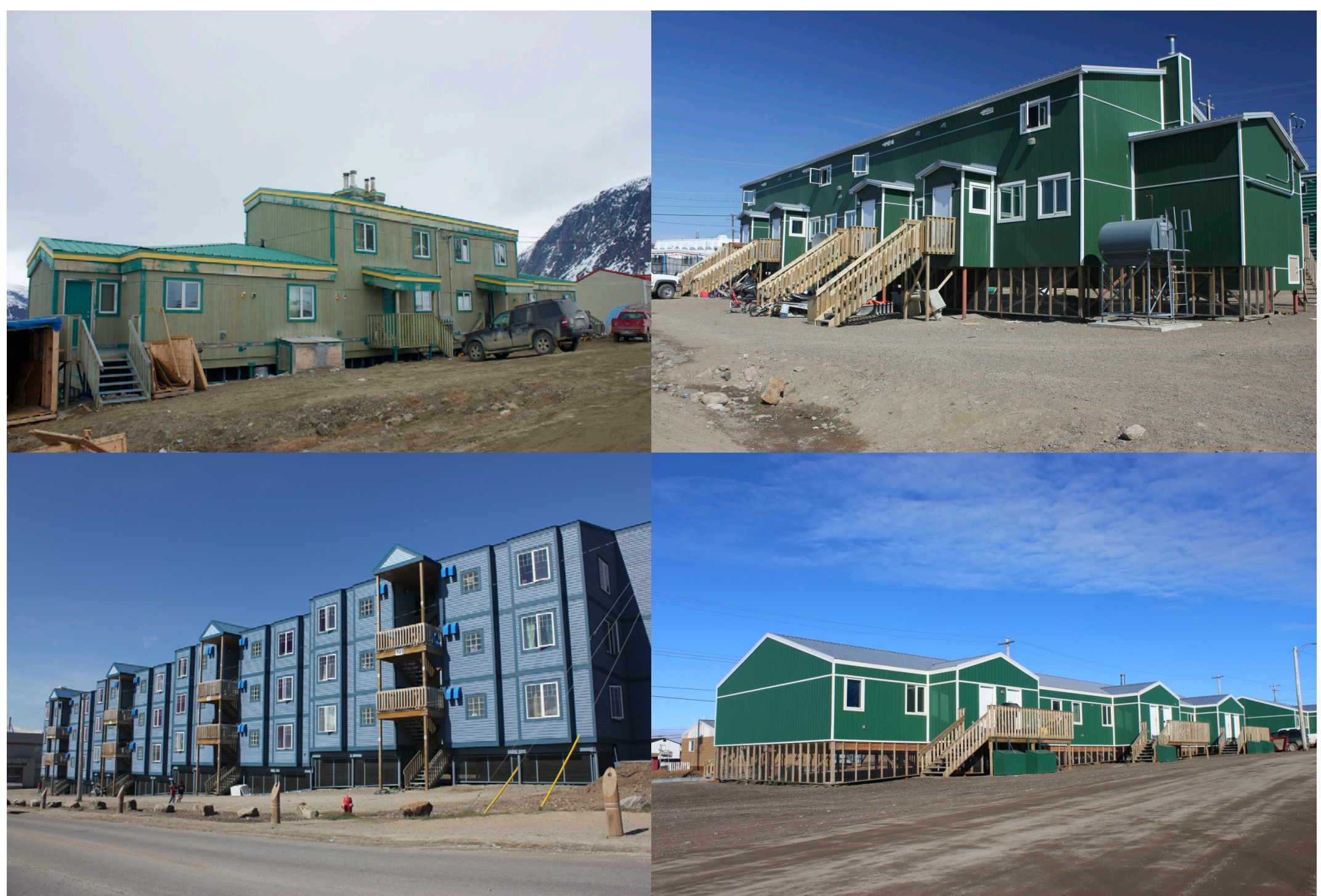

Figure $5.16(\mathrm{e}-\mathrm{h})-\mathrm{NHC}$ Housing Stock 
97. Battle, K., \& Torjman, S. (2013). Poverty and Prosperity in Nunavut. Caledon Institute of Social Policy. Ottawa: Caledon Institute of Social Policy.

98. Nunavut Housing Corporation (2013). NHC's New Housing Allocation System. Iqlauit: Nunavut Housing Corporation.

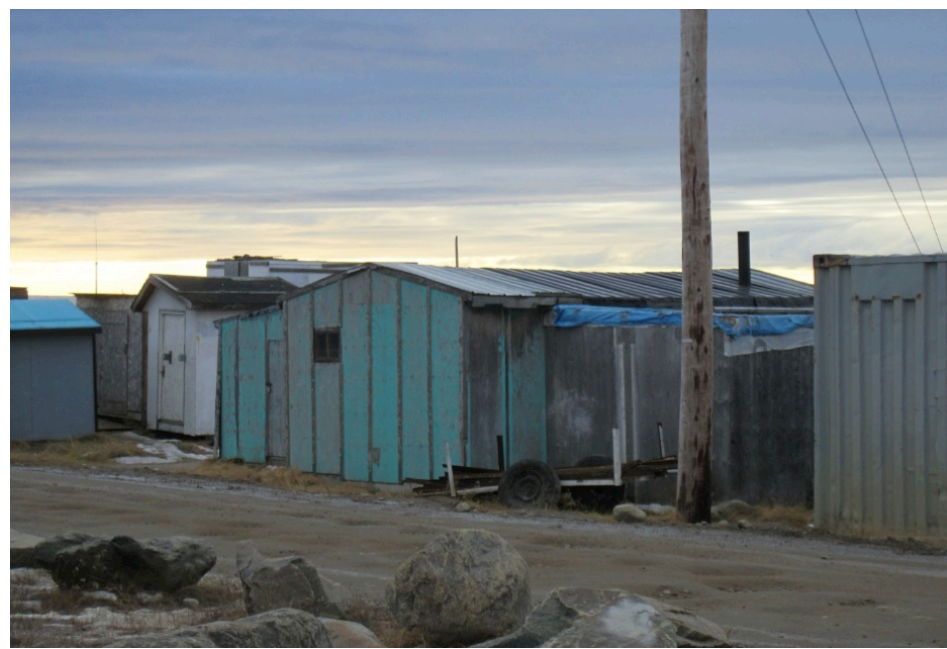

Figure 5.17 - Shacks along Iqaluit's Beach (Sijanga District)
Iqaluit's housing stock is divided into six categories; emergency shelters, non-market rental (public housing), non-market (student), non-market (staff housing), private rentals, and home ownership. Although not considered part of the housing stock, some Inuit live in informal shacks by the shore (figure 5.17) or tents next to an overcrowded house. Public housing makes up approximately 20 percent of Iqaluit's housing stock. Iqaluit has a total of 496 public housing (figure 5.18) units scattered among various other buildings. Many problems of the past persist today; overcrowding, buildings in need of repair, long wait list for housing units and inappropriate design for the Inuit culture. Of this, 30 percent are overcrowded or in need of major repair. Although the number looks meager compared to Nunavut's over-all 50 percent rating, public housing across Canada, by contrast, comprises approximately 6 percent. ${ }^{97}$ The Capital is rapidly growing, in comparison to the other communities, and the number is expected to almost double in the next 20 years. Iqaluit's waitlist, seen as having the greatest demand among all the Nunavut communities, is approximately 267 families and individuals. The waitlist number across Nunavut, divided by the housing units in stock, is what NHC uses to determine where new units will be built. Iqaluit is ranked first with 54\%, second to Repulse Bay with $47 \%$ as a waitlist percentage of stock. ${ }^{98}$ Nuna-Slums are now an epidemic in Iqaluit and Nunavut as a whole.

Overcrowding is a legacy that has been carried over for decades. Today it is a persistent problem for Inuit Families living in public housing, since the construction of new units and repairs of existing has fallen short. The hidden homeless, are those without a home, but are not seen in the street because of the 


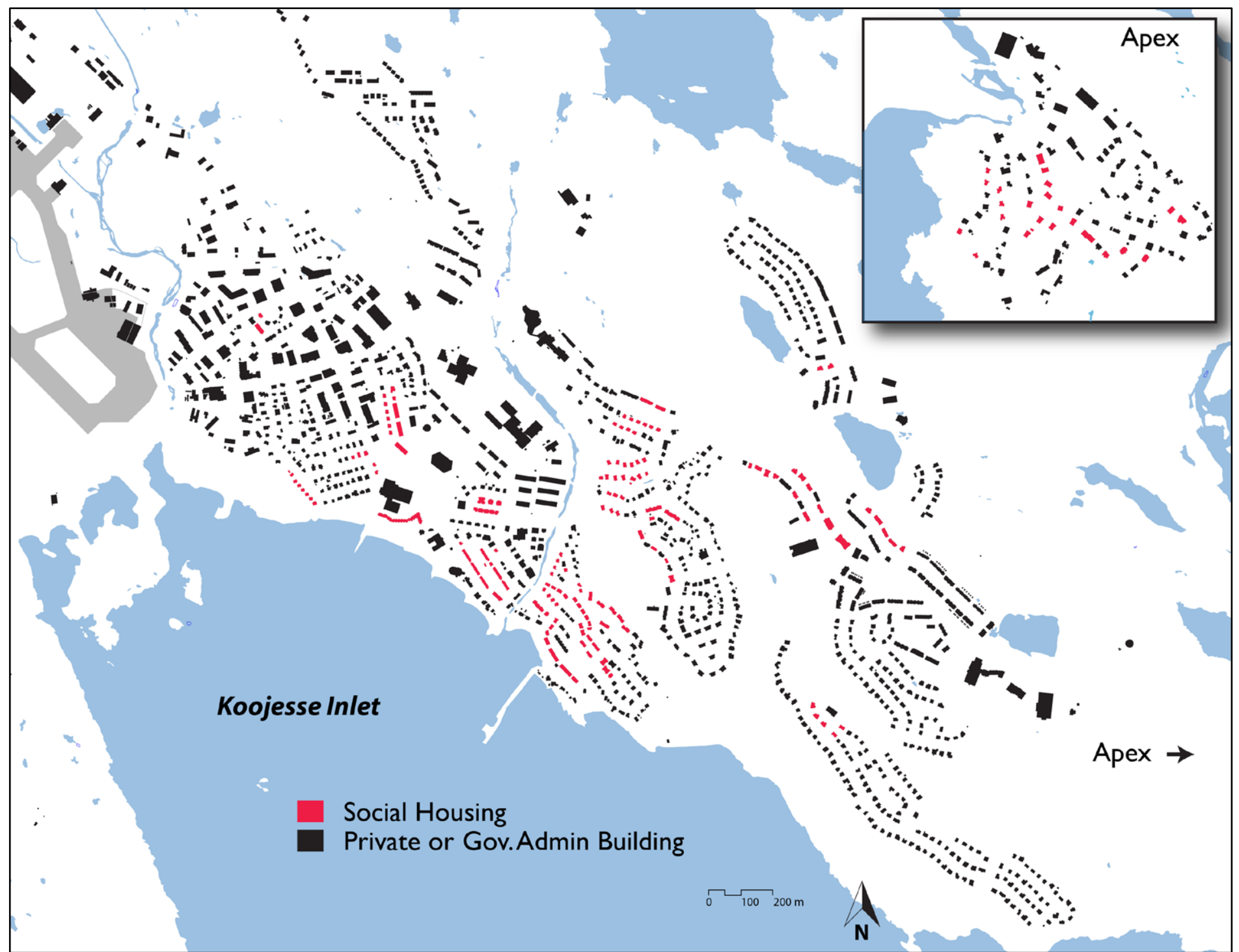

Figure 5.18 - Iqaluit Social Housing Map (unofficial) 
99. Anderson, E. (2008). Canada's Relationship with Inuit. Minister of Indian Affairs and Northern

Development. Ottawa:

Public History Inc. arctic climate. Many of them stay in the shelters or with friends and relatives. The Inuit culture is somewhat egalitarian and mandates that shelter is something that must be shared; as a result, overcrowding is the only option for housing the homeless. The impacts of overcrowding are threatening to health and wellbeing of the tenants. For example, overcrowding is a factor in the spread of illnesses such as tuberculosis and bacteria, including E. Coli.

"Overcrowded housing, homes that lack basic amenities, and homes in poor repair have contributed to a housing crisis that, "impacts on Inuit women's health, safety, education, economic status, employment and business development opportunities, and interactions with the justice system." Similarly, overcrowding does not permit places for quiet study, which negatively affects school performance and is linked to bigh drop out rates" 99

There are numerous side effects, both direct and indirect. The following image (Figure 5.19) was taken of a family of 12 in Arviat, Nunavut. Here the reporter was given an intimate look into an overcrowded two-bedroom housing unit. The walls are damaged with large holes and graffiti. Water is trucked, but not frequently enough for the capacity, causing cleanliness issues. Sleeping is a challenge (Figure 5.20), with many of sleeping in one room. Furniture, including proper beds, is a luxury. Although taken in Arviat, the problem is identical and needs to be addressed in Iqaluit. Part of the issue lies in the design of the housing unit. Many larger families would prefer living together. This could include up to four generations and/or multiple children. In some situations, too many children can be a burden financially and in an operations and maintenance (O\&M) perspective. Unlike the Euro-Canadian normative of grow-up-and-move-out, the Inuit have stronger bonds and remain connected for a lifetime. Many of the house designs are configured for small families. Policies are set with Southern principles are not suited for Inuit's cultural lifestyle. 
100. Iqaluit Fire Department. (2012). Annual Statistical Report 2012: Iqaluit Fire Department. Iqaluit: Iqaluit Fire Department.
Many of the units are in need of serious repair. Factors to blame are, to name a few: limited budgets, minor problems compounding, harsh arctic climate and terrain, vandalism, use beyond their design capacities, and tenant negligence or ignorance. Regarding the budget, the NHC is under pressure to construct more units for those on the waiting list; maintenance and repair tend to be less important because of the high cost of constructing in the arctic and limited budgets. Unfortunately, many issues get worse over time, and the tenants generally feel that they are being neglected. I once was informed of a mother and child requesting for a window to be repaired. Snow piled up on the floor inside, with black mold surrounding the frame. The individual doing the assessment stated that it might take months to repair. This may have been an isolated case, but the scenario is not unheard of. There needs to be a larger budget on maintenance and repair. Overcrowding has negative effects on the fixtures and finishes. Because of the added moisture from bathing, cooking and breathing, mold tends to build up quickly, damaging windows, walls, etc.

Damage from violent behavior is becoming worse. Unlike in the south, daylight hours reach 24 hours, in the summer months. Children can be found on the streets at 2:00am. Some of them like to throw rocks through windows for fun. This issue is difficult to control, since certain parents are either intoxicated or busy. Alcohol and drugs in the North have created many of the social problems seen today. Iqaluit tries to reduce the impact alcohol has on families by restricting how much comes into the city by one person. Bars have no issues with kicking people out at the slightest hint of being intoxicated. Substance abuse contributes to the majority of domestic conflicts. Iqaluit suffers from the highest rates of domestic violence per capita for any city in Canada. Many holes in walls and damaged doors are a result. Arson is also a serious problem. 


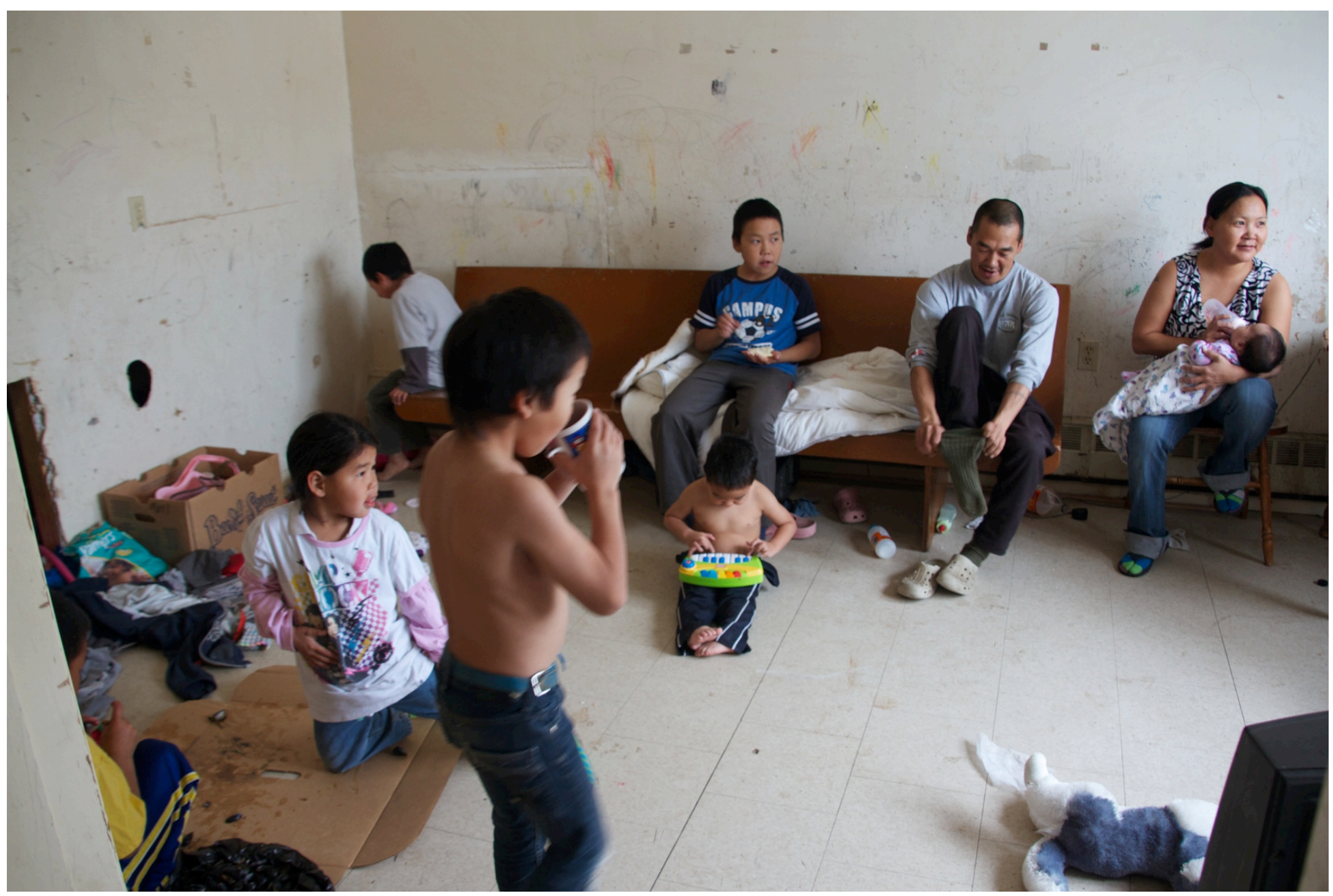

Figure 5.19-Overcrowded House, Arviat, Nunavut "The main piece of furniture they have in the house is an old church pew, used as a couch." By Vincent Desrosiers/CBC 


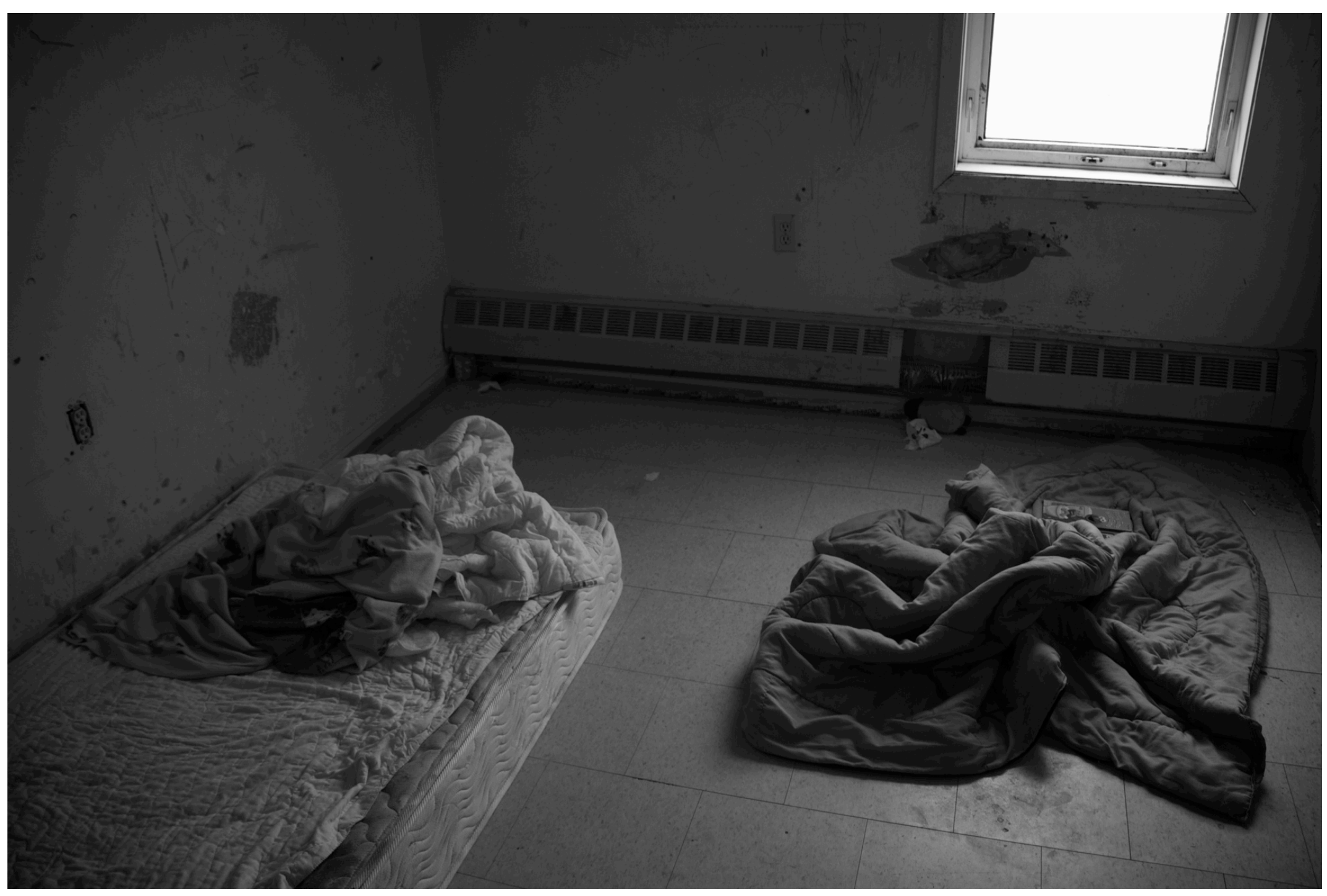

Figure 5.20 - Overcrowded House, Arviat Nunavut "The older kids sleep here, while the younger kids crowd in with mom and dad. 'One of them moves, everybody moves, 'says father Rene Aggark." By Vincent Desrosiers/CBC 
In 2012, nineteen fires were of either arson or suspicion of arson. The damage summed to over 7.5 million dollars with 2-casualties. ${ }^{100}$ Each year for the past three years, a full building burns down to the piles. Unfortunately, the fire department does not have the equipment for putting out the fire, just to suppress it from spreading. Fire repairs end up being severe and costly. As a result, buildings in the North are expensive to insure.

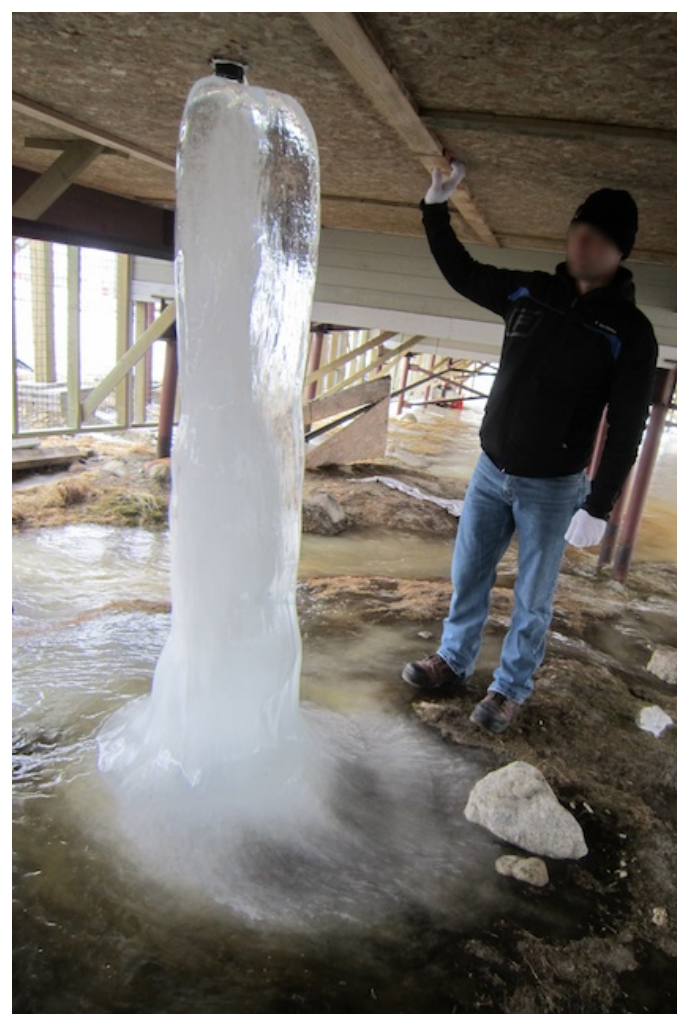

Figure 5.21 - Clogged drainpipe under building
Climate and terrain can have a devastating effect on the housing. Gale force winds can strip the siding and lift the roof. Snow drifting can engulf the house creating unusually loads on the structure. And the Permafrost can shift and tear the building apart, leaving large drywall cracks and rough openings bent. Preventative measures can be addressed at the design level (Norditecture) to avoid costly deficiencies over time. The arctic life is abusive enough for interior finishes. During the year, summer dust or winter snow gets tracked in, damaging floor finishes. Fly infestations leave feces along window frames. The dry air damages natural materials or separates adhesive bonds, such as vinyl sheet flooring. The cold can freeze and burst pipes or clog vents. Figure 5.21 is an example of a water pipe broken, leaving the liquid to flow through a hole outside. One can notice that the cold temperatures froze the water up from the ground quickly, resulting in a clogged drainpipe. Many of these issues can either be prevented or mitigated early before getting worse. Unfortunately, tenants need to be educated as to what should be reported.

As mentioned previously, many of the housing models are used beyond their design capabilities. Human agency plays a large part in how people inhabit a space especially those designed for another culture. Inuit tenants impose their lifestyles, creating a slightly dysfunctional relationship between house and user, at times damaging to contemporary finishes. For example, high levels of steam 
from the consistent boiling of country food and moisture from a large family exhaling contribute to mold and mildew problems. With buildings designed to be air tight for heat retention, a house becomes a petri dish with moisture locked inside.

Today, Iqaluit's social housing is lacking in both quantity and condition. Many of which are problems set 60 years ago. Iqaluit suffers from a housing shortage that needs to be addressed; at the same time, many units are in disrepair. This situation is magnified in public housing. Although administrators are trying to make a change, there needs to be a restructuring of policies and methodologies, as well as, proper investments in place to see rapid infrastructure growth. In the past, military budgets paid for big budget projects, today new ideas need to be cultivated and alternative sources of funding needs to be utilized.

\subsubsection{Interview with Tenants}

As a part of this research, interviews were conducted to ascertain how Inuit tenants felt about living in Iqaluit's social housing. Select interviews are in the appendix. Names have been changed to protect the identity of the interviewee. Although the needs and desires alter from person to person, some common issues were evident. It is important to clarify that it is essential to conduct further interviews to get a comprehensive understanding of what the Inuit really need in their living spaces and what form it should take.

The interviews have some common issues. The major one that was brought up was overcrowding. As a result majority of the interviewees would rather quantity of housing over quality of housing; however, it is unanimous that no one has ever seen a house that truly works for today's Inuit 
families. As generations are becoming more modernized and questionably more "westernized," there is a change in the family unit. Opinions show that Inuit need both nuclear and multigenerational typologies. There are some families with more than three children. Unlike the southern populations, the Inuit have a more assorted need for diverse house layouts and sizes. The majority of the interviewees would appreciate bigger kitchens and additional rooms such as, a cold storage, bedroom or recreational room. Regarding ownership, half of the interviewees said they would like to own, but many prefer the housing maintenance that comes with the present situation. Although conducting interviews is valuable, housing policies should be developed based on statistics and forecasting. However, policies should allow for flexibility that address specific tenant concerns. 


\section{Chapter: Agency Theory and the Inuit}

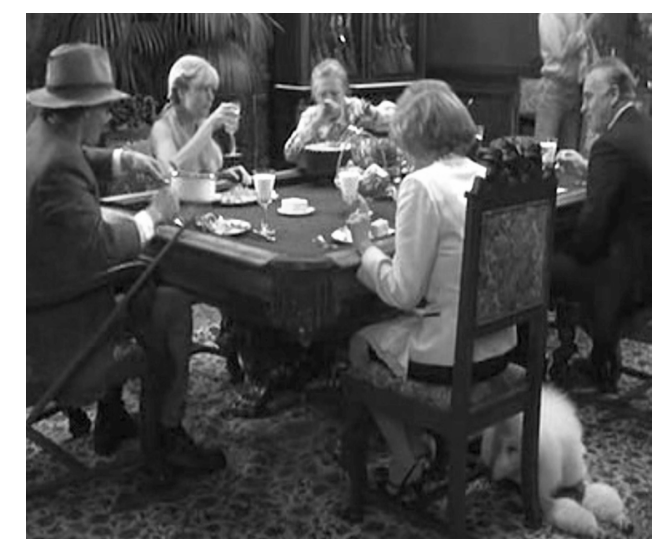

Figure 6.1 - Scene from The Beverly Hillbillies Movie, 1993

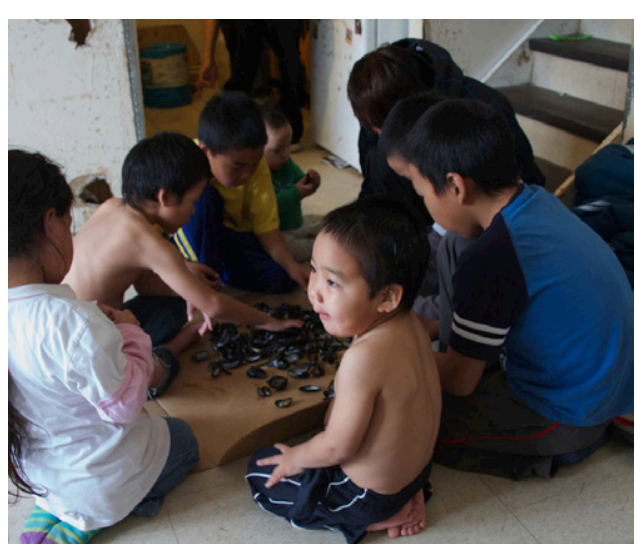

Figure 6.2 - Overcrowded House, Arviat Nunavut "The children eat mussels together on the floor." By Vincent Desrosiers/CBC
W

hen one thinks about human agency they may think of that 1960 s television sitcom The Beverly Hillbillies. The show is about a poor hillbilly family that became rich from oil and moved to the elitist world of Beverly Hills. It was full of humor as they engaged with unfamiliar things, from shopping carts to dining rooms. The onlookers were mortified by how the family was acting, such as eating road kill, or dining on the pool table. (Figure 6.1) This situation is similar to the Canadian Inuit. The image on the lower right shows an Inuit family, eating mussels on cardboard at the floor level. Locals call the cardboard "Eskimo china". Archeologist Peter Dawson closely reflects the issues of agency theory regarding the Inuit.

\begin{abstract}
"Agency theory maintains that the actions of individuals (agents) are both constrained and enabled by the institutional structures they produce through the enactment of daily life. Houses are an embodiment of this process because they are spatially configured to facilitate these enactments. But what happens when people are forced to inhabit houses designed around the concepts of family life of another culture? Do they mimic the domestic practices of those seeking cultural domination? Or do they retain traditional ways of doing things as an expression of resistance, or as a denial of the changes that they face?" 101
\end{abstract}

There is a battle between Inuit culture and Euro-Canadian housing standards. Both sides are attempting to make the other submissive through internal and external agency. Inuit are pushing to keep traditions alive, resulting in damage to housing infrastructure. Alternatively, Euro-Canadian design spatially redefines the relationship that Inuit have within the living space. Agency theory means that habits of everyday life allow human "agents" to reproduce the social structures they inhabit. 
101, 102, 103. Dawson, P. C. (2008). Unfriendly Architecture: Using Observations of Inuit Spatial

Behavior to Design Culturally

Sustaining Houses in Arctic

Canada. Housing Studies , 23 (1), 111-128.

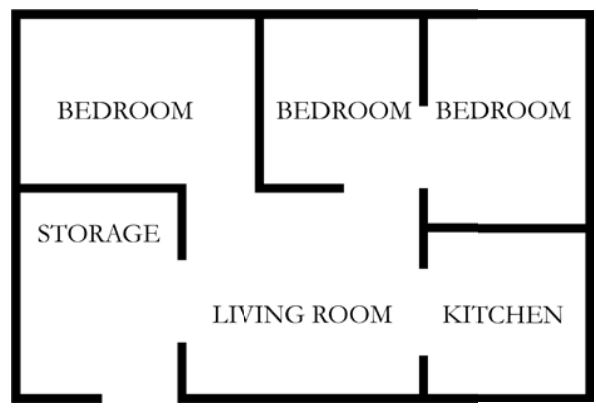

VS.

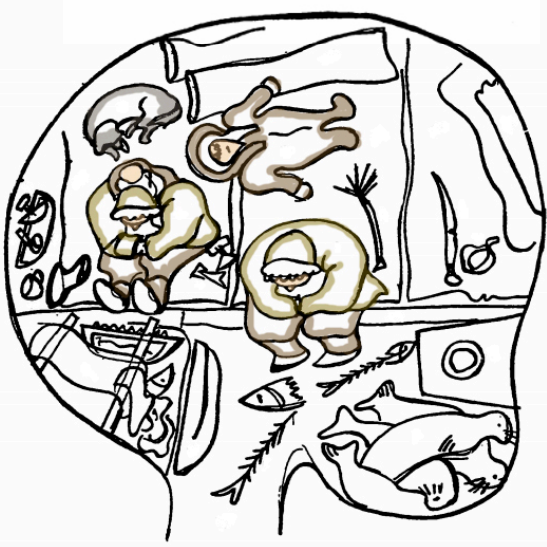

Figure 6.3 - Contemporary Euro-

Canadian Segregated Housing versus

Traditional Inuit Housing
"Spatially, Euro-Canadian house designs define and facilitate the domestic practices of Euro-Canadian families. These practices, in turn, serve to reproduce the various economic, social, political, and ideological institutions of mainstream Euro-Canadian society ... Inuit continue to use their houses as if they were traditional dwellings. These expressions of spatial agency have allowed many families to retain their cultural identities, as well as remain economically and socially viable within a semi-traditional lifestyle." 102
Euro-Canadian houses are commonly organized into programmatic designations such as bedrooms, kitchens, living rooms and porches. However, the lifestyle of Inuit families often do not match the functions associated with them. ${ }^{103}$ Dawson states that it would be inappropriate to design houses as large rooms, similar to the traditional igloo, but have an interconnected circulation pathway allowing the users to have both visual and audible connect. In some cases, slight adjustment to the typical residential layout is enough to accommodate particular functional practices. For example, Inuit cook with large pots, but cabinets are too small to store them. Socially, Euro-Canadian designs of having separate living and sleeping areas are in contrast to the traditional buildings. (Figure 6.3) Traditional designs consisted of a multifunctional space that fostered maximum intimacy and communication. Today, overcrowdedness is not the only reason for families sleeping together; many small singlefamily homes have everyone sleeping in the same room. As part of the agency theory, Dawson lists modifications that Inuit residents have made on their households,

- Replaced the standard front door handle with a heavy duty industrial handle, and spring loaded the door with bungee cords so that it closes automatically. Prior to this, the constant stream of visitors to and from his house resulted in the door being left open, thereby increasing his beating bills. 
- Replaced the 5 gallon toilet he and his family use with a foot peddle version which uses less water, thereby saving on utility costs.

- He spent $\$ 500.00$ on linoleum which he fastened to the lower portions of the walls of his house to prevent damage caused by the scratching and drawing of children.

- The L-shaped layout of the kitchen and living room prevented people in one area observing the activities of people in the other. In order to solve this problem, the resident suspended a parabolic surveillance mirror on a wall that increased what could be seen from the perspective of both spaces. 104

104. Dawson, P. C. (2003) Examining the impact of EuroCanadian architecture on Inuit families living in Arctic Canada. Calgary: 4th International Space Syntax Symposium London.

105. Dawson, P. (1994) Unsympathetic Users: An Ethnoarchaeological Examination of Inuit Responses to the Changing Nature of the Built Environment. Arctic Institute of North America. Arctic Institute of North America.
Many of these modifications were for energy efficiency but doing them would help pay for other activities, like fishing and hunting. To design effective spaces, it would be important to establish a dialogue of the needs and practices of any culture, in this case the Inuit. Canadian policy needs to change its attitude toward Inuit housing design. There is a dynamic relationship that exists between house and culture. There is a risk of losing culture to unfamiliar environments. Dawson states, "different cultures are characterized by distinctive types of economic, social, and ideological relationships, they require different forms of spatial order to sustain them." 105

Inuit culture has undergone a transformation. Today, there is a modern Inuit culture that accepts technology such as the Internet, cellphones, and snowmobiles. It would be unwise to try and design for the Inuit 50 years ago. There need to be a synthesis of the two sides, both Inuit and EuroCanadian designs, resulting in a form of "neo-Inuit architecture." This architecture should embody all the benefits of both. Neo-Inuit architecture would be an example of successful Norditecture. 


\section{Chapter: Vision to Intervention}

7.1 Design Principles

W

ith all the failed attempts at designing for the Northern Inuit, it is clear that there needs to be a new approach. Many principles (See diagrams 1-5) must be established

to accommodate Inuit culture while adhering to national building codes. A true Inuit typology would emerge to both respect modern-Inuit lifestyles and mitigate the problems of today. First it needs to be culturally appropriate. Successful solutions will ascribe to a participatory design approach having all stakeholders collaborating to create a functional and suitable design methodology. To clarify, the intent is not to initiate policies that inhibit or stunt the design process by establishing committees. In this approach, it is hoped that there develops a new architectural language specifically for the Inuit.

1. Participatory Design Approach

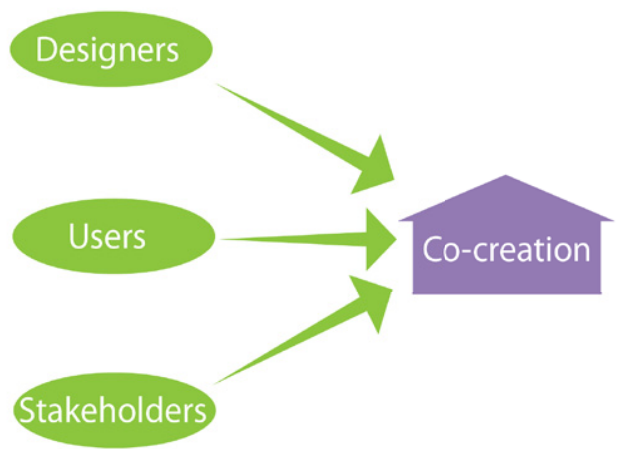

2. Create a New Architectural Language
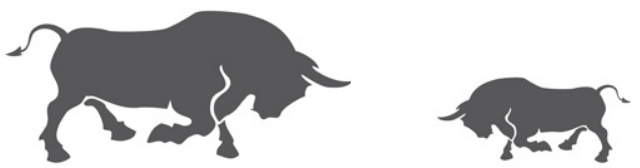

Canadian Standards Modern Inuit Lifestyle

Project

Politics

Participation

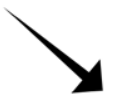

Neo-Inuit Architecture 


\section{Iterative Design}

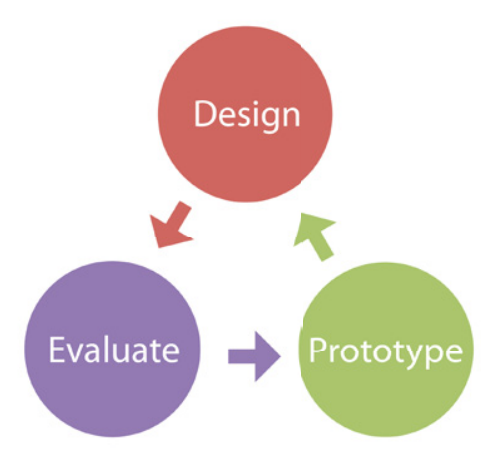

\section{Infill Design}
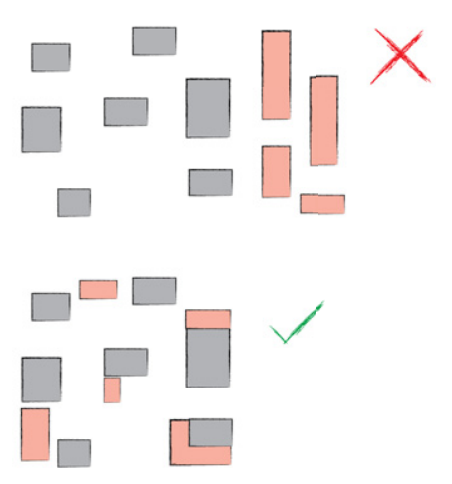

Figures 7.1-5 - Design Principles

\section{Integrative Design Approach}
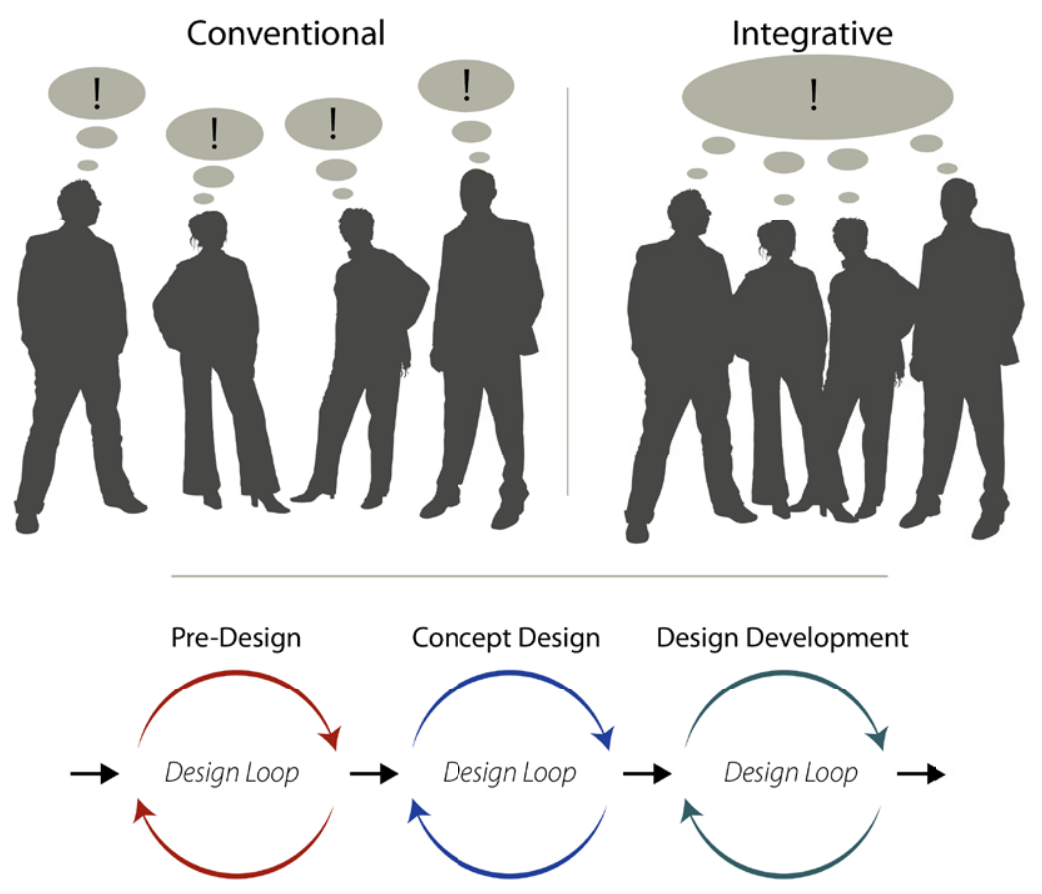

Function is the key to survival in Canada's Arctic. It was true in the past with the Inuit, and still is today. An important strategy and principle that should be prescribed is the Integrative Design Approach. This is where there is collaboration at all phases of the project from pre-design to postoccupancy. There needs to be implementation of this approach in conjunction with the Participatory Design Approach in order to have an effective product. Once an agreeable methodology has been found, design and construction costs would diminish over time. It must be 
emphasized that this should not be seen as the 'perfect' solution. Iterative designs are best for extreme conditions coupled with a unique culture. It allows for a continual evolution of the neoInuit architecture. Finally, any design must respect that the northern landscape is changing and becoming all-inclusive with differing cultures and economic classes. It is important to stress social integration by use of urban infilling with existing fabric. Any program should avoid creating urban islands, as Ikaluit and Apex Hill were.

\subsection{Proposal}

To establish discussion among all stakeholders, a proposal was developed to act as a catalyst for initiating a participatory design approach. This proposal is based on research, Northern design experience, interviews conducted, and myself living in Iqaluit. This proposal will introduce macro methodologies down to micro planning. There will be a response to specific concerns of overcrowding, accommodation of the Inuit family unit, extending of the building lifecycle, and its use by the Inuit. It is intended to begin the formalization of a neo-Inuit Architecture.

\subsubsection{Construction Methodology}

Over the years, millions of dollars have been spent in the procurement and transportation of construction material to Canada's north. This process has it short comings and has met with its fair share of mishaps and scheduling crises. With such a short construction season and specialized labor force having to be shipped in; our approach to the construction methodology needs to be 


\section{Step 1 - Construct Soccer Dome (2 yr. Const.)}

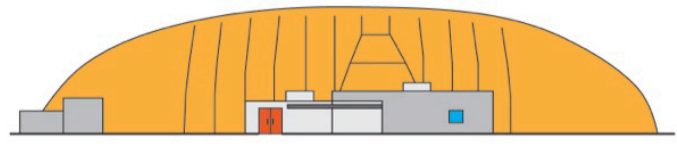

\section{Step 2 - Use Dome as Manufacturing Plant (5-7 yrs.)}

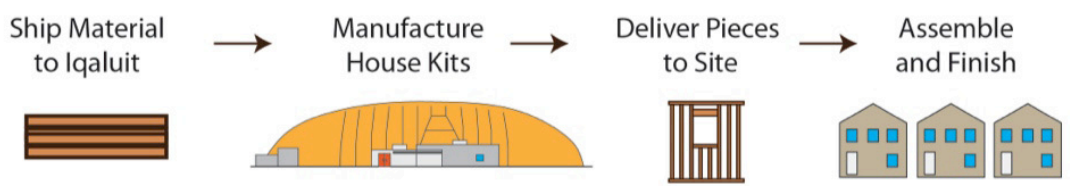

\section{Step 3 - Turn Dome Over to City}

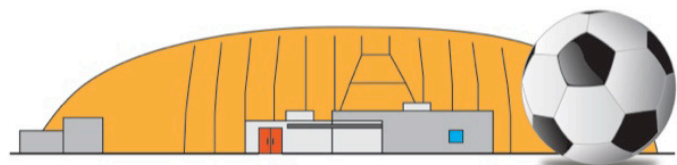

Figure 7.6 - Soccer Dome as Manufacturing Plant Lifecycle

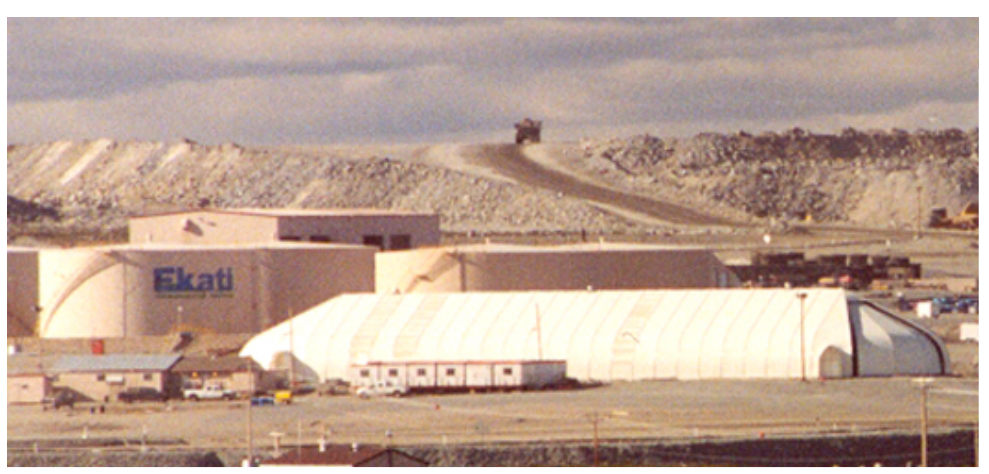

Figure 7.7 - Ekati Diamond Mine 88' x 320' Storage Facility revisited. In order to address the overcrowding problem in Iqaluit, a large number of houses need to be built rapidly. In the present situation, building hastily can be risky and expensive.

I am proposing the intervention of a phased housing construction project. The first step would be to construct an indoor soccer dome to house the production of prefabricated housing components between construction seasons. The dome will be composed of an insulated tensioned fabric structure. This typology is selected since it is easy to construct and can be repurposed. The idea is to order construction materials to construct housing for approximately 200 families over a 5-7 year period. See Figure 7.6 for project phases. The soccer dome will have assigned locations for storage, assembly, training and testing.

The most complex aspect to installing a tensioned fabric dome in Iqaluit will be the foundation system. This will need to be poured concrete (for manufacturing loads) on steel deck resting on 6" diameter steel piles; raised above grade to allow for permafrost protection. As the structure is custom designed it can be configured to sit in a variety of locations in Iqaluit. Suggested site locations (see Figure 7.9) would include Upper Base (1), Federal Road between the RCMP station and building 1501 (2), or Road to Apex opposite the Arctic Winter Games Arena (3). All these sites can be developed with minimal impact on the existing tundra while 


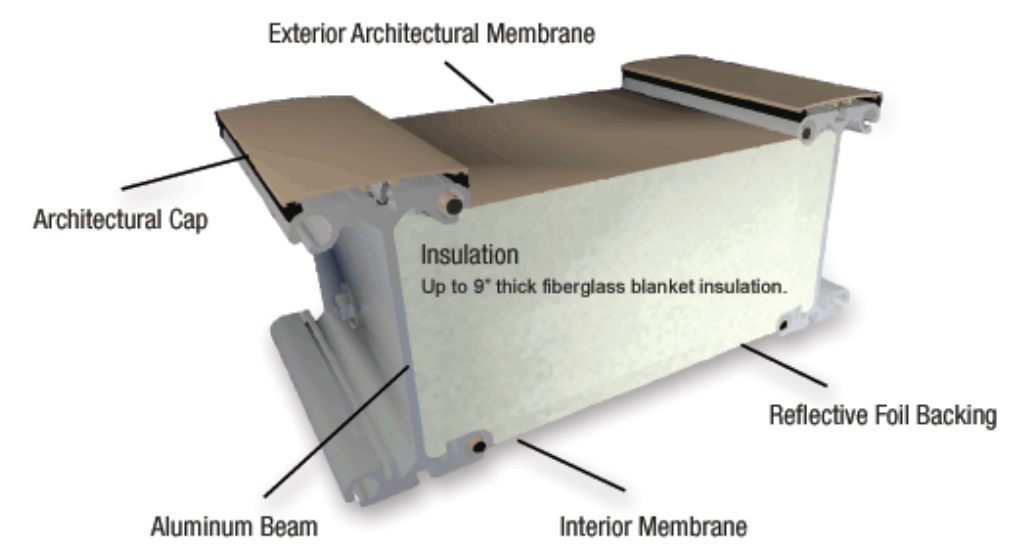

Figure 7.8 - Example of Insulation for Fabric Dome

106, 107. Sprung Instant Structures

Ltd. . (2010). Ekati Diamond Mine Case Study - Sprung Instant Structures.

Retrieved 03 23, 2014, from

http://archive.sprung.com

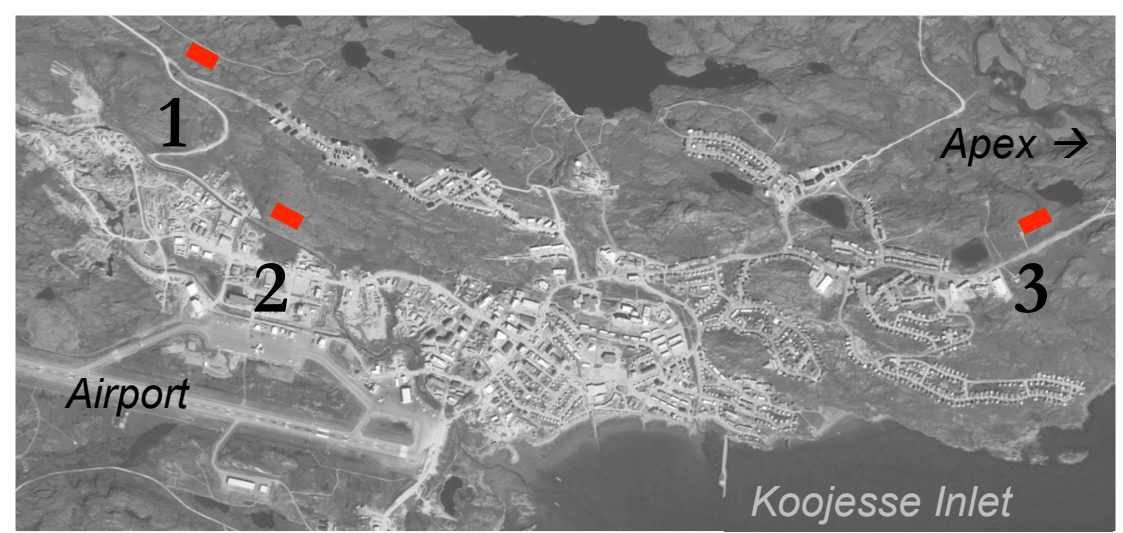

Figure 7.9 - Potential Site Locations in Iqaluit, Nunavut providing easy access for transporting finished products to the various potential construction sites.

An example of the dome's use in Canada's Arctic today is the EKATI Diamond Mine, (see Figure 7.7) which is located approximately 300 kilometers northeast of Yellowknife, 200 kilometers south of the Arctic Circle in the Northwest Territories, Canada, and 100 kilometers north of the tree-line, in an area of continuous permafrost. ${ }^{106}$ These structures have been in use since 1993. They have so far enjoyed the longevity of withstanding the harsh winter conditions with minimal maintenance and repairs. As they are constructed to the client specifications, HVAC, electrical and other maintenance systems are modified accordingly.

The unique aluminum beam and architectural membrane reinforcing system of the fabric dome allows it to move with heavy winds and act in an aerodynamic fashion thereby providing excellent lateral reinforcement against gale force winds. Reacting similar to systems installed in New Orleans, that withstood the Category 3 winds of Hurricane Katrina. It takes a lot of pressure and force to tear the fabric on these domes, but if the skin tears it is easily replaceable. Insulation is very important in the North; the building envelope will consist of 9" 


\section{Existing Construction Cycle}

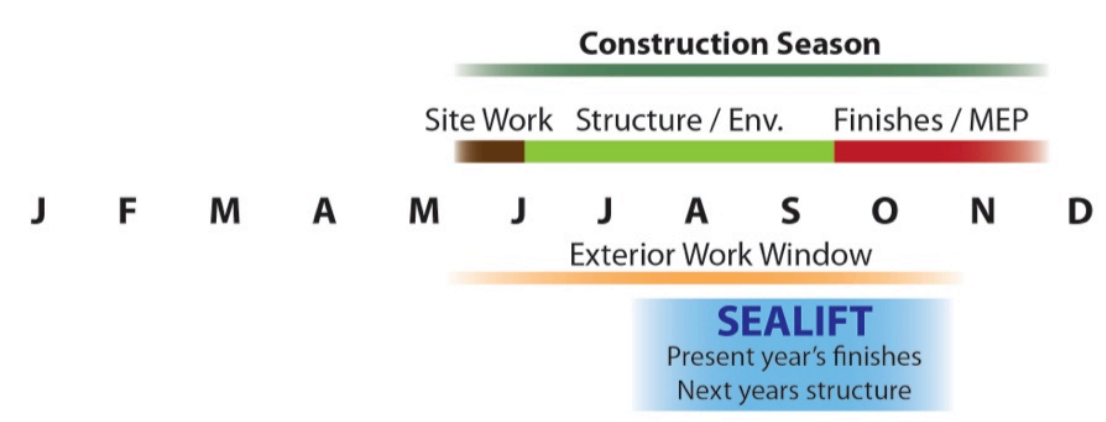

\section{Proposed Construction Cycle}

Construction Year-round

\begin{tabular}{llllllllllll}
\hline & & & \multicolumn{3}{c}{ Next Year's Site Work } \\
& Manufacturing & & \multicolumn{3}{c}{ Assembly } & \multicolumn{3}{c}{ Finishes / MEP } \\
\hline J & F & M & A & M & J & J & A & S & O & N & D
\end{tabular}

\section{SEALIFT}

Figure 7.10 - Existing Construction Cycle versus Proposed Construction Cycle fiberglass insulation (33.3 R-value) sandwiched between the exterior and interior membranes. (see Figure 7.8)

Size, weight and transportability of a replacement skin will be nominal when compared to transporting replacement materials to Canada's North. These structures are also easy to relocate and repurpose, as needed, which is why this proposal incorporates it being repurposed as a soccer field when finished. The construction cost is approximately $6-$ 12 million, ${ }^{107}$ but this can be offset from the burden placed on NHC with alternative capital funding based on repurposing and Inuit training initiatives.

Prefabricated houses designed for the arctic that have been approved will be assembled in parts. The work force will combine trained carpenters and unskilled Inuit laborers interested in learning the skill. They will get on the job training in assembling these components. It is expected that a constant turn over of trainees will happen, but it means more people will be trained in this trade. If they make it to the end of the season, they can be tested and certified by a professional organization. One problem that many general contractors have today is that many of the Inuit would prefer to go hunting and fishing than work during the warmer months. For example, a contractor I know had half of his crew drop all their tools on spot and went running to hunt a 
108. Canada Mortgage and Housing Corporation. (1994) Permafrost and Foundation Types Technical Series 94-214. Retrieved 03 23, 2014, from ftp://ftp.cmhcschl.gc.ca/cmhc/94_214.html whale that was spotted in the bay. With the majority of the assembly completed in the winter, fewer people would be needed to assemble in the summer. Refer to Figure 7.10 for a comparison between the existing construction cycle and the proposed construction cycle.

Each house will be prefabricated over the winter and transported out for erection during the summer. Different models will be designed to accommodate various family units. Walls and trusses will be prefabricated with all but the interior finishes installed. Walls will be raised with all envelope components, minus the drywall (making it easier to transport), and designed to easily lock-up with other building elements. Sub-trades will finish the work after assemblage on site.

To alleviate the reliance on drilling piles and potential frost heaving, a uniform 'multi-point spaceframe foundation' will be utilized and pre-assembled in the soccer dome. The space frame is a truss system comprised of aluminum tubing (chords) and connectors (hubs). When assembled, it acts as a floating slab. Due to the shifting permafrost, CMHC would recommend this foundation type for a reduction on racking stresses. The CHMC states, "Multi-point spaceframe foundations are designed to withstand major shifting and settling of the soil while maintaining a level plane for the building."108 Beneficial for training purposes, the system is easy to assemble without specialized labour. Its lightweight, and low volume makes it cheaper for shipping. The site will be prepped a year prior to assembly by leveling the grade with stamped gravel. The year will help the ground to settle. In cases of pre-existing level grade, gravel may be eliminated based on the recommendations of a geotechnical assessment. 
Prefabricating components will give control over the quality of construction and increase the quantity of homes ready for occupancy. This manufacturing process typically reduces the overall cost by approximately $25 \%$. Training grants may additionally offset the cost even more by reducing the typical labour overhead. The more trained Inuit workers become, fewer tradesmen would need to be flown into Iqaluit.

One problem that NHC has today is that materials are typically stored from the previous year and are prone to damage and theft. Many items are stored outside. The soccer dome will act as a storage facility and minimize the replacement costs. When the quantity of housing is satisfied, the soccer field dome will be turned over to the city, since there is a serious lack of recreational facilities.

\subsubsection{Durability}

Buildings in the North are very expensive and need to have a longer life span than southern buildings. This requires that many elements be especially durable to keep both the building and users healthy. Buildings in disrepair need just as much attention as new construction today. NHC needs to concentrate efforts to new construction to help alleviate the overcrowding problem. This would lessen the stress on existing infrastructure. There are various ways that a building can be made durable: install hardier materials; users become better stewards; ownership transfers to tenants. Durability of materials is vital to keeping maintenance costs low. Since much of Northern construction is experimental, lessons should be learned from all the materials selected over the past 60 years. A forum needs to be established to allow contractors to share knowledge. For example, linoleum flooring fails in high traffic areas. Many people have dogs and wear ice grips on their shoes ending up tearing sheet flooring. Durability by stewardship is important. Users need to be 
properly educated as to taking care of a unit and know when to report problems. By training more Inuit in construction, repairs could be made faster and more properly. If they were the tenants, their units would potentially be in better condition.

The best form of durability for a home is ownership since it promotes a pride of place. A big challenge is moving social housing tenants into home ownership. This is difficult since many have become complacent. Programs need to be in place to encourage the transition. Tenants need to be properly prepared for home ownership through training. It is a known problem that there are some tenants that have difficulty in understanding the importance of monthly payments. A mix of rent to own and volunteer with training points programs may be explored as a method for evaluating candidates for ownership. Although NHC loses a building from their portfolio, they have one less to maintain, resulting in more money free for construction. Inuit would become progressively independent and out of the welfare condition.

\subsubsection{Example of Model Design}

It is intended that there will be other models developed over time to accommodate varied family units and needs. Further is one example of what a particular model would look like. (see Figure 7.11) This design is intended to embody elements that accommodate of Inuit lifestyle including, larger families, health, and durability. Any architectural project should be functional, beautiful and economical.

This duplex model can either accommodate two large families or act as a boarding unit for singles. Due to the high suicide rates in Nunavut, having more social units for singles would help to alleviate 
this problem. Each four-bedroom unit is approximately $1800 \mathrm{ft}^{2}$ with ample living areas. The assembly is of wood-frame construction with standards similar to R-2000. The building's form represents ice with its varying rooflines, but remains simple enough to prefabricate. The design intent is to get away from the standard box-like housing unit and hopefully provoke a pride of place for the tenant.

The program is designed to merge both the northern and Inuit lifestyles. As the user enters into the building they pass through a vestibule with an open closet that accommodates large parkas. Vestibules are necessary in reducing rapid heat loss with the door opening and closing constantly, since Inuit have an active land and home life. As the users enter into the living room, they can socialize with family members throughout the house, because of its interconnectivity. Bedrooms have large rolling doors to connect rooms (refer to floor plans). Food is a big part of Inuit culture. The unit has a kitchen with an island stove with a range hood that takes the moisture out of the house. Many Inuit dishes are boiled, and with larger families and typical gatherings; big pots are required. Large amounts of moisture would need to be removed in order to avoid mold and mildew. Country food is a large part of their diet; to accommodate large game a cold storage is part of the program. A one-foot high granite table in the dining area is installed to allow for cutting and serving medium game. Inuit use the floor in existing housing conditions; so by having a table installed the floor finished will be protected. In the North, storage is premium but should be seen as a necessity for designing homes. There are no basements. Outdoor equipment, food storage, and personal effects usually require more room than southern homes. 
It is intended that the building be placed on the site for optimum solar gain. The design allows for southern light to enter into the living space from either end of the building. The site would need to be leveled prior to construction. This particular model is designed to connect to the cities' utilidor; other models should be designed for areas without water/sewage connection such as Apex. It would be advised that a shed be constructed in accordance to the city of Iqaluit's General Plan. These can be mass produced in the soccer dome and placed in summer.

Materials are just as important as the structure. The exterior walls are clad with Hardi-panel siding and the roof with metal standing seam panels with a thick gauge that can withstand both the harsh wind and solar radiation. The windows are to be triple-paned with insulated frames. The foundation is to be left exposed to allow snowdrifts to pass beneath the structure and keep the permafrost frozen. The mechanical room is to be accessed from the exterior. Under the NHC's authority they will need to be accessed without disturbing the tenants. Additionally, there is a tendency to use it as a storage area if accessed from the inside, creating a fire hazard. The interior finishes are to be durable, but easy to replace if necessary. Walls should have a protective layer, possibly wainscot if many children are present. This will reduce the likelihood of damages to the GWB finish. Laminate flooring has proven to be most durable and is therefore recommended. Solid wood cabinets and doors will reduce the need for repair. Cabinets should be larger than typical to accommodate bigger cooking pots. 


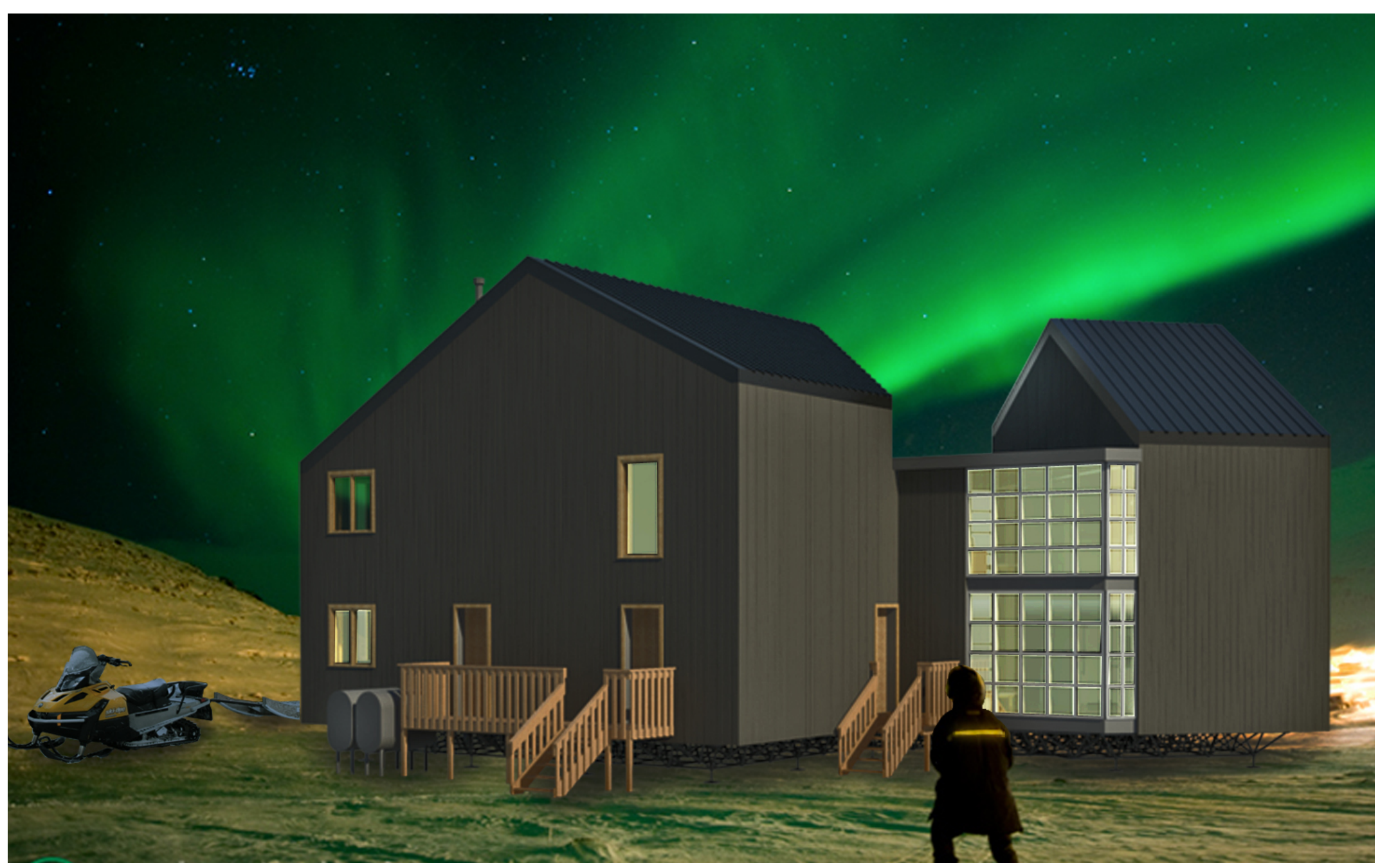

Figure 7.11 - Model House Front Rendering at Night 


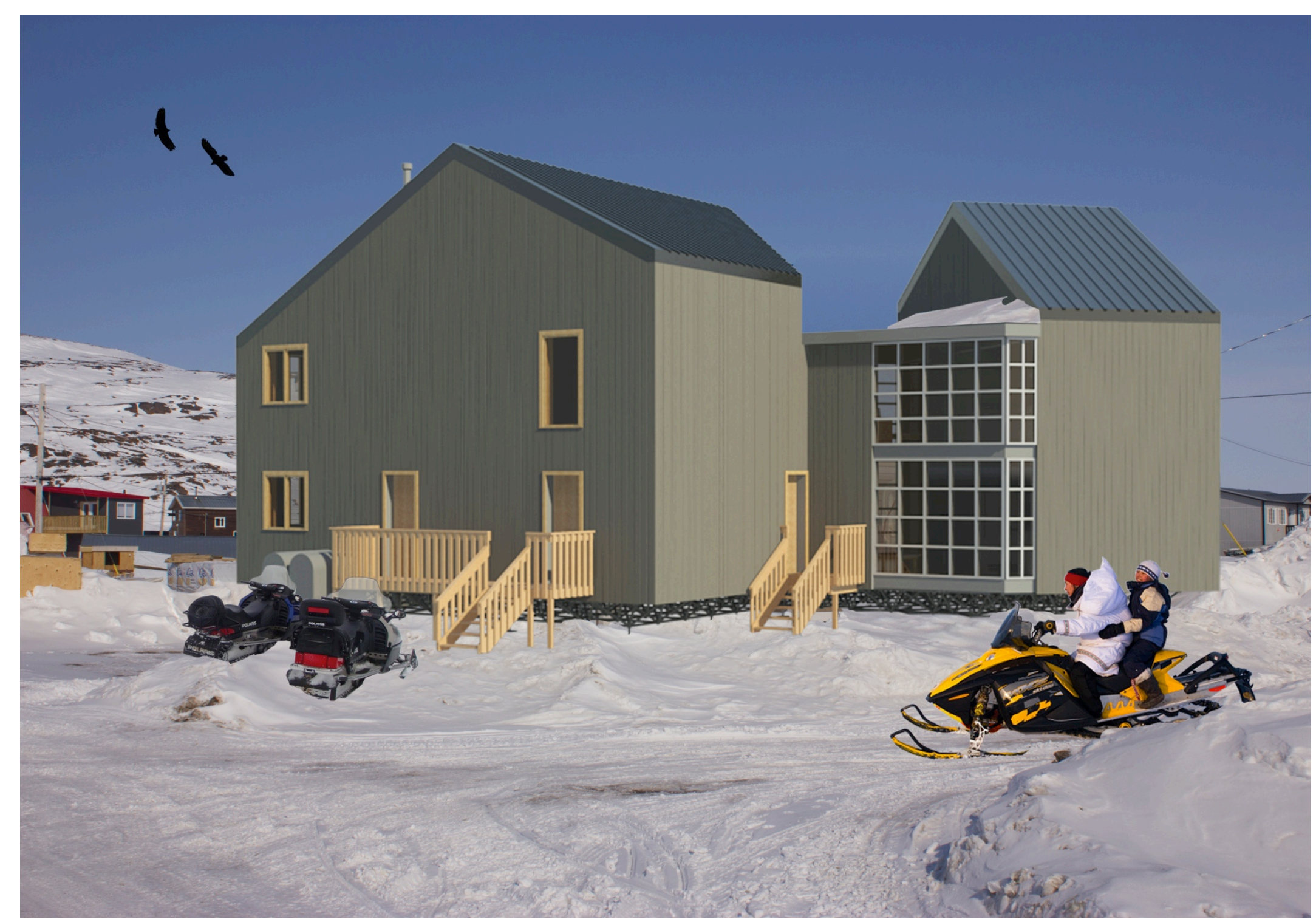

Figure 7.12 - Model House Front Rendering at Day 


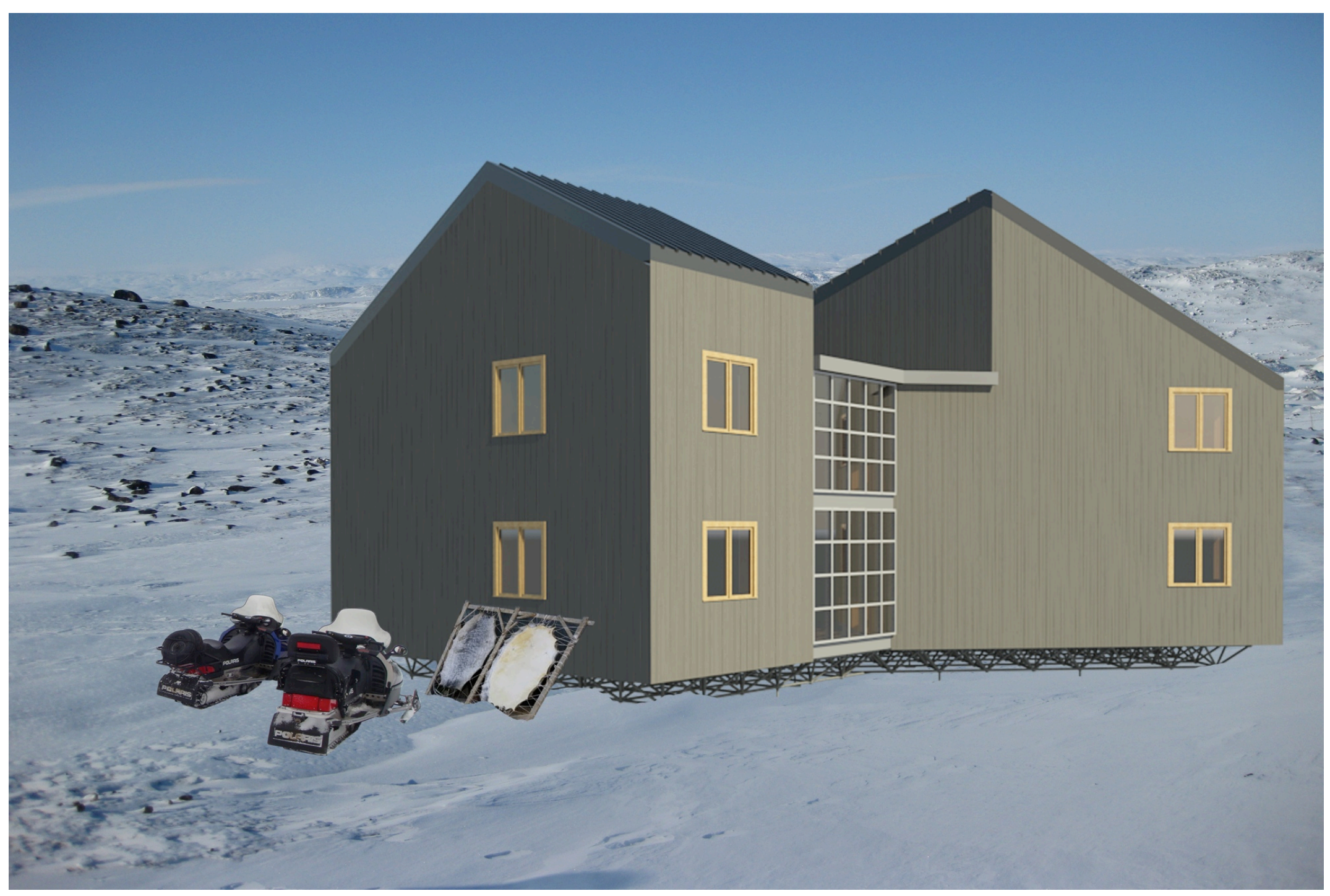

Figure 7.13 - Model House Rear Rendering at Day 


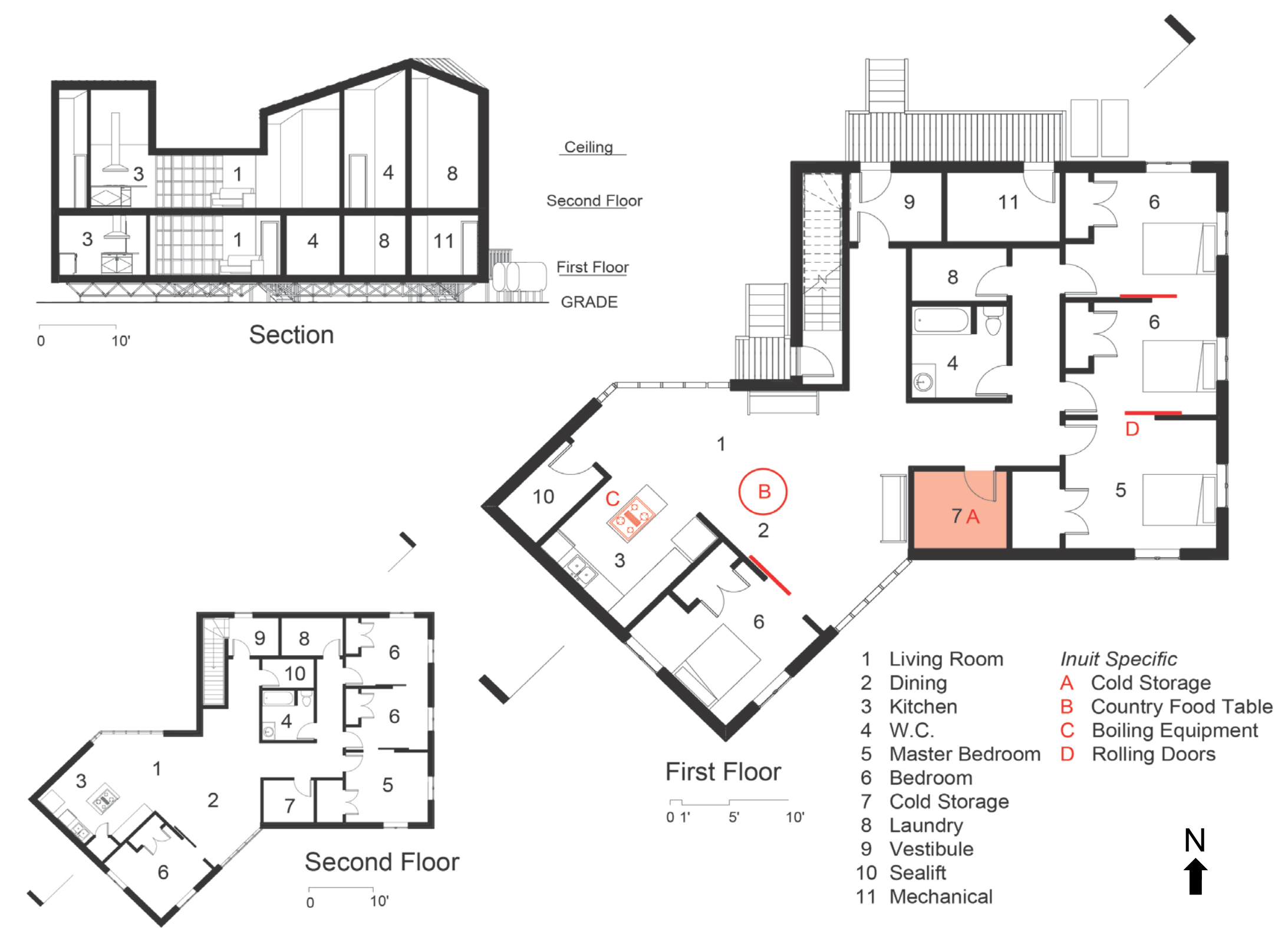

Figure 7.14 - Model House Plans and Section 


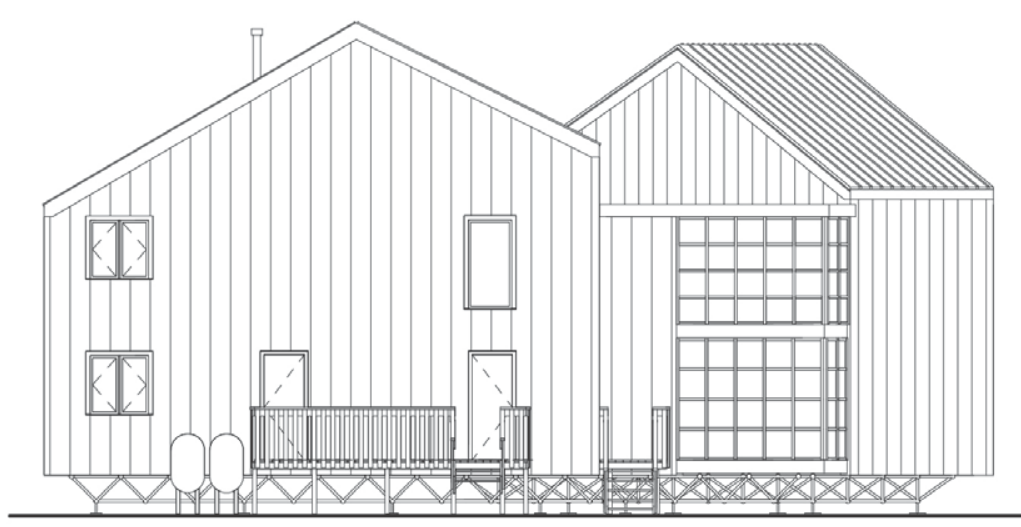

$\longdiv { 0 1 0 ^ { \prime } }$

Front Elevation

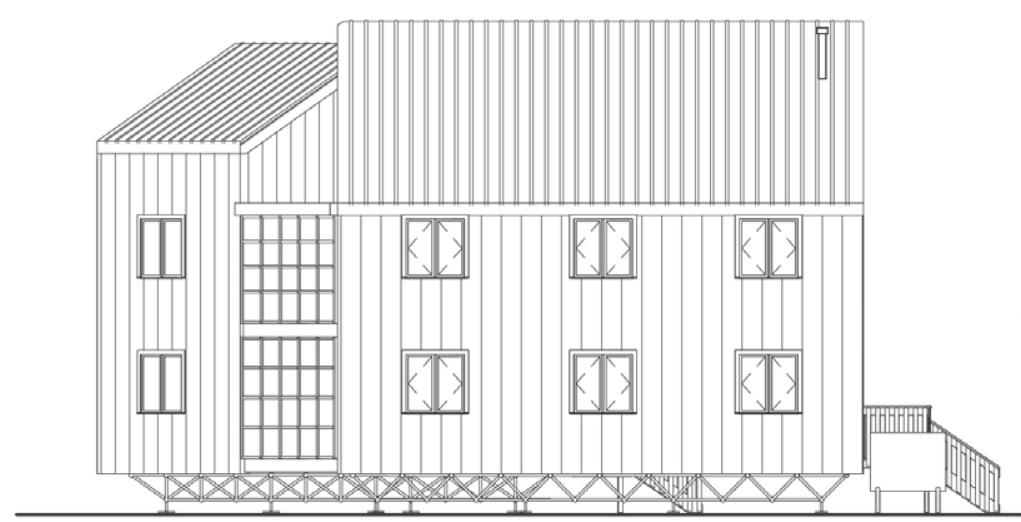

Left Elevation

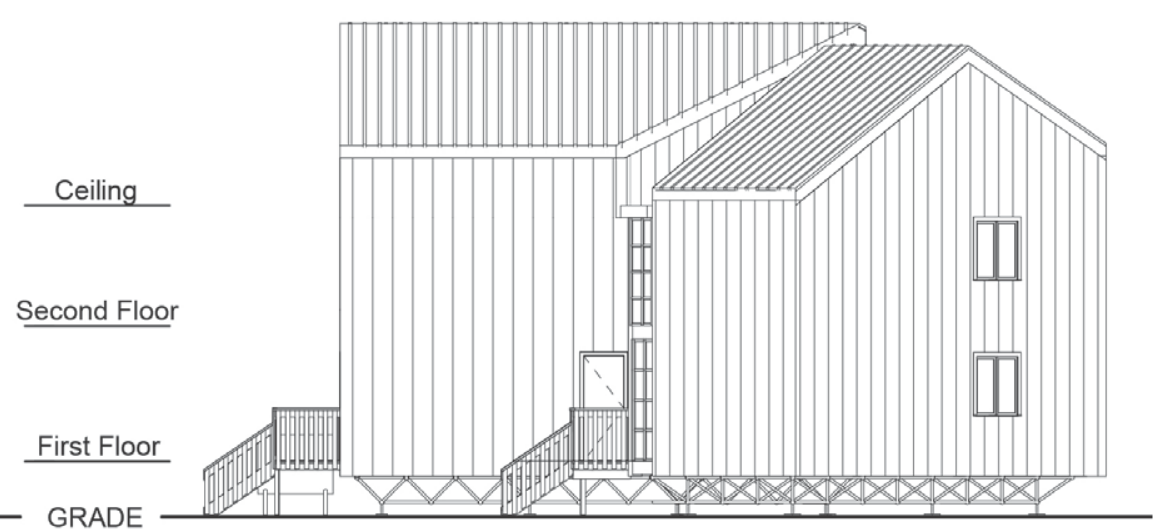

Right Elevation

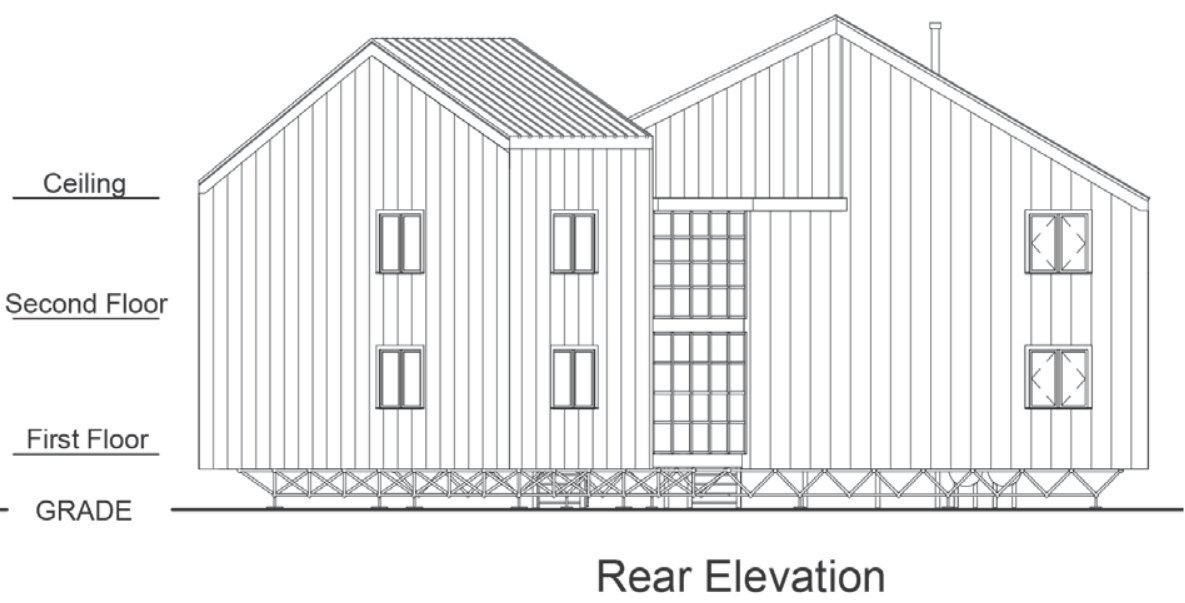

Figure 7.15 - Model House Elevations 


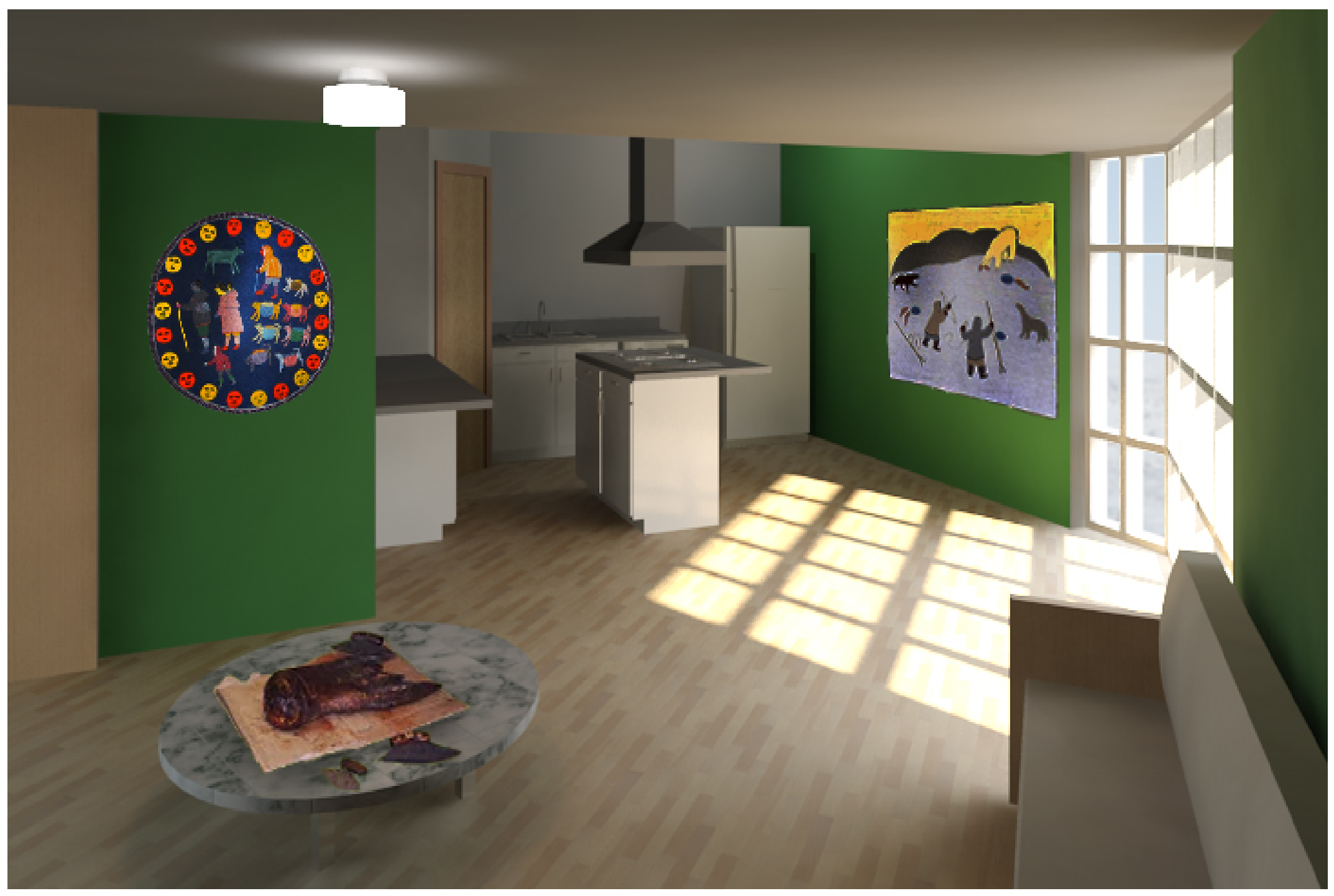

Figure 7.16 - Model House Interior Rendering at Living Room 


\section{Conclusion}

The Inuit have been around for thousands of years; only in the past century has there been such an abrupt change. For the past 60 years, up to today, many Inuit have been living in "slums." Canada has failed them and it is up to professionals such as Architects to invoke a change in how social housing is interpreted in the North.

This thesis has explored Iqaluit's social housing. Its primary intent was to objectively critique its evolution from inception in the 1950s to present day while reviewing how the standard of living is sub-par when compared to their social housing counterparts found in the south. According to the UN-Habitat much of Nunavut's social housing would be considered a 'slum' by definition.

Historically, the social housing in the Arctic has adapted poorly to the Inuit culture and the extreme northern climate. With international pressure and the Cold War in the minds of the federal politicians the need for social change in the North was hastily addressed. Evidence of this can be observed today.

Welfare comes into question when culture becomes subservient to universal methodologies. Housing designs tend to be imported from the South and constructed with little regard to regional and environmental needs. Socio-political forces have pushed for urbanization in the North and this, coupled with Inuit flocking to permanent settlements, resulted in a degradation of Inuit's cultural identity. The concept of the "urban Inuit" is less than 65 years old. The separation from land has been costly. 
Today, problems such as overcrowding, communicable diseases, and inferior construction are just a few that have persisted since the beginning of the housing programs in Canada's Arctic. Over time, these issues have produced generational social ills such as, substance abuse, mental illness and an overwhelming sense of hopelessness leading to suicide. Lack of adequate and culturally responsive housing impedes economic and personal development.

The Inuit lifestyle, overcrowding and poor maintenance is prevalent in existing domiciles and are damaging the infrastructure. Through a process of [RE] interpreting the design approaches, such as the participatory and the integrative design approach, a new architectural typology will emerge. Further studies like Peter Dawson's research into Inuit's spatial behavior needs to continue, in order to be fully aware of how the Inuit live with the built environment. It is a known fact that the only way to mitigate overcrowding is to build more houses, however, this should not be undertaken without forethought. It is the architect's role to learn how the user will function within the space, and design culturally adaptive living spaces. For example, the model design in this thesis embodies various attributes requested by the Inuit interviewed. Emphasis was placed on the use of the kitchen and living room. There was also a request for additional bedrooms and a cold storage. The building form was to break away from the typical rectangle, while retaining qualities of easy to assemble houses. Although it can be seen as minor interventions within a southern context, these features are not included in social housing prototypes that exist today. These changes would be seen as radical within the northern context. 
Today there are no successful examples of true neo-Inuit architecture and it will take time to develop. This direction is vital in helping to sustain the Inuit culture and avoid making the same mistakes of the past.

The rapid growth of the city coupled with major housing shortages will require a unique solution that should attempt to accommodate the needs of both the Inuit and the City as a whole. Architecture has continually failed to embody a distinctly Iqaluit language. Other communities observe the capital and mimic architectural successes. Since the creation of Nunavut in 1999, there has been a push to become autonomous; however, the majority of its annual revenue comes from the federal government.

Iqaluit is suffering from rapid growth and housing shortages. With the advent of mining and shipping routes, resulting from the North West Passage, the city may grow exponentially in the years to come. Iqaluit cannot handle the existing population, any more will overwhelm and damage existing infrastructure further. Radical solutions, such as the proposal in this thesis, need to be evaluated and actioned. As a capital city, solutions would spread to other Nunavut communities.

Architects have a social responsibility to not only adhere to the economic and geo-physical concerns, but also allow for cultural expression and adaptation of the users, no matter their status. A design focus should be on adaptation and flexibility to social needs, a remap of the existing paradigms and institute new praxis. 


\section{References: List of Figures and Tables}

Figure 1.1 - White, P. (Photographer). (2011, April 04). Housing shortages and overcrowding are commonplace in Nunavut. [Web Photo]. Retrieved from http://salo-forum.com

Figure 1.2 - Canada, S. (2010). An analysis of the housing needs in Nunavut (pg. 5). Statistics Division, Statistics Canada for the Nunavut Housing Corporation.

Figure 1.3 - Aupaluktuq, C. (Photographer). (2013, October 21). Mushrooms growing out of the walls [Web Photo]. Retrieved from http://www.cbc.ca

Figure 1.4 - Pootoogook, A. (Artist). (2002). Memory of my life: Breaking bottles [Web Drawing]. Retrieved from http://drinkanddrawmtl.com

Figure 1.5 - Based on: Hamlin, L. (Designer). (2006, August 15). Nordicity map [Web Map]. Retrieved from http://www.thecanadianencyclopedia.com

Figure 1.7 - Lee, B. (Designer). (2012). Comparative Plan Drawing [Print Graphic]. Retrieved from http://d284f45nftegze.cloudfront.net/brijlee/ArticReduced.pdf.

Figure 1.8 - Frobisher Bay new town aerial perspective. (Library and archives canada, nMc 122830.) via Waldron, Andrew, Frobisher Bay Future: Megastructure in a Meta Land, Architecture and Ideas, vol. viii.

Figure 1.9 - (Department of Northern Affairs and National Resources. 1960. proposed New Town, Frobisher Bay, North West Territories.) via Waldron, Andrew, Frobisher Bay Future: Mega-structure in a Meta Land, Architecture and Ideas, vol. viii.Figure 1.10 - Arctic Town Proposal - 1971

Figure 1.10 - Frei Otto : complete works : lightweight construction, natural design, Birkhäuser (2005)

Figure 1.11 - Moshe Safdie Hypermedia Archive, The, McGill University, cac.mcgill.ca

Figure 1.12 - Ralph Erskine's Northern Studies and Proposal for Resolute Bay, 1973. Iker, V.. (2010, 11 19). Erskine urban project for architecture _ Arctic areas in memory [Web Graphic]. Retrieved from http://hacedordetrampas.blogspot.ca

Figure 2.1 - Thule whalebone shelter. From "Iqaluit" by N. Newberry, 2009, Iqaluit, NU, Canada: Nortext Publishing Corporation.

Figure 2.2 - Snow village at Oopungnewing. Hall, C. F. (1866). Arctic Researches and Life Among the Esquimaux (pg. 291). New York: CreateSpace Independent Publishing Platform.

Figure 2.3 - Qarmaq (sod house) dwelling. Canada., \& Canada. (1960). Eskimo mortality and housing. Ottawa: Information Services Division, Dept. of National Health and Welfare.

Figure 2.5 - Flaherty, R. J. (Artist). (2009). Nyla (Nanook's wife in the film) \& child, Cape Dufferin, QC, 1920-21 [Web Drawing]. Retrieved from http://www.mccord-museum.qc.ca

Figure 2.6 - Harrington, R. (Photographer). (1949). Inuit woman sewing, accompanied by two children. [Web Photo]. Retrieved from http://collectionscanada.gc.ca

Figure 2.7 - Idrobo, J. (2010, July ). An Inuit wearing Snow goggles [Web Photo]. Retrieved from http://en.wikipedia.org/wiki/File:Inuit_snow_goggles.jpg Figure 2.8 - Inuit man catching a seal from a breathing hole. From "Iqaluit” by N. Newberry, 2009, Iqaluit, NU, Canada: Nortext Publishing Corporation. 
Figure 2.9 - Robinson, B. (2013, August ). Sedna [Web Photo]. Retrieved from http://static4.wikia.nocookie.net

Figure 2.10 - Miniature carving. From Carpenter, E. (1973). Eskimo Realities. New York, New York, United States: Holt, Rinehart and Winston.

Figure 2.11 -Mikkigak, Ohotaq. (Artist). (2011). Houses in Cape Dorset [Web Photo]. Retrieved from http://www.canadianart.ca

Figure 2.12 -Pootoogook, A. (Artist). (2006). Cape Dorset Freezer [Web Drawing]. Retrieved from http://drinkanddrawmtl.com

Figure 2.13 - Grant, T. (Photographer). (2008, 03 19). Hon. George Hees, Minister of Transport, visits the Eskimos [Web Photo]. Retrieved from http://www.canadianart.ca

Figure 2.14 - Based on: Johnson, C. (Designer). (2010). The trio of early warning radar lines erected on Canadian soil [Web Map]. Retrieved from http://www.journal.forces.gc.ca

Figure 2.15 - Pitseolak, J. (Artist). (2006). Snowmobile [Web Photo]. Retrieved from http://blogs.ottawacitizen.com

Figure 2.16 - Celebration of Nunavut becoming an official territory, 1999. From "Iqaluit" by N. Newberry, 2009, Iqaluit, NU, Canada: Nortext Publishing Corporation.

Figure 2.17 - Today's version of traditional Inuit women's clothing. From “Iqaluit” by N. Newberry, 2009, Iqaluit, NU, Canada: Nortext Publishing Corporation.

Figure 2.18 - Government of Nunavut. (2013). Hazardous Waste and Waste Reduction [Web Photo]. Retrieved from http://www.hazardouswasteinnunavut.ca/

Figure 3.1 - Based on: MacBain, S. K. (1970). The Evolution of Frobisher Bay as a Major Settlement in the Canadian Eastern Arctic, 42.

Figure 3.2 - A. Forbes in Forbes, 1953. Reprinted with permission from A.I. Forbes

Figure 3.3 - National Air Photo Library. (1948). Frobisher Bay 1948 [Web Photo]. Retrieved from http://jproc.ca

Figure 3.4 -Unknown. (Photographer). (1954). This village off limits [Web Photo]. Retrieved from http://67.69.104.76:84/Pinetreeline

Figure 3.5 -National Archives of Canada. (2005). Frobisher Bay Airfield, 1955 [Web Photo]. Retrieved from http://67.69.104.76:84/rcaf-atc

Figure 3.6 - Source Unknown. (1948). Aerial of Crystal II, 1948 [Aerial Photograph]. Iqaluit, Nunavut, Canada: Natural Resources Canada

Figure 3.7 - Source Unknown. (1958). Aerial of Frobisher Bay Airbase, 1958 [Aerial Photograph]. Iqaluit, Nunavut, Canada: Natural Resources Canada

Figure 3.8 - Source Unknown. (1969). Aerial of Frobisher Bay Airbase, 1969 [Aerial Photograph]. Iqaluit, Nunavut, Canada: Natural Resources Canada

Figure 3.9 - Source Unknown. (1995). Aerial of Town of Iqaluit, 1995 [Aerial Photograph]. Iqaluit, Nunavut, Canada: Natural Resources Canada

Figure 3.10 - Source Unknown. (2000). Aerial of Town of Iqaluit, 2000 [Aerial Photograph]. Iqaluit, Nunavut, Canada: Natural Resources Canada

Figure 3.11 - City of Iqaluit. (2012). Aerial of City of Iqaluit, 2012 [Aerial Photograph]. Iqaluit, Nunavut, Canada: Planning and Development Department

Figure 3.12 - Frobisher Bay new town aerial perspective. (Library and archives canada, nMc 122830.) via Waldron, Andrew, Frobisher Bay Future: Megastructure in a Meta Land, Architecture and Ideas, vol. viii.

Figure 3.13 - Frobisher Bay new town aerial perspective. (Library and archives canada, nMc 122830.) via Waldron, Andrew, Frobisher Bay Future: Megastructure in a Meta Land, Architecture and Ideas, vol. viii. 
Figure 3.14 - Public Works in Canada 7:10 [October 1959]. Retrieved from Alia, V. (1998. Indigenous Peoples and Media Ethics in Canada. Aboriginal Media, Aboriginal Control.

Figure 3.15 - Based on Drawing: B. Lee with information from Waldron, Andrew, Frobisher Bay Future: Mega-structure in a Meta Land, Architecture and Ideas, vol. viii.

Figure 3.16 - Based on Drawing: B. Lee with information from Waldron, Andrew, Frobisher Bay Future: Mega-structure in a Meta Land, Architecture and Ideas, vol. viii.

Figure 3.17 -Three-dimensional mock-up of the design with prevailing winds. (Department Of Northern Affairs and National Resources. 1960. Proposed New Town, Frobisher Bay, Northwest Territories.)

Figure 3.18 -Drawing of the new town as seen from the south looking north. (Department Of Northern Affairs And National Resources. 1960. Proposed New Town, Frobisher Bay, Northwest Territories.)

Figure 3.19 - Safdie, M. (Photographer/Designer). (1974). Photo of site model [Web Photo]. Retrieved from http://cac.mcgill.ca

Figure 3.20 - Based on Drawing: B. Lee with information from Moshe Safdie Hypermedia Archive, The, McGill University, cac.mcgill.ca

Figure 3.21 - Safdie, M. (Photographer/Designer). (1974). Photo of site model, housing units [Web Photo]. Retrieved from http://cac.mcgill.ca

Figure 3.22 -Safdie, M. (Photographer/Designer). (1974). Sectional perspective [Web Photo]. Retrieved from http://cac.mcgill.ca

Figure 3.23 - Safdie, M. (Photographer/Designer). (1974). Site Plan [Web Photo]. Retrieved from http://cac.mcgill.ca

Figure 3.24 - Safdie, M. (Photographer/Designer). (1974). Unit Plans [Web Photo]. Retrieved from http://cac.mcgill.ca

Figure 3.25 - Kasten, S. (Photographer). (2011, September 05). Astro Hill Complex, Iqaluit [Web Photo]. Retrieved from http://upload.wikimedia.org

Figure 4.6 -Based on: Harris, S. A. (Designer). (2010, July 07). Permafrost Areas [Web Map]. Retrieved from http://www.thecanadianencyclopedia.com

Figure 4.8 - Left diagram, Base on: Strub, H. (1996). Bare Poles: Building Design for High Latitudes. (pg. 117) MQUP.

Figure 4.9 - Based on: Gaisma. Iqaluit, Canada - Sun path diagram [Web Drawing]. Retrieved from http://www.gaisma.com/en/location/iqaluit.html

Figure 4.11 -Base on: Strub, H. (1996). Bare Poles: Building Design for High Latitudes. (pg. 42) MQUP.

Figure 5.1 - Anonymous. (Photographer). (1954). Inuit housing in the village of Ikaluit. Military POL and communications facilities in background - 1954. [Web Photo]. Retrieved from http://67.69.104.76:84/Pinetreeline

Figure 5.2 - Anonymous. (Photographer). (1954). Tent Housing used by Inuit during the summer months. Lower base facilities in background - 1954 . [Print Photo]. Retrieved from http://67.69.104.76:84/Pinetreeline

Figure 5.3 - Lunney, G. (1956). Inuit woman and children inside an igloo. Frobisher Bay, N.W.T.: Library and Archives Canada.

Figure 5.4 - Canada., \& Canada. (1960). Eskimo mortality and housing. Ottawa: Information Services Division, Dept. of National Health and Welfare. (pg. 163)

Figure 5.5 - Doucette, W. (Photographer). (1951, July ). Dr. C. Davies examines eyes of Lee Teea, an Inuit woman of Frobisher Bay area while Rev. G.A. Russell acts as interpreter [Web Photo]. Retrieved from http://www.collectionscanada.gc.ca 
Figure 5.7 - Based on: Northwest Territories Housing Corporation. (1988). Northern Housing Identification Guide. (M. Aquin, Ed.) (pg. 176). Rankin Inlet, Nunavut: Northwest Territories Housing Corporation.

Figure 5.8 - Canada., \& Canada. (1960). Eskimo mortality and housing. Ottawa: Information Services Division, Dept. of National Health and Welfare. (pg. 168)

Figure 5.10 - Based on: Northwest Territories Housing Corporation. (1988). Northern Housing Identification Guide. (M. Aquin, Ed.) (pg. 177). Rankin Inlet, Nunavut: Northwest Territories Housing Corporation.

Figure 5.11 - Tester, F. J. (2006). Iglutaq (in my room): The implications of homelessness for Inuit : a case study of housing and homelessness in Kinngait, Nunavut Territory. s.l.: s.n.. (pg. 7)

Figure 5.12 -Image From McElroy, A. (Producer). (1969). A three-room, government-built "512" house in Apex Hill, Frobrisher Bay [Print Photo] Retrieved from http://books.google.ca 1512 model, plans. Based on: Northwest Territories Housing Corporation. (1988). Northern Housing Identification Guide. (M. Aquin, Ed.) (pg. 175). Rankin Inlet, Nunavut: Northwest Territories Housing Corporation.

Figure 5.13 - The Angirraq, plans and image Based on: Northwest Territories Housing Corporation. (1988). Northern Housing Identification Guide. (M. Aquin, Ed.) (pg. 188). Rankin Inlet, Nunavut: Northwest Territories Housing Corporation.

Figure 5.14 -Based on: Northwest Territories Housing Corporation. (1988). Northern Housing Identification Guide. (M. Aquin, Ed.) (pg. 7). Rankin Inlet, Nunavut: Northwest Territories Housing Corporation.

Figure 5.19 - Desrosiers, V. (Photographer). (2013, November 01). The main piece of furniture they have in the house is an old church pew, used as a couch. [Web Photo]. Retrieved from http://www.cbc.ca

Figure 5.20 - Desrosiers, V. (Photographer). (2013, November 01). The older kids sleep here, while the younger kids crowd in with mom and dad. 'One of them moves, everybody moves,' says father Rene Aggark. [Web Photo]. Retrieved from http://www.cbc.ca

Figure 6.1 - Scene from: Spheeris, P., Bryce, I., Konner, L., Varney, J., Leachman, C., Coleman, D., Tomlin, L., ... Copyright Collection (Library of Congress). (1993). The Beverly hillbillies. United States: 20th Century Fox.

Figure 6.2 - Desrosiers, V. (Photographer). (2013, November 01). The children eat mussels together on the floor. [Web Photo]. Retrieved from http://www.cbc.ca

Figure 6.3 - Based on: Dawson, P. C. (1997). Variability in traditional and non-traditional Inuit architecture, AD. 1000 to present. (pp. 261-2)

Figure 7.7 - Sprung Instant Structures Ltd. . (2010). Ekati Diamond Mine Case Study - Sprung Instant Structures. Retrieved 03 23, 2014, from http://archive.sprung.com/IndustryGallery/ProjectsDefault.php?pid=22

Figure 7.8 - Sprung Instant Structures Ltd. (2014). Sprung Arenas Insulation - Sprung Arenas. Retrieved 03 23, 2014 , from Sprung Performance Arenas: http://www.sprungarenas.com/insulation

Table 1.1 - Hamelin, L. E. (1979). Canadian nordicity: it's your north too. Montreal: Harvest House.

Table 2.2 - Hamelin, L. E. (1979). Canadian nordicity: it's your north too. Montreal: Harvest House.

Table 3.1 - MacBain, S. K. (1970). The evolution of Frobisher Bay as a major settlement in the Canadian eastern Arctic. S.I. 
Appendix 


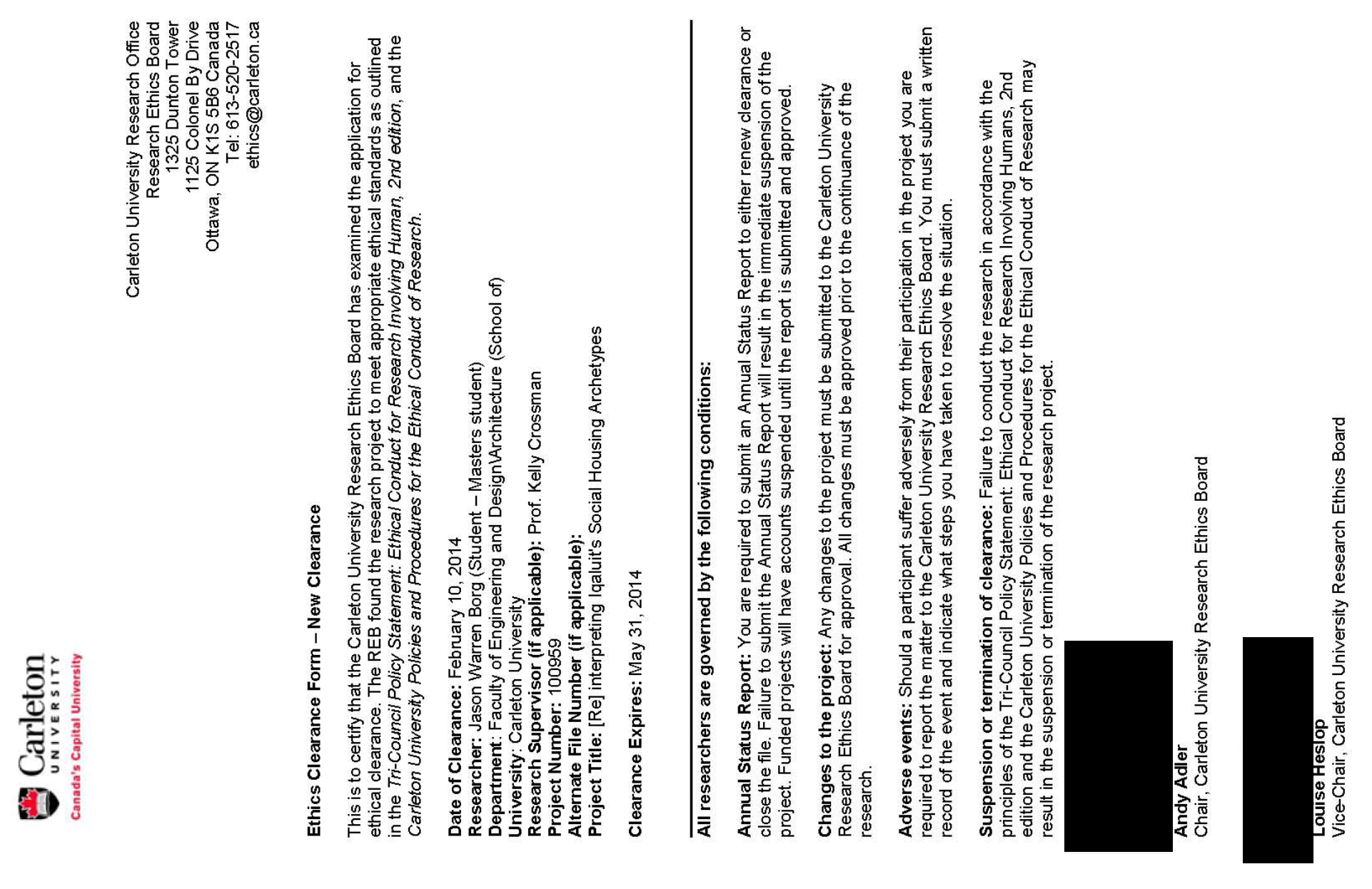




\section{Interview \#1: Janet}

Bio: Female, Early 40's

Q. How long have you lived in social housing?
A. 8 years

Q. Do u like where you live?

$$
\text { A. Yes }
$$

Q. Do you like to spend more time on the land?

\section{A. Yes, whenever I can but especially at springtime}

$\mathrm{Q}$. How big is your housing unit and how many people live there?

\section{A. I live in a one-bedroom unit with two other people.}

Q. Is it just your immediate family, extended family (i.e. your parents), or friends and family?

\section{A. It is just my immediate family}

$\mathrm{Q}$. Do you feel like your unit is large enough?

$$
\text { A. Yes }
$$

Q. Do you prefer living with your extended family or your immediate family?

\section{A. I prefer living with relatives}

Q. In your current unit, is it difficult to keep up with your traditions?

$$
\text { A. No }
$$

Q. Would you rather own your own home?

$$
\text { A. No }
$$

Q. What do you find hard about your living conditions and do you feel powerless about the situation?

$$
\text { A. No }
$$

Q. Have you ever been to a house that you've seen work for an Inuit family? if yes, what did it look like or what did you like about it?

\section{A. No}

Q. If you were to add a special purpose room to your unit what would you use it for?

\section{A. Extra storage and/or a bigger kitchen}

Q. What would you say is more important, quality of housing or quantity of housing in Iqaluit?

\section{A. More bousing units}




\section{Interview \#2: Lee}

Bio: Male, Early 50's

Q. How long have you lived in social housing?

$$
\text { A. All my life }
$$

Q. Do u like where you live?

$$
\text { A. Yes }
$$

Q. Do you like to spend more time on the land?

$$
\text { A. Yes }
$$

Q. How big is your housing unit and how many people live there?

\section{A. I live in a two-bedroom unit with four other people.}

Q. Is it just your immediate family, extended family (i.e. your parents), or friends and family?

\section{A. It is just my immediate family}

Q. Do you feel like your unit is large enough?

$$
\text { A. No }
$$

Q. Do you prefer living with your extended family or your immediate family?

\section{A. I prefer living with my immediate family}

Q. In your current unit, is it difficult to keep up with your traditions?

\section{A. It's ole}

Q. Would you rather own your own home?

$$
\text { A. Yes }
$$

Q. What do you find hard about your living conditions and do you feel powerless about the situation?

\section{A. I'm ok with my conditions}

Q. Have you ever been to a house that you've seen work for an Inuit family? If yes, what did it look like or what did you like about it?

\section{A. No}

Q. If you were to add a special purpose room to your unit what would you use it for?

\section{A. Extra bedroom}

Q. What would you say is more important, quality of housing or quantity of housing in Iqaluit?

\section{A. Quality of bousing}




\section{Interview \#3: Joe}

Bio: Male, Mid 40's

Q. How long have you lived in social housing?

\section{A. Most of my life}

$\mathrm{Q}$. Do u like where you live?

$$
\text { A. Yes }
$$

Q. Do you like to spend more time on the land?

$$
\text { A. } 50 / 50
$$

Q. How big is your housing unit and how many people live there?

\section{A. I live in a one-bedroom unit with three other people.}

Q. Is it just your immediate family, extended family (i.e. your parents), or friends and family?

\section{A. It is just my immediate family}

$\mathrm{Q}$. Do you feel like your unit is large enough?

\section{A. No}

Q. Do you prefer living with your extended family or your immediate family?

\section{A. I prefer living with my immediate family}

Q. In your current unit, is it difficult to keep up with your traditions?

$$
\text { A. No }
$$

Q. Would you rather own your own home?

$$
\text { A. Yes }
$$

Q. What do you find hard about your living conditions and do you feel powerless about the situation?

\section{A. Yes, a bit. All changes have to be approved}

Q. Have you ever been to a house that you've seen work for an Inuit family? If yes, what did it look like or what did you like about it?

\section{A. No}

Q. If you were to add a special purpose room to your unit what would you use it for?

\section{A. Extra bedroom}

Q. What would you say is more important, quality of housing or quantity of housing in Iqaluit?

\section{A. More bousing units}

Additional comment(s): Rooms need to be a bit bigger 


\section{Interview \#4: Kenny}

Bio: Male, Mid 20's

Q. How long have you lived in social housing?

$$
\text { A. } 4 \text { years }
$$

Q. Do u like where you live?

\section{A. Kinda}

Q. Do you like to spend more time on the land?

$$
\text { A. Of course }
$$

Q. How big is your housing unit and how many people live there?

\section{A. I live in a one-bedroom unit.}

Q. Is it just your immediate family, extended family (i.e. your parents), or friends and family?

\section{A. Just me plus an occasional friend}

Q. Do you feel like your unit is large enough?

\section{A. No}

Q. Do you prefer living with your extended family or your Immediate family?

\section{A. I prefer living alone}

Q. In your current unit, is it difficult to keep up with your traditions?

$$
\text { A. No }
$$

Q. Would you rather own your own home?

$$
\text { A. No }
$$

Q. What do you find hard about your living conditions and do you feel powerless about the situation?

\section{A. No, I'm ok with the maintenance agreement.}

Q. Have you ever been to a house that you've seen work for an Inuit family? If yes, what did it look like or what did you like about it?

A. No

Q. If you were to add a special purpose room to your unit what would you use it for?

\section{A. Recreation}

Q. What would you say is more important, quality of housing or quantity of housing in Iqaluit?

\section{A. Better bousing units}




\section{Interview \#5: Samuel}

Bio: Male, Late 30's

Q. How long have you lived in social housing?

$$
\text { A. } 12 \text { years }
$$

Q. Do u like where you live?

\section{A. I'm a drifter, I couch surf.}

Q. Do you like to spend more time on the land?

$$
\text { A. No }
$$

Q. How big is your housing unit and how many people live there?

\section{A. They vary}

Q. Is it just your immediate family, extended family (i.e. your parents), or friends and family?

\section{A. I stay with occasional friend}

Q. Do you feel like your unit is large enough?

A. No

Q. Do you prefer living with your extended family or your immediate family?

\section{A. I prefer living with immediate family}

Q. In your current unit, is it difficult to keep up with your traditions?

A. Yes

Q. Would you rather own your own home?

\section{A. I do own a bouse in Qik.}

Q. What do you find hard about your living conditions and do you feel powerless about the situation?

\section{A. Moving from place to place}

Q. Have you ever been to a house that you've seen work for an Inuit family? If yes, what did it look like or what did you like about it?

\section{A. No}

Q. If you were to add a special purpose room to your unit what would you use it for?

\section{A. Extra Bedroom}

Q. What would you say is more important, quality of housing or quantity of housing in Iqaluit?

\section{A. More bousing units}

Additional comment(s): They need to make the waiting list more reasonable. The wait time is too long. 